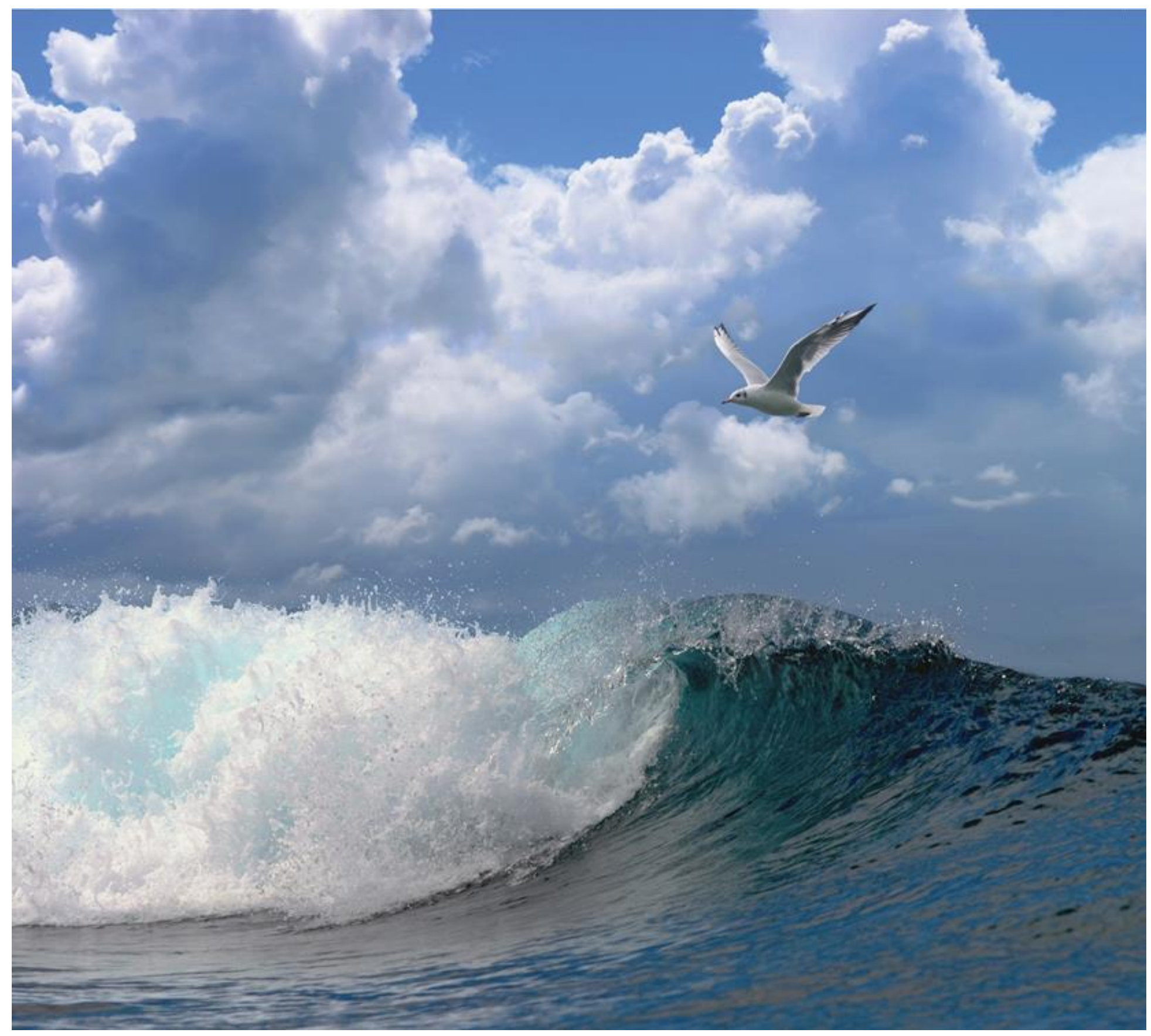

\title{
Gemini T-c: aerial surveys and passive acoustic monitoring of harbour porpoises 2015
}




\section{Gemini T-c: aerial surveys and passive acoustic monitoring of harbour porpoises 2015}

Author(s): $\quad$ SCV Geelhoed, E Friedrich, M Joost, MAM Machiels \& N Stöber

Publication date: 21 December 2018 
Client: $\quad$ Luuk Folkerts

Attn.: Gemini Windpark

Amstelveenseweg 760

NL-1081 JK, Amsterdam

Wageningen Marine Research is ISO 9001:2015 certified.

This report can be downloaded for free from https://doi.org/10.18174/410635

Wageningen Marine Research provides no printed copies of reports

(C) Wageningen Marine Research

Wageningen Marine Research, an institute Wageningen Marine Research accepts no liability for consequential damage, nor within the legal entity Stichting for damage resulting from applications of the results of work or other data Wageningen Research (a foundation under obtained from Wageningen Marine Research. Client indemnifies Wageningen Dutch private law) represented by Dr. Marine Research from claims of third parties in connection with this application. M.C.Th. Scholten, Managing Director All rights reserved. No part of this publication may be reproduced and / or

KvK nr. 09098104, published, photocopied or used in any other way without the written permission WMR BTW nr. NL 8113.83.696.B16.

Code BIC/SWIFT address: RABONL2U IBAN code: NL 73 RABO 0373599285 


\section{Contents}

\section{Summary}

$\begin{array}{lll}1 & \text { Introduction } & 7\end{array}$

$\begin{array}{llr}1.1 & \text { Background } & 7\end{array}$

$\begin{array}{lll}1.2 & \text { Aims of T-c research } & 8\end{array}$

$\begin{array}{llr}1.3 & \text { Harbour porpoise } & 8\end{array}$

$2 \quad$ Materials and Methods $r$

$\begin{array}{ll}2.1 & \text { Survey area } \\ \end{array}$

$\begin{array}{lll}2.2 & \text { Gemini windfarm construction activities } & 11\end{array}$

$\begin{array}{ll}2.3 \text { Aerial surveys } & 11\end{array}$

$\begin{array}{ll}\text { 2.3.1 Survey design } & 11\end{array}$

$\begin{array}{ll}\text { 2.3.1 Data collection } & 11\end{array}$

$\begin{array}{llr}2.3 .2 & \text { Analysis } & 13\end{array}$

$\begin{array}{llr}2.4 & \text { Passive acoustic monitoring } & 14\end{array}$

$\begin{array}{lll}2.4 .1 & \text { Study design } & 14\end{array}$

$\begin{array}{ll}\text { 2.4.1 Description of CPOD } & 15\end{array}$

$\begin{array}{ll}2.4 .2 \quad \text { Data collection } & 16\end{array}$

$\begin{array}{ll}2.4 .3 \quad \text { Post-processing } & 16\end{array}$

$\begin{array}{llr}2.4 .4 & \text { Analysis } & 17\end{array}$

$\begin{array}{llr}3 & \text { Gemini wind farm construction activities } & 18\end{array}$

$\begin{array}{llr}3.1 & \text { Pre-pile driving activities } & 18\end{array}$

$\begin{array}{ll}3.2 & \text { Pile driving } \\ \end{array}$

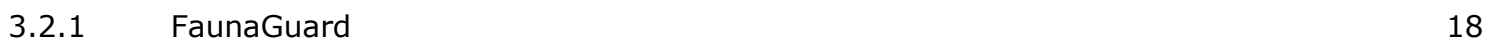

$\begin{array}{ll}\text { 3.2.1 Timing of piling } & 20\end{array}$

$\begin{array}{llr}3.3 & \text { Post-pile driving activities } & 20\end{array}$

$4 \quad$ Aerial surveys $\quad 21$

$\begin{array}{llr}4.1 & \text { Effort } & 21\end{array}$

$\begin{array}{ll}4.2 & \text { Sightings } \\ & 22\end{array}$

4.3 Spatial and seasonal pattern of harbour porpoise occurrence 22

$5 \quad$ Passive acoustic monitoring $\quad 26$

$\begin{array}{llr}5.1 \text { Effort } & 26\end{array}$

5.2 Spatial and seasonal pattern of harbour porpoise occurrence 26

6 Harbour porpoise occurrence during T-0 and T-c 33

$\begin{array}{lll}6.1 & \text { Aerial surveys } & 33\end{array}$

$\begin{array}{lll}6.2 & \text { Passive acoustic monitoring } & 35\end{array}$

$7 \quad$ Effect of construction activities on harbour porpoise occurrence 38

$\begin{array}{llr}7.1 & \text { Aerial surveys } & 38\end{array}$ 
$\begin{array}{lll}7.2 & \text { Passive acoustic monitoring } & 40\end{array}$

7.2.1 Harbour porpoise's acoustic activity during piling 40

7.2.2 Effect of pile driving on harbour porpoise's acoustic activity 43

$\begin{array}{lll}\text { 7.2.3 Effect of FaunaGuard } & 46\end{array}$

$\begin{array}{lll}\text { 7.2.4 Effect of simultaneous pile driving } & 47\end{array}$

8 Discussion/synthesis $\quad 49$

$\begin{array}{lll}8.1 & \text { Aerial surveys versus passive acoustic monitoring } & 49\end{array}$

8.2 Spatial and seasonal pattern of harbour porpoise in the North Sea 49

8.3 Effect of construction activities on harbour porpoise occurrence 51

$\begin{array}{lll}8.4 & \text { Effects on population level } & 54\end{array}$

9 Conclusions $\quad 55$

10 Quality Assurance $\quad 56$

$\begin{array}{ll}\text { References } & 56\end{array}$

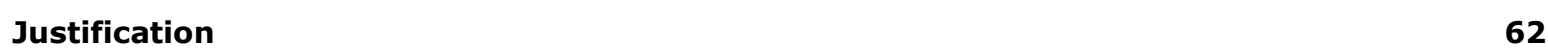

Annex 1 Coordinates for aerial transects and CPOD-positions 63

$\begin{array}{ll}\text { Annex } 2 \text { Characteristics of pile driving events } & 65\end{array}$

$\begin{array}{lr}\text { Annex } 3 \text { CPOD post-processing data } & 69\end{array}$

$\begin{array}{ll}\text { Annex } 4 \text { Seasonal patterns in acoustic activity of Harbour porpoise } & 70\end{array}$

$\begin{array}{ll}\text { Annex } 5 \text { Calibration results: Ppp vs receiving levels } & 78\end{array}$

Annex 6 Calibration results: Ppp vs frequency $\quad 92$ 


\section{Summary}

In accordance with the monitoring and evaluation plan (MEP) for the 'Gemini Offshore Wind Farm' ecological monitoring of harbour porpoises was carried out, concerning the distribution, especially distance and numbers, of harbour porpoises around the wind farm during the first construction phase with pile driving of the fundaments $(T-c)$, without noise mitigation. This study focusses on:

- the effects of the construction of wind turbines at Project Gemini on the presence of harbour porpoises at the construction sites and adjacent areas;

- the assessment of the range and duration of effects during the construction phase;

Furthermore, the questions are addressed if there is an effect on harbour porpoises:

- when using an acoustic porpoise deterrent, the so-called FaunaGuard, before pile driving starts,

- during simultaneous pile driving in both Gemini wind farm areas Buitengaats and ZeeEnergie

For this purpose aerial surveys as well as passive acoustic monitoring (PAM) were performed.

In total, five survey flights with 8 out of 10 full flight days were conducted at an average height of 183 $\mathrm{m}$ (600 ft) between June and October 2015, covering a total survey area of nearly 7,800 km².

For the passive acoustic monitoring, fifteen CPODs were deployed in a design spreading $40 \mathrm{~km}$ to the west and $15 \mathrm{~km}$ to the south of the centre of the wind farm site. Between June 2015 and February 2016 2,228 days of CPOD recordings were obtained during the construction phase.

Overall 469 harbour porpoises (Phocoena phocoena) were recorded during the aerial surveys. This yields harbour porpoise densities between 0.05 and 3.3 individuals $/ \mathrm{km}^{2}$ during the five surveys (on average 1.2 individuals $/ \mathrm{km}^{2}$ ). The maximum density was observed on 3 July 2015, two days after the start of pile driving in the Gemini wind farm site. The porpoise density was almost the same on 30 June 2015, one day before the piling started, but the distribution was slightly different. In general, densities of harbour porpoise tended to be lower in the south-western and north-eastern parts of the survey area. Overall, the harbour porpoise density showed a clear decline during the $2015 \mathrm{~T}$-c survey period from a very high level in June to an average level in August/September and a very low level in October.

During passive acoustic monitoring harbour porpoises were detected on $96.2 \%$ of days sampled. Harbour porpoise acoustic activity showed a strong seasonal pattern. There was a peak in detections in June, followed by lower acoustic activity till the end of the year, and an increase from December onwards.

During $\mathrm{T}-\mathrm{O}$ and $\mathrm{T}-\mathrm{c}$ the same underlying factors explained most variation in acoustic activity. During Tc, however, overall acoustic activity was lower.

PAM shows a decrease in acoustic activity before pile driving starts, followed by an increase to pre-piling levels after pile driving stopped. This is interpreted as avoidance of the piling source by harbour porpoises.

PAM shows that the avoidance distance of harbour porpoises lies in the range of $10-20 \mathrm{~km}$. These results are supported by the aerial surveys, which suggest avoidance of a pile driving location during pile driving in a radius from $<15 \mathrm{~km}$ up to $25 \mathrm{~km}$. Though the data is scant, the aerial surveys indicate a return to the avoided area a few hours after pile driving has stopped. The avoidance distance might be a restricted by the length of the piling event, that lasted on average too short to allow harbour porpoise to swim further away than 10-20 km during a pile driving event.

PAM did not show a harbour porpoise deterring effect of the FaunaGuard. However, the study design was not primarily aimed at measuring an effect. 
PAM could not detect an effect of simultaneous pile driving in both Gemini wind farm areas Buitengaats and ZeeEnergie. However, simultaneous pile driving occurred on nine occasions, albeit with short overlap in time (ca $30 \mathrm{~min}$ ). 


\section{Introduction}

\subsection{Background}

Project Gemini is a $600 \mathrm{MW}$ offshore wind farm, and contains 150 turbines. The Gemini wind farms are located $55 \mathrm{~km}$ north of the island of Schiermonnikoog in the southern North Sea, in water depths that range between 28 and $36 \mathrm{~m}$. Project Gemini consists of two sites both $34 \mathrm{~km}^{2}$ in size, Buitengaats (54.04 N, 6.04 E) and ZeeEnergie (54.03 N $5.89 \mathrm{E}$ ( Figure 1)). The nearest large port to the Gemini area is Eemshaven and a submarine power-cable connects the wind farm with this port. The monopile foundations for the turbines plus eight piles for the foundations of the two offshore high voltage stations (OHVSs) were pile driven into the seabed to a depth of approximately 18-24 m from July $1^{\text {st }}$ until October $18^{\text {th }}$ 2015. Installation of Wind Turbine Generators (WTG's) started in February 2016, while full energy production started in October 2016. The WTG's are connected to two offshore transformer platforms, from which two sets of offshore cables export the power to an onshore public grid owned by TenneT.

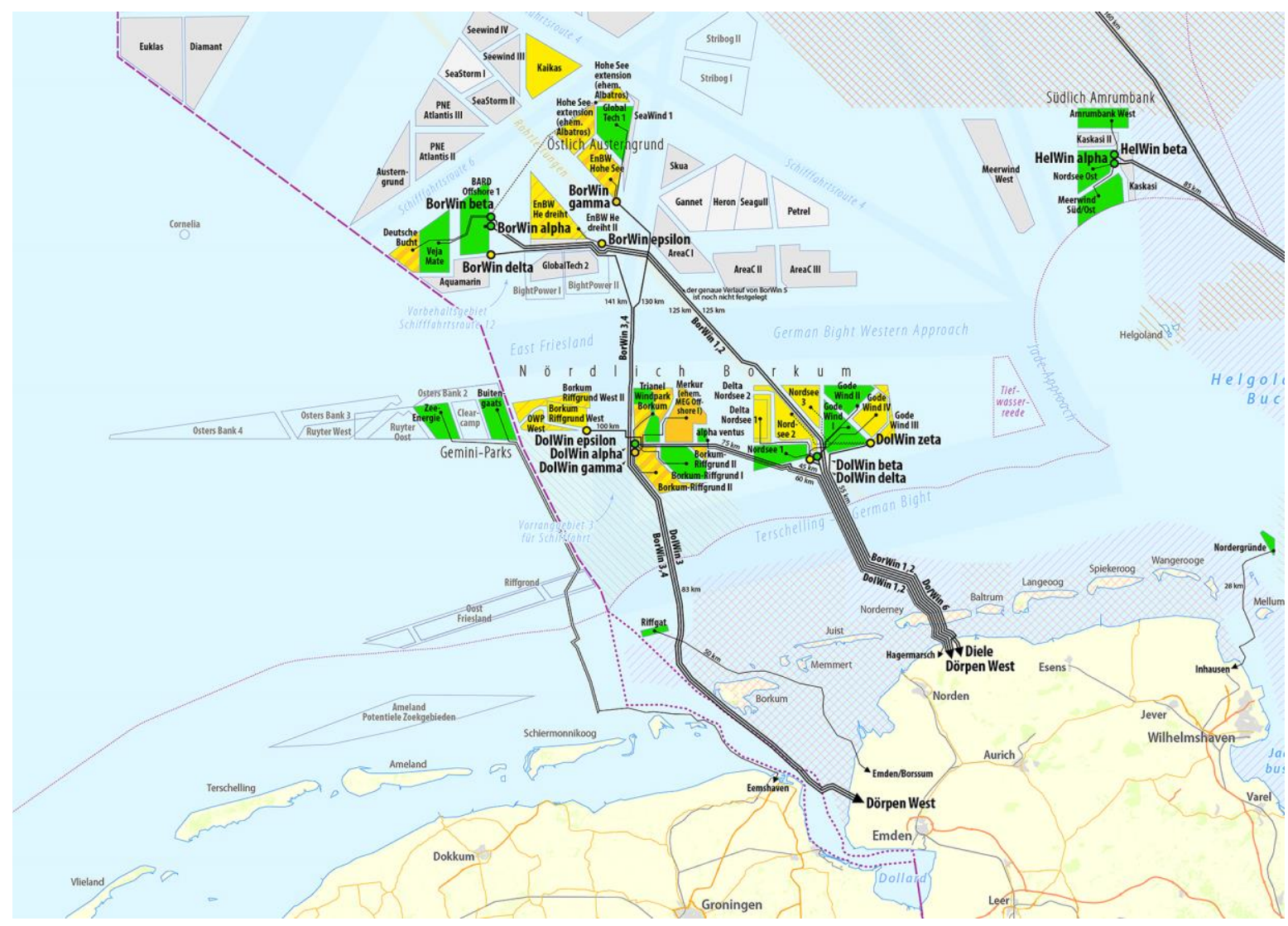

Figure $1 \quad$ Location of Gemini offshore wind farm, and surrounding windparks planned (yellow), in construction (orange) and operational (green). Details from "Karte Offshore-Windkraftanlagen in der Deutschen Bucht" by Maximilian Dörrbecker (Chumwa).

For the period prior to construction of the Gemini offshore wind farms Buitengaats and ZeeEnergie until the operational phase, a 'Monitoring and Evaluation Plan' (MEP) was written, which contained nine topics, including: Monitoring of harbour porpoises in relation to the offshore wind farm. This topic was addressed prior to construction during T-0 by Geelhoed et al. (2015a) using aerial surveys and Passive Acoustic Monitoring (PAM). In total, seven of eight planned survey flights were conducted between August 2013 and June 2014. For the passive acoustic monitoring, fifteen CPODs were deployed in a design spreading $40 \mathrm{~km}$ to the west and $15 \mathrm{~km}$ to the south of the intended wind farm site. Between September 2011 
and July 2014, almost 7000 days of CPOD recordings were obtained during two distinct one-year sampling periods.

The T-0 results showed that harbour porpoises were permanently present in the study area. Both the aerial surveys as well as PAM showed the same seasonal pattern. The aerial surveys yielded harbour porpoise densities between 0.3 and 1.5 individuals $/ \mathrm{km}^{2}$ (on average $1.0 / \mathrm{km}^{2}$ ). The maximum density was observed in April 2014, following lowest numbers in February and early March. Densities of harbour porpoise tended to be higher in the central part of the survey area where the Gemini wind farm is located now. By passive acoustic monitoring harbour porpoises were detected on $93.2 \%$ of days sampled. Harbour porpoise acoustic activity showed a strong seasonal pattern. There was a peak in detections in March and lowest acoustic activity occurred in May-June and December-January. Detection peaks were also associated with high-tide cycles and morning periods. Analysis of the PAM data demonstrates the effect of underlying factors (e.g. day of year, tide) on the recorded acoustic activity of harbour porpoises in the area (Geelhoed et al., 2015a).

This study describes the results of aerial surveys and passive acoustic monitoring to determine the distribution and numbers of harbour porpoises in and around the Gemini offshore wind farm, during construction ( $\mathrm{T}-\mathrm{c})$.

The acoustic data are fed into broader scale international modelling studies to improve the knowledge on the impacts of offshore wind farms on harbour porpoises, specifically the GESCHA project led by BioConsult and the DEPONS project (Disturbance effects on the harbour porpoise population in the North Sea) led by Aarhus University.

\subsection{Aims of $\mathrm{T}-\mathrm{c}$ research}

This report describes the T-c surveys in and around the Gemini offshore wind farms Buitengaats and ZeeEnergie. The aim of this report is to describe the harbour porpoise temporal and spatial distribution patterns in the vicinity of the Gemini offshore wind farms during the construction phase with pile driving of the fundaments.

The report focusses on:

- the effects of the construction of wind turbines at Project Gemini on the presence of harbour porpoises at the construction sites and adjacent areas;

- the assessment of the range and duration of effects during the construction phase.

Furthermore, the following questions are addressed to determine if there is an effect on harbour porpoises:

- $\quad$ when using an acoustic porpoise deterrent, the so-called FaunaGuard, before pile driving starts;

- during simultaneous pile driving in both Gemini wind farm areas Buitengaats and ZeeEnergie.

\subsection{Harbour porpoise}

The harbour porpoise (Phocoena phocoena) is a small cetacean that is the most abundant marine mammal species in the North Sea. The Greater North Sea population is estimated at 345,000 animals in 2016 (Hammond et al., 2017). In recent years, the harbour porpoise population has undergone a redistribution across its range (Hammond et al., 2002, 2013, 2017), resulting in an increase in harbour porpoise abundance in Dutch waters (Camphuysen, 2004). The maximum numbers in Dutch waters were estimated at ca 86,000 animals in March 2011 (Geelhoed et al., 2013) and ca 47,000 animals in July 2017 (Geelhoed et al., 2018).

The harbour porpoise is a protected species in Dutch waters. It is protected under European legislation (i.e. the EU Habitats Directive) and The Netherlands has signed international (North Sea Conservation Plan ASCOBANS) and national agreements on the protection of the harbour porpoise in the Dutch 
Bruinvisbeschermingsplan (Camphuysen \& Siemensma, 2012). Therefore, potential negative effects of construction activities on harbour porpoises should be quantified and mitigated.

Harbour porpoises spend their entire life in the water. They are mammals and have to come to the surface to breathe. Tagged porpoises $(n=35)$ showed that the time spent at the surface varies between 3.4 and $6 \%$ of the time, whereas time spent in the upper layer, 0-2 $\mathrm{m}$ below the sea surface, varies between 42.5 and $61.5 \%$ of the time (Teilmann et al., 2013). This behaviour makes aerial surveys a feasible method, since porpoises in the North Sea can be typically seen till about $2 \mathrm{~m}$ below the surface.

Harbour porpoises use echolocation as an active sensory system for information about their environment, and to a lesser extent as a means of communication. For echolocation harbour porpoises use clicks that are extremely directional (Villadsgaard et al., 2007) and are emitted in a narrow beam in both the horizontal and vertical plane. These echolocation signals are distinctive in lasting about 50150 microseconds, and containing virtually no energy below $100 \mathrm{kHz}$. The main part of the energy is around $132 \mathrm{kHz}$ in a narrow band between 120-150 kHz (Au et al., 1999). These characteristics make acoustic detection and identification of harbour porpoise clicks relatively easy.

Porpoises have extremely sensitive hearing, which makes them vulnerable to noise-induced effects from anthropogenic activities at sea (Kastelein et al., 2010; 2012a-b; 2013a-d; 2014a-b; Lucke et al., 2009). Behavioural changes are expected to occur before hearing effects take place. Sound is the main mediator for behavioural reactions in harbour porpoises. Kastelein et al. (2013d) exposed a single harbour porpoise in a pool (under very quiet conditions) to playbacks of pile driving sounds and recorded the animal's behaviour. They found a threshold of Sound Exposure Level or SEL $1=136 \mathrm{~dB}$ re $1 \mu \mathrm{Pa}^{2} \mathrm{~s}$ (Sound Pressure Level or SPL $=145 \mathrm{~dB}$ re $1 \mu \mathrm{Pa}$ ) which corresponds to a theoretical avoidance distance of ca $30 \mathrm{~km}$ for this animal in the North Sea under quiet conditions (no masking). This threshold was used in Dutch Environmental Impact Assessments of the effects of offshore wind farms on harbour porpoises. A study using CPODs in the German Borkum West II wind park resulted in a threshold of SEL $\mathrm{L}_{1}=144 \mathrm{~dB}$ re $1 \mathrm{\mu Pa}^{2} \mathrm{~s}$ (Diederichs et al., 2014). A recent review advised to adjust this threshold to $140 \mathrm{~dB}$ re 1 $\mu \mathrm{Pa}^{2} \mathrm{~s}$ (Heinis et al., 2015). The avoidance distance of $30 \mathrm{~km}$ is theoretically the maximum distance; the actual distance will vary depending on the source level, propagation conditions, wind, and background noise.

Studies in the North Sea during construction of offshore wind farms have shown that pile driving displaces harbour porpoises (Brandt et al., 2011, Dähne et al., 2013, Tougaard et al., 2009). The most important aspect for the effect range on harbour porpoises of the construction of offshore wind farms is sound production and sound propagation. The pile-driving impulse sound is audible to harbour porpoises over wide ranges and in open waters it propagates more or less evenly in all directions. Passive acoustic monitoring studies at wind farms in German and Danish waters show that pile-driving can result in lower detections of porpoises over a range of $20 \mathrm{~km}$ or more from the piling source (Brandt et al., 2011, Dähne et al., 2013, Tougaard et al., 2009). Thompson et al. (2010) could not detect changes in harbour porpoise abundance at a single location $40 \mathrm{~km}$ from the piling source at the Beatrice wind farm. A recent review of pile driving effects during the construction of seven offshore wind farms in the German Bight showed that an avoidance effect of pile driving extends to on average $17 \mathrm{~km}$ (Brandt et al., 2016). The pile driving during the construction of these wind farms was mitigated to stay below the German threshold of $160 \mathrm{~dB}$ at $750 \mathrm{~m}$ from the piling location. In the BARD and Global Tech I wind farms, north of Gemini, effect ranges up to 30-34 km were modelled. Most measured avoidance distances, however, are lower than the calculated maximum avoidance distance.

Several studies demonstrate that the acoustic activity of harbour porpoises started decreasing about a day before piling started, and reached a minimum around piling. It started increasing again after piling stopped. The acoustic activity reached pre-piling levels between 9 and 28 hrs after piling stopped and continued to increase until about 16 to 46 hrs after piling (Brandt et al., 2016). This increase was considered an indication that short-term avoidance does not lead to long-term displacement (Thompson et al., 2013). However, their results can also be explained by immigration of new individuals. The initially exposed porpoises might have left the area completely, and could have been replaced by immigration of new animals from areas outside the noise exposed area (Aarts et al., 2016). 


\section{Materials and Methods}

Harbour porpoises were surveyed using two methods: aerial surveys and Passive Acoustic Monitoring (PAM). Aerial surveys allow covering a large area, including the entire potential impact area, in a short period of time. The acoustic monitoring, on the other hand, continuously records the acoustic activity of harbour porpoises within a small radius $(<300 \mathrm{~m})$ around the PAM device. A combination of both methods provides quantitative data, comprising good spatial coverage (aerials) and high local resolution (PAM). Data on the construction activities was provided by Gemini and combined into a relational database (Brasseur et al., 2016).

\subsection{Survey area}

The location for Gemini offshore wind farms is approximately $55 \mathrm{~km}$ north of the island of Schiermonnikoog, in the Dutch EEZ, at the Dutch-German border (Figure 2). Substantial anthropogenic sound already comes from a number of sources in the area. Immediately to the north of Gemini there are intensively used shipping routes that require designated traffic separation lanes. To the north and to the east, in German waters, within $50 \mathrm{~km}$ of Gemini, there were three operational wind farms during $\mathrm{T}-0$ and several under construction (Figure 1).
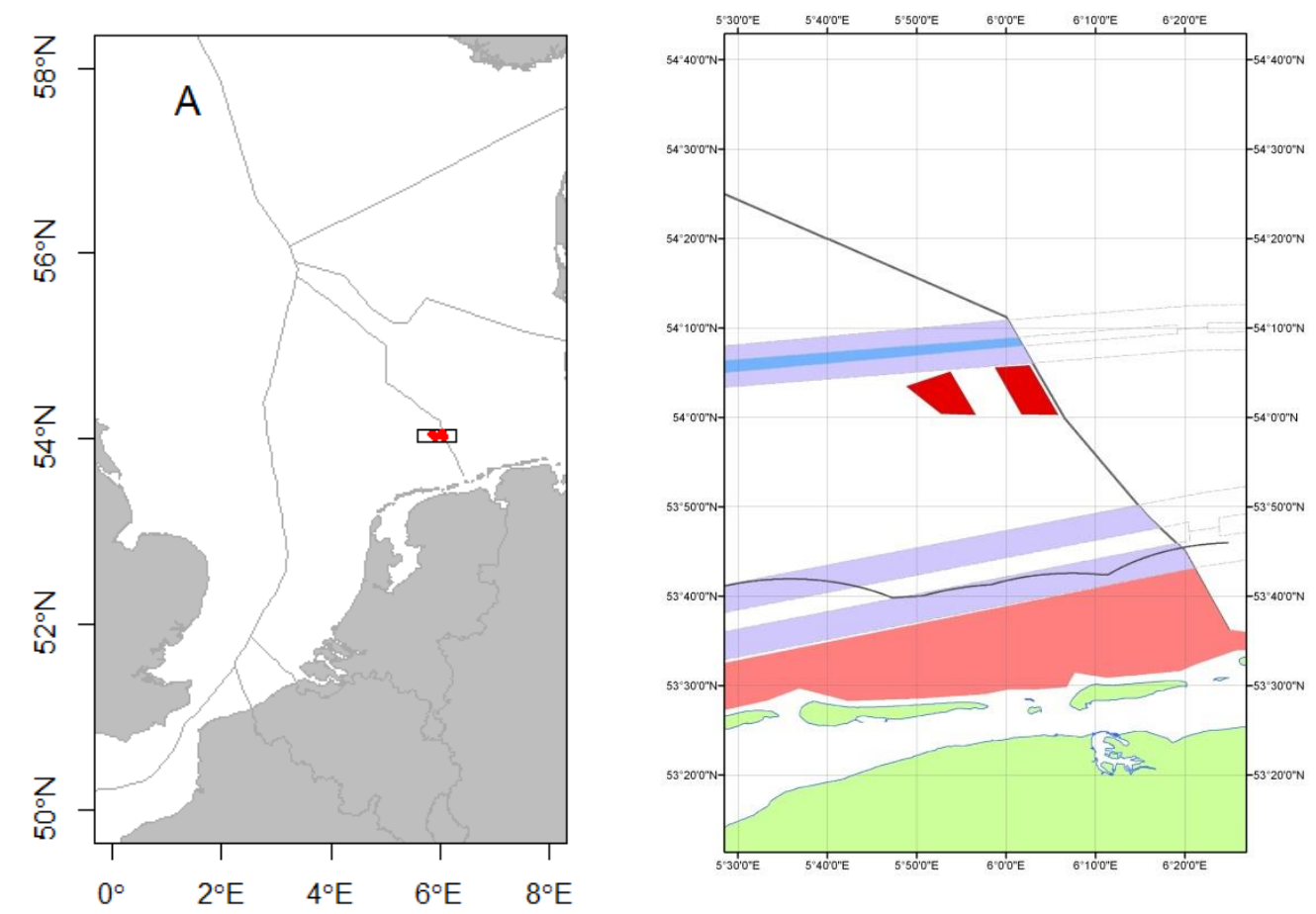

Figure 2 Left panel: location of study area in the North Sea. Right panel: detail of the Gemini wind farm area (dark red); shipping lanes in purple, land in green

In order to study and assess the potential impact of Gemini wind farm construction and operation on harbour porpoises, an aerial survey was designed to collect data from an area with a range of ca $40 \mathrm{~km}$ to the north, ca $55 \mathrm{~km}$ to the South and ca $30 \mathrm{~km}$ to the east and west of the both wind parks (Figure 4). Passive acoustic monitoring of harbour porpoises was conducted using CPODs (Continuous Porpoise Detectors, from Chelonia Limited, UK). These were deployed in a smaller area that extended ca $15 \mathrm{~km}$ to the SSE from Buitengaats and ca $40 \mathrm{~km}$ to WSW from ZeeEnergie. The study area also covers the Borkum Riffgrund area which is a special protected area in German waters. 


\subsection{Gemini windfarm construction activities}

Most disturbance of harbour porpoises is expected to occur during pile driving activities. Other associated activities, however, such as movement and light from vessels may also affect harbour porpoise behaviour. The construction activities in the Gemini windfarm area include:

- Preparation of the field, including unexploded ordnance clearance

- $\quad$ Stone dropping for scour protection at monopile pads and cable crossings

- $\quad$ Pile driving of monopile foundations

- Cable installation

- Attachment of towers and turbines to monopile foundations

Gemini provided data on these activities. Preparation of the field and stone dropping for scour protection took place after monitoring for T-0 had ceased, but before monitoring for T-c had begun. Attachment of towers and turbines started after monitoring for T-c had stopped.

\subsection{Aerial surveys}

\subsubsection{Survey design}

For the aerial surveys, the same design as in T-0 was used (Figure 3), which comprises 12 parallel transect lines each between 93 and $116 \mathrm{~km}$ long, with a total length of ca 1,275 km. The transect lines are spaced $6.1 \mathrm{~km}$ apart. The survey area covers approximately $7,800 \mathrm{~km}^{2}$. The transect lines extend out from the coastline of the western Wadden Sea Islands in a NNW direction and run perpendicular to depth contours (see Annex 1 for the coordinates of the transects).

The study area was surveyed within one day using two airplanes/teams simultaneously during the T-0 monitoring. For the T-c monitoring in 2015 only one airplane could be provided by the airport FLN FrisiaLuftverkehr $\mathrm{GmbH}$. Thus the survey was divided into two flight days with six transects flown each day; alternating transects were assigned to the subsets 'red' and 'green' (see Figure 3). By surveying a subset the whole study area was covered during each flight day. In this case the distance between the transect lines was $12.2 \mathrm{~km}$. Thus each flight day comprised the surveying of 6 transect lines, whereby after line 4 a stop for refuelling at the German island Borkum was necessary. Surveys were conducted in weather conditions safe for flying operations (no fog or rain, no chance of freezing rain, visibility $>3 \mathrm{~km}$ ) and suitable for porpoise surveys (Beaufort sea state $\leq 3$ ). The transects were flown in an order and direction to maximize the best possible sighting conditions.

Five surveys were scheduled for the T-c monitoring, originally planned with one survey each month from July to November. Due to excellent weather conditions one survey was scheduled on short notice end of June right before the start of piling. The second survey was carried out two days after the start of piling, as well as another three monthly flights from August to October.

\subsubsection{Data collection}

Aerial surveys were conducted with a Britten-Norman BN-2 Islander, a high-winged twin-engine airplane equipped with bubble windows. These planes are identical in construction and are without difference concerning observing conditions as the planes used during T-0. Surveys were conducted flying at an altitude of ca $183 \mathrm{~m}$ (600 feet) with a speed of ca $186 \mathrm{~km} / \mathrm{hr}$ (ca 100 knots). Every four seconds, the time and the aircraft's position were recorded automatically onto a laptop computer connected to a GPS. Surveys were conducted by a team of three people. Sighting information and details on environmental conditions were entered by one person (the navigator) at the beginning of each transect and whenever conditions changed. Observations were made by two dedicated observers located at bubble windows on each side of the aircraft. For each observation of a cetacean or seal, the observer acquired the following data: species, declination angle (measured with an inclinometer from the aircraft abeam to the group), group size, presence of calves, behaviour (see Table 1), swimming direction, cue and reaction to the survey plane. The perpendicular distances from the transect to the sighting were later calculated from aircraft altitude and declination angle. Environmental data included sea-state (Beaufort scale), turbidity (4 classes, assessed by visibility of objects below the sea surface), cloud cover (in octaves), glare and 
subjective sighting conditions (Table 2). These sighting conditions represent each observer's subjective view of the likelihood that the observer would see a harbour porpoise within the primary search area ( $<300 \mathrm{~m}$ from the track line) should one be available for detection, and this qualification could differ between left and right sides of the airplane.

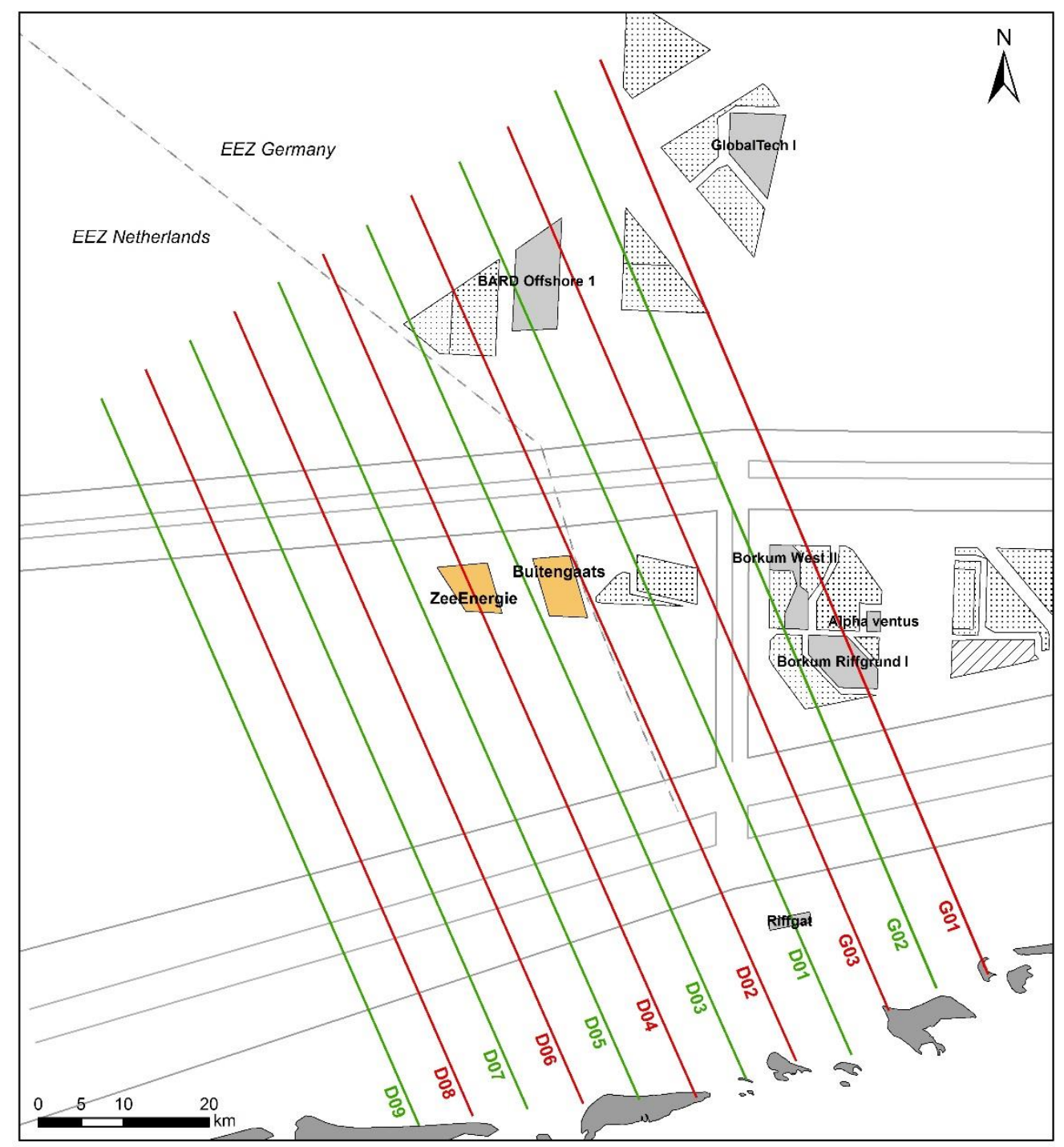

\section{Overview Aerial surveys}

\begin{tabular}{|c|c|c|}
\hline & OWF approved & - Transects Part 1 \\
\hline & OWF under construction & Transects Part 2 \\
\hline & OWF in operation & Ship traffic seperation \\
\hline & OWF Gemini & _ _ International boundary \\
\hline & Coastline & \\
\hline
\end{tabular}

Figure $3 \quad$ Survey design of the aerial surveys.

Table 1 Behavioural codes and description for marine mammals.

\begin{tabular}{ll}
\hline Code & Behaviour \\
\hline Swim & Directional swimming \\
Slswim & Slow directional swimming \\
Fasw & Fast directional swimming or porpoising \\
Mill & Milling, non-directional swimming \\
Rest/Log & Resting/logging: not moving at the surface \\
Feed & Feeding \\
Headup & Spy-hop of seals vertically in the water column \\
Other & Other behaviour, noted down in comments \\
\hline
\end{tabular}


Table 2 Description of subjective sighting conditions.

\begin{tabular}{ll}
\hline Sighting conditions & Description \\
\hline Good $(\mathrm{G})$ & $\begin{array}{l}\text { Observer's assessment that the likelihood of seeing a porpoise, should one be } \\
\text { available to be seen within the search strip, is good. Normally, good subjective } \\
\text { conditions will require a sea state of two or less and a turbidity of less than } \\
\text { two. }\end{array}$ \\
$\begin{array}{l}\text { Observer's assessment that the likelihood of seeing a porpoise, should one be } \\
\text { available to be seen within the searching area, is moderate. Further differentiation } \\
\text { into "good" moderate conditions (W - wicked) and "poor" moderate conditions (S - sucks) } \\
\text { if appropriate. } \\
\text { Observer's assessment that it is unlikely to see a porpoise, should one be } \\
\text { available to be seen within the search strip. } \\
\text { Observer off effort due to adverse circumstances (e.g. rain or fog) }\end{array}$ \\
\hline
\end{tabular}

\subsubsection{Analysis}

All collected data was checked post-survey and any errors, e.g. consistency of codes, were corrected. This checked data was subsequently stored in the Dutch aerial survey database. During line-transect distance sampling, the perpendicular distance of a sighting to the track line is measured. To measure the distance, the plane flies at a constant height $(600 \mathrm{ft}=183 \mathrm{~m})$ and the vertical or 'declination' angle to the animal is measured when it is (estimated) abeam. These distances are used in the later analyses to estimate the effective strip-width (ESW) covered by the observers. The ESW is essential to calculate the density of animals along the track line. The ESW is calculated using the distance sampling software DISTANCE 6.0 (Thomas et al. 2010). It is determined by the detection function that describes the distribution of the sightings. The latter typically shows a non-linear decline with increasing perpendicular distance from the transect line (Buckland et al. 2001).

For analysis only transects flown at "good" or "moderate" sighting conditions and at sea-states equal or less than Beaufort 4 are used. The DISTANCE software adjusts a detection function using variations of key parameters (cosine, hazard rate) and adjustment terms if necessary (uniform, half-normal). The best fitted function was chosen by the smallest AIC (Akaike Information Criterion) value. Based on the recorded data the effective strip width (ESW) is $219 \mathrm{~m}$ in good and $218 \mathrm{~m}$ in moderate sighting conditions (Table 3 ). The $95 \%$ confidence intervals are also calculated as a measure of possible variation in densities of animals.

Table 3 Effective strip width (ESW) for good and moderate sighting conditions. Lower $95 \%$ confidence interval (LCI) and higher $95 \%$ confidence interval (HCI) are given.

\begin{tabular}{lll}
\hline Sighting conditions & Good & Moderate \\
\hline ESW & $219 \mathrm{~m}$ & $218 \mathrm{~m}$ \\
ESW LCI & $182 \mathrm{~m}$ & $205 \mathrm{~m}$ \\
ESW HCI & $264 \mathrm{~m}$ & $233 \mathrm{~m}$ \\
Model, key function & hazard-rate & hazard-rate \\
\hline
\end{tabular}

One of the assumptions of line-transect distance sampling is that all animals are detected on the track line, which would mean that the chance to see all animals at a distance of $0 \mathrm{~m}$ from the track line is 1 $(100 \%)$. For cetaceans this assumption is not true. A correction factor, called $g(0)$, needs to be obtained to correct for the proportion of animals missed on the track line, in order to calculate actual density estimates from the observations. In practice there are two reasons why animals are not recorded: 1 . the animals are not "available" to be seen, (e.g. because they are submerged) or 2. they are missed by the observers ("observer bias"). So, the proportion of present animals that is detected by the observer team must be known. Of these, the observer bias is a potential problem when using two (identical) airplanes as the different teams might have different values for observer bias. We deal with this problem by randomizing observers over observer teams, so that we end up with a single $g(0)$ for the entire team.

To calculate $\mathrm{g}(0)$, we use the 'racetrack' method (Hiby \& Lovell 1998, Hiby 1999), where the plane circles back over a section of the transect line and re-samples it. This allows an estimate to be made of the resightability of an animal which is known to be present (and detection of animals that were not available to the observer on the first pass). In general 50-100 racetracks are needed to determine a reliable $\mathrm{g}(0)$ for a particular area. Seven racetracks were flown during the five aerial surveys in 2015 and another 18 racetracks during the T-0 monitoring. The total number of racetracks is still too low to 
calculate a $\mathrm{g}(0)$ at this stage. The porpoise monitoring for Gemini was expected to be done, using the same method, during five years in the operational phase. The idea was to use these five years to estimate Gemini-specific $\mathrm{g}(0)$ s. Spreading the racetrack flights over the entire duration of the project is also preferred from a statistical point of view, assuming the survey team does not change considerably. Therefore alternatively the $\mathrm{g}(0)$ values used by IMARES (WMR) in Dutch waters and by ITAW in German waters are used (Scheidat et al., 2008): $g(0)$ of 0.37 for good sighting conditions and 0.14 for moderate conditions.

The data can also be analyzed without 'Gemini-specific' $g(0)$ s. Having these would result in absolute density estimates and would allow comparison of observations with other density estimates, and would hence strongly improve the degree to which the data from this project can be put into a broader perspective. From a scientific standpoint, such a wider perspective is needed, as survey observations (even repeated observations) are still isolated snapshots in time.

In distance analyses, detection probability of clusters of individuals is modelled. This means that the resulting density represents the density of clusters of individuals. To achieve a density of individuals, the density of clusters needs to be multiplied by the average group size.

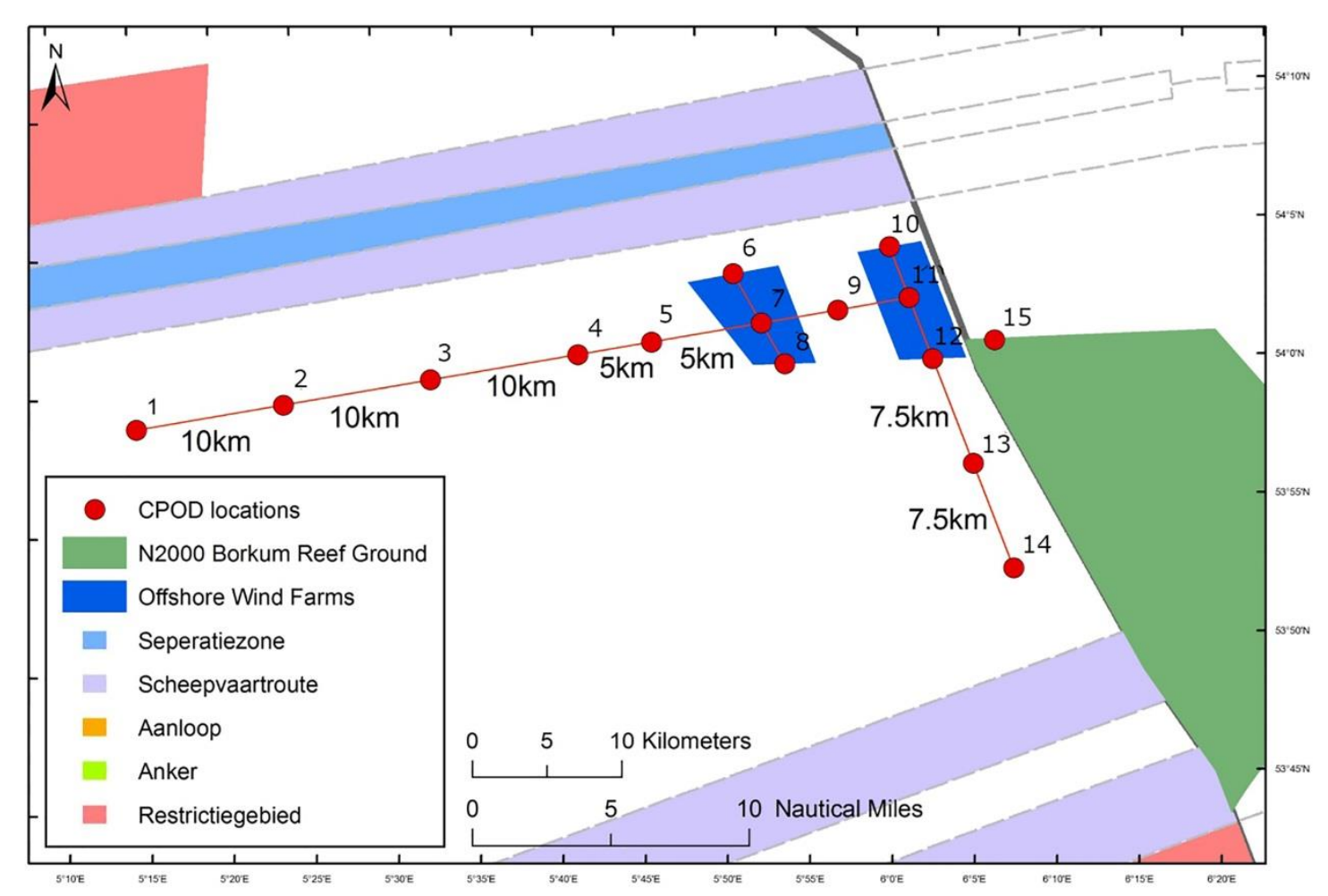

Figure 4 Location of the CPODs during T-c. Note the different numbering of the locations and the slightly different locations compared to T-O Table 4 (Geelhoed et al., 2015a).

\subsection{Passive acoustic monitoring}

\subsubsection{Study design}

For the passive acoustic monitoring during T-c, the design comprised of fifteen CPODs (Figure 4, Table 3). The positions of the CPODs were restricted by the shipping lane in the north, and the German border, as well as planned and operational wind farms in Germany, in the east. Six CPODs were positioned in the ZeeEnergie and Buitengaats wind farm areas. The numbering of the CPOD locations was changed to facilitate servicing by RWS-vessel Terschelling (Table 4). The line of CPODs in Buitengaats was extended with two more CPODs, thus perpendicular to depth gradients (locations GEM 13 and 14). Another series 
of CPODs was positioned along a gradient parallel to the ship traffic route. One CPOD was positioned in German waters at GEM 15, east of Gemini.

Table 4 Location of CPODs in the Gemini-study area. Coordinates in UTM 31N ETRS89 are presented in Annex 1.

\begin{tabular}{|c|c|c|c|c|c|c|}
\hline \multicolumn{2}{|c|}{$\frac{\text { T-C }}{\text { CPOD location Description }}$} & \multirow{2}{*}{$\begin{array}{c}\text { Lat } \\
(\mathbf{N}) \\
53.98\end{array}$} & Lon & \multirow{2}{*}{\begin{tabular}{|l|}
-0 \\
Old name \\
GEM 01
\end{tabular}} & \multirow{2}{*}{$\begin{array}{c}\text { Lat } \\
(\mathbf{N}) \\
53.98\end{array}$} & \multirow{2}{*}{$\begin{array}{r}\text { Lon } \\
\text { (E) } \\
5.247\end{array}$} \\
\hline GEM 01 & $40 \mathrm{~km}$ west of Gemini & & 5.247 & & & \\
\hline GEM 02 & $30 \mathrm{~km}$ west of ZeeEnergie & 53.99 & 5.398 & GEM 15 & 54.01 & 5.549 \\
\hline GEM 03 & $20 \mathrm{~km}$ west of Gemini & 54.01 & 5.459 & GEM 02 & 54.02 & 5.701 \\
\hline GEM 04 & $10 \mathrm{~km}$ west of Gemini & 54.02 & 5.701 & GEM 03 & 54.02 & 5.776 \\
\hline GEM 05 & $5 \mathrm{~km}$ west of Gemini & 54.02 & 5.776 & GEM 04 & 54.06 & 5.862 \\
\hline GEM 06 & ZeeEnergie North & 54.06 & 5.862 & GEM 05 & 54.03 & 5.889 \\
\hline GEM 07 & ZeeEnergie centre & 54.03 & 5.889 & GEM 06 & 54.01 & 5.911 \\
\hline GEM 08 & ZeeEnergie South & 54.01 & 5.911 & GEM 07 & 54.04 & 5.968 \\
\hline GEM 09 & between ZeeEnergie and Buitengaats & 54.04 & 5.968 & GEM 08 & 54.07 & 6.023 \\
\hline GEM 10 & Buitengaats North & 54.07 & 6.023 & GEM 09 & 54.04 & 6.041 \\
\hline GEM 11 & Buitengaats & 54.04 & 6.041 & GEM 10 & 54.01 & 6.063 \\
\hline GEM 12 & Buitengaats South & 54.01 & 6.063 & GEM 11 & 53.94 & 6.099 \\
\hline GEM 13 & $7.5 \mathrm{~km}$ south of Buitengaats & 53.94 & 6.099 & GEM 12 & 53.88 & 6.136 \\
\hline GEM 14 & $15 \mathrm{~km}$ south of Buitengaats & 53.88 & 6.136 & GEM 13 & 54.02 & 6.126 \\
\hline GEM 15 & Outside Buitengaats & 54.01 & 6.126 & GEM 14 & 53.99 & 5.398 \\
\hline
\end{tabular}

\subsubsection{Description of CPOD}

A CPOD relies on the stereotypical nature of porpoise echolocation signals. These are distinctive in lasting about 50-150 microseconds, and containing virtually no energy below $100 \mathrm{kHz}$. The main part of the energy is in a narrow band between $120-150 \mathrm{kHz}$, peaking at around $132 \mathrm{kHz}$, which makes the signals ideal for automatic detection. Detection of harbour porpoise clicks is basically done by a comparison of the energy of the acoustic signal in a small band around a high and a low frequency, the so-called Aand B-filter. Acoustic signals that have substantially more energy in the A-filter are indicating a click produced by a harbour porpoise. Most other sounds in the sea, except some boat sonars, are more broadband or have more energy at lower frequencies. Although many non-porpoise clicks are also recorded, these, as well as boat sonars and echo-sounders, are filtered out during post-processing, by analysing the time intervals between successive clicks. Porpoise click trains are recognisable by a gradual change of click intervals and amplitudes throughout a click sequence. In comparison boat sonars and echo-sounders have highly consistent inter-click intervals. Clicks of other origins tend to occur at random with highly irregular intervals, so a probability model of a train is used as the basis of the train filter. For this study, the A-filter frequency was set at $100 \mathrm{kHz}$ and the B-filter frequency was set to $80 \mathrm{kHz}$. The train quality filter was set to record $\mathrm{Hi}(\mathrm{gh})$ and Mod(erate) quality click trains from porpoiselike clicks and dolphin clicks. This setting filters out click trains of low quality and thus reduces the number of false detections.

The sensitivity of the CPODs was standardized by the manufacturer (Chelonia Ltd) before shipping to IMARES/Wageningen Marine Research. To check the sensitivity of each CPOD, it is rotated in a sound field and adjusted to give a radially averaged, temperature corrected, sound pressure reading within $5 \%$ of the standard at $130 \mathrm{kHz}( \pm 0.5 \mathrm{~dB})$. Calibration was undertaken by the National Physical Laboratory in the United Kingdom. Only CPODs that have a radial variation $< \pm 3$ dB relative to the mean sensitivity are used. On top of the manufacturer's standardization, the calibration of all CPODs was rechecked twice in the accredited German Meeresmuseum in Stralsund on 7 August 2015 and 7 December 2015. The CPODs were tested in a test tank to estimate the variation in sensitivity, using calibrated hydrophones as receiver and transmitter. The transmitter sent out acoustic signals at different 
frequencies that were measured by a calibrated hydrophone. This hydrophone was then replaced by a CPOD for sound exposure to the same calibration signals. The same procedure was repeated on four different positions along the PODs horizontal axis in order to measure directional variation. The sensitivity of a CPOD is compared to the received levels and mean peak-to-peak pressures (Ppp) of the calibrated hydrophones. Detection thresholds and the relationship between receiving level and the corresponding Ppp-values for each CPOD were calculated with two methods: $50 \%$ detection thresholds and linear regression models. Details of these calculations and the calibration method can be found in Verfuß et al. (2010).

For the calibrations, the received levels of mean peak-to-peak pressures (Ppp) emitted frequencies of $100,110,120,130$ and $140 \mathrm{kHz}$ are examined for each individual CPOD. Since the main part of the energy of a porpoise click is around $132 \mathrm{kHz}$ the differences at $130 \mathrm{kHz}$ are the most applicable for comparison. The highest variation in peak-to-peak pressure at $130 \mathrm{kHz}$ lies between 110 and $120 \mathrm{~dB}$ re $\mu 1 \mathrm{~Pa}$ for most PODS. This difference in peak-to-peak pressure corresponds to a difference in received sound level of less than $3 \mathrm{~dB}$. Three CPODs (1884, 1744 \& 1549) had Ppp-levels above $120 \mathrm{~dB}$ re $\mu 1 \mathrm{~Pa}$, corresponding to a difference in received sound level of less than $5 \mathrm{~dB}$ (pers comm Anne Hermann, Meeresmuseum). The results of the calibrations showed that all CPODs were operating within the maximum accepted variation recommended by the international AMPOD-project (Verfuß et al., 2010, see Annex 5 and 6).

\subsubsection{Data collection}

For the purpose of this study, a pool of 30 CPODs ( 1 , Version 1 ) was used, to have fifteen in the water at a time, and replace those periodically. Retrieved CPODs had their memory cards removed and downloaded and were cleaned and equipped with new batteries for following deployments. The first deployments at the fifteen CPOD locations were made in June 2015. The CPOD locations were serviced three times (29 Sep, $3 \& 27$ Oct 2015). CPODs at each location were replaced with new CPODs, and all equipment was recovered in December 2015 respectively February 2016.

The mooring used for the CPODs was similar to the moorings used previously in Dutch studies (Brasseur et al., 2010). This included using robust material, i.e. buoys, chains and concrete anchors. The CPODs were secured with a mooring of two buoys, of which the larger was equipped with a yellow warning lantern. The second buoy served as an extra security measure to avoid the risk of collision with vessels (e.g. trawlers) in the area. The CPOD floats approximately $1 \mathrm{~m}$ above the concrete anchoring and thus approximately $1 \mathrm{~m}$ above the sea bed.

CPODs do not record the actual time, therefore the time of data collection needs to be assigned to the CPOD-files after retrieval of the data. During deployment of PODs the following times are recorded in GMT: activation time of the CPOD and time the CPOD hits the water surface. During recovery the time the CPOD emerges from the water is recorded, as well as the time the CPOD is deactivated.

\subsubsection{Post-processing}

Following recovery of the CPODs, the memory card is taken out and the data downloaded and processed with the software "CPOD.exe" version 2.024. Before downloading the files a date and a start time is assigned to the so-called CP1-files; this should be the activation time of the CPOD. To validate the data the file is checked visually, if the three other times that are noted during deployment and retrieval correspond with the times CPOD.exe assigned to the data. Each file was truncated at the start and end to delete erroneous data. The CP1-files were converted to so-called CP3-files with the software's detection algorithm 2.024 to identify series of harbour porpoise clicks. A sample of the CP3-files was screened for errors by visually checking graphs that show different parameters, like click frequency, angle of the CPOD, and temperature measured by the CPOD.

After analysis of the data it turned out that the assigned start time of the CP1-files was incorrect, the time at water surface was used instead of the activation time. As a consequence all CP3-files were checked (again), the times were corrected, and erroneous data were deleted (see Annex 3 for corrections). 


\subsubsection{Analysis}

Data were exported and further analysed using Excel and R-software (R Development Core Team, 2009). We use click frequency as an indicator of harbour porpoise presence (Carstensen et al., 2006, Van Polanen Petel et al., 2012; Teilmann et al., 2009; Tougaard et al., 2006a \& b). Click frequency is based on the fundamental unit of clicks-per-minute. This consists of many zero observations (minutes without click trains), as well as Porpoise Positive Minutes. The click activity was aggregated into daily values of:

Proportion of Porpoise Positive Minutes (DPM) per hour per day

$$
=\frac{\text { Number of minutes with clicks }}{\text { Total number of minutes }}=\frac{N\left\{x_{t}>0\right\}}{N_{\text {total }}} * 60
$$

The acoustic data is used to analyse if the construction of wind turbines has an effect on the distribution and behaviour of harbour porpoises; the working hypothesis is that pile driving results in lower acoustic activity of harbour porpoises. The following questions are of specific interest: if there is a negative effect of pile driving, in which range is there an effect? And secondly how long after pile driving stopped does the effect continue?

Similar to T-0, Generalized Additive Mixed Models (GAMM) were used to describe the spatial and temporal distribution of harbour porpoises - expressed as acoustic activity (DPM/h) - in the area. A GAMM describes patterns in a parameter (e.g. acoustic activity) caused by multiple variables taking the underlying patterns caused by all these variables into account. To describe harbour porpoise acoustic activity in the area a GAMM takes different potential sources of variation, including CPOD number, season, data gaps, temporal correlation (day of the year), longitude, latitude, and environmental covariates such as time to high tide, wind speed etc. into account. For some of these variables (e.g. longitude) a non-linear effect is expected, in which case a smooth function was incorporated in the model. Time of the day and time to high tide are cyclic variables, for which cyclic smoothers were used. This means that the smooth function is restricted in such a way that the first value of the smoother needs to connect to the last value.

To determine which covariate has the largest effect on the number of porpoise positive minutes, a (stepwise) forward selection procedure, based on the Akaike Information Criterion (AIC), is applied. The model with the best fit and the least number of covariates has the lowest AIC and is selected as best fitting model for this particular set of variables. The covariate that produced that best model is then taken out and the step-wise procedure continues with the remaining covariates. If adding a variable leads to a lower AIC, it means that the inclusion of that variable significantly describes the variability in porpoise detections. Based on the final model, a prediction is made of the daily mean DPM/h as a function of individual covariates. The result is graphically presented as a solid line with $95 \%$ confidence intervals, which show the variation in the predicted DPM/h (e.g. Figure 14).

To analyse the effects of pile driving on acoustic activity of harbour porpoises, pile driving events are added to the GAMM. We analysed the effect on acoustic activity of distance to the pile driving source $(\mathrm{km})$, time relative to pile driving $(\mathrm{hr})$ and the length of pile driving $(\mathrm{hr})$. 


\section{Gemini wind farm construction activities}

\subsection{Pre-pile driving activities}

Construction of the Gemini wind farms consisted of several activities, of which pile driving is supposed to be the most adverse for harbour porpoises. Therefore, the focus of this report is on pile driving. Before the start of pile driving the field in which the wind farm is to be installed, needs to be surveyed to determine exact bathymetries and sediment types at the tower installations. The area was surveyed for unexploded ordnance and those located were detonated on site using TNT explosives. Between 11 May and 25 June 2015, nine underwater explosions were required to clear ordnance that was located within the windfarm areas. The last explosion took place five days before piling started.

To inhibit scouring by water movement around the base of monopiles, layers of stones are dropped to form pads on the sea-floor prior to installation of the towers. The stone-dropping vessel positions over the site and stones are steadily pushed overboard. Sonar scans during stone-dropping provide accurate monitoring of the shape of the scour protection pads on the sea bottom. Scour protection took place between 15 February and 9 September 2015.

\subsection{Pile driving}

For Gemini wind farms, pile driving was conducted by two jack-up vessels, Aeolus and Pacific Osprey, in the period 1 July to 17 October 2015. The vessels operated from Eemshaven. Generally, three monopiles were loaded on board of a jack-up vessel and, weather allowing, the vessel sailed to the Gemini area. At the right position, the vessel lowered its' four legs to the seafloor and jacked up. A monopile was craned over the side of the vessel, positioned into a holding frame and lowered to the seafloor. Once in place, the hammer mechanism was fixed to the top of the monopile. The time between arrival of the vessel and piling lasted at least $4 \mathrm{hrs}$. On average it lasted $5 \mathrm{hrs}$, and occasionally longer than 6 hrs.

Each monopile had a unique pile driving record. Typically, hammering commenced with a 'soft-start', i.e. no (or light) power. This was to ensure the tower seated well and penetrated the substrate in a controlled manner. As the monopile penetrated further into the substrate, the power to the hammer and blow frequency generally increased. Hammering was at a rate of 40-50 blows per minute. Energy levels reached up to a maximum of $80 \%$ capacity, which was approximately $1400 \mathrm{~kJ}$. Hammering was not continuous through a pile driving event. For periods of several seconds, initial hammering was followed by breaks in hammering of up to several minutes for observation and adjustment. Durations of hammering tended to increase through each pile driving event up to durations of continuous hammering in the later stages lasting 30 minutes or longer.

Upon achieving a required depth, the hammer was removed from the monopile, fixtures (e.g. platform) were attached, and the vessel jacked-down and moved to the next location. After all monopiles had been installed (or bad weather delayed further installation) the vessel returned to Eemshaven to restock before returning to install further monopiles. This resulted in a gap in pile driving by that vessel of 2-3 days.

\subsubsection{FaunaGuard}

Before piling of the monopiles started, a so-called FaunaGuard (an acoustic porpoise deterrent, SEAMARCO Ltd) was switched on. This device produced sounds at ultra-sonic frequencies $(60-150 \mathrm{kHz})$, which were higher than could be detected by seals, whose frequency range for best hearing is 0.5 to 40 $\mathrm{kHz}$ (Kastelein et al. 2009). The spectrum of the transmitted sounds varies, increasing the effect of the unit and reducing habituation to the emitted sound by porpoises. When starting the unit, the sound level is slowly ramped up. This prevents potential damage to porpoise hearing (i.e. animals are given time to swim away). Maximum source level is $172 \mathrm{~dB}$ re $1 \mu \mathrm{Pa}$ at $1 \mathrm{~m}$. The FaunaGuard's aim was to scare away 
harbour porpoises from the immediate vicinity prior to the start of pile driving, so as to avoid potential injuries to them from the underwater sound produced by the pile driving. After completion of pile driving, the FaunaGuard was switched off.

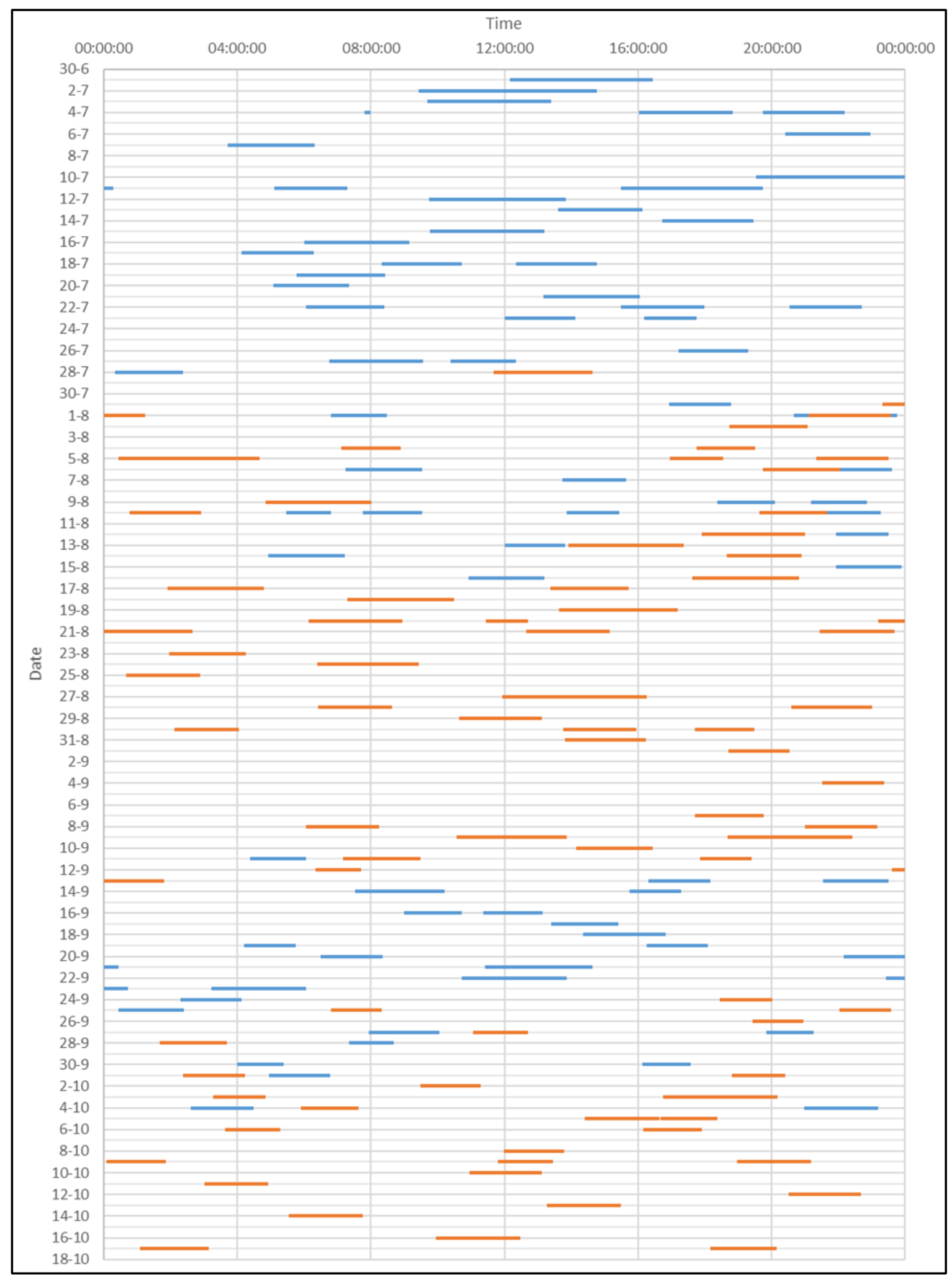

Figure 5 Timing of pile driving activity in ZeeEnergie (orange) and Buitengaats (blue), 1 July - 17 October 2015. Bars show timing and duration of pile driving (see Annex 2 for details).

Data on FaunaGuard activation was available for $91 \%$ of the piling events $(n=158)$. It was activated on average 73 minutes before piling started. It was switched on at the latest 24 min before piling started. On the few occasions when the start of pile driving was delayed (5, 17, 21 \& 25 Aug, 25 Sep) the FaunaGuard was switched on up to $13 \mathrm{hrs}$ before piling started and switched off after piling stopped. 
During most piling events $(n=144)$, the FaunaGuard was switched off on average 26 min after piling stopped, albeit it was switched off on four occasions 28 min before piling ceased.

\subsubsection{Timing of piling}

Pile driving occurred between 1 July 2015 and 17 October 2015 (Figure 5). Pile driving occurred on 84\% of all days $(n=110)$. No piling activities took place on 5, 8-9, 24-25, 29-30 July, 3, 8, 11, 22 \& 26 August, 2-3, 5-6 \& 15 September and, 7 October. Piles required an average of approximately 79 minutes (57-110 $\mathrm{min}$ ) to be driven in to their required depth, and 127 minutes (76-254 min) between the start of piling and the final blow. When a pause of $>60 \mathrm{~min}$ was taken, the pile driving was considered to be separate multiple events. In total there were 158 monopiles driven into the seabed, comprising 150 turbine foundations and eight Offshore High Voltage Stations (OHVSs). However, some of these pile driving events were considered to be multiple events as more than an hour break was taken between them, resulting in a total of 166 pile driving events. The time between pile driving events lasted on average 8:01 hrs (SD 7:48 hr).

Pile driving occurred in Buitengaats 1-28 July, and 13-24 September. In ZeeEnergie pile driving occurred 16 August-13 September, and 5-17 October. Gemini was granted special permission to conduct simultaneous pile driving in both Buitengaats and ZeeEnergie. Pile driving could occur simultaneously in both wind parks in two periods: 28 July 2015 11:00 till 16 August 2015 16:00, and 24 September 2015 12:00 till 5 October 2015 0:00. During these periods pile driving overlapped in time on nine occasions.

\subsection{Post-pile driving activities}

After scour protection was made, towers and turbines were attached to the monopile foundations. This required further visits to each site by a jack-up vessel and craning the structures into position on the foundation monopile. These activities started in February 2016, after monitoring stopped.

Cables connecting all turbines with the OHVSs and a cable to a facility at Eemshaven were installed between half January and half October 2015. Cables to the OHVS were laid from half May to half October 2015. 


\section{Aerial surveys}

\subsection{Effort}

Between June and October 2015, five aerial surveys were carried out by a team of seven observers and two navigators from IMARES/Wageningen Marine Research and IBL Umweltplanung (Table 5). The observer team was kept as constant as possible to minimize observer variation. In comparison to the T0 monitoring only one person was replaced.

One full survey was carried out 29 and 30 June 2015 right before the piling started. The other surveys took place during the pile driving phase. A last survey scheduled for the time after pile driving could not be conducted due to long-lasting adverse weather conditions.

Each survey consists of two flight days covering the subsets "green" and "red" (see Figure 2), which resulted in 10 flight days. Two flights had to be aborted after the first two transect lines due to unsuitable weather conditions and are excluded from the following calculations. The other 8 flights were fully completed.

Table 5 Planes and observers per aerial survey.

\begin{tabular}{lllllll}
\hline Flight date & Part & Planes & Observer & Observer & Navigator & Comments \\
\hline 29 Jun 2015 & green & D-ILFH & H Verdaat* & M Joost & U von Elsberg & Before construction \\
30 Jun 2015 & red & D-ILFH & H Verdaat* & M Joost & N Stöber & Before construction \\
3 Jul 2015 & red & D-ILFH & H Verdaat* & M Schilz & N Stöber & After first piling \\
4 Jul 2015 & green & D-ILFH & H Verdaat* & M Schilz & N Stöber & Flight aborted \\
1 Aug 2015 & red & D-ILFH & A Michalik & H Wendeln & U von Elsberg & \\
2 Aug 2015 & green & D-ILFH & A Michalik & N Stöber & U von Elsberg & \\
21 Sep 2015 & red & D-IFTI & M Joost & N Stöber & U von Elsberg & \\
23 Sep 2015 & green & D-IFTI & M Joost & B Hielen & N Stöber & \\
3 Oct 2015 & red & D-IFTI & M Joost & M Schilz & N Stöber & Flight aborted \\
4 Oct 2015 & red & D-IFTI & H Wendeln & M Schilz & N Stöber & \\
* = IMARES/Wageningen Marine Research; all other observers from IBL Umweltplanung &
\end{tabular}

Table 6 Effort per survey. Survey effort is the sum of the surveyed distance on both sides under good and moderate sighting conditions.

\begin{tabular}{|c|c|c|c|c|c|c|c|c|c|}
\hline \multirow[t]{3}{*}{ Survey Date } & \multirow{3}{*}{$\begin{array}{l}\text { Distance } \\
\text { Covered } \\
(\mathrm{km})\end{array}$} & \multicolumn{7}{|c|}{ Surveyed distance $(\mathrm{km})$ both sides } & \multirow{3}{*}{$\begin{array}{l}\begin{array}{l}\text { Survey } \\
\text { effort }\end{array} \\
(\mathrm{km})\end{array}$} \\
\hline & & \multirow[b]{2}{*}{$0 / 1$} & \multicolumn{2}{|c|}{ Sea-state } & \multirow[b]{2}{*}{4} & \multicolumn{3}{|c|}{ Sighting conditions } & \\
\hline & & & 2 & 3 & & $\mathrm{~g}$ & $\mathrm{~m}$ & $\mathrm{p} / \mathrm{x}$ & \\
\hline $29 \& 30$ Jun 2015 & 1,237 & 981 & 996 & 497 & 0 & 309 & 1,981 & 183 & 2,291 \\
\hline 3 Jul 2015 & 595 & 377 & 814 & 0 & 0 & 74 & 948 & 169 & 1,022 \\
\hline $1 \& 2$ Aug 2015 & 1,223 & 902 & 1,134 & 409 & 0 & 854 & 1,592 & 0 & 2,446 \\
\hline $21 \& 23$ Sep 2015 & 1,228 & 737 & 516 & 1,204 & 0 & 903 & 1,550 & 2 & 2,454 \\
\hline 4 Oct 2015 & 605 & 0 & 9 & 666 & 535 & 14 & 1,107 & 90 & 663 \\
\hline Total & 4,889 & 2,997 & 3,470 & 2,776 & 535 & 2,155 & 7,178 & 444 & 8,876 \\
\hline
\end{tabular}

Over the five surveys, a total of 4,907 km were flown (Table 6, racetracks excluded). For each survey the total effort was calculated as kilometer covered on each side, e.g. a $10 \mathrm{~km}$ track line covered by both observers results in $20 \mathrm{~km}$ survey effort. On most survey flights some sections had to be excluded from evaluation due to unsuitable sighting conditions (sea-state $>3$, sighting conditions $\mathrm{P}$-poor or $\mathrm{X}-$ off effort). The residual total effort is listed for each flight in Table 6, summing up to a total of 8,876 $\mathrm{km}$. 


\subsection{Sightings}

Overall, 469 harbour porpoises, 11 harbour seals, 68 unidentified seals, 1 minke whale and 1 unidentified dolphin were observed during the surveys between June and October 2015. From June to September 38 calves were identified among the harbour porpoises. The calf rate ranged between $7.0 \%$ (June) and $12.3 \%$ (August) during four of the five surveys.

The unidentified seals very likely belong to one of the two native species harbour seal and grey seal. Related to effort, most seals were observed in July. The actually flown transect lines and all recorded marine mammals are illustrated in detail for each flight in Figure 25 \& Figure 26.

Table 7 Overview of recorded marine mammals. Total number of individuals observed per survey, including sightings under poor sighting conditions.

\begin{tabular}{|c|c|c|c|c|c|}
\hline Survey date & $\begin{array}{c}\text { Harbour Porpoise } \\
\text { (calves) }\end{array}$ & Harbour Seal & Seal & Minke Whale & Dolphin \\
\hline $29 \& 30$ Jun 2015 & $227(16)$ & & 21 & 1 & \\
\hline 3 Jul 2015 & $121(10)$ & & 20 & & 1 \\
\hline $1 \& 2$ Aug 2015 & $57(7)$ & 11 & 4 & & \\
\hline $21 \& 23$ Sep 2015 & $62(5)$ & & 23 & & \\
\hline 4 Oct 2015 & 2 & & & & \\
\hline Total & $469(38)$ & 11 & 68 & 1 & 1 \\
\hline
\end{tabular}

\subsection{Spatial and seasonal pattern of harbour porpoise occurrence}

In total 356 groups of harbour porpoises totalling 457 animals were sighted under moderate or good sighting conditions during the five flight surveys from June to October 2015 (Table 8). The mean group size for all surveys was 1.3 porpoise per sighting (Table 8). Highest group sizes were observed in August and September. The densities ranged between 0.05 porpoises $/ \mathrm{km}^{2}$ in October and 3.3 porpoises $/ \mathrm{km}^{2}$ in July. Reaching 3.2 porpoises/ $\mathrm{km}^{2}$ the density on 30 June was almost as high as on 3 July. These two flights ('red' transects) were conducted shortly before and shortly after the start of pile driving in the Gemini wind farm on 1 July 2015. The average density in the Gemini study area was about 1.2 porpoises $/ \mathrm{km}^{2}$ during the five month survey period (Table 8 ).

Table 8 Harbour porpoise density $\left(\mathrm{n} / \mathrm{km}^{2}\right)$ for each of the five surveys (lower $95 \%$ confidence interval (LCI) and higher $95 \%$ confidence interval (HCI) are given).

\begin{tabular}{|c|c|c|c|c|c|c|c|}
\hline Survey date & $\begin{array}{l}\text { Survey } \\
\text { area* } \\
\left(\mathbf{k m}^{2}\right)\end{array}$ & $\begin{array}{l}\text { Porpoise } \\
\text { sightings }\end{array}$ & N porpoises* & $\begin{array}{l}\text { Group } \\
\text { size }\end{array}$ & Density & $\begin{array}{l}\text { Density } \\
\text { LCI** }\end{array}$ & $\begin{array}{l}\text { Density } \\
\text { HCI** }\end{array}$ \\
\hline $29 \& 30$ Jun 2015 & 85.5 & 181 & 222 & 1.23 & 2.60 & 2.34 & 2.86 \\
\hline 30 Jun only*** & 49.9 & 131 & 161 & 1.23 & 3.23 & 2.87 & 3.60 \\
\hline $3-j u l-15$ & 34.9 & 89 & 116 & 1.30 & 3.32 & 3.04 & 3.60 \\
\hline $1 \& 2$ Aug 2015 & 117.8 & 42 & 57 & 1.36 & 0.48 & 0.42 & 0.55 \\
\hline $21 \& 23$ Sep 2015 & 120.5 & 43 & 61 & 1.42 & 0.51 & 0.44 & 0.58 \\
\hline 4 Oct 2015 & 21.0 & 1 & 1 & 1.00 & 0.05 & 0.04 & 0.05 \\
\hline Total & 379.7 & 356 & 457 & 1.28 & 1.20 & 1.06 & 1.35 \\
\hline
\end{tabular}

* = under good and moderate sighting conditions; area calculation based on $\mathrm{g}(0)=0.37$ (Scheidat et al. 2008 ) and ESW $=219 \mathrm{~m}$ for good sighting conditions and $\mathrm{g}(0)=0.14$ (Scheidat et al. 2008) and ESW $=218 \mathrm{~m}$ for moderate sighting conditions; $* *=$ based on ESWHCI and ESWLCI for good and moderate sighting conditions, see Table $3 ; * * *=$ for comparison of red transect part on 30 Jun/3 Jul before/after first pilings. 


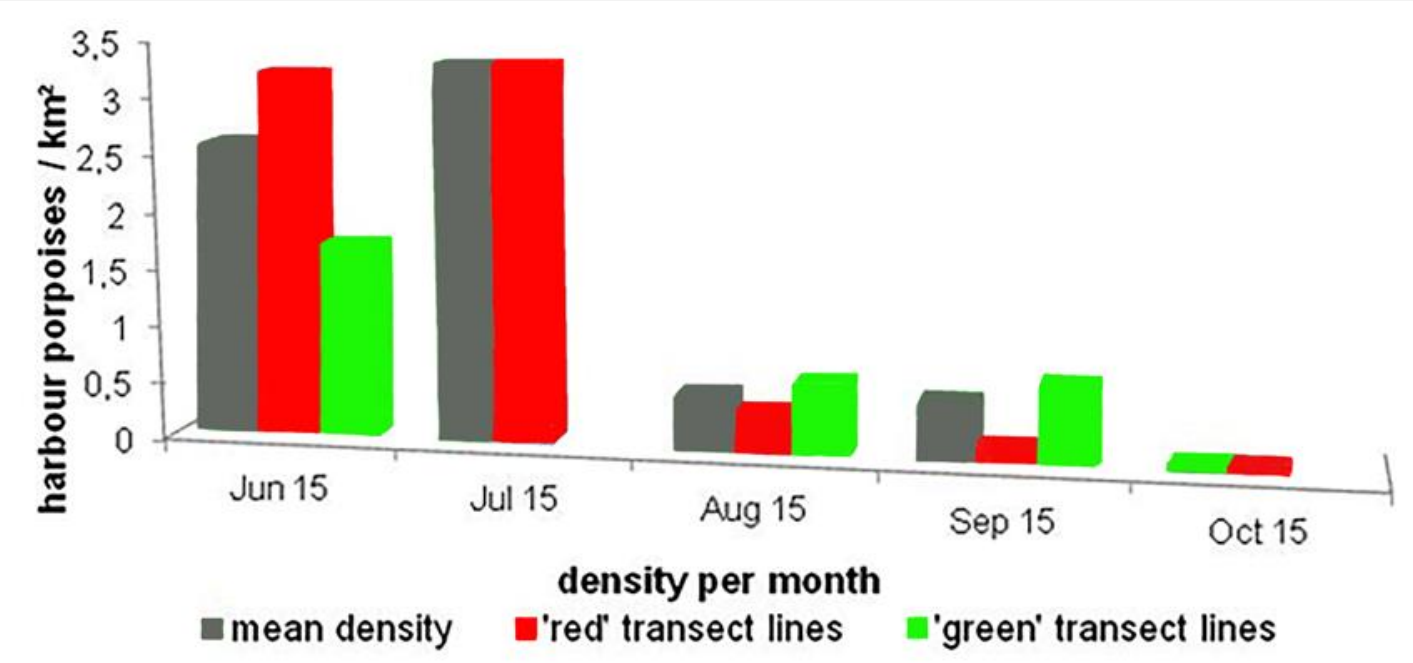

Figure 6 Harbour porpoise density $\left(\mathrm{n} / \mathrm{km}^{2}\right)$ per month.

The phenology of harbour porpoise abundance in the wider Gemini area shows a clear decline during the 2015 T-c survey period from early summer to late summer and autumn (Figure 6). After the maximum value was reached at more than 3 porpoises $/ \mathrm{km}^{2}$ around 1 July, the abundance decreased to an average level at about 0.5 individuals $/ \mathrm{km}^{2}$ in August and September. Subsequently the abundance seemed to drop fast to a very low level at the beginning of October (Table 8 and Figure 6).

At 30 June, the harbour porpoise density was noticeably higher along the 'red' transect lines than along the 'green' lines flown the day before (Figure 6). As both transect lines cover the whole survey area (see Figure 3), the difference was rather caused by differences in the distribution of the local 'population' between the survey days than by differences in survey coverage. The same applies for the August and September surveys, when the 'green' lines yielded much higher densities.

The distribution map combining all five T-c surveys shows a tendency towards higher densities along a diagonal from the northwest to the southeast of the area (Figure 7). The two Gemini wind farm sites are situated within this higher density area. Densities in the south-western part and especially in the north-eastern part around the BARD Offshore 1 wind farm tended to be lower.

Figure 8 shows the porpoise distribution during the five surveys from June to October 2015. The results of the surveys in June, July and August exhibit the predominant diagonal distribution pattern mentioned above. In September the pattern tended to shift a bit more to the southwest. In October one on effort sighting of a harbour porpoise was made in the survey area (only 'green' transect lines were flown). 


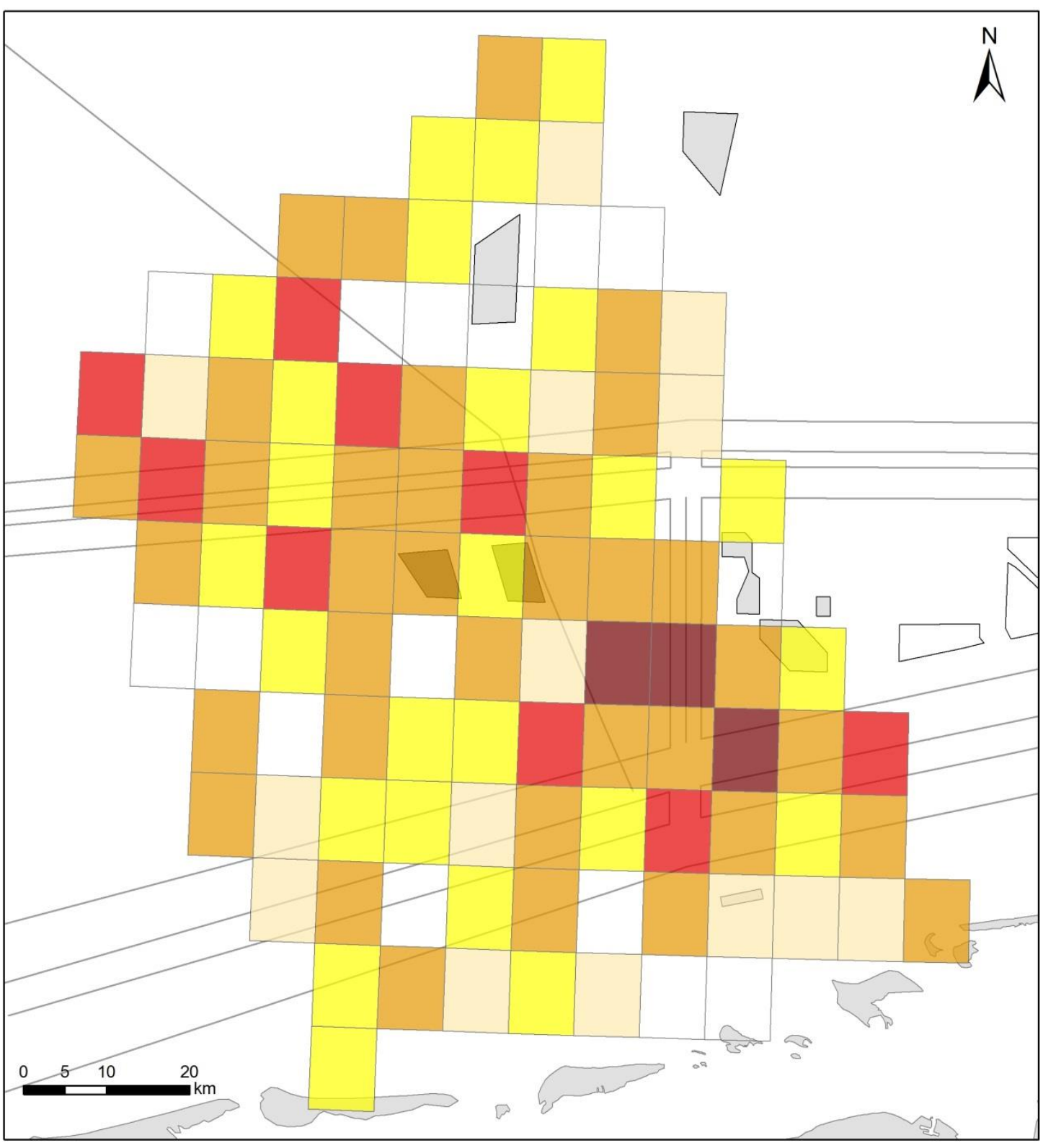

2015

Effort $\left[\mathrm{km}^{2}\right]$

Density [Porpoises $\left./ \mathrm{km}^{2}\right]$

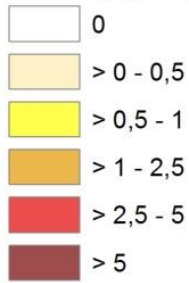

0

$M / 1>0-0,1$

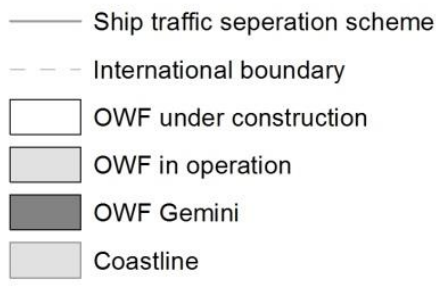

5

Figure 7 Harbour porpoise distribution $\left(\mathrm{n} / \mathrm{km}^{2}\right)$ based on five flight surveys from June to October 2015 (8 $\times 10 \mathrm{~km}$ rectangular grid). 


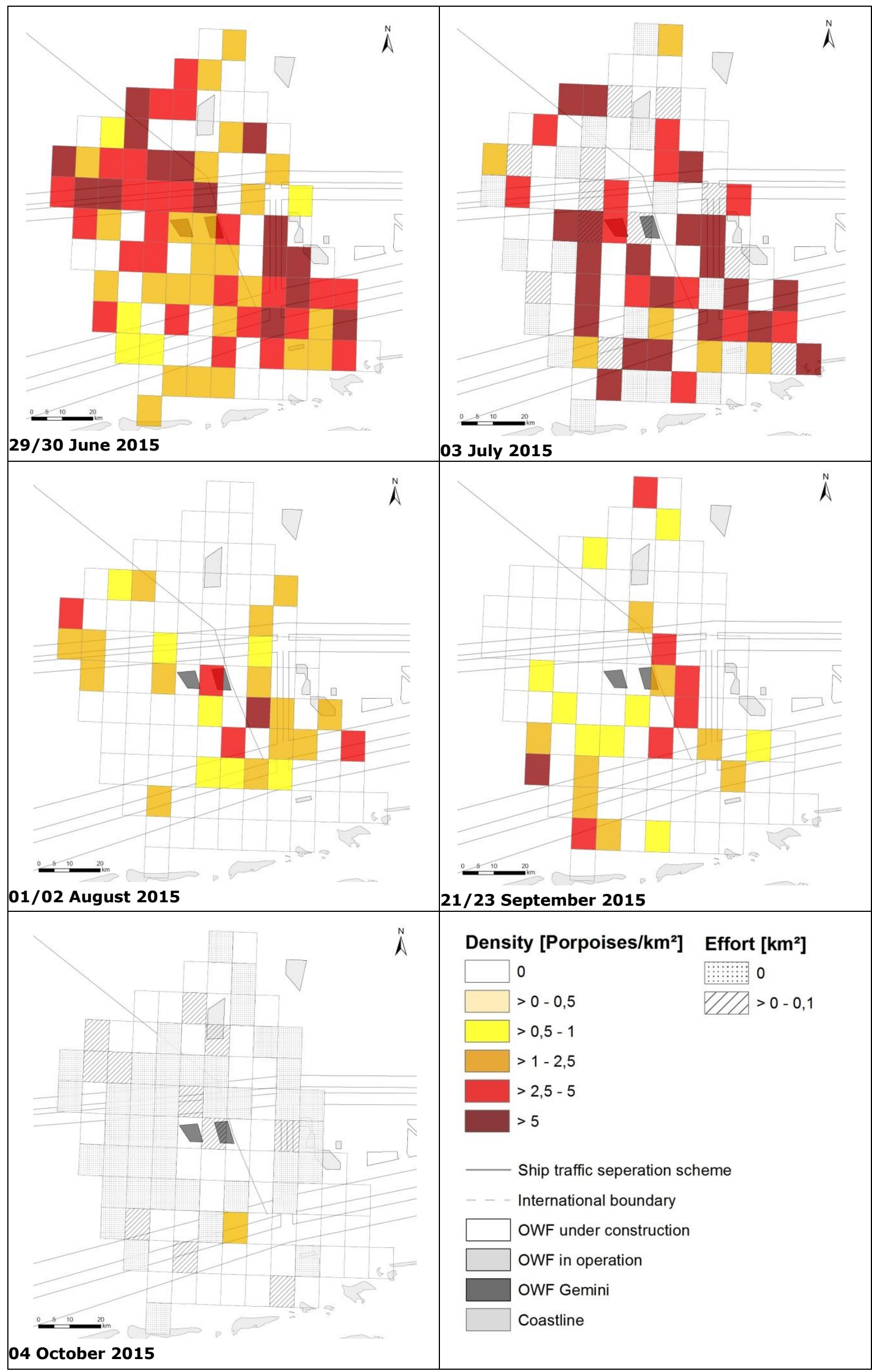

Figure 8 Harbour porpoises distribution $\left(\mathrm{n} / \mathrm{km}^{2}\right)$ for each survey month from June to October 2015 (5 surveys; $8 \times 10 \mathrm{~km}$ rectangular grid). Note that the July survey covered only half of the transects, i.c. the red transects. 


\section{Passive acoustic monitoring}

\subsection{Effort}

Between 23 June 2015 and 15 February 2016, 2,288 days of CPOD data were obtained at 15 CPOD locations. At individual CPOD locations, the amount of data collected was influenced by individual qualities of the CPODs, such as battery life, memory capacity, amount of ambient noise filling the memory capacity, technical problems like memory cards being dislodged from slots, and occasional loss of the CPODs. The exact causes of losses could not be determined, but they were attributed to failure of - improved - mooring lines due to exceptionally rough weather, or interactions with vessels (such as trawler-fishing nets). One of the CPODs that disappeared was found back in Germany, and contained several months of data. The other dislocated CPODs haven't been found back.

The data collected from individual locations ranged from 91 days at GEM 03 (ca $10 \mathrm{~km}$ west of ZeeEnergie) to 196 days at GEM 09 (between Buitengaats and ZeeEnergie). The three CPODs within ZeeEnergie collected data on 551 days, whereas the three CPODs within Buitengaats collected data on 414 days.

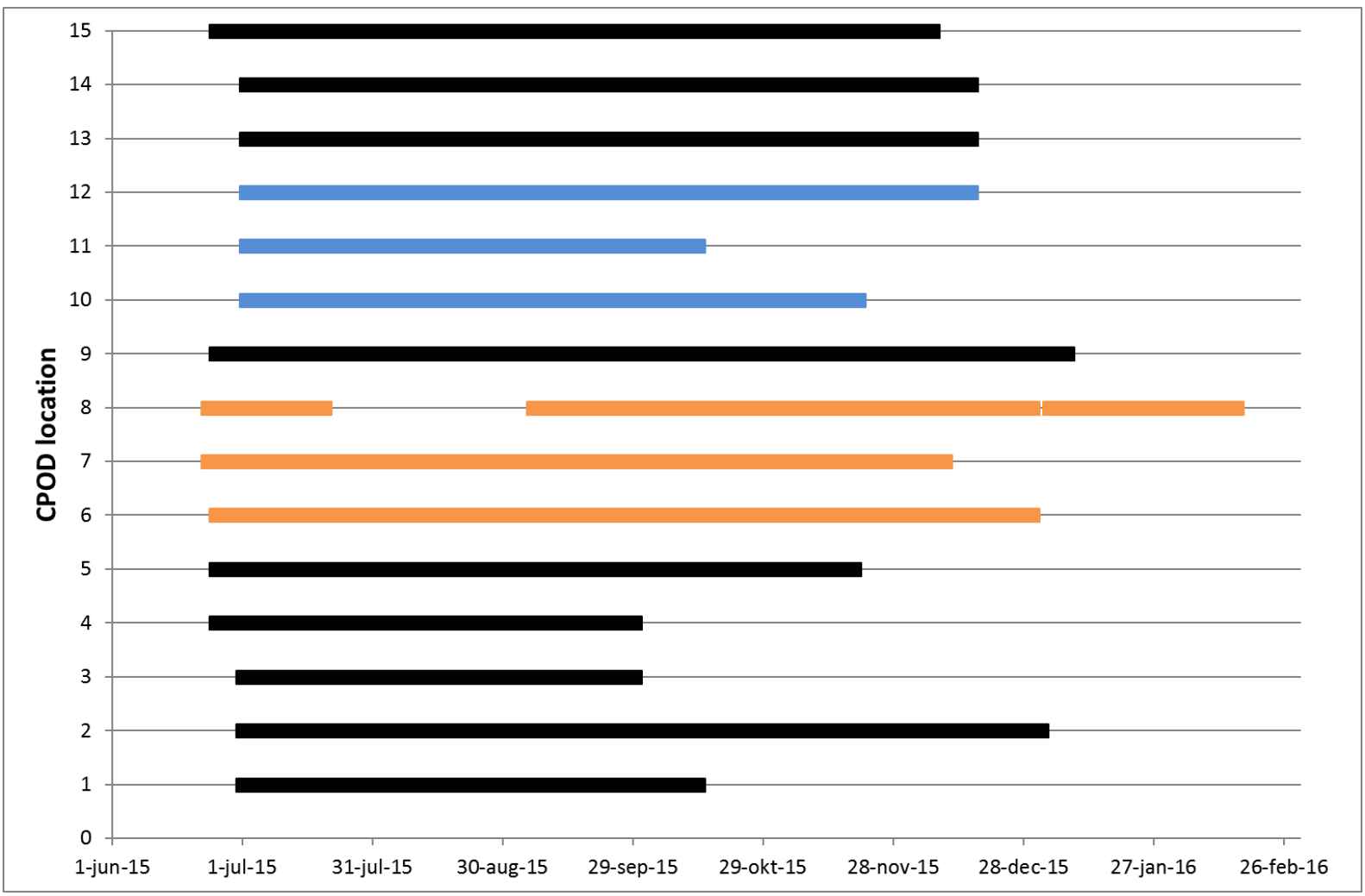

Figure 9 Daily recording effort per CPOD location. The lines represent recording effort: orange = ZeeEnergie, blue = Buitengaats.

\subsection{Spatial and seasonal pattern of harbour porpoise occurrence}

Harbour porpoises were detected on $96.2 \%$ ( $\min 80.9 \%$, max $100.0 \%$ ) of days sampled (Table 9). This high rate indicates that harbour porpoises were continuously present in the study area. It should be noted that a direct comparison of all raw data of the CPODs is not possible, due to differences in recording effort (Figure 9). Harbour porpoise acoustic activity showed strong daily variation. Seasonal patterns per CPOD expressed as daily click frequency, expressed as DPM/hr, are shown in Annex 4. 
Table 9 Total effort expressed as number of days that CPODs were deployed and data were retrieved and the percentage of those days in which harbour porpoise clicks were detected.

\begin{tabular}{lcc}
\hline CPOD location & Days with data & \% days HP detected \\
\hline GEM 01 & 106 & 97.2 \\
GEM 02 & 186 & 96.2 \\
GEM 03 & 91 & 98.9 \\
GEM 04 & 96 & 100.0 \\
GEM 05 & 145 & 100.0 \\
GEM 06 & 188 & 97.3 \\
GEM 07 & 176 & 91.4 \\
GEM 08 & 187 & 98.9 \\
GEM 09 & 196 & 95.4 \\
GEM 10 & 142 & 95.0 \\
GEM 11 & 105 & 80.9 \\
GEM 12 & 167 & 96.4 \\
GEM 13 & 167 & 100.0 \\
GEM 14 & 168 & 98.2 \\
GEM 15 & 165 & 97.5 \\
\hline Total & 2,288 & 96.2 \\
\hline
\end{tabular}

To demonstrate the seasonal patterns inside and outside the wind farms the data expressed as DPM/hr are shown for West of Gemini, South of Gemini, in Buitengaats and in ZeeEnergie (Figure 13). Outside the wind farm the CPODs West of Gemini and the CPODs south of Gemini are pooled, inside the wind farm the CPOD data are shown for ZeeEnergie and Buitengaats separately. Though the patterns for each CPOD location differs on details, overall a similar pattern emerges. On average the daily click frequency is lower than $2 \mathrm{DPM} / \mathrm{hr}$ on most of the days, but periods with higher click frequencies occur regularly: end of June-half July, end of August, end of October and half December. The variation in click frequency and the average click frequency in the wind farm areas ZeeEnergie and Buitengaats are smaller than at the locations West of Gemini, and South of Gemini (Figure 13).

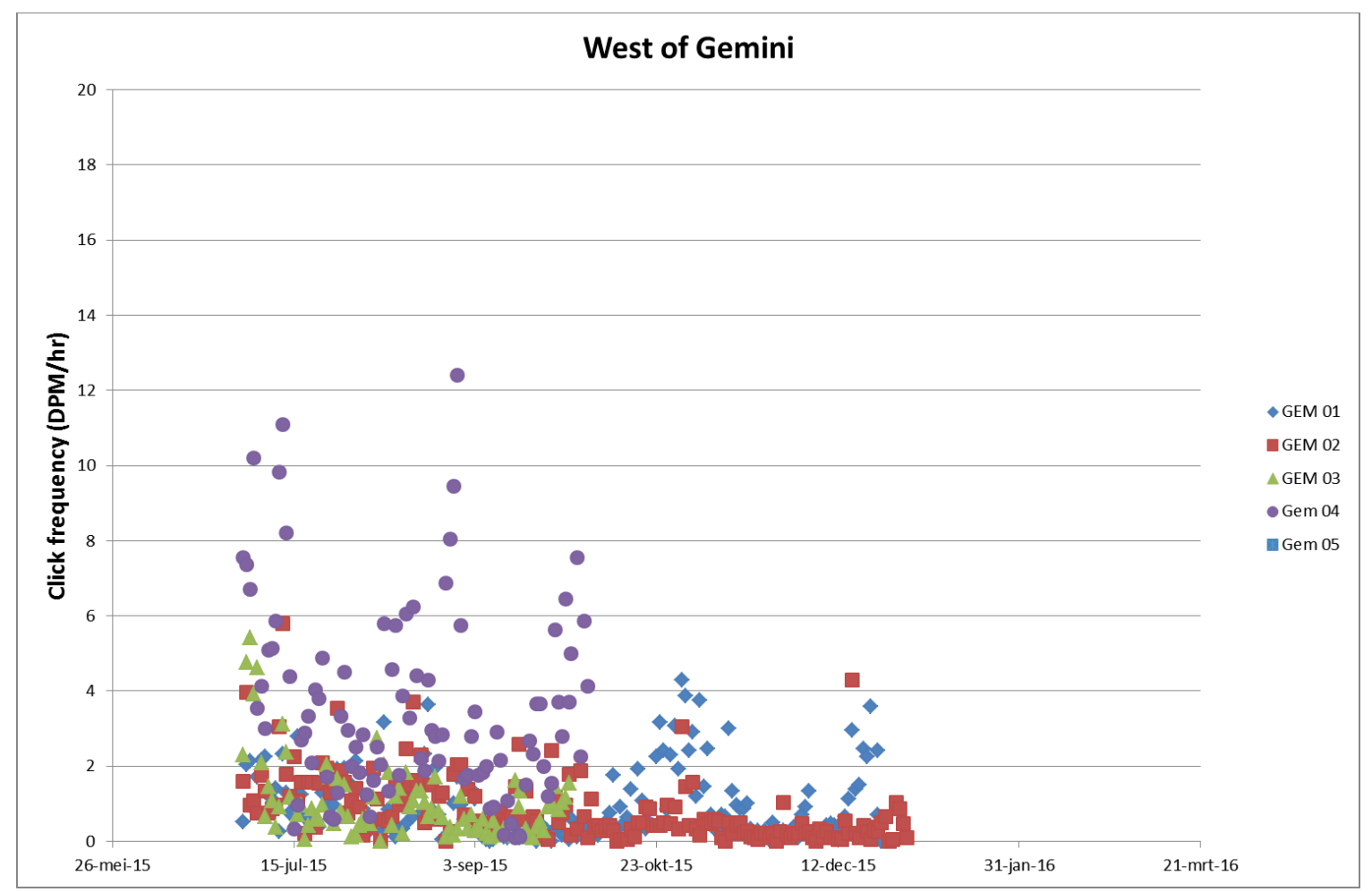

Figure 10 Harbour porpoise acoustic activity (DMP/hr) West of Gemini. 


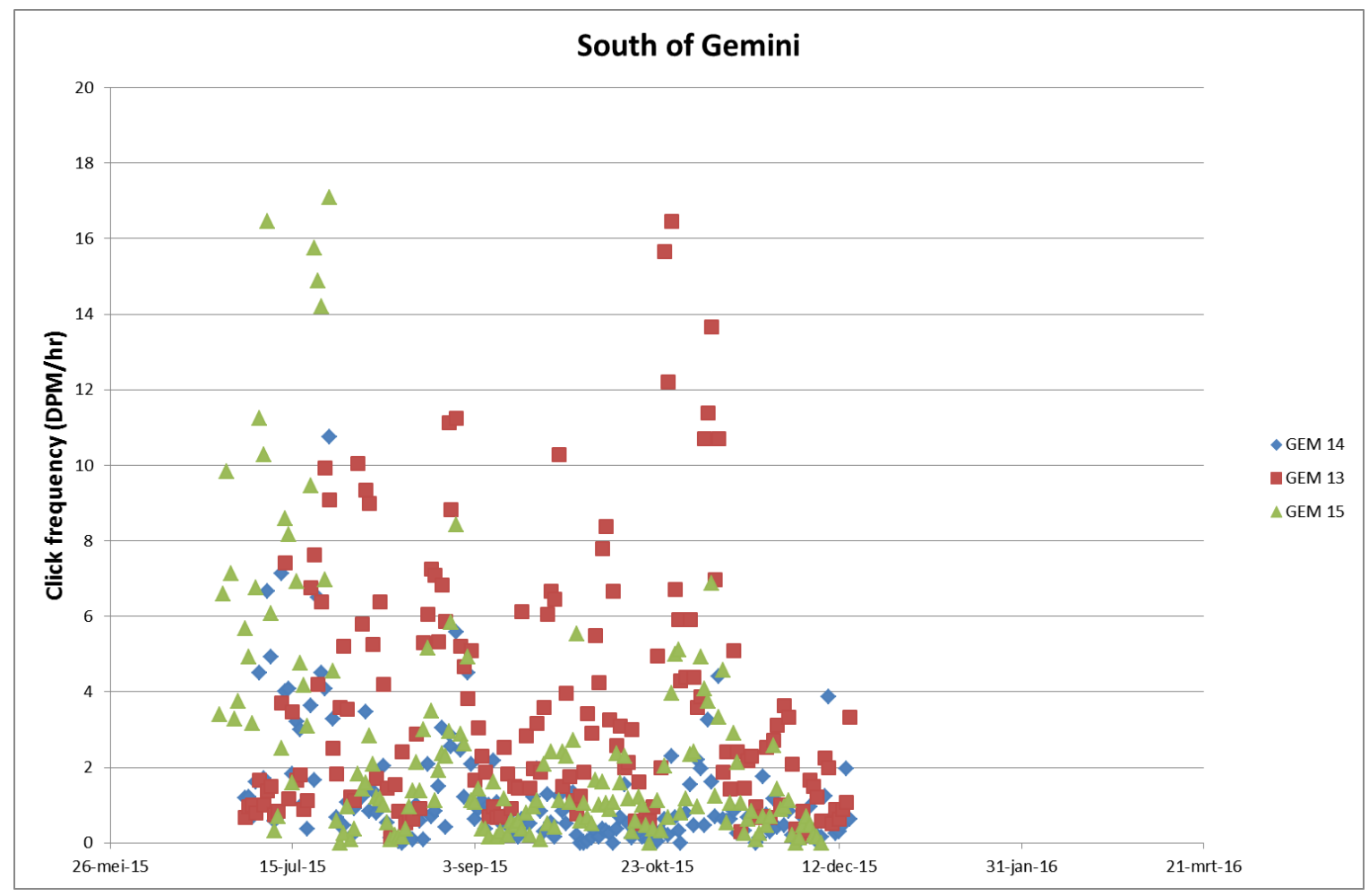

Figure 11 Harbour porpoise acoustic activity (DMP/hr) South of Gemini.

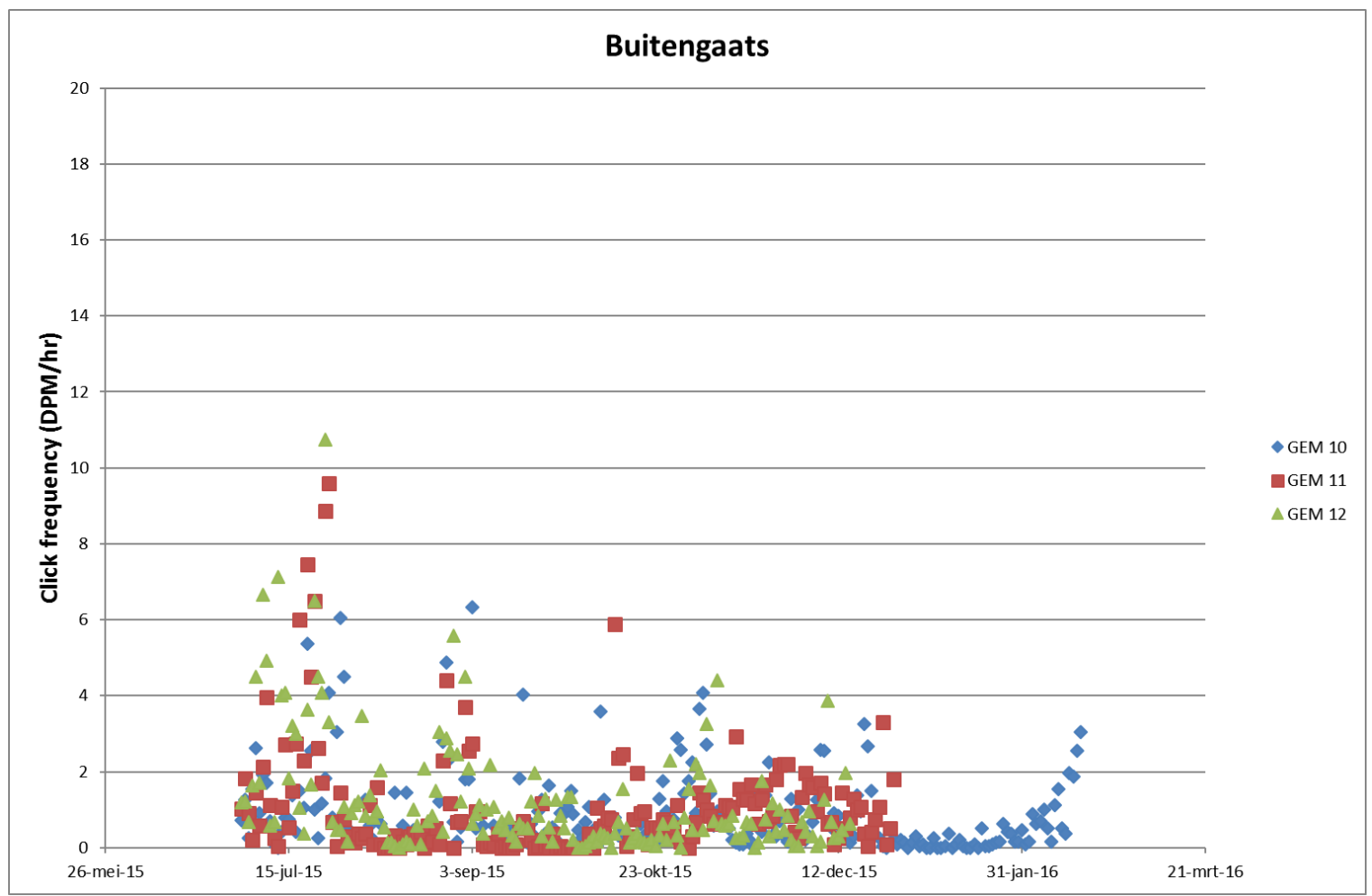

Figure 12 Harbour porpoise acoustic activity (DMP/hr) in Buitengaats. 


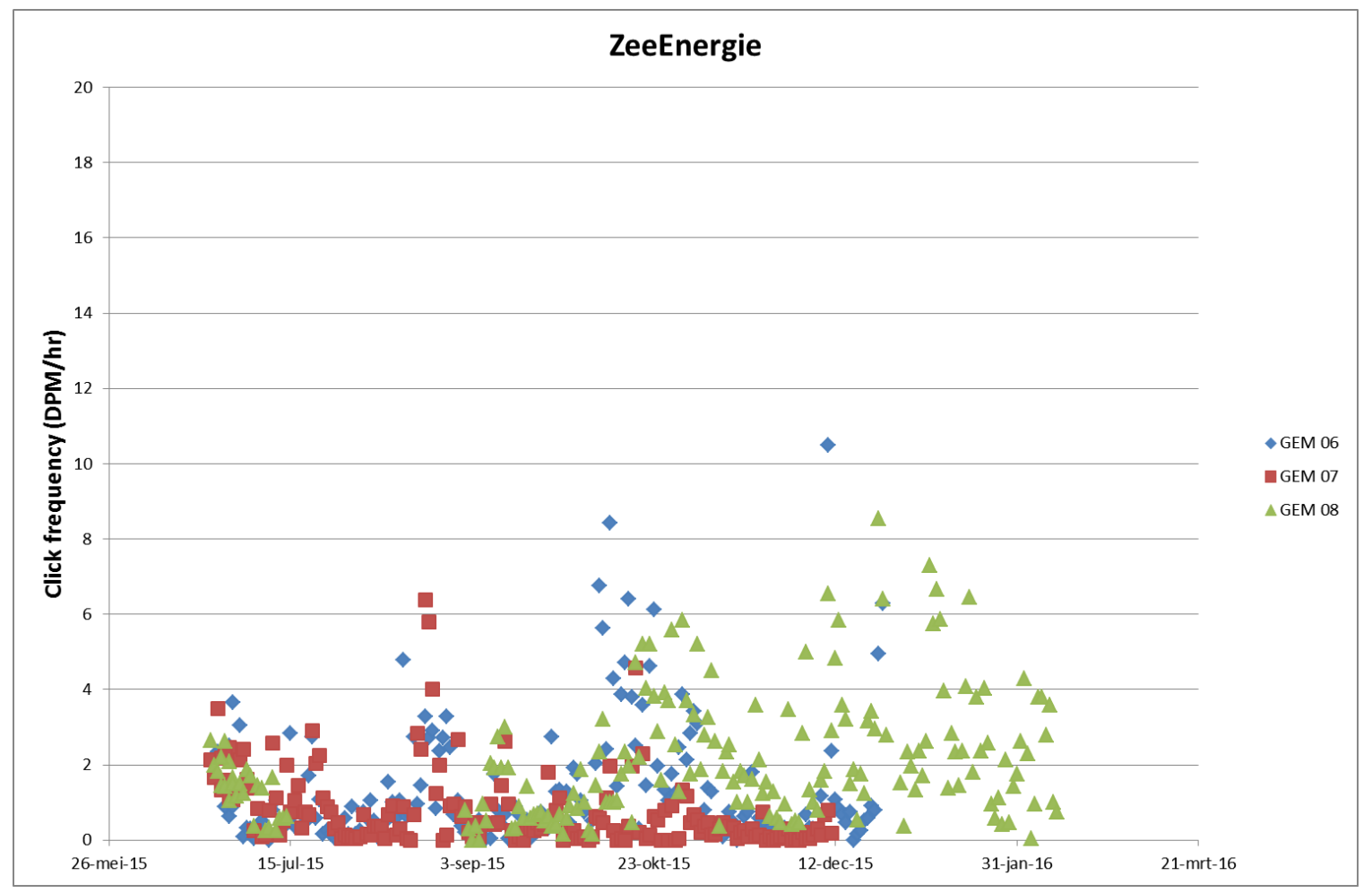

Figure 13 Harbour porpoise acoustic activity (DMP/hr) in ZeeEnergie.

Table 10 Variables selected by the step-wise forward selection GAMM-analysis as best explaining variation in the harbour porpoise acoustic detection frequency data; $k=$ number of 'knots' (inflection points) which constrains the smooth of the curve. Lower AICs mean the variable explains less variation in acoustic activity.

\begin{tabular}{ll}
\hline Variable & AIC \\
\hline Latitude $(\mathrm{k}=3)$ & 357991.4 \\
Wind force $(\mathrm{k}=4)$ & 352205.7 \\
Hour $(\mathrm{k}=4)$ & 347241.6 \\
Day of year $(\mathrm{k}=4)$ & 344772.3 \\
Temperature $(\mathrm{k}=4)$ & 344155.6 \\
Time to high tide $(\mathrm{k}=4)$ & 343567.7 \\
\hline
\end{tabular}

The GAMM-analysis to explore underlying patterns in acoustic activity of harbour porpoises indicated that the acoustic activity, expressed as DPM/hr, was best explained by six variables, which in order of influence on data variability were: 1 . Latitude; 2 . Wind force; 3. Hour of the day; 4 . Day of the year; 5. Temperature and 6 . Time to high tide (Table 10). Adding the Longitude to the model leads to a small decrease in AIC $(<2)$. This means that the effect of longitude on the acoustic activity is negligible in comparison to the other variables. The explained variance is high; $2.2 \%$ expressed as the difference between the deviance in the GAM residuals and the GAM results.

The relationships between each variable and the acoustic activity of harbour porpoises are presented in Figure 14 to Figure 19. Of the weather variables, wind force and temperature explained the variation in detected porpoise clicks significantly. After the location (latitude) wind force explained most of the variation in porpoise detections. The number of detected clicks remained more or less constant during low wind speeds. With increasing wind speed, the number of detections drops (Figure 15). The location of the CPOD was also important. The relationship along a north-south axis was interesting as this involved a relatively small spatial scale (ca $20 \mathrm{~km}$ ). Detections were higher at the more southerly locations (Figure 1Figure 14). There was also a peak in harbour porpoise detections associated with morning periods (Figure 16) and with high-tide cycles (Schiermonnikoog which has the same cycle as the Gemini-area, Figure 19). The relatively large decrease in the AIC after adding the effect of hour of the day to the model, suggests this covariate significantly influences the variability in porpoise 
detections. With respect to Day of the year (Figure 17), a seasonal pattern was evident. There was a decrease in harbour porpoise detections shortly after deployment of the CPODs in June. Overall the acoustic activity decreased till August and increased towards a second lower peak at the end of the year. The number of detections decreased again in January. Increasing temperature was correlated with an increase in porpoise detections, probably intertwined with the seasonal pattern (Figure 18).

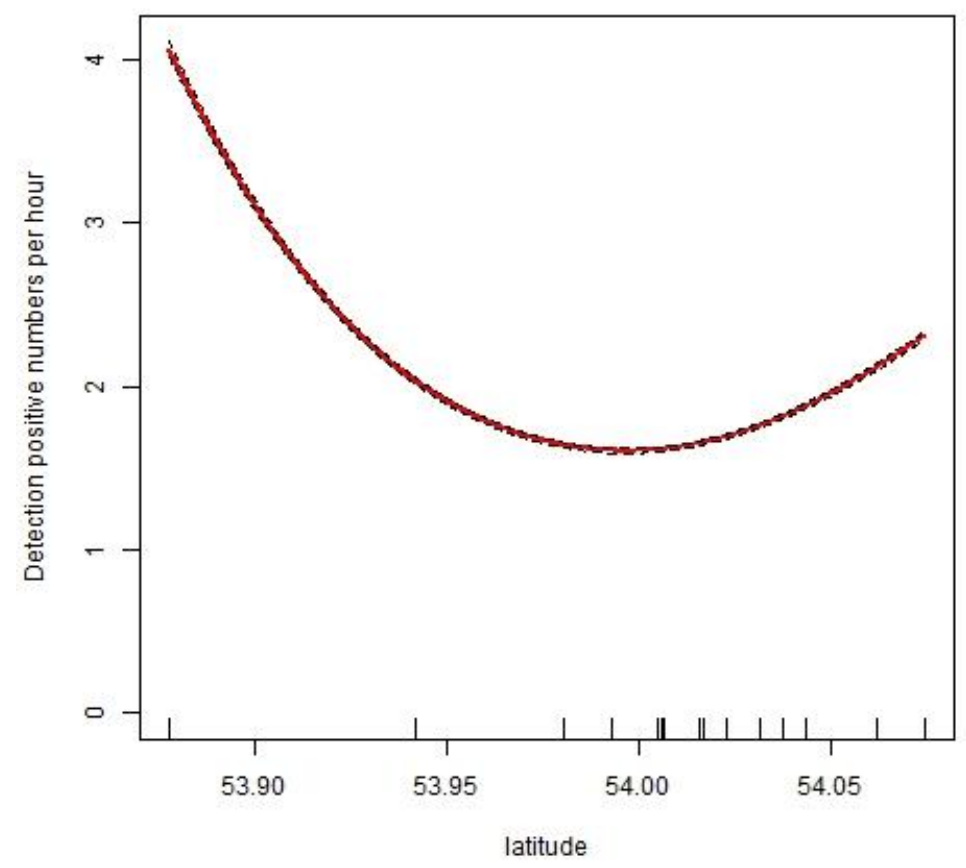

Figure 14 Harbour porpoise acoustic activity (DMP/hr) in the Gemini-area (solid red line) in relation to latitude with $95 \%$ confidence limits (dashed line) as modelled with a GAMM. Data points are indicated by inside tick marks.

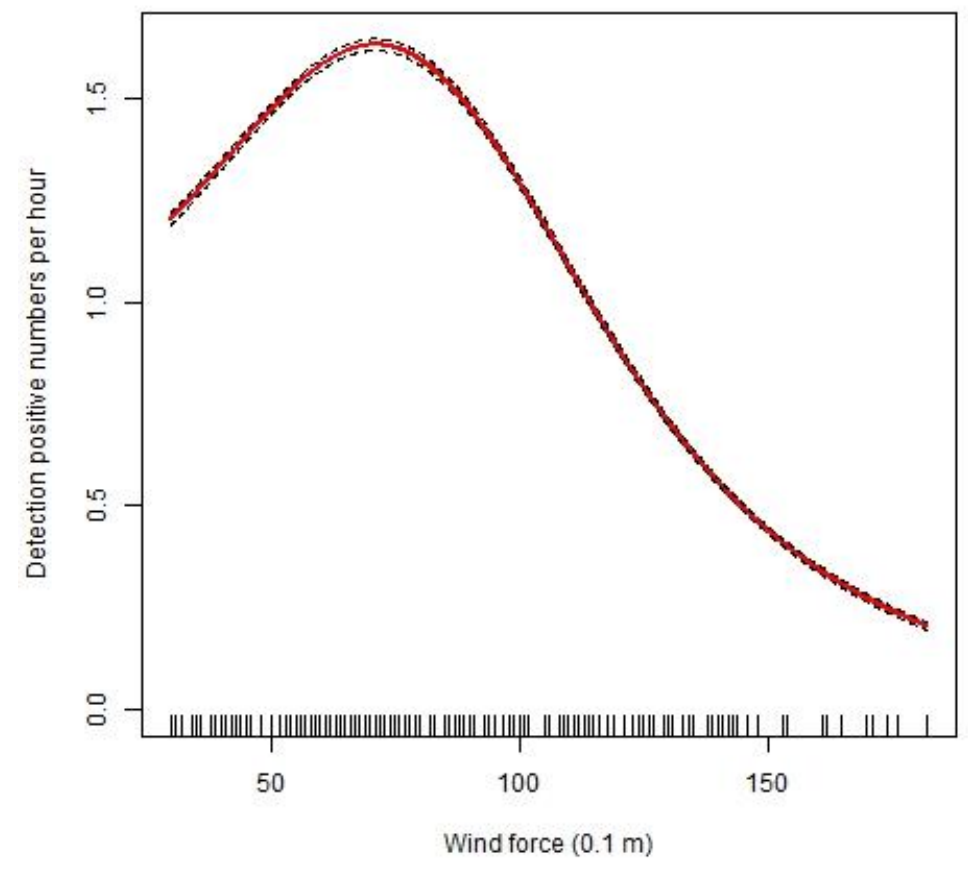

Figure 15 Harbour porpoise acoustic activity (DMP/hr) in the Gemini-area (solid red line) in relation to wind force with 95\% confidence limits (dashed line) as modelled with a GAMM. Data points are indicated by inside tick marks. 


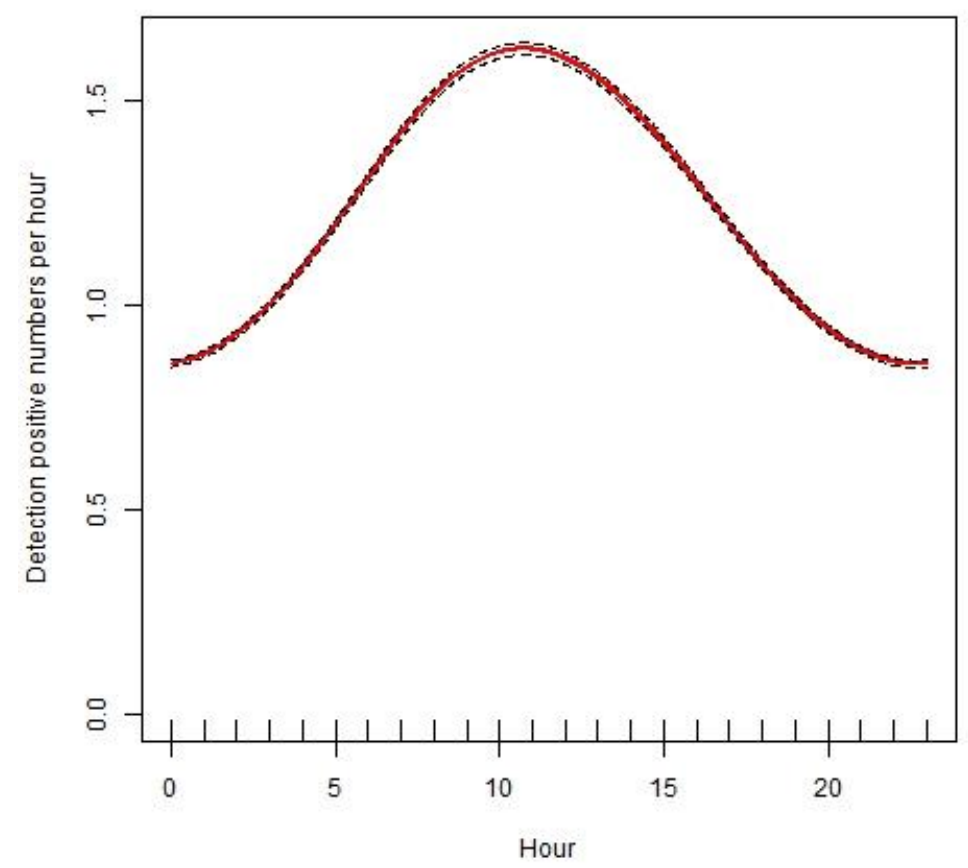

Figure 16 Harbour porpoise acoustic activity (DMP/hr) in the Gemini-area (solid red line) in relation to hour of the day with 95\% confidence limits (dashed line) as modelled with a GAMM. Data points are indicated by inside tick marks.

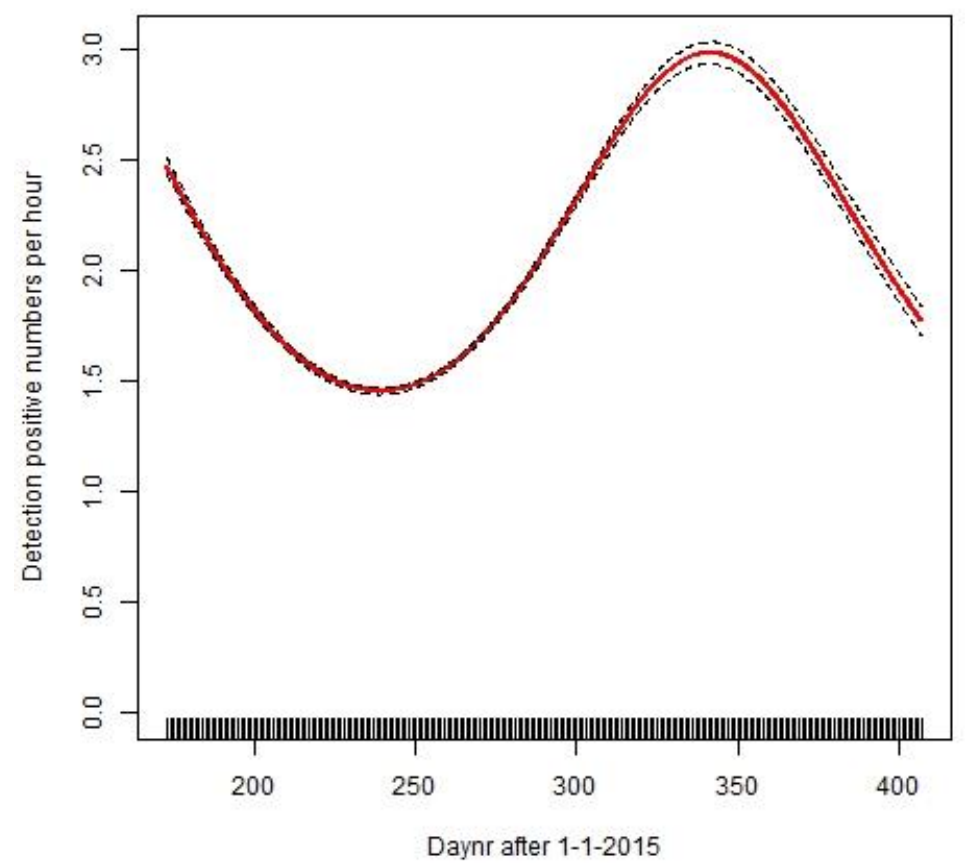

Figure 17 Seasonal pattern of Harbour porpoise acoustic activity (DMP/hr) in the Gemini-area (solid red line) with $95 \%$ confidence limits (dashed line) as modelled with a GAMM. Data points are indicated by inside tick marks. 


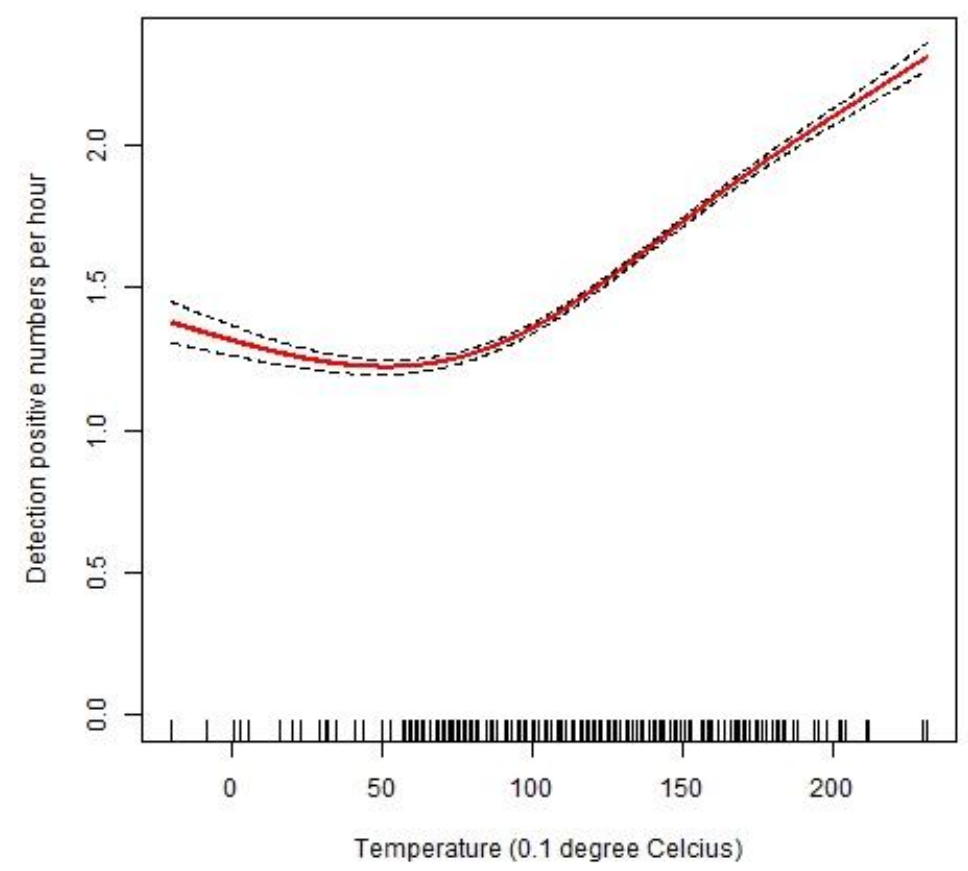

Figure 18 Harbour porpoise acoustic activity (DMP/hr) in the Gemini-area (solid red line) in relation to temperature with 95\% confidence limits (dashed line) as modelled with a GAMM. Data points are indicated by inside tick marks.

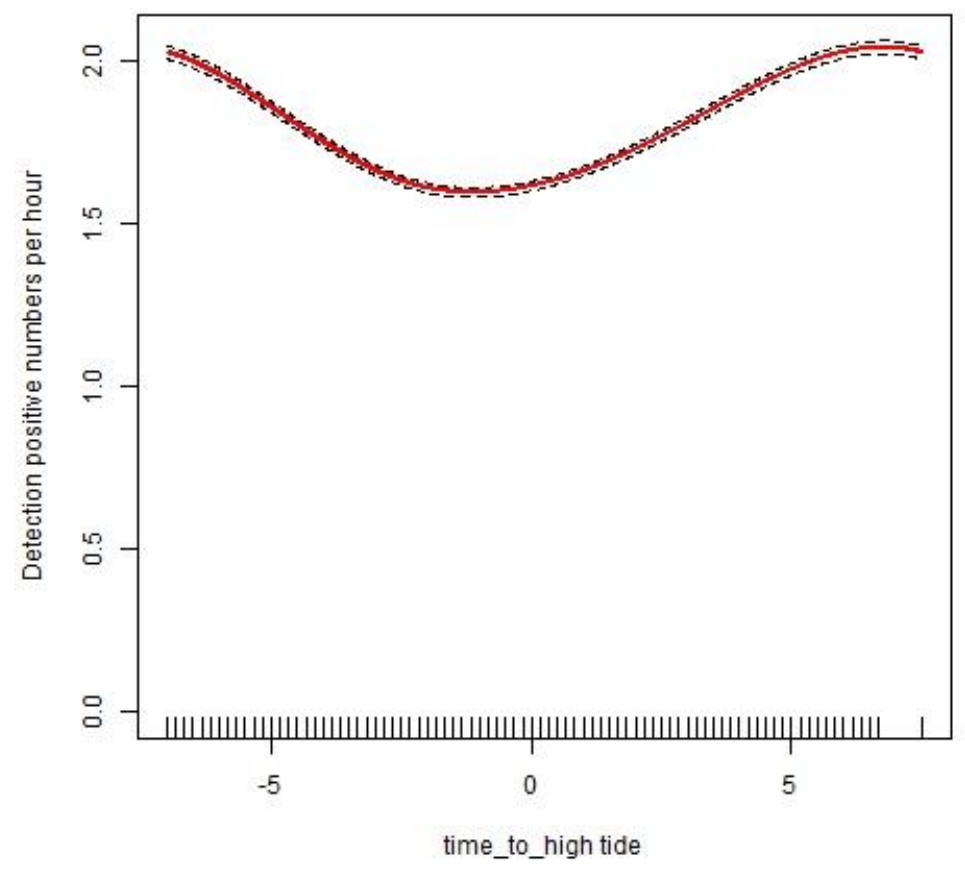

Figure 19 Harbour porpoise acoustic activity (DMP/hr)in the Gemini-area (solid red line) in relation to high tide on Schiermonnikoog with 95\% confidence limits (dashed line) as modelled with a GAMM. Data points are indicated by inside tick marks. 


\section{Harbour porpoise occurrence during T-0 and $\mathrm{T}-\mathrm{C}$}

\subsection{Aerial surveys}

Compared to the T-0 aerial survey monitoring in 2013/2014 (Geelhoed et al., 2015a), only three months (June, July, October) were surveyed in both T-0 and T-c. The June and July aerial surveys of 2015 yielded densities about twice as high as the T-0 maximum in April 2014 (Figure 20). In October the density was very low during T-c. When looking at all surveys combined, mean density during T-0 monitoring (ca 1.0 porpoise $/ \mathrm{km}^{2}$ ) was in the same order of magnitude as during the T-c monitoring (ca 1.2 porpoise $/ \mathrm{km}^{2}$ ). However, because survey effort differed, these values cannot directly be compared.

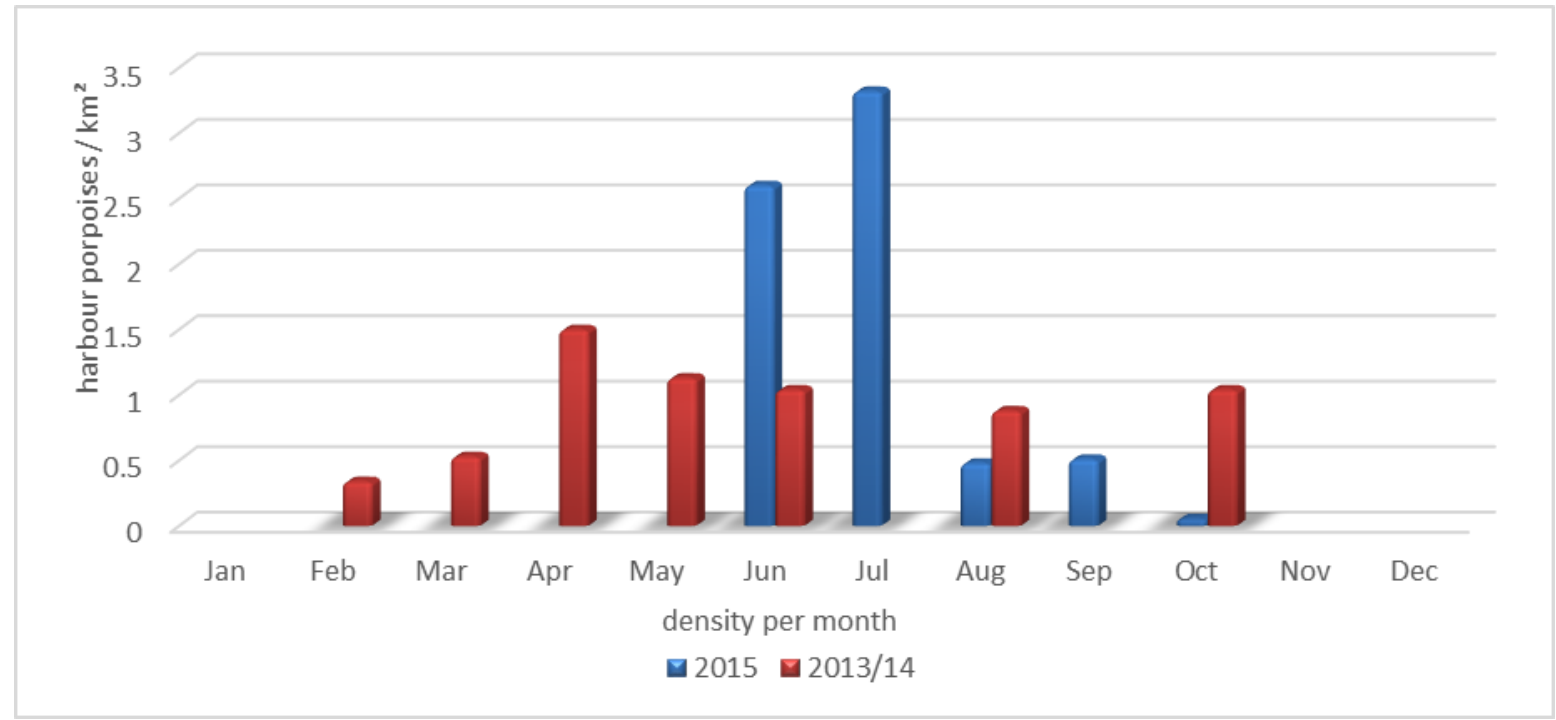

Figure 20 Harbour porpoise density $\left(\mathrm{n} / \mathrm{km}^{2}\right)$ per aerial survey month during the $T$ - 0 and T-c monitoring.

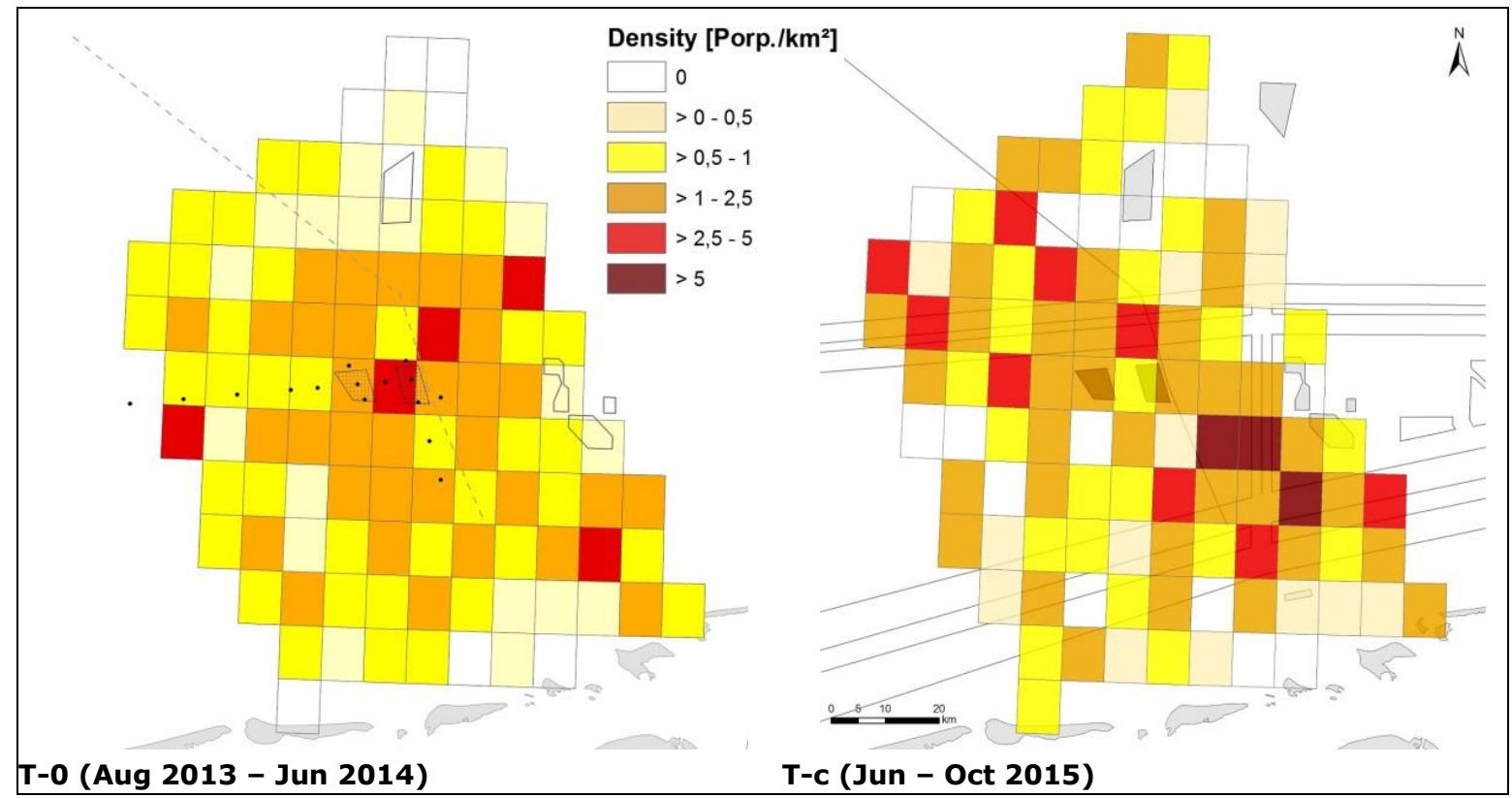

Figure 21 Mean distribution of harbour porpoises ( $\mathrm{n} / \mathrm{km}^{2}, 8 \times 10 \mathrm{~km}$ rectangular grid) during T-0 monitoring (August 2013 to June 2014; 7 surveys) and T-c monitoring (June to October 2015; 5 surveys). 


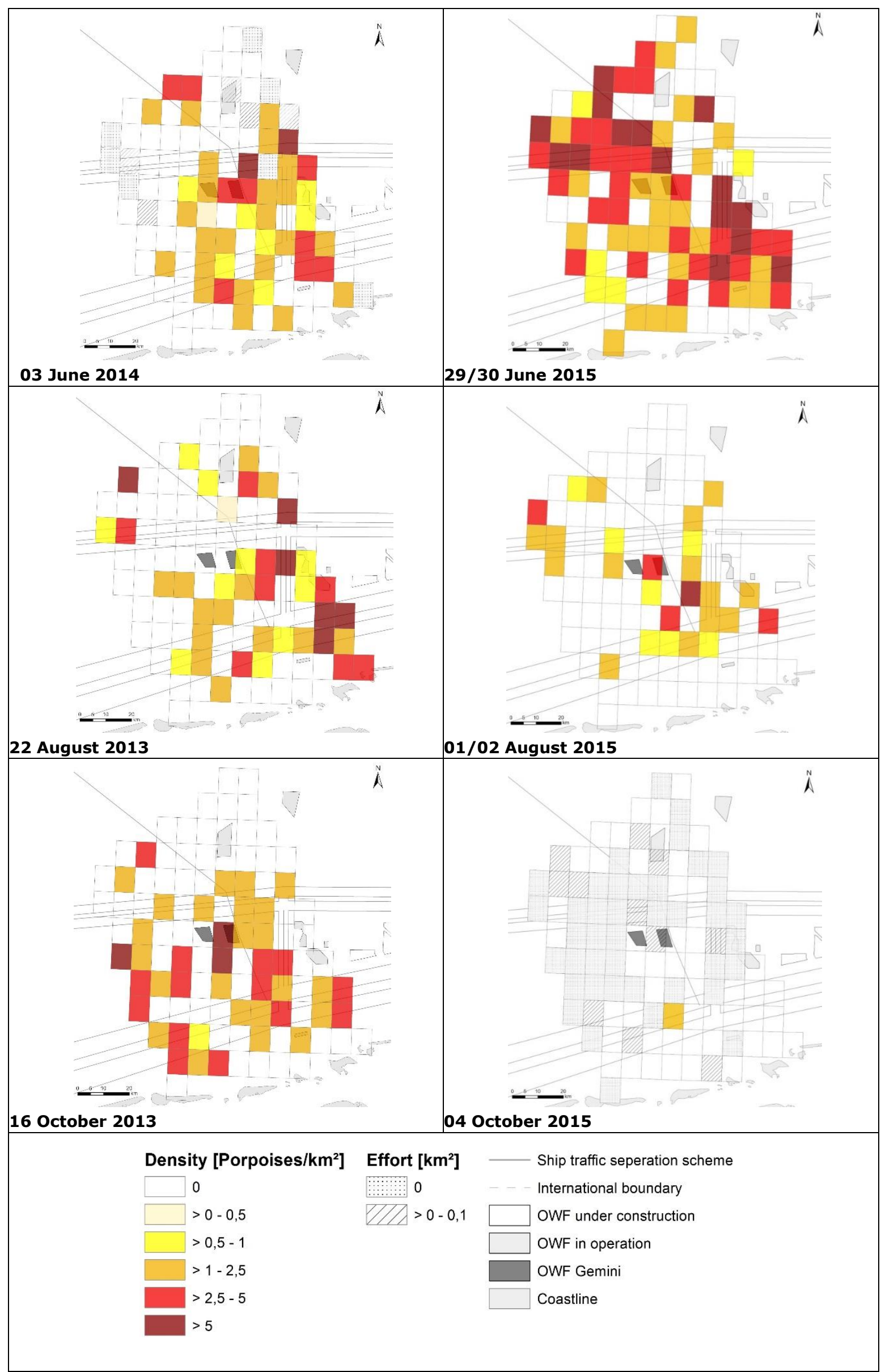

Figure 22 Distribution of harbour porpoises $\left(\mathrm{n} / \mathrm{km}^{2}\right)$ in June, August and October during T-O monitoring (2013/2014) and T-c monitoring (2015) (8 x $10 \mathrm{~km}$ rectangular grid). 
During the T-0 monitoring the mean distribution of harbour porpoises (Figure 21, left) was similar to the overall distribution pattern found in 2015 (Figure 21, right). Over both periods, low densities were mainly present in coastal areas and in the north-east of the survey area, around BARD Offshore 1.

The distribution during the three comparable months June, August and October shows a more consistent porpoise occurrence in August and October during the T-0 monitoring. June shows a more widespread distribution during $\mathrm{T}-\mathrm{c}$, before construction started (Figure 22). The harbour porpoises not only reached a similar overall density during these months in T-0 (Figure 20), they also showed a quite stable distribution pattern (Figure 22, left). North-west of the Gemini wind farm sites, the porpoise density was low in June, August and October during the T-0 monitoring, whereas it was very high in June 2015 during T-c (Figure 22, top right). While strongly decreasing from June to August 2015, harbour porpoises showed no evident shift in distribution pattern. They were seen in the whole survey area (Figure 22, right).
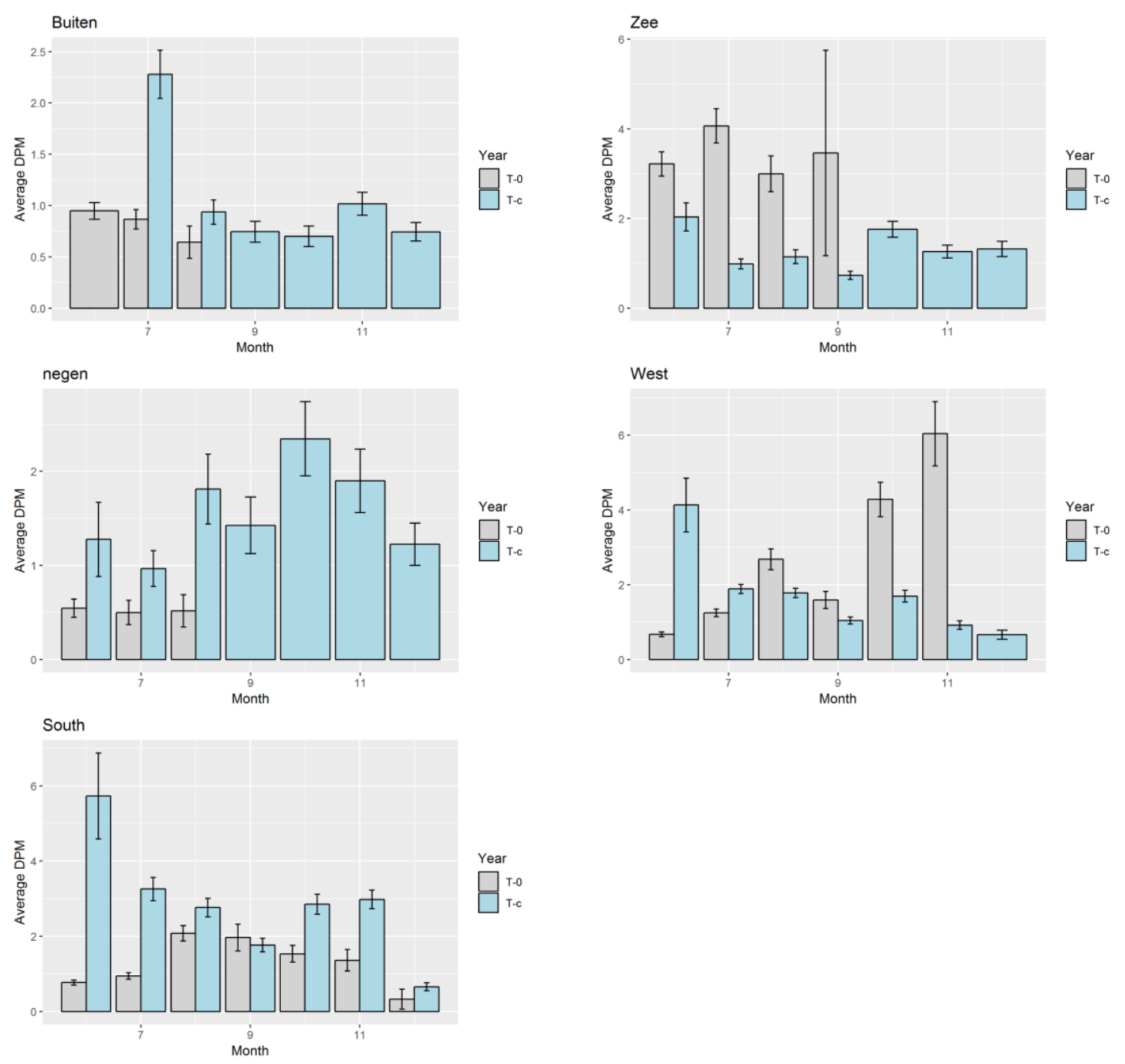

Figure 23 Harbour porpoise acoustic activity (DMP/hr) per sub area during T-O (grey) and T-c (blue), June-December. Difference between $T-0$ and $T-C$ is significant when the error bars do not overlap.

\subsection{Passive acoustic monitoring}

To compare the results of passive acoustic monitoring between $\mathrm{T}-\mathrm{O}$ and $\mathrm{T}-\mathrm{c}$ the average click frequencies, expressed as Detection Positive Minutes (DPM) per hour, are aggregated per sub area (Figure 23). In the Buitengaats area two months were monitored in both periods; July and August, which both showed higher acoustic activity during $\mathrm{T}-\mathrm{c}$ than during $\mathrm{T}-0$. In the ZeeEnergie area all months in 

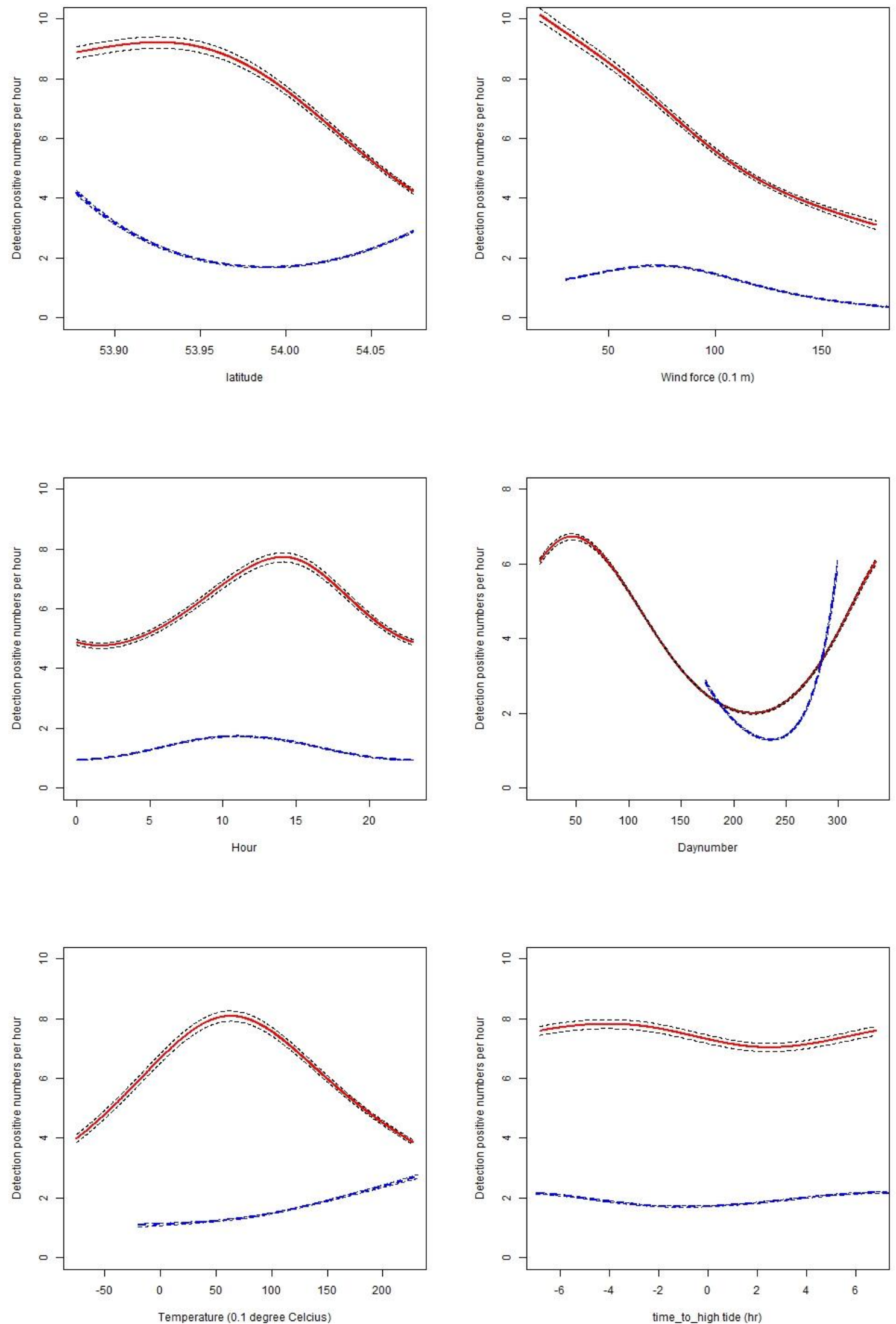

Figure 24. Harbour porpoise acoustic activity (DMP/hr) in the Gemini-area during T-0 (red line) and during $T$-c (blue line) in relation to variables selected by the step-wise forward selection GAMM-analysis as best explaining variation of harbour porpoise acoustic activity during $T$-c (Table 10). Dashed lines show $95 \%$ confidence limits. 
June-September showed lower acoustic activity during T-c than during T-0. GEM 09 positioned in between both wind parks showed on average higher acoustic activity during T-c than during T-0, both during pre-exposure in June and during pile driving in July and August. West of Gemini acoustic activity was higher during T-c in June and July, whereas the acoustic activity was lower during T-c from August to November. South of Gemini acoustic activity was higher in all months during T-c, except in September and December.

The GAMM-analysis to explore underlying patterns in acoustic activity of harbour porpoises indicated that the acoustic activity, expressed as DPM/hr, was best explained by five variables in 2014 (T-0), which in order of influence on data variability were: 1 . Day of the year; 2 . Hour of the day; 3 . Wind force; 4. Latitude; and 5. Time to high tide. In 2014 the same variables explained the data variability, but the order of explained variance differed from 2015; 1 . Latitude; and 2 Wind force. explained most of the variance, whereas temporal variables Day of the year and Hour of the day explained less than in T-0. A shorter study period during T-c, only covering the second part of the year can partly account for this difference. To visualize differences and similarities for these variables T- 0 and T-c are combined in one graph (Figure 24, note that the shape of T-0 data can differ slightly from Geelhoed et al., 2015a, due to combining $\mathrm{T}-0$ and $\mathrm{T}-\mathrm{c}$ in one graph). The relations between the variables and acoustic activity are similar for T-0 and T-c. The acoustic activity during T-c is lower than during T-0.

All in all, the results of the aerial surveys yielded higher densities in June prior to the start of piling activities, and lower densities in August and October during T-c for the whole study area. A comparison of monthly averages of click frequencies shows a less clear picture. In Buitengaats wind farm higher acoustic activity was recorded in June-July during $\mathrm{T}-\mathrm{c}$ than during $\mathrm{T}-\mathrm{O}$. In the ZeeEnergie wind farm all months from June-September showed lower acoustic activity during T-c. West of Gemini the acoustic activity was lower during T-c, whereas this was higher during T-0 south of Gemini in most months. The GAMM-analyses show similar underlying patterns for T-0 and T-C. In other words, overall the acoustic activity of harbour porpoises in the study area is shaped by the same variables. The GAMM-analyses, however, show more acoustic activity of harbour porpoises during T-0 than during T-c. During T-c, obviously several construction activities occurred that did not took place during T-0. In the next chapter the potential effects of these construction activities on the acoustic activity and distribution of harbour porpoises will be sketched. 


\section{Effect of construction activities on harbour porpoise occurrence}

Potential effects of construction activities on the occurrence of harbour porpoises can be assessed by looking at differences between the periods before, during and after construction activities. The primary focus for the construction activities is hereby on piling activities. The aerial surveys allow a large-scale broad comparison of changes in occurrence (and local density) with piling activity, whilst the acoustic monitoring data allow for a detailed comparison of changes in acoustic activity on a fine temporal scale.

\subsection{Aerial surveys}
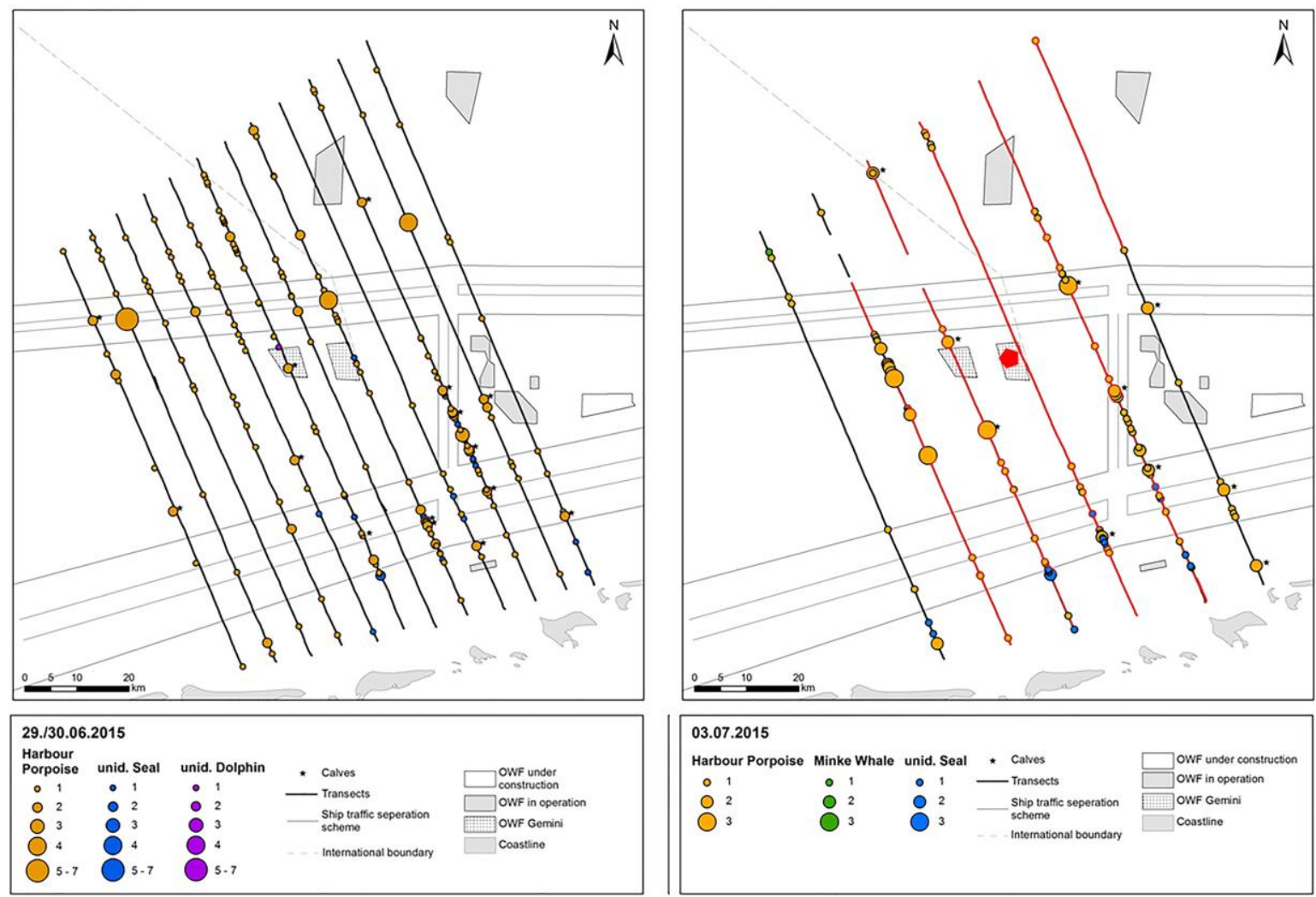

Figure 25. Sightings of harbour porpoises, seals, minke whale and unidentified dolphin during the surveys on 29 and 30 June (before piling) and 3 July 2015 (after piling). Piling took place on 1, 2 and 3 July in Buitengaats (red symbol, see Figure 5 for timing). Transects surveyed during piling are shown in red. 

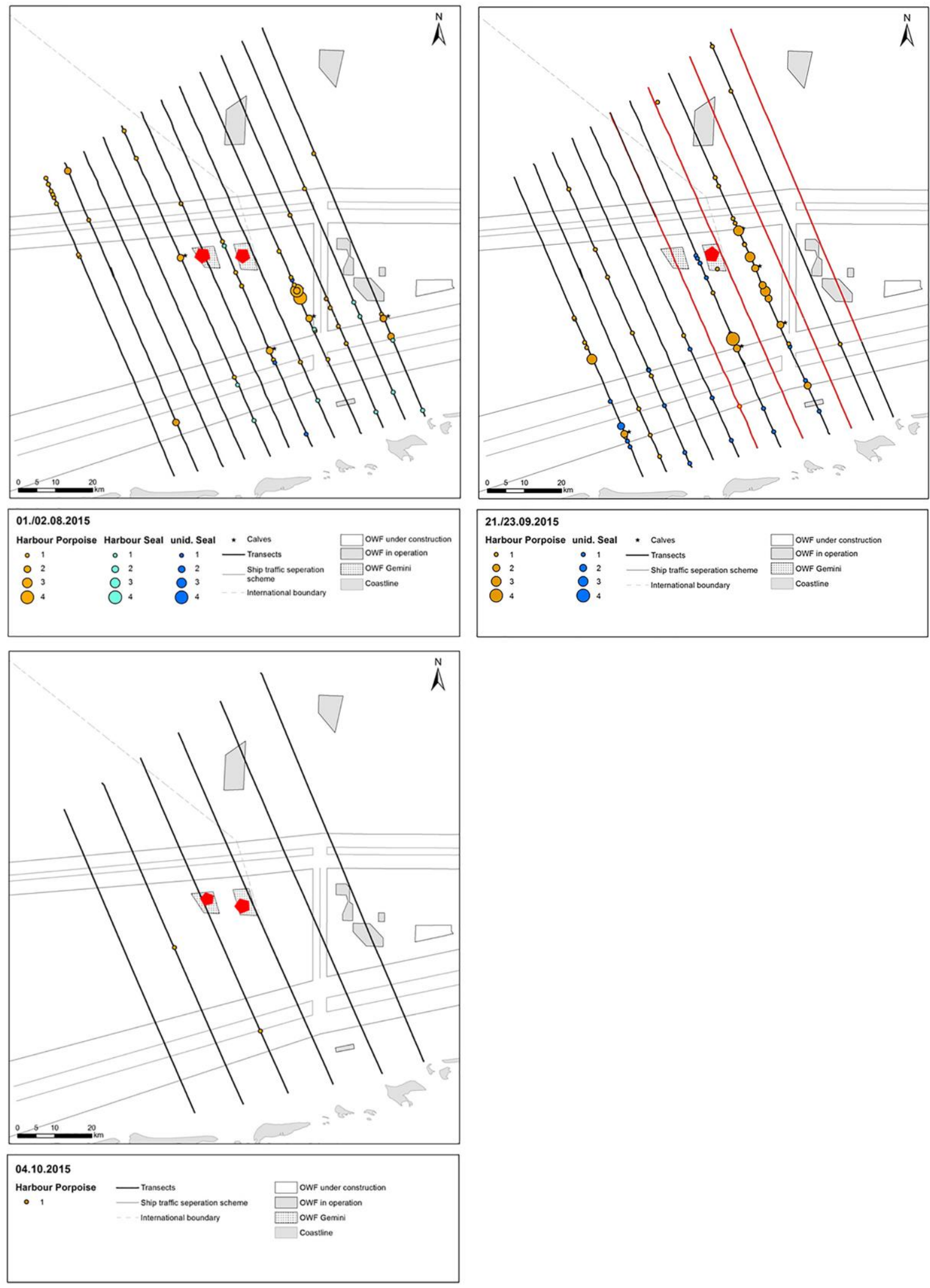

Figure 26, Sightings of harbour porpoises, and seals during the surveys on 1 and 2 August, 21 \& 23 September and 4 October 2015. Simultaneous piling took place in both wind farms on 1 and 2 August and on 4 October. During the September surveys piling took place in Buitengaats only (red symbol, see Figure 5 for timing). Transects surveyed during piling are shown in red.

Since pile driving took place almost continuously from 1 July 2015 onwards, most aerial surveys were conducted in 'disturbed' conditions, except 29 and 30 June 2015. Prior to pile driving commenced on 1 July, all transects were surveyed during two days with good sighting conditions. On the subsequent days one pile a day was driven into the sea bottom on three different locations in the north western part of 
Buitengaats (Figure 5). Pile driving took place from 12:09-16:26 hrs on $1^{\text {st }}$ July and from 9:25-14:46 hrs on $2^{\text {d }}$ July and 9:42-13.24 hrs on the $3^{\text {rd }}$ July. Due to deteriorating weather conditions the window for conducting aerial surveys was too small to survey all transects. One survey flight covering half of the transects, surveyed on 30 June as well, could be conducted on 3 July under mostly moderate sighting conditions. This survey flight started half an hour before pile driving commenced (8:57 hrs) and continued till 13:57 hrs, when pile driving was still ongoing. The survey started in the west, and worked gradually to the east. Thus, except the westernmost transect all transects were surveyed when piling actually took place in Buitengaats. The survey flight on 4 July was aborted due to bad sighting conditions, that lasted for a few days. When correcting the sighting data for the different sighting conditions, a direct comparison of the flight results before and during pile driving suggests avoidance of the Buitengaats area after piling commenced (Figure 8). In June porpoise sightings were distributed over a large area, including the Buitengaats area. In July the sightings were more unevenly distributed, with a lack of sightings in and around Buitengaats, and more sightings west of ZeeEnergie (Figure 25). The transects surveyed before and after pile driving commenced, showed higher numbers in June. Corrected for sighting conditions overall a slightly higher density was found in July (Table 8). The lack of sightings in a radius of up to ca $20 \mathrm{~km}$ around Buitengaats in July suggests a behavioural reaction of harbour porpoise with evasive movement away from the piling activities in this area. The resulting porpoise distribution expressed as density per grid cell show that porpoises were present in the whole study area in June. During piling in the first days of July, their distribution showed higher densities south of ZeeEnergie and Buitengaats, and zero densities in the Buitengaats area and in the north eastern part of the study area (Figure 8).

The surveys after July were conducted during pile driving periods. During the surveys on 21 and 23 September pile driving occurred $11: 24-14: 37 \mathrm{hrs}$ on the $21^{\text {st }}$ and 0:00-0:45 hrs and 3:13-6.03 hrs and on the $23^{\text {rd }}$ September in Buitengaats. Thus overlapping with the survey on the $21^{\text {st }}$ of September of most parts of the four easternmost transects. These transects yielded 2 observations, whereas the remaining transects resulted in 3 sightings. The survey on the $23^{\text {rd }}$ took place more than seven hours after pile driving stopped (Figure 26). Sightings were concentrated east and south of Buitengaats. One porpoise was seen in the southern part of Buitengaats wind farm. The September surveys tentatively suggest avoidance at a distance of more than $25 \mathrm{~km}$, and a return after at least $7 \mathrm{hrs}$ after piling ceased.

The surveys in August and October took place in a period when simultaneous pile driving in both wind parks was allowed. Pile driving took place 0:00-1:15 hrs, 6:47-8:28 hrs, 20:40-23:49 hrs and 21:0621:34 hrs on $1^{\text {st }}$ August, and 18:30-21:04 hrs on the $2^{\text {nd }}$ August. The flight on $1^{\text {st }}$ August, with a transect crossing ZeeEnergie and a transect along the border of Buitengaats, yielded no sightings up to $25 \mathrm{~km}$ from both wind farms. The survey on 2 August, between two piling events, resulted in a few sightings between the wind farms and a concentration of sightings in the south-eastern part of the area. The survey on $4^{d}$ October was conducted at least six hours after pile driving at 2:37-4:29, and before pile driving at 20:58-23:11 hrs. Under predominantly moderate sighting conditions only two sightings were made, one $<15 \mathrm{~km}$ WSW of the last piling location in ZeeEnergie, and one ca $30 \mathrm{~km}$ south of the wind farm area. These surveys suggest avoidance at distances $<15 \mathrm{~km}$.

\subsection{Passive acoustic monitoring}

To look into more detail at effects of construction activities on porpoises the results of the passive acoustic monitoring were used. To show potential effects of piling on harbour porpoise's acoustic activity the results are presented in two sections. In the first section the acoustic data are presented without confiding factors. In the second section parameters that shape acoustic activity are included.

\subsubsection{Harbour porpoise's acoustic activity during piling}

Each piling event (at a certain location during a certain period in time) can be related in time and space to porpoise acoustic activity recorded by each CPOD. Figure 27 shows an overview of the acoustic activity for all possible combinations. Most are within a distance of $27 \mathrm{~km}$ from the piling location, but some extend to more than $50 \mathrm{~km}$. The figure shows more points above the axis closer to a piling location, indicating a predominant higher acoustic activity after piling than before piling. On average the acoustic activity before, during and after piling is $1.32,1.15 \& 1.53 \mathrm{DPM} / \mathrm{hr}$. Acoustic activity both before and after piling differs significantly from piling $\left(X^{2}=0.70, P<0.05\right)$. 


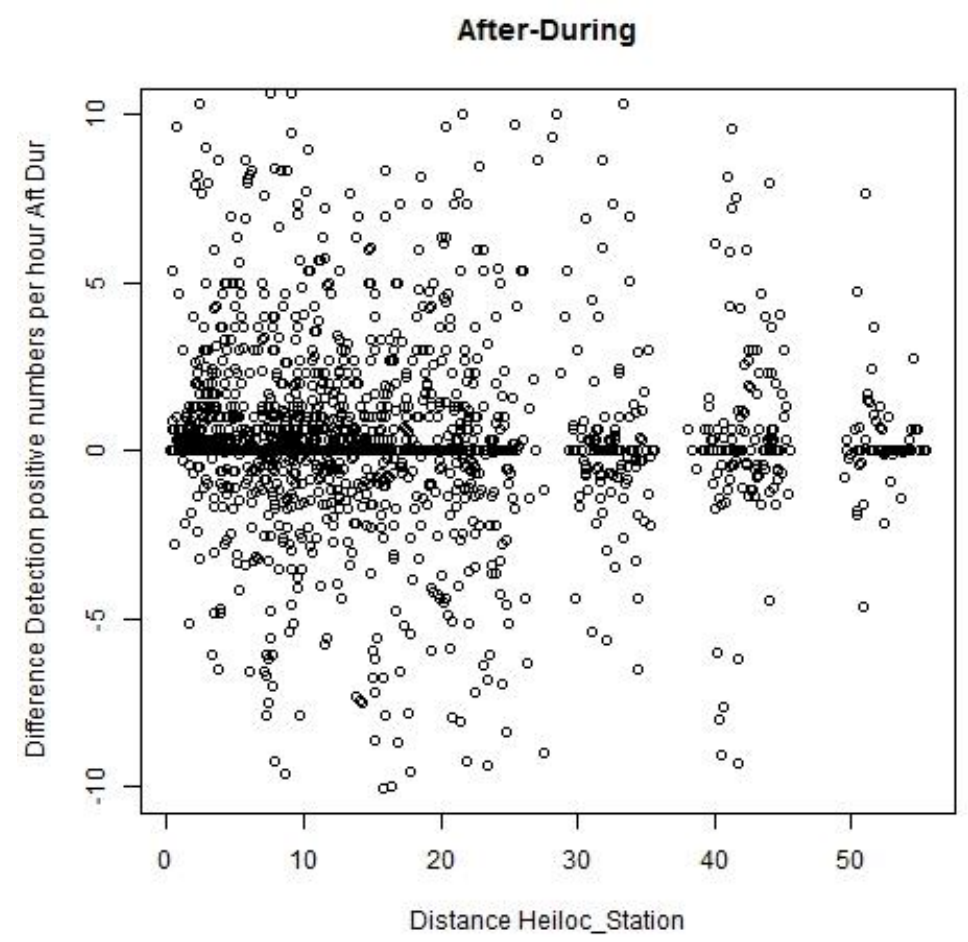

Figure 27. Harbour porpoise acoustic activity (DPM/hr) before and after piling in relation to distance to the piling location.

The uncorrected porpoise detections are aggregated per hour to show the acoustic activity of harbour porpoises during a period of twelve hours before, to twelve hours after piling for the distance bins $<5$ $\mathrm{km}, 5-10 \mathrm{~km}, 10-20 \mathrm{~km}$ and $>20 \mathrm{~km}$ away from the piling location (Figure 28). The distance bins are chosen to ensure a homogenous distribution of acoustic data and to show as much detail as possible. The porpoise activity fluctuated in all distance bins. The acoustic activity during pile driving as lowest for distances up to $5 \mathrm{~km}$ from the piling locations, and increased at distances further away. For distances up to $5 \mathrm{~km}$ from the piling locations the porpoise activity showed a minimum during piling till the two hours after piling stopped. At distances $5-10 \mathrm{~km}$ the lowest activity is recorded 5-8 hrs before pile driving started; two hrs after pile driving a second decrease in acoustic activity is recorded. At distance $>10$ $\mathrm{km}$ the acoustic activity shows on average higher levels post-piling than pre-piling. The 2 hrs after pile driving showed a lower activity than during piling. Note, however, that the confidence intervals of the hourly averages of acoustic activity overlap. Therefore, differences are statistically not significant. 
$\mathrm{FG}=-0.5 \mathrm{hr} ;$ distance $(\mathrm{km}) \quad 0<5$
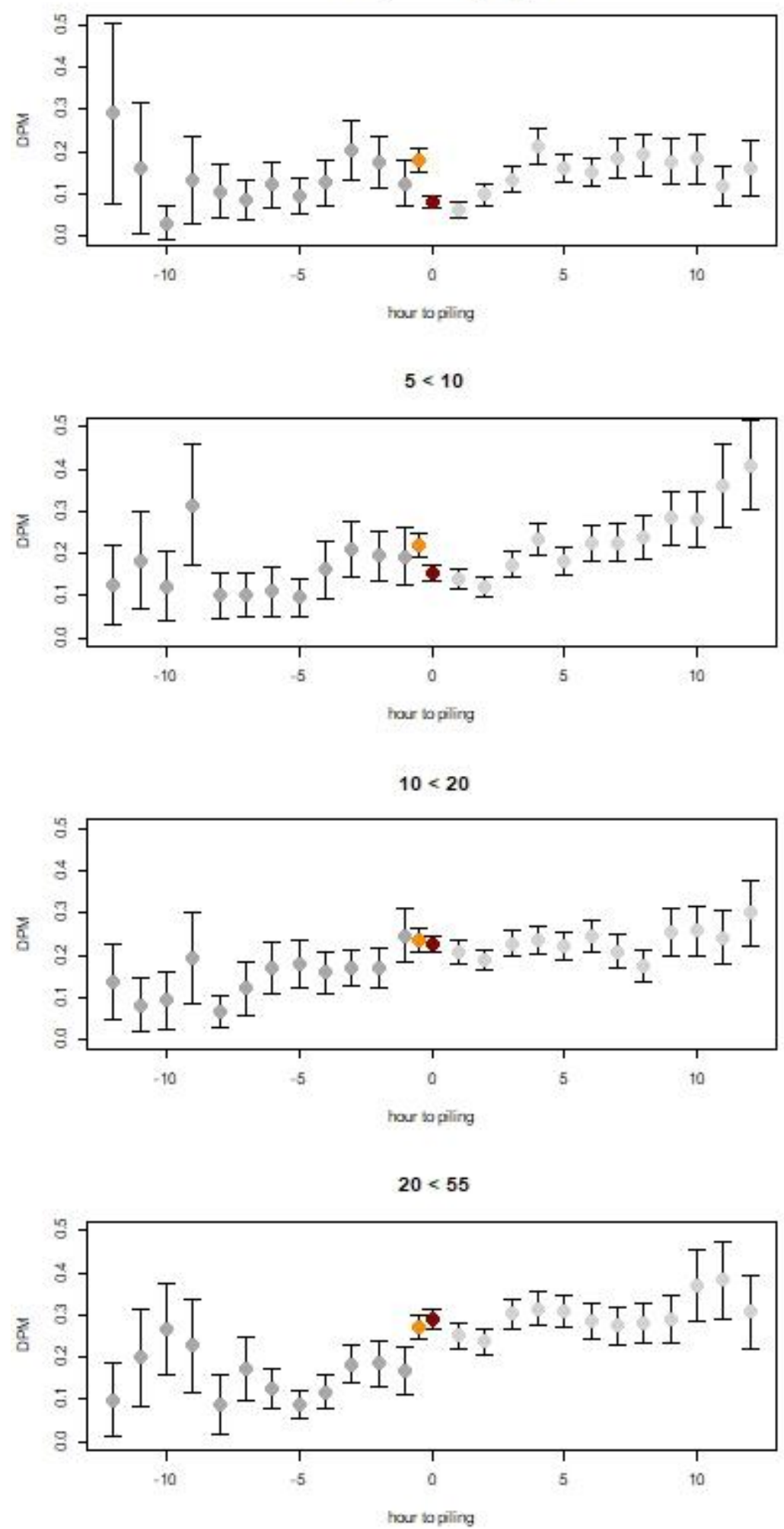

Figure 28 Harbour porpoise acoustic activity (DPM/hr) twelve hours before and after piling (hours =0) for different distance bins between CPODs and piling locations. Orange symbol is the period the FaunaGuard was activated, starting before piling continuing till piling stopped. Red symbol is the piling period. Note that the length of both piling and FG activation differs. 


\subsubsection{Effect of pile driving on harbour porpoise's acoustic activity}

The GAMM-analysis showed that the acoustic activity during T-c was best explained by six variables: 1 . Latitude; 2 . Wind force; 3. Hour of the day; 4. Day of the year; 5 . Temperature and 6 . Time to high tide (Table 10). Apart from temperature these variables also explained the variation in acoustic activity during T-O best.

By adding pile driving-related variables to the GAMM-analysis the effect of these variables can be quantified, taking variance due to the six variables into account. We modelled the effect on acoustic activity of distance to the pile driving source $(\mathrm{km})$, time relative to pile driving (hr) and the length of pile driving (hr).

Acoustic activity varies with distance to the piling location (Figure 29). Activity is lowest within $10 \mathrm{~km}$ of the piling location, and higher further away. Activity peaks around $20 \mathrm{~km}$, and decreased at greater distances.

Overall, acoustic activity starts decreasing ca 3 hrs before piling, continues decreasing after piling stopped and starts increasing again ca $3 \mathrm{hrs}$ after piling. After six hours the level of the pre-piling period has not been reached yet (Figure 30). The duration of piling events did not influence the porpoise's acoustic activity. Acoustic activity remained at a constant level regardless of the duration of piling events (Figure 31).

Figure 32 shows harbour porpoise acoustic activity before, during and after piling for several distance bins. The acoustic activity closer to the piling location is lower than further away. The pattern sketched in Figure 30 is more pronounced for distances less than $20 \mathrm{~km}$ from the piling location than further away. Acoustic activity at distances of more than $20 \mathrm{~km}$ from piling locations showed less fluctuations before and after piling (Figure 32).

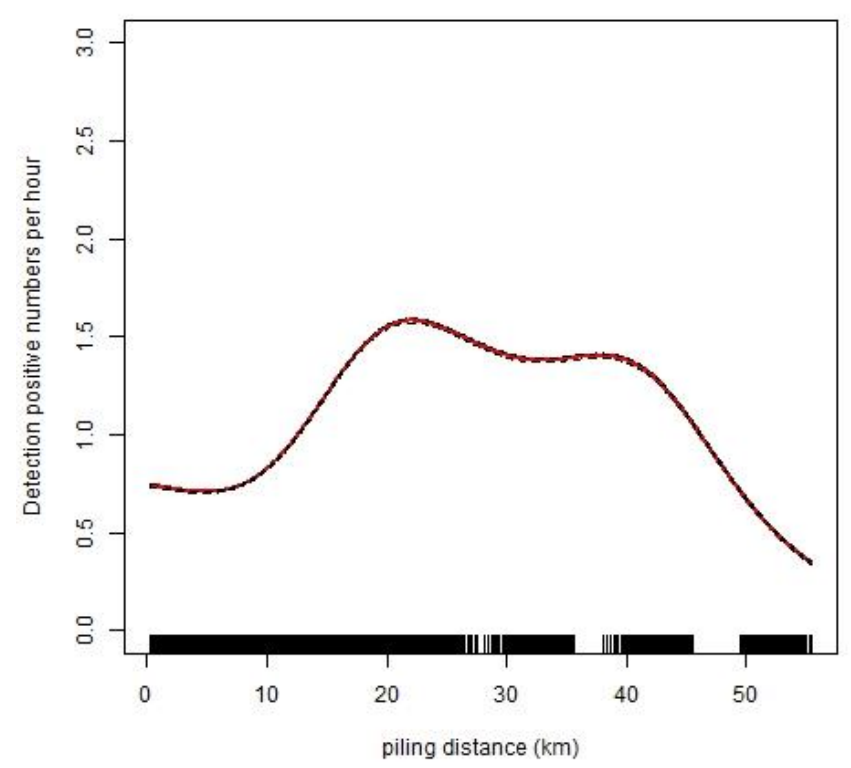

Figure 29. Harbour porpoise acoustic activity (DPM/hr, solid red line)) in relation to distance to the piling location with $95 \%$ confidence limits (dashed line) as modelled with a GAMM. Data points are indicated by inside tick marks. 


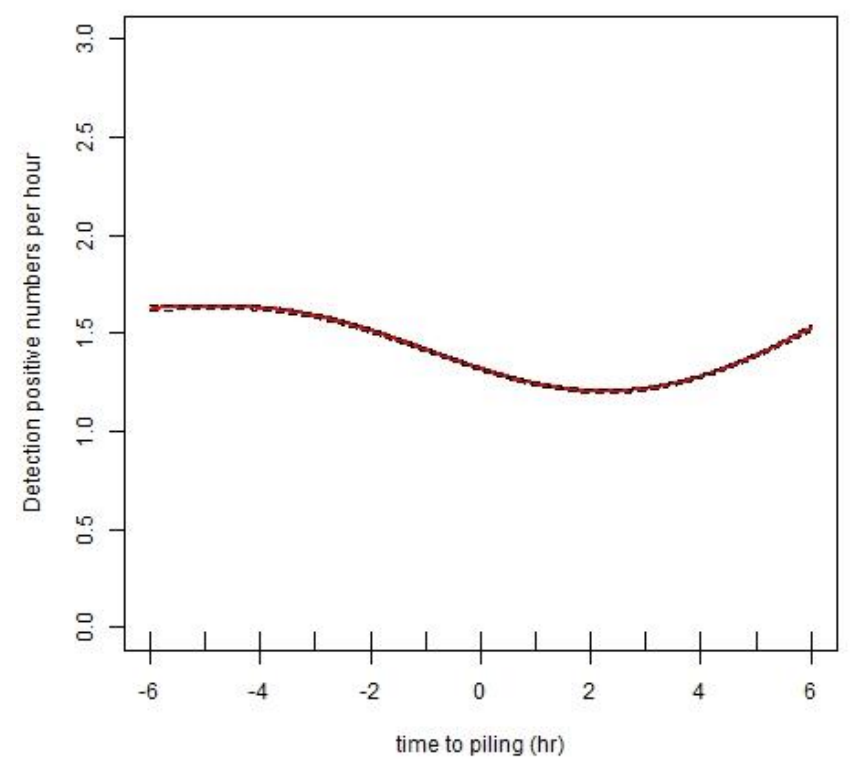

Figure 30. Harbour porpoise acoustic activity (DPM/hr, solid red line) before and after piling $(t=0)$ for all distances between CPODs and piling locations with 95\% confidence limits (dashed line) as modelled with a GAMM. Data points are indicated by inside tick marks.

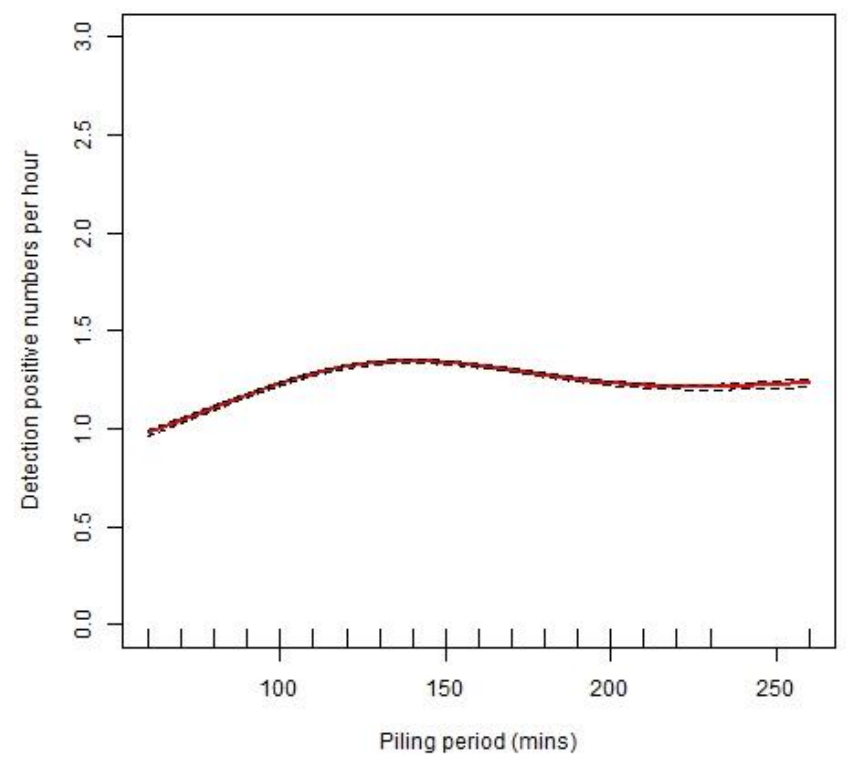

Figure 31 Harbour porpoise acoustic activity (DPM/hr solid red line) in relation to the length pf piling events with $95 \%$ confidence limits (dashed line) as modelled with a GAMM. Data points are indicated by inside tick marks. 


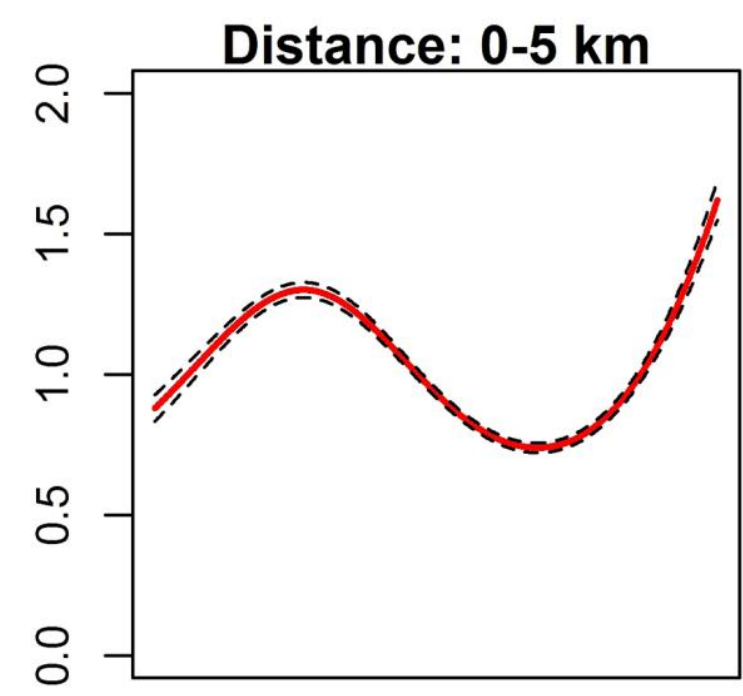

Distance: $5-10 \mathrm{~km}$
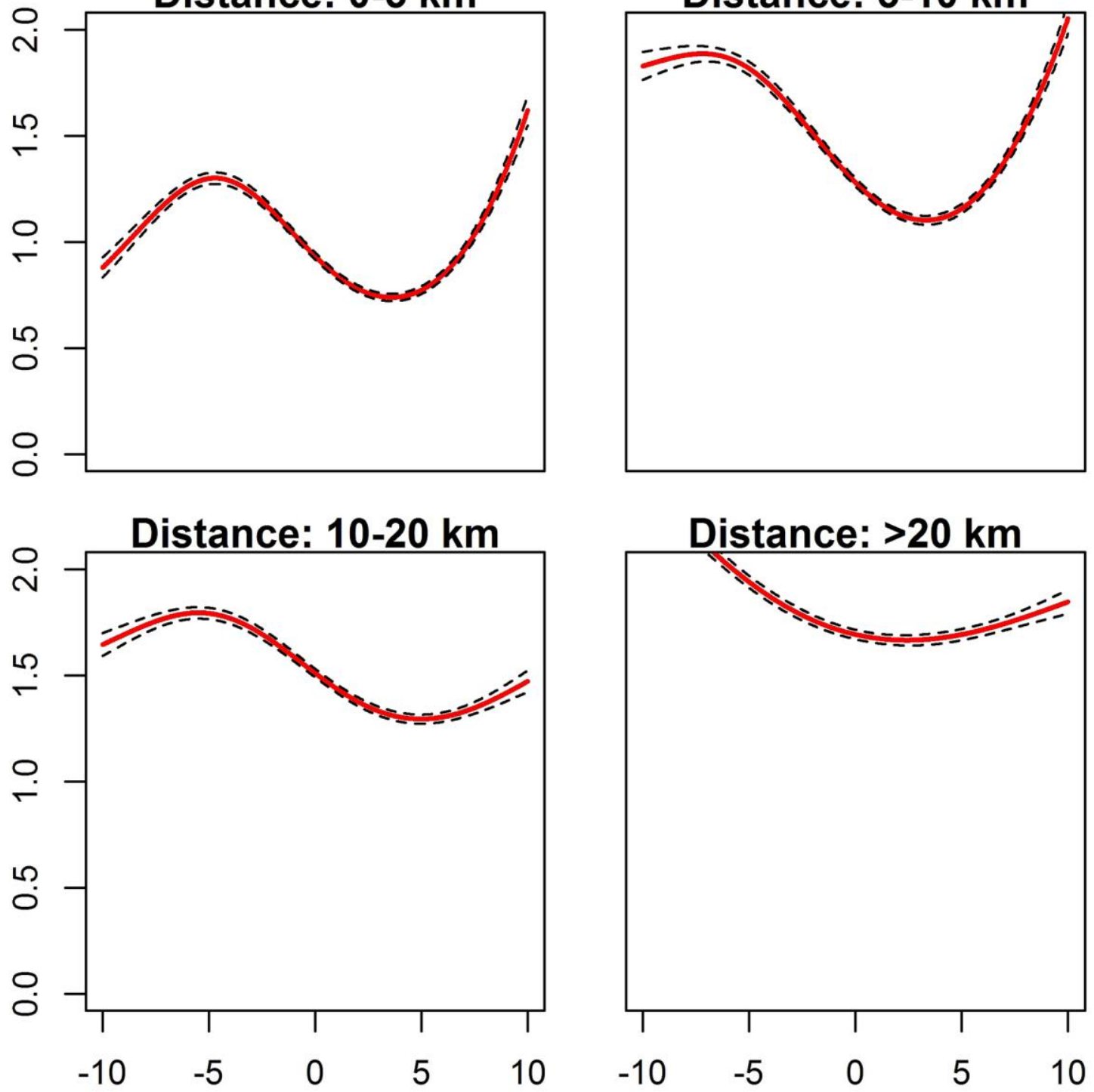

Figure 32. Harbour porpoise acoustic activity (DPM/hr, solid red line) before and after piling $(t=0)$ for distances between CPODs and piling locations for several distance bins with $95 \%$ confidence limits (dashed line) as modelled with a GAMM. Data points are indicated by inside tick marks. 
FaunaGard $=0 \mathrm{hr}$; distance $(\mathrm{km}) \quad 0<1$

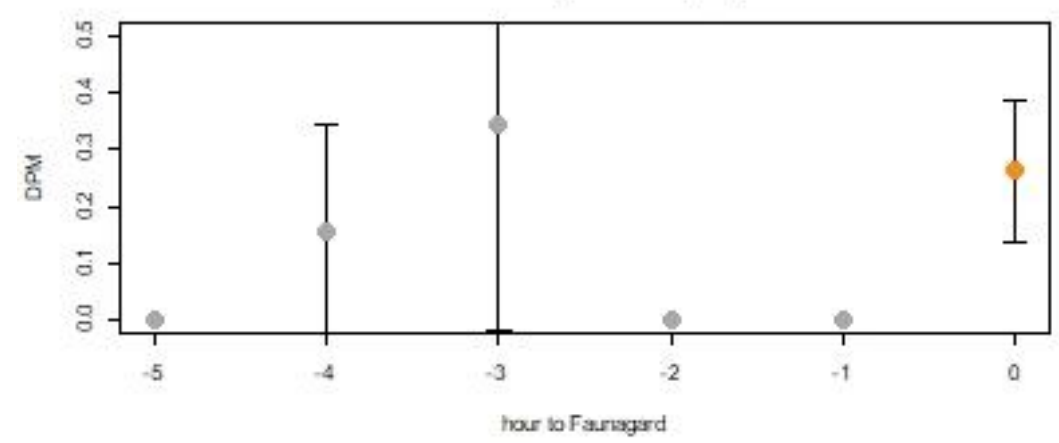

$1<2$

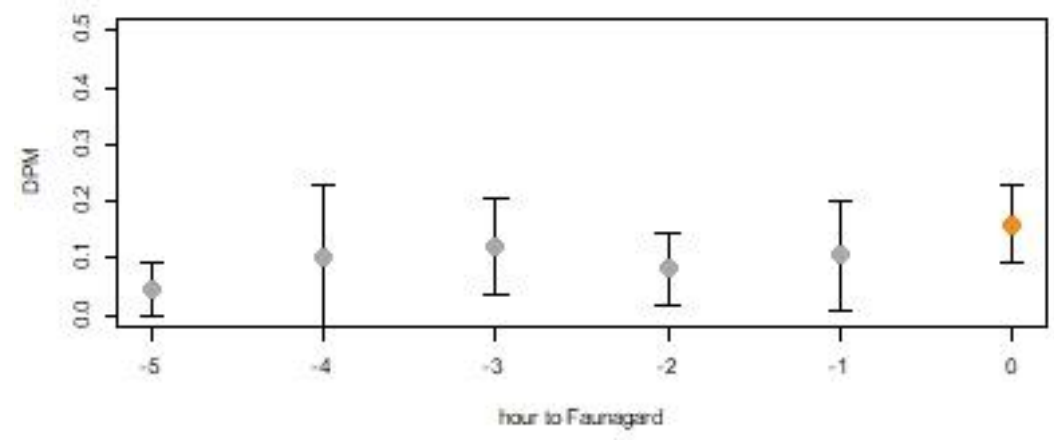

$2<3$

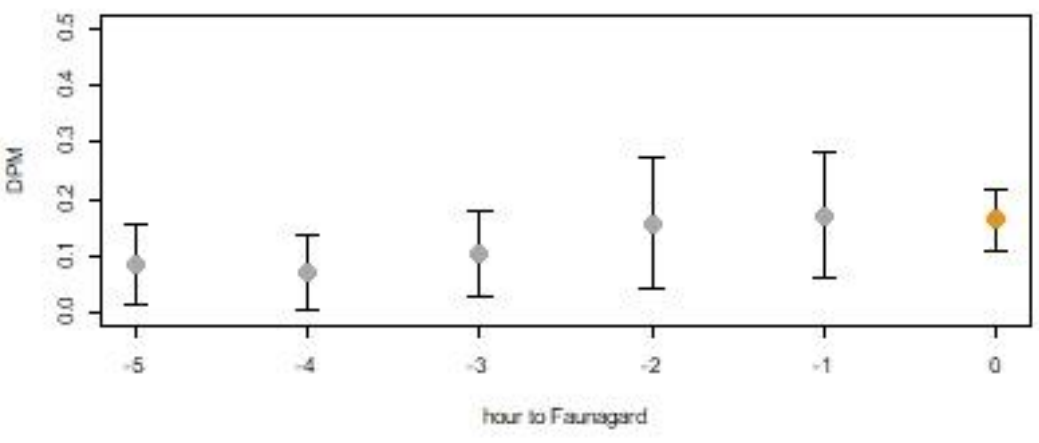

$>3$

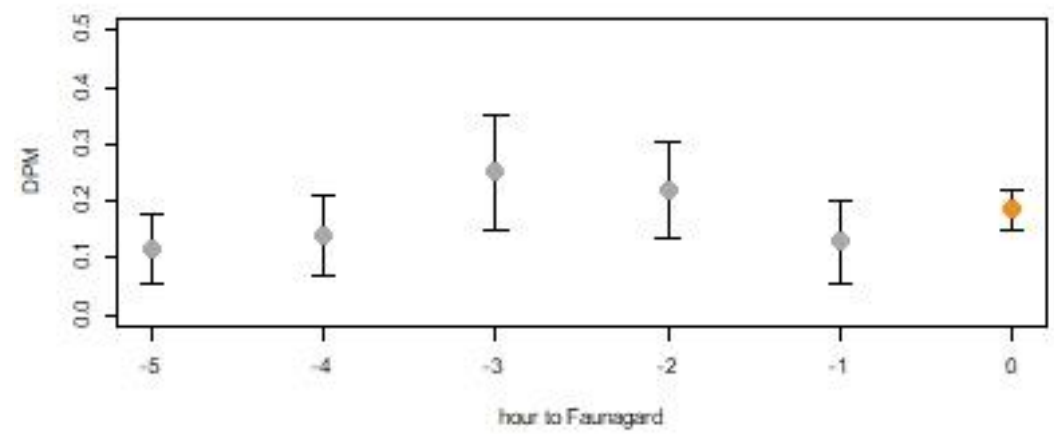

Figure 33. Harbour porpoise acoustic activity (DPM/hr) five hours before and during activation of FaunaGuard (orange symbol, hours =0) for different distance bins ( $\mathrm{km}$ 's) between CPODs and FaunaGuard locations. Orange symbol is the period the FaunaGuard was activated.

\subsubsection{Effect of FaunaGuard}

Figure 28 shows the effect of the FaunaGuard and pile driving on acoustic activity for distances $<5 \mathrm{~km}$, 5-10 km and further away. The FaunaGuard was switched on before pile driving started. The graphs show no effect on porpoise acoustic activity. For distances up to $20 \mathrm{~km}$ the acoustic activity during the 
period the FaunaGuard was activated did not differ from the activity in the preceding hour(s). At distances $>20 \mathrm{~km}$ the acoustic activity was higher than the previous twelve hour(s). Since an effect of the FaunaGuard is expected at closer range than $5 \mathrm{~km}$ the acoustic activity is shown in more detail in Figure 33. Neither distance bin showed lower acoustic activity during period the FaunaGuard was activated than the five hours before activation. Note, however, that the confidence intervals of the hourly averages of acoustic activity overlap. Thus, differences are not statistically significant.

\subsubsection{Effect of simultaneous pile driving}

Table 11. Simultaneous pile driving events.

\begin{tabular}{lccccc}
\hline Date & Start 1 (hrs) & Start 2 (hrs) & End 1 (hrs) & End 2 (hrs) & Overlap (min) \\
\hline 12 Jul & $7: 45$ & $9: 36$ & $9: 47$ & $11: 50$ & 11.5 \\
1 Aug & $18: 40$ & $19: 06$ & $20: 25$ & $21: 34$ & 79 \\
6 Aug & $17: 43$ & $19: 36$ & $19: 50$ & $21: 35$ & 14 \\
10 Aug & $17: 38$ & $18: 27$ & $19: 03$ & $20: 12$ & 36.5 \\
20 Aug & $21: 11$ & $22: 21$ & $23: 02$ & $0: 39$ & 41.5 \\
24 Aug & $4: 23$ & $5: 07$ & $6: 16$ & $7: 24$ & 69 \\
27 Aug & $9: 55$ & $12: 06$ & $12: 09$ & $14: 15$ & 3.5 \\
18 Sep & $12: 21$ & $12: 53$ & $13: 41$ & $14: 49$ & 48 \\
21 Sep & $9: 24$ & $10: 31$ & $10: 47$ & $12: 37$ & 16.5 \\
\hline
\end{tabular}

Table 12. Comparison between acoustic activity during two overlapping pile driving events and pre- and post-overlapping periods, per CPOD (bold pod in wind farm). For numbers $<1$ the acoustic activity during overlapping pile driving is lower, for numbers $>1$ the acoustic activity is higher. Bold = significant difference.

\begin{tabular}{lcccccccc}
\hline POD \date & $\mathbf{1 2 - j u l}$ & $\mathbf{1 - a u g}$ & $\mathbf{6 - a u g}$ & $\mathbf{2 0 - a u g}$ & $\mathbf{2 4 - a u g}$ & 27-aug & 18-sep & 21-sep \\
\hline $\begin{array}{l}\text { Overlap } \\
\text { (min) }\end{array}$ & 11.5 & 79 & 14 & 41.5 & 69 & 3.5 & 48 & 16.5 \\
\hline GEM01 & 0.52 & $\mathbf{1 . 5}$ & 0.42 & 0.43 & $\mathbf{1 . 4 1}$ & 0.52 & 0.54 & 0.54 \\
GEM02 & 0.32 & $\mathbf{- 1 . 3}$ & 0.22 & $\mathbf{1 . 2 3}$ & $\mathbf{1 . 2 1}$ & 0.32 & $\mathbf{1 . 3 4}$ & 0.34 \\
GEM03 & 0.22 & $\mathbf{- 1 . 2}$ & 0.12 & 0.14 & 0.11 & 0.22 & 0.24 & 0.24 \\
GEM04 & 0.17 & 0.15 & 0.08 & $\mathbf{- 1 . 0 9}$ & 0.06 & 0.17 & $\mathbf{1 . 1 9}$ & 0.19 \\
GEM05 & 0.11 & 0.08 & 0.01 & 0.03 & 1.03 & 0.12 & 0.14 & 0.13 \\
GEM06 & 0.09 & 0.08 & 0.03 & 0.02 & 0.02 & 0.1 & 0.12 & 0.12 \\
GEM07 & 0.09 & 0.09 & 0.06 & 0.05 & 0.04 & 0.09 & 0.11 & 0.11 \\
GEM08 & 0.04 & NA & NA & NA & NA & NA & 0.07 & 0.07 \\
GEM09 & 0.04 & 0.02 & 0.1 & 0.08 & 0.12 & 0.04 & $\mathbf{1 . 0 6}$ & $\mathbf{1 . 0 3}$ \\
GEM10 & 0.01 & 0.04 & 0.11 & 0.09 & $\mathbf{1 . 1 2}$ & 0.01 & 0.03 & 0.02 \\
GEM11 & 0.04 & 0.09 & 0.14 & 0.12 & 0.13 & 0.04 & 0.02 & 0.06 \\
GEM12 & 0.12 & 0.16 & 0.2 & 0.18 & $\mathbf{1 . 1 8}$ & 0.11 & 0.09 & 0.13 \\
GEM13 & 0.19 & $\mathbf{1 . 2 3}$ & $\mathbf{- 1 . 2 6}$ & 0.25 & 0.25 & 0.19 & $\mathbf{- 1 . 1 7}$ & 0.2 \\
GEM14 & 0.07 & $\mathbf{1 . 1 1}$ & $\mathbf{1 . 1 7}$ & $\mathbf{1 . 1 5}$ & 0.17 & 0.06 & 0.04 & 0.06 \\
GEM15 & 0.42 & 0.4 & 0.32 & $\mathbf{- 1 . 3 3}$ & 0.31 & 0.42 & 0.44 & 0.44 \\
\hline
\end{tabular}




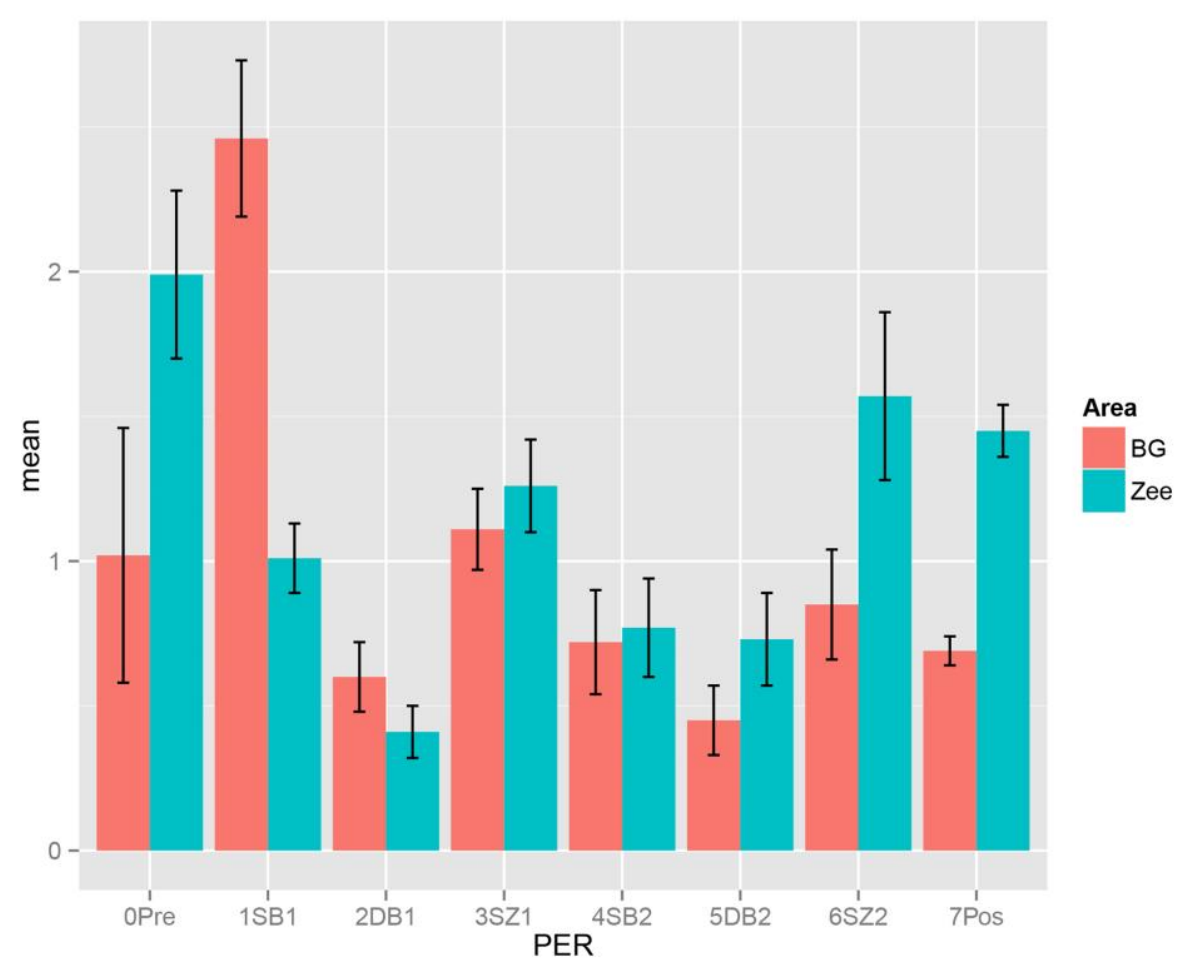

Figure 34. Harbour porpoise acoustic activity in relation to periods with several pile driving regimes. The $x$-axis shows OPre $=$ pre-piling $(<1 \mathrm{Ju}), 1 \mathrm{SB} 1=$ pile driving in Buitengats $(1-28 \mathrm{July}), 2 \mathrm{DB} 1=$ pile driving in both wind farms (28 Jul-16 Aug), 3SZ1 = pile driving in ZeeEnergie (16 Aug-13 Sep), 4SB2 = pile driving in Buitengaats (13-24 Sep), 5DB2 = pile driving in both wind farms (24 Sep-5 Oct), 6SZ2 = pile driving in ZeeEnergie (5-18 Oct), and 7Pos = post pile driving (> 18 Oct). Difference between T-O and $T-c$ is significant when the error bars do not overlap.

During the construction of the Gemini wind farms simultaneous pile driving was permitted during two periods: 28 July-16 August, and 24 September-5 October. Actual simultaneous pile driving occurred in nine instances (Table 11). Pile driving overlapped on average 35 minutes (3.5-79 min). For each of these simultaneous events the acoustic activity per CPOD location is compared to the acoustic activity before and after the simultaneous pile driving events. Table 12 shows the results of this analysis. The acoustic activity is lower during $89.6 \%$ of the possible combinations. However, the difference is significant in six combinations only. The acoustic activity is significantly higher during 15 combinations, that show no clear pattern in POD location in relation to piling location, nor a relation with the length of overlapping pile driving events.

If we compare the acoustic activity of harbour porpoises in Buitengaats and ZeeEnergie for different pile driving regimes (no piling, piling in one wind farm, simultaneous piling, Figure 34), both periods with simultaneous pile driving showed lowest activity in both wind farms. For the first period of simultaneous pile driving (28 Jul-16 Aug, 2DB1) the acoustic activity is significantly lower than during pile driving in Buitengaats (1SB1 \& 4SB2) or in ZeeEnergie (3SZ1 \& 6SZ2) only. During the second period of simultaneous pile driving (24 Sep-5 Oct, 5DB2) Buitengaats showed significant lower acoustic activity than piling only in Buitengaats and ZeeEnergie separately. The acoustic activity in ZeeEnergie during simultaneous pile driving (5DB2) did not differ from pile driving in Buitengaats only, and showed significant lower activity than piling in ZeeEnergie only (3SZ1 \& 6SZ2). The acoustic activity in Buitengaats was highest in the period 1-28 July, when pile driving took place in Buitengaats only (1SB1). Simultaneous pile driving did not result in a consistent effect on acoustic activity of harbour porpoises. In Buitengaats the acoustic activity was significantly lower during both simultaneous pile driving periods than during pile driving in one wind farm. ZeeEnergie showed the same differences, except the second simultaneous pile driving period when the acoustic activity did not differ from the acoustic activity during piling in Buitengaats only. 


\section{Discussion/synthesis}

\subsection{Aerial surveys versus passive acoustic monitoring}

Aerial surveys were conducted between June and October 2015. Applying distance sampling methods and an existing correction factor $(\mathrm{g}(0))$ to correct for animals not seen, these surveys resulted in estimates of harbour porpoise densities. They also provided information on the distribution of porpoise in the study area and the changes thereof with piling activity.

From June 2015 until February 2016, CPODs collected data on the presence of harbour porpoises on fifteen locations within the Gemini wind farm area and surroundings during $70.2 \%$ of all potential (deployment) days. Compared to the $44.2 \%$ of data collection during T-0 this is a substantial increase. Dislocation of CPODs was the main cause for the discontinuous series of recorded data, during both $\mathrm{T}$ 0 and $\mathrm{T}-\mathrm{C}$.

As described in the T-0 report acoustic detections by CPODs can give a reliable picture of the acoustic activity of harbour porpoises. Acoustic detections are considered as an approximation of the occurrence of harbour porpoises derived from their acoustic activity. Until recently harbour porpoises were considered to echolocate almost continuously, but recent studies indicate that behaviour influences echolocation rates; e.g. sleeping (Wright et al., 2013), travelling, or feeding. A recent study on four subadult and one adult porpoises equipped with high-resolution sound and movement recording DTAGs demonstrated again that porpoises forage continually, but that they show different feeding patterns during the day (Wisniewska et al., 2016). At this point in time acoustic data, however, cannot be used to assess the numbers and densities of porpoises. Several studies are underway to develop methods that will allow the use of acoustic activity to derive density estimates (e.g. Kyhn et al., 2008, 2012), but the general consensus is that it will take some time to achieve this. A reduction in acoustic activity can not only indicate a drop in local density, but it can also indicate a change in behaviour. Harbour porpoise can change their acoustic behaviour when disturbed, for example by a reduction in foraging behaviour when seismic surveys take place close by (Pirotta et al., 2014). For this study both reactions - moving out of the impact area or change in acoustic behaviour - can be indicative of a response to the emitted sound from the piling event.

Aerial and acoustic surveys collect very distinct types of data sets regarding the spatial and temporal scale. The CPODs are permanently monitoring porpoises within a limited radius around the POD $(<300$ $\mathrm{m}$ ). The aerial surveys are covering a large area, nearly $7,800 \mathrm{~km}^{2}$, but are only taking snapshots in time.

Nevertheless, both methods showed a similar seasonal pattern in 2015, with density/acoustic activity peaking in June, and in general decreasing towards winter. The finer scale temporal resolution of the passive acoustic monitoring data showed several shorter periods with higher activity during the whole study period though. both methods combined should give a better understanding of the effect of pile driving.

\subsection{Spatial and seasonal pattern of harbour porpoise in the North Sea}

The results of both the aerial surveys and the acoustic monitoring show a distinct seasonal pattern in abundance and acoustic activity of harbour porpoises; a peak is recorded in June with decreasing activity/density. Aerial surveys showed a decrease until the last survey in October, whereas acoustic monitoring showed a decrease until August, followed by a small increase towards the end of the year. A number of studies have shown that for porpoises 2015 was an aberrant year. In coastal waters the numbers of observed and stranded harbour porpoises were much lower in 2015 than in previous years (Haelters \& Geelhoed, 2015). The numbers in the coastal zone in 2015 were as low as the late nineties. However, the aerial surveys in the DCS conducted in 2015 (Geelhoed et al., 2015b) show that the abundance of porpoises in Dutch waters did not change. While porpoises occurred in similar numbers as the previous summer their distribution was more offshore in the summer of 2015, with few sightings in 
the coastal zone and larger areas with high densities in the northern part of the DCS. In July 2015 the overall density in the Dutch EEZ (DCS) was $0.70 \mathrm{n} / \mathrm{km}^{2}$ (Geelhoed et al., 2015b). The mean density in the Frisian Front area was lower at $0.44 \mathrm{n} / \mathrm{km}^{2}$ (Figure 35 ).

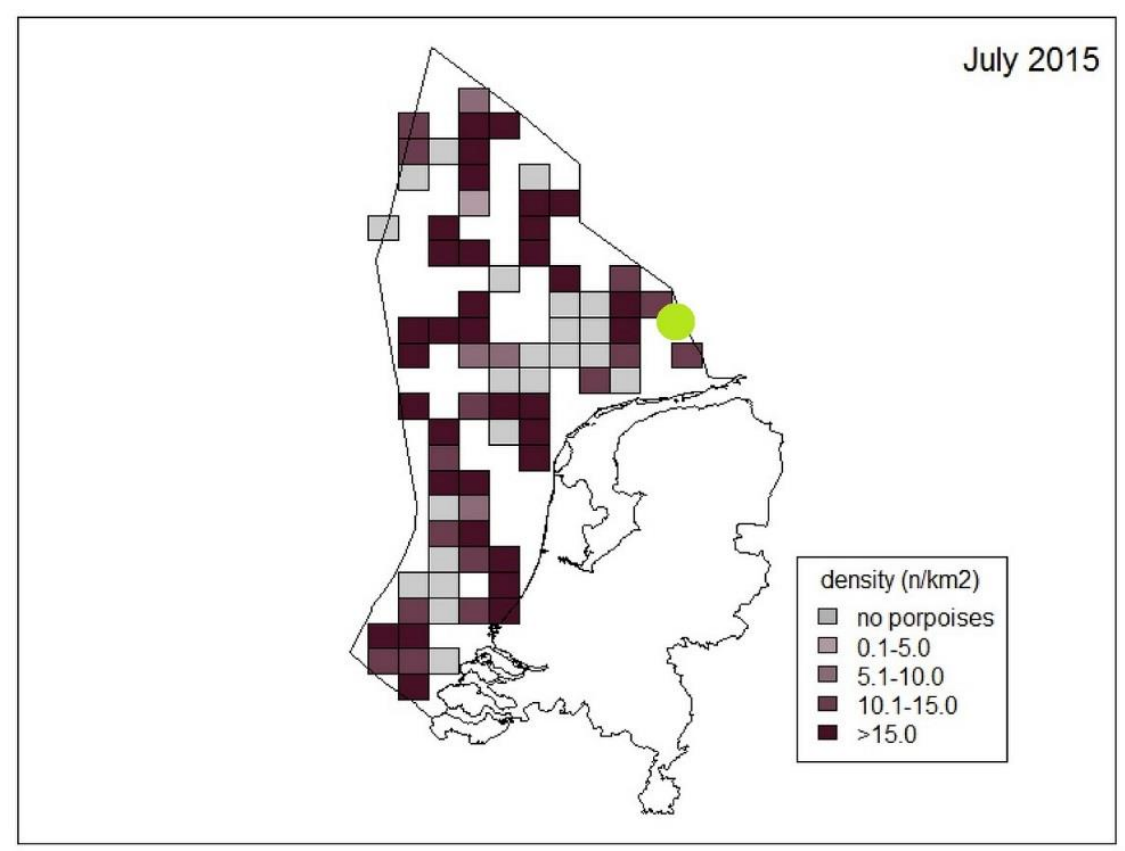

Figure 35 Distribution of harbour porpoises $\left(\mathrm{n} / \mathrm{km}^{2}\right)$ in the Dutch EEZ in July 2015 (1/9 ICES grid) (Geelhoed et al., 2015b). Location of Gemini wind farms indicated by a green dot.

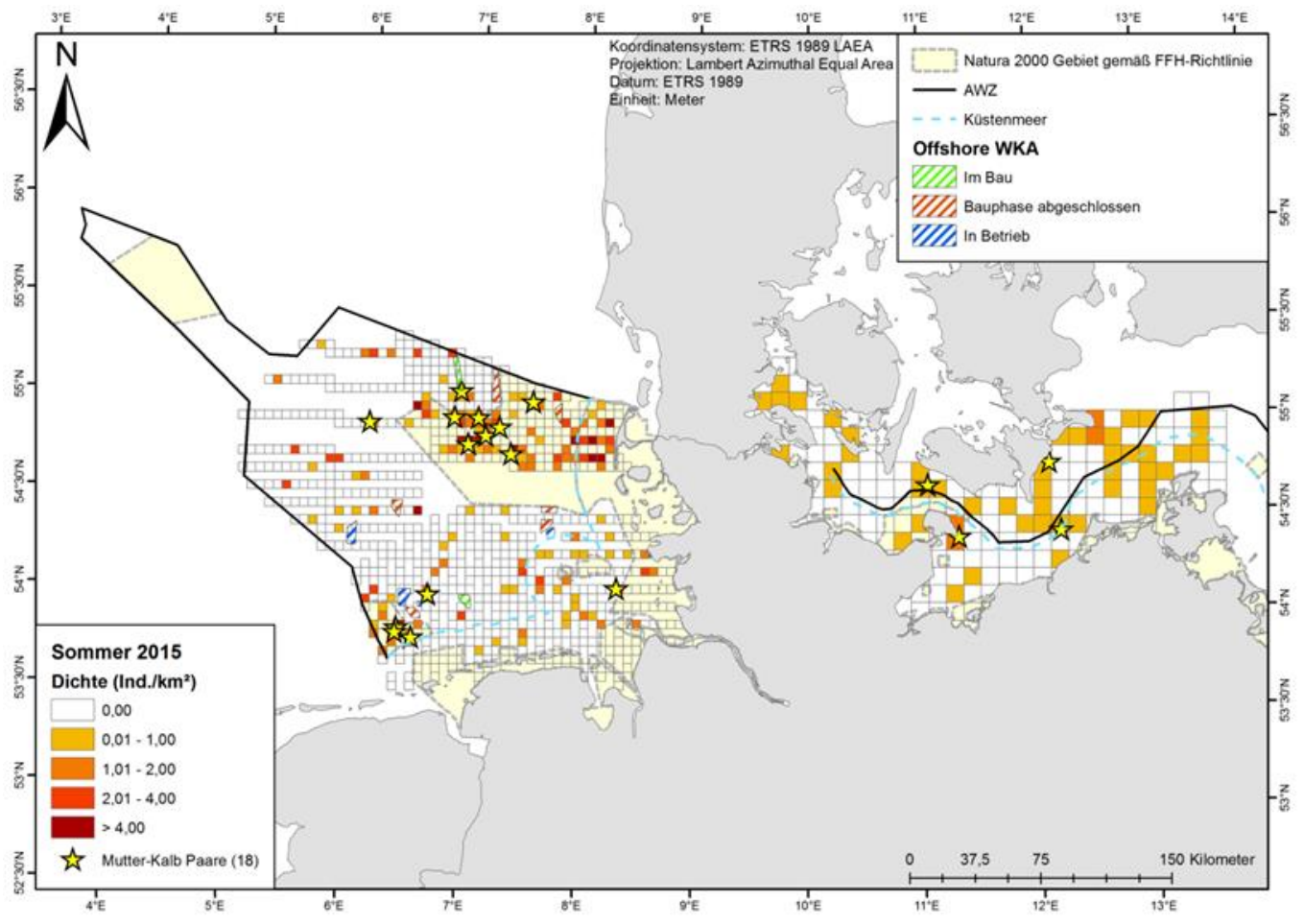

Figure 36 Distribution of harbour porpoises $\left(\mathrm{n} / \mathrm{km}^{2}\right)$ in the German EEZ in summer 2015 (5 x $5 \mathrm{~km} \mathrm{grid,}$ ICES, 2016).

Results of flight surveys conducted in summer 2015 in the adjacent German EEZ are summarized by ICES (2016). Effort-corrected density and abundance estimates for harbour porpoises were generated using a bootstrapping method (Figure 36 ). The estimated abundance was 17,609 individuals (95\% CI: 
$11,905-36,152)$ in the German North Sea, resulting in an estimated density of $0.55 \mathrm{n} / \mathrm{km}^{2}$ (95\% CI: $\left.0.32-0.97 \mathrm{n} / \mathrm{km}^{2}\right)$. Density values are within the range found in previous years, but lower than the estimates in $2009\left(1.05(0.57-2.03) \mathrm{n} / \mathrm{km}^{2}\right.$ (Gilles et al., 2010)) and $2012(0.71(0.39-1.40)$ n/km² (Gilles et al., 2013)). As in previous years (e.g. Viquerat et al. 2015) above-average harbour porpoise densities close to the Gemini wind farm sites, covering most of the Borkum Riffgrund area were found.

Aerial surveys on the Dutch Continental Shelf show a peak in March and lower densities in summer and autumn (Geelhoed et al., 2013; Geelhoed \& Scheidat, 2018; Scheidat et al., 2012). In the German North Sea bordering Dutch waters, the highest densities occur in spring. Whereas older aerial surveys indicated much lower porpoise densities during the rest of the year (Gilles et al. 2009, 2011), more recent surveys showed that density levels around Borkum Reef can still be high throughout the summer (ICES 2016, Gilles et al. 2012, Hansen et al. 2013, Höschle et al. 2011, Siebert et al. 2012, 2013). The results of the DCS flight surveys in 2015 (Geelhoed et al., 2015b) indicate a similar trend for the adjacent Dutch waters.

The area further north along the German coast is characterized by a peak in May and June (Gilles et al., 2009). Along the Danish west coast aerial surveys show that densities are highest between April and August, with a peak in August, although data for June-July are lacking (Teilmann et al., 2008). In the western part of the North Sea, porpoise numbers peak in April along the south eastern coast of England; up north along the eastern coast numbers peak in August (Evans et al., 2003).

In the Dutch North Sea passive acoustic monitoring studies have been conducted in and around the Offshore Wind farm Egmond aan Zee (OWEZ) and Prinses Amalia Wind Park (PAWP) wind farm sites off the mainland coast. In OWEZ, Scheidat et al. (2011) found most acoustic detections in the winter months (Dec-Mar) and virtually no detections in May and June. In PAWP, the click frequency showed a distinct temporal pattern with higher activity in March and December, and the least activity in April-May (Van Polanen Petel et al., 2012). A slightly different pattern has been shown along the Dutch-German border, where a row of CPODs was deployed from the island of Borkum into the Eems-Dollard estuary. These CPODs recorded the lowest click frequency in April-July and a higher click frequency between August and December (Brasseur et al., 2010). The pattern in the Gemini study area in 2015 differs from the sketched picture. In the study area the highest click frequency was recorded in June, after which it decreased.

\subsection{Effect of construction activities on harbour porpoise occurrence}

The aerial surveys in June and July before and during pile driving suggest avoidance of the piling location in a radius up to ca $20 \mathrm{~km}$ by harbour porpoise. Aerial surveys in July-October that were conducted during pile driving, showed a lack of porpoise sightings in a radius from $<15 \mathrm{~km}$ up to around $25 \mathrm{~km}$ around the piling location. Surveys a few hours after pile driving had stopped, yielded some sightings of porpoises closer to the piling locations. This suggests a return of deterred animals or an influx of 'new' animals into the previously avoided area. A lack of sightings theoretically does not necessary mean a lack of porpoises. As explained in 2.3.2 not all harbour porpoises on the line transect are detected. Under good observation conditions ca two third of the present porpoises probably remain undetected, and under moderate observation conditions more than $80 \%$ of the animals probably remain undetected. In other words, more porpoises could have been present, but could be invisible for aerial observers. Furthermore the transects are designed to provide a representative sample of the area, as such they will not cover the complete surface where porpoises could be present. Nevertheless the cautious conclusion can be drawn from the aerial surveys that: avoidance distance during construction of the Gemini wind farms probably lies between $<15$ and $25 \mathrm{~km}$.

Passive acoustic monitoring did not start before piling commenced. Therefore the effect of the first pile driving events in comparison to the pre-piling period could not be described. The acoustic data, however, showed that porpoises were present indeed in the wind farm areas during pile driving when aerial surveys were conducted. 
The acoustic data showed on average a lower overall harbour porpoise acoustic activity in the study area during $\mathrm{T}-\mathrm{c}$ than during $\mathrm{T}-\mathrm{O}$. This can partly be explained by seasonal differences. During T-c no data were collected in the first half of the year, when highest acoustic activity was measured during $T$ 0 . The acoustic activity of harbour porpoises differed in details per CPOD location, but showed a similar temporal pattern for each location. The variation in click frequency and the average click frequency in the wind farm areas ZeeEnergie and Buitengaats were smaller than at the locations outside the wind farm areas West of Gemini, and South of Gemini. This difference was not evident during T- 0 . When using acoustic activity as a proxy for harbour porpoise presence this can be interpreted as bigger fluctuations of porpoise numbers in the wind farm areas during $\mathrm{T}-\mathrm{c}$ than during $\mathrm{T}-\mathrm{O}$.

For both T-0 and T-c the GAMM-analyses showed similar relations between the following variables and harbour porpoise acoustic activity: latitude (and longitude in 2014), wind force, hour of the day, day of the year, temperature and time to high tide. On top of these the GAMM results showed an effect of pile driving on harbour porpoise acoustic activity. There was a correlation between acoustic activity and distance to piling locations. Pile driving resulted in a drop of acoustic detections in a radius of $10 \mathrm{~km}$. Further away from the piling location the number of detections increased again up to a distance of 20 $\mathrm{km}$, and gradually decreased at greater distances. It should be noted that CPODs only were deployed at distances up to $20 \mathrm{~km}$ west and south of the wind farm areas, and that they were deployed at distances further away west of the wind farms only. The conclusion that can be drawn based on the passive acoustic monitoring is that avoidance distance of harbour porpoise during construction of the Gemini wind farms lies between 10 and $20 \mathrm{~km}$.

A number of studies have been conducted by means of passive acoustic monitoring to investigate avoidance behaviour of harbour porpoise in reaction to pile driving. Danish studies were conducted by Tougaard et al. (2009) and reported reactions to pile driving at Horns Reef 1 offshore wind farm at distances beyond $21 \mathrm{~km}$. Similar reaction distances $(18 \mathrm{~km}$ ) were observed by Brandt et al. (2011) at Horns Reef 2 offshore wind farm. Brandt et al. (2016) reviewed the effects on harbour porpoises of pile driving for the construction of seven offshore wind farms in the German Bight, that used mitigation measures to reduce sound emission. They found that porpoise acoustic detections were always lowest during piling at the nearest distance to the construction site. Porpoise detections increased with time and distance relative to piling. The detection rates declined $68 \%$ at $<5 \mathrm{~km}$ from piling locations, and $26 \%$ between $10-15 \mathrm{~km}$. These acoustic studies show that an avoidance effect of pile driving extends to on average $17 \mathrm{~km}$. Aerial survey data in some of the German wind farms showed an avoidance distance of ca $20 \mathrm{~km}$ (Brandt et al., 2016).

A number of passive acoustic monitoring studies have been conducted to investigate avoidance behaviour of harbour porpoise in reaction to pile driving, with mitigation measures to reduce sound emission. Despite a lack of sound mitigation measures, the Gemini results are consistent with results from these studies on Danish and German wind farms, that show avoidance distances between 17-21 km (Brandt et al., 2011, 2016; Tougaard et al. (2009). Since avoidance effects decrease with distance from the piling source, the available area for porpoises increases exponentially. Avoidance becomes more difficult to prove at greater distances since the number of displaced individuals are spread out over a bigger area; to have an equal chance of detecting this the number of CPODs should theoretically be increased exponentially as well. It is also important to note that there are a number of poorly understood factors that could influence the reaction of porpoises. It is likely that for instance the location of the area (e.g. feeding ground), the composition of the local porpoise population (e.g. juveniles vs adults), the adaptability of the animals (e.g. used to shipping noise) as well as the season (e.g. reproductive) when the piling occurs can play an important role in determining the response of an individual harbour porpoise. Thus, while we would expect a general reaction to a negative stimulus (loud noise) of this species by moving away from the noise, the extent of the reaction is likely to vary between individual events due to the difference in behavioural responses based on biological factors. The same is true for the time it would take porpoises to return to their previous habitat.

An example of individually different behavioural responses was described by Van Beest et al. (2018), who equipped three porpoises with high-resolution location and dive loggers and exposed them to a single airgun noise pulse. One individual displayed rapid movements away from the sound source, and two individuals made shorter and shallower dives (Van Beest et al., 2018). These individual differences might be caused by individually different disturbance levels and may lead to incomplete displacement of porpoises around a piling location. 
We found a negative effect of pile driving activities on acoustic activity, which commenced prior to the actual piling. Acoustic activity started decreasing ca 3 hrs before piling commenced and started increasing again ca 3 hrs after piling stopped. The results show that harbour porpoises already avoid piling activities up to $3 \mathrm{hrs}$ prior to the commencement of the actual piling. The actual moment of decreasing detection rates differed per piling event.

Brandt et al. (2016) demonstrated the acoustic activity started decreasing about a day before piling started, and reached a minimum around piling. It started increasing after piling stopped till 'normal' levels were reached between 9 and 28 hrs after piling and continued to increase until about 16 to 46 hrs after piling. In our study we modelled the effects from 12 hrs prior to 12 hrs after piling, due to the relatively short intervals between successive piling events. We could not determine when 'normal' levels were reached, since the time between subsequent piling events in Buitengaats and ZeeEnergie, however, was on average shorter than the range Brandt et al (2016) found for returning to 'normal' levels.

A decrease in harbour porpoise acoustic activity is probably caused by an increase in (shipping) activity to prepare the actual piling by a jack-up vessel. These preparations commence on average 5 hrs before piling starts. Though shipping noise typically consists of low-frequency levels, it contains low-levels of mid to high frequency sound. Dyndo et al. (2015) found a negative effect on porpoises in a pen that were exposed to the noise of vessel passages. In northwest Ireland harbour porpoise presence is shown to be reduced by construction-related activity (Culloch et al., 2016).

We could not show an effect of the FaunaGuard on the presence of harbour porpoises, most likely due to methodological problems. The CPOD study was not designed to measure an effect of the FaunaGuard. Based on a study with captive porpoises that were exposed to the FaunaGuard by Kastelein et al. (2014c) the theoretical effective range was modelled to be $1.3 \mathrm{~km}$ for the Dutch mainland coast under conditions with little wind (de Jong \& Binnerts, 2014). A field study by means of mainly visual camera observations in the Marsdiep, between Den Helder and Texel, concluded that the FaunaGuard deterred harbour porpoises up to distances of at least 1000 meters (Geelhoed et al., 2017). To demonstrate effects of the FaunaGuard in the Gemini wind parks a design with CPODs in a fine-scale grid around the FaunaGuard would have been necessary. With the changing locations of the FaunaGuard and the number of CPODs needed this was not feasible.

We found indications of a negative effect of simultaneous pile driving in both wind farms on the acoustic activity of harbour porpoises. During simultaneous pile driving acoustic activity in both wind farms was lower than during piling in one wind farm, or did not differ between ZeeEnergie during the second simultaneous pile driving period and pile driving in Buitengaats. However, the actual number of overlapping pile driving events was low $(n=9)$ and the overlap was short (ca $35 \mathrm{~min}$ ).

Our results did not show an effect of the duration of pile driving, whereas Dähne et al. (2013) found a negative correlation between acoustic activity and the length of pile driving events, which varied between 376-802 min per monopile. Piling events in Gemini (76-234 min), however, were shorter than the minimum piling length in Germany.

The described effects of pile driving are presumably caused by underwater noise (Kastelein et al., 2010; 2012a-b; 2013a-d; 2014a-b; Lucke et al., 2009), generated by the piling activities. TNO measured the underwater noise at three fixed and one flexible positions (MP1-MP4) during pile driving of two different monopiles in Buitengaats. Thus sound was measured at four distances from the piling location, ranging from ca $700 \mathrm{~m}$ to more than $60 \mathrm{~km}$. The results show that the SELss threshold for avoidance behaviour of harbour porpoises of $140 \mathrm{~dB}$ re $1 \mu \mathrm{Pa} 2_{\mathrm{s}}$ (Heinis et al., 2015) is exceeded by $4 \mathrm{~dB}$ at MP3 (28-32 km from the pile) and is $10 \mathrm{~dB}$ lower at MP4 (62-66 km from the pile). Interpolation of these measurements indicates that a SEL of $140 \mathrm{~dB}$ re $1 \mu \mathrm{Pa} 2_{\mathrm{s}}$ is reached at $36-38 \mathrm{~km}$ from the piling location (De Jong, 2016). This distance is well above the calculated maximum avoidance distance of $30 \mathrm{~km}$, and well above the avoidance distances we found. This discrepancy can be explained by the lack of so-called species specific frequency weighing to calculate auditory thresholds for harbour porpoise. A generic M-filter (Southall et al., 2007) was used, whereas harbour porpoise frequency weighting would require a model less conservative than the M-weighting function (Tougaard et al., 2015). 
Sounds travels much faster than porpoises. In the Gemini wind farm area pile driving lasted on average 127 minutes (76-254 min). The swim speed of harbour porpoise is thought to be $1.4 \mathrm{~m} / \mathrm{s}$ (Otani et al., 2001), while short bursts up to $6 \mathrm{~m} / \mathrm{s}$ are possible (Lucke et al., 2000; Van Beest et al., 2018). Theoretically, a porpoise can swim $10.7 \mathrm{~km}$ in a straight line during an average piling event of 127 minutes, or 6.4 to $21,4 \mathrm{~km}$ during the shortest and the longest piling events. These distances are presumably lower, since porpoises generally do not swim in a straight line for a longer period of time. In other words, in the Gemini wind farm harbour porpoises that are present near a piling location are not able to avoid piling noise during the duration of a piling event up to distances of $36-38 \mathrm{~km}$ where the SEL is lower than $140 \mathrm{~dB}$ re $1 \mu \mathrm{Pa} 2 \mathrm{~s}$. Porpoises that are present further away from the piling location when piling starts could reach distances further away. Avoidance, however, becomes more difficult to measure at greater distances with the used CPOD design, and 'dilution' of porpoises. Two other mechanisms can obscure the measured effects of piling: habituation of harbour porpoises to noise, or movement of harbour porpoises from areas outside the noise exposed range (Aarts et al., 2016). These animals show no or less avoidance behaviour and can swim towards the sound source.

\subsection{Effects on population level}

Disturbance of harbour porpoises can eventually lead to reduced fitness. Porpoises have to feed and do feed almost continually (e.g. Wisniewska et al., 2016) to meet their energy demands. Failure to acquire sufficient food may have rapid and severe fitness consequences, giving them low resilience to disturbance. Individual porpoises have been reported to starve to death in less than a week (Kastelein et al., 1997). A negative impact of human induced sound was found for seismic surveys. Analysis of CPOD data from a seismic survey that displaced harbour porpoises (Thompson et al., 2013) showed a reduction in buzzing activity by $15 \%$ in the remaining porpoises (Pirotta et al., 2014). This reduction could reflect disruption of feeding or social activities. At which level reduction of feeding leads to reduced fitness is unknown. As a consequence the effect of disturbance of harbour porpoises cannot yet be translated to consequences for individual animals and thus not for populations.

As a first step the acoustic data from the Gemini offshore wind farm are used to compare methods which can provide a direct measure of foraging activity (Berges et al., in prep). 


\section{Conclusions}

The results of the T-c monitoring of harbour porpoises for the intended Gemini offshore wind farm show that harbour porpoises are permanently present in the area. Both the aerial surveys and the passive acoustic monitoring show a similar seasonal pattern, with a peak in early summer and dwindling densities and lower acoustic activity later in the year. On a finer scale the pattern differs between the acoustic monitoring and aerial surveys. This differs from the pattern during T-0 in 2014, and the Dutch Contintenal Shelf in general, where the numbers showed a dip in June and July and a peak in winter and early spring.

Passsive Acoustic Monitoring (PAM) shows the effect of underlying factors on the acoustic activity (and thus occurrence) of harbour porpoises in the area. During T-0 and T-c the same factors explained most variation in acoustic activity. During $\mathrm{T}-\mathrm{c}$, however, overall acoustic activity was lower.

PAM shows a decrease in acoustic activity before pile driving starts, followed by an increase to pre-piling levels after pile driving stopped. This is interpreted as avoidance of the piling source by harbour porpoises.

PAM shows that the avoidance distance of harbour porpoises lies in the range of $10-20 \mathrm{~km}$, which is supported by the aerial surveys that suggest changes in distribution in a radius from $<15 \mathrm{~km}$ up to 25 $\mathrm{km}$ around a pile driving location during piling. The avoidance distance might be restricted by the length of the piling event, that lasted on average too short to allow harbour porpoise to swim further away during this period.

PAM did not show a harbour porpoise deterring effect of the FaunaGuard. However, the study design was not primarily aimed at measuring an effect.

An effect of simultaneous pile driving in both Gemini wind farm areas Buitengaats and ZeeEnergie could not be detected. Simultaneous pile driving occurred on nine occasions, albeit with short overlap in time (ca $30 \mathrm{~min}$ ). 


\section{Quality Assurance}

Wageningen Marine Research utilises an ISO 9001:2015 certified quality management system. This certificate is valid until 15 December 2021. The organisation has been certified since 27 February 2001. The certification was issued by DNV GL.

Furthermore, the chemical laboratory at IJmuiden has NEN-EN-ISO/IEC 17025:2005 accreditation for test laboratories with number L097. This accreditation is valid until $1^{\text {th }}$ of April 2021 and was first issued on 27 March 1997. Accreditation was granted by the Council for Accreditation. The chemical laboratory at IJmuiden has thus demonstrated its ability to provide valid results according a technically competent manner and to work according to the ISO 17025 standard. The scope (L097) of de accredited analytical methods can be found at the website of the Council for Accreditation (www.rva.nl).

On the basis of this accreditation, the quality characteristic $Q$ is awarded to the results of those components which are incorporated in the scope, provided they comply with all quality requirements. The quality characteristic $Q$ is stated in the tables with the results. If, the quality characteristic $Q$ is not mentioned, the reason why is explained.

The quality of the test methods is ensured in various ways. The accuracy of the analysis is regularly assessed by participation in inter-laboratory performance studies including those organized by QUASIMEME. If no inter-laboratory study is available, a second-level control is performed. In addition, a first-level control is performed for each series of measurements.

In addition to the line controls the following general quality controls are carried out:

- Blank research.

- Recovery.

- Internal standard

- Injection standard.

- Sensitivity.

The above controls are described in Wageningen Marine Research working instruction ISW 2.10.2.105. If desired, information regarding the performance characteristics of the analytical methods is available at the chemical laboratory at IJmuiden.

If the quality cannot be guaranteed, appropriate measures are taken. 


\section{References}

Aarts G, von Benda-Beckmann A, Lucke K, Sertlek H, van Bemmelen R, Geelhoed S, Brasseur S, Scheidat M, Lam F, Slabbekoorn $H$ \& Kirkwood R, 2016. Harbour porpoise movement strategy affects cumulative number of animals acoustically exposed to underwater explosions. Marine Ecology Progress Series 557: 261-275.

Au WWL, Kastelein RA, Rippe T \& Schooneman NM, 1999. Transmission beam pattern and echolocation signals of a harbor porpoise (Phocoena phocoena). Journal of the Acoustical Society of America 106(6): 3699-3705.

van Beest FM, Teilmann J, Hermannsen L, Galatius A, Mikkelsen L, Sveegaard S, Balle JD, Dietz R \& Nabe-Nielsen J. 2018 Fine-scale movement responses of free-ranging harbour porpoises to capture, tagging and short-term noise pulses from a single airgun. R. Soc. open sci. 5: 170110. http://dx.doi.org/10.1098/rsos.170110Brandt MJ, Diederichs A, Betke K \& Nehls G, 2011. Responses of harbour porpoise to pile driving at the Horns Rev II offshore wind farm in the Danish North Sea. MEPS 421: 205-216.

Berges BJP, Scheidat M, Tougaard M \& Geelhoed SCV, in prep. Comparison of methodologies for the detection of harbour porpoises foraging from CPOD data. Wageningen Marine Research, Ijmuiden.

Brandt MJ, Hansen S, Diederichs A \& Nehls G, 2014. Do man-made structures and water depth affect the diel rhythms in click recordings of harbor porpoises (Phocoena phocoena)? Marine Mammal Science 30/3: 1109-1121.

Brandt MJ, Dragon A-C, Diederichs A, Schubert A, Kosarev V, Nehls G, Wahl V, Michalik A, Braasch A, Hinz C, Ketzer C, Todeskino D, Gauger M, Laczny M \& Piper W, 2016. Effects of offshore pile driving on harbour porpoise abundance in the German Bight- assessment of noise effects. Final report. IBL, IFAÖ \& BioConsult.

Brasseur SMJM, Van Polanen-Petel T, Geelhoed SCV, Aarts GM \& Meesters HWG, 2010. Zeezoogdieren in de Eems 2009: overzicht van de verkregen data. Research Report IMARES Wageningen UR Institute for Marine Resources \& Ecosystem Studies, Report C023/10.

Brasseur S, Kirkwood R \& Aarts G, 2016. Seal monitoring and evaluation for the Gemini offshore windfarm: Tconstruction - 2015 report. IMARES Wageningen UR - Institute for Marine Resources \& Ecosystem Studies, Report C043/16.

Camphuysen CJ, 2004. The return of the harbour porpoise (Phocoena phocoena) in Dutch coastal waters. Lutra 47(2): 113-122.

Camphuysen CJ, 2011. Recent trends and spatial patterns in nearshore sightings of harbour porpoises (Phocoena phocoena) in the Netherlands (Southern Bight, North Sea ), 1990-2010. Lutra 54: 39-47.

Camphuysen CJ \& Siemensma ML, 2011. Conservation plan for the Harbour Porpoise Phocoena phocoena in The Netherlands: towards a favourable conservation status. NIOZ Report 2011-07, Royal Netherlands Institute for Sea Research, Texel.

Carstensen J, Henriksen OD \& Teilmann J, 2006. Impacts on harbour porpoises from offshore wind farm construction: Acoustic monitoring of echolocation activity using porpoise detectors (T-PODs). Mar Ecol Prog Ser 321: 295-308.

Culloch RS, Andwerwald P, Brandecker A, Haberlin D, McGovern B, Pinfield R, Visser F, Jessopp M \& Cronin M, 2016. Effect of construction-realted activities iand vessel traffic on marine mammals Mar Ecol Porg Ser 549: 231-242.

Dähne M, Gilles A, Lucke K, Peschko V, Adler S, Kruegel K, Sundermeyer J \& Siebert U, 2013. Effects of pile-driving on harbour porpoises (Phocoena phocoena) at the first offshore wind farm in Germany. Environmental Research Letters 8(2),

Diederichs A, Pehlke H, Nehls G, Bellmann M, Gerke P, Oldeland J, Grunau C, Witte S \& Rose A, 2014. Entwicklung und Erprobung des Großen Blasenschleiers zur Minderung der Hydroschallemissionen bei Offshore-Rammarbeiten. BMU Förderkennzeichen 0325309A/B/C, BioConsult SH, Husum. 
Dyndo M, Wiśniewska DM, Rojano-Doñate L \& Madsen PT, 2015. Harbour porpoises react to low levels of high frequency vessel noise. Scientific Reports 5:11083.

Dähne M, Gilles A, Lucke K, Peschko V, Adler S, Krügel K, Sundermeyer J \& Siebert U, 2013. Effects of pile-driving on harbour porpoises (Phocoena phocoena) at the first offshore wind farm in Germany. Environ. Res. Lett. 8: 025002.

Evans PGH, Anderwald P \& Baines M, 2003. UK cetacean status review. Sea Watch Foundation, Oxford, UK.

Evans PGH, Fisher P, Rees I, Wainwright J, Farrell J \& Mayo W, 1993. Foraging ecology of harbour porpoises in Shetland. European Research on Cetaceans 7: 33-38.

Gaskin DE, Arnold PW \& Blair BA, 1974. Phocoena phocoena. Mammalian Species 42:1-8.

Geelhoed S, Scheidat M, Aarts G, van Bemmelen R, Janinhoff N, Verdaat H \& Witte, R, 2011. Shortlist Masterplan Wind - Aerial surveys of harbour porpoises on the Dutch Continental Shelf. Research Report IMARES Wageningen UR - Institute for Marine Resources \& Ecosystem Studies, Report No. C103/11.

Geelhoed SCV, Scheidat M, van Bemmelen RSA \& Aarts G, 2013. Abundance of harbour porpoises (Phocoena phocoena) on the Dutch Continental Shelf, aerial surveys in July 2010-March 2011. Lutra 56(1): 45-57.

Geelhoed SCV, Friedrich E, Joost M, Juhre H, Kirkwood R, van Leeuwen PW, Machiels M, Stöber N \& Verdaat H, 2015a. Gemini T-0: passive acoustic monitoring and aerial surveys of harbour porpoises. P. 110. IMARES Wageningen UR - Institute for Marine Resources \& Ecosystem Studies, Report No. C144/15.

Geelhoed SCV, Lagerveld S \& Verdaat JP, 2015b. Marine mammal surveys in Dutch North Sea waters in 2015. IMARES Wageningen UR - Institute for Marine Resources \& Ecosystem Studies, Report No. C189/15.

Geelhoed SCV, von Asmuth R, Al Abbar F, Leopold MF \& Aarts GM, 2017. Field testing the efficiency of the FaunaGuard Porpoise Module (FG-PM) in the Marsdiep area. Wageningen, Wageningen Marine Research (University \& Research centre), Wageningen Marine Research report C076/17.

Geelhoed SCV, Janinhoff N, Lagerveld S, Lehnert LS \& Verdaat JP, 2018. Marine mammal surveys in Dutch North Sea waters in 2017. Wageningen Marine Research (University \& Research centre), Wageningen Marine Research report C030/18.

Geelhoed SCV \& Scheidat M, 2018. Abundance of harbour porpoises (Phocoena phocoena) on the Dutch Continental Shelf, aerial surveys 2012-2017. Lutra 61(1): 127-136.

Gilles A, Scheidat M \& Siebert U, 2009. Seasonal distribution of harbour porpoises and possible interference of offshore wind farms in the German North Sea. Marine Ecology-Progress Series 383: 295-307.

Gilles A, Adler S, Kaschner K, Scheidat M \& Siebert U, 2011. Modelling harbour porpoise seasonal density as a function of the German Bight environment: implications for management. Endangered Species Research 14: 157-169.

Gilles A, Peschko V \& Siebert U, 2012. Monitoring von marinen Säugetieren 2012 in der deutschen Nordund Ostsee. Visuelle Erfassung von Schweinswalen. Endbericht für das Bundesamt für Naturschutz, pp 11-51.

Haelters J \& Geelhoed S, 2015. Minder bruinvissen in de zuidelijke Noordzee? Zoogdier 26(4): 1-3.

Hammond PS, Berggren P, Benke H, Borchers DL, Collet A, Heide Jorgensen MP, Heimlich S, Hiby AR, Leopold MF \& Oien N, 2002. Abundance of harbour porpoise and other cetaceans in the North Sea and adjacent waters. Journal of Applied Ecology 39(2): 361-376.

Hammond P, Macleod K, Berggren P, Borchers D, Burt M, Cañadas A, Desportes G, Donovan G, Gilles A, Gillespie D, Gordon J, Hiby L, Kuklik I, Leaper R, Lehnert K, Leopold M, Lovell P, Øien N, Paxton C, Ridoux V, Rogan E, Samarra F, Scheidat M, Sequeira M, Siebert U, Skov H, Swift R, Tasker M, Teilmann J, Van Canneyt O \& Vázquez J, 2013. Cetacean abundance and distribution in European Atlantic shelf waters to inform conservation and management. Biological Conservation 164:107-122.

Hammond PS, Lacey C, Gilles A, Viquerat S, Börjesson P, Herr H, Macleod K, Ridoux V, Santos MB, M Scheidat M, Teilmann J, Vingada J \& Øien N, 2017. Estimates of cetacean abundance in European Atlantic waters in summer 2016 from the SCANS-III aerial and shipboard surveys. Report to ICES Working Group on Marine Mammal Ecology. 26pp. 
Hansen S, Höschle C, Diederichs A, Nehls G, Laczny M \& Piper W, 2013. Offshore-Testfeld Alpha ventus Fachgutachten Meeressäugetiere 2. Untersuchungsjahr der Betriebsphase (Januar - Dezember 2011). BioConsult SH \& IfAÖ.

Heinis F, Jong CAF de \& RWS Werkgroep Onderwatergeluid, 2015. Cumulatieve effecten van impulsief onderwatergeluid op zeezoogdieren. TNO-rapport TNO 2015 R10335.

Hiby AR, 1998. The objective identification of duplicate sightings in aerial survey for porpoise. In: Marine Mammal Survey and Assessment Methods Rotterdam. Balkema.

Hiby AR \& Lovell P, 1996. Using aircraft in tandem formation to estimate abundance of harbour porpoise. Biometrics 54: 1280-1289.

Höschle C, Diederichs A, Nehls G, Laczny M \& Piper W, 2011. Statusbericht Meeressäugetiere im Bereich des Offshore-Testfeldes Alpha Ventus. Im Auftrag der Stiftung Offshore-Windenergie; Bioconsult SH \& Biola.

ICES, 2016. Report of the Working Group on Marine Mammal Ecology (WGMME), 8-11 February 2016, Madrid, Spain. ICES CM 2016/ACOM:26.

Jong $C$ de, 2016. Initial validation underwater noise model calculatons Gemini (projectnr 060.17991). TNO notitie DHW-TS-2016-0100293509

Jong de, CAF \& Binnerts B, 2014. Calculation of the startle response distance FaunaGuard Porpoise Module (FG-PM) at Offshore wind farm ENECO Luchterduinen (in Dutch), TNO memorandum, TNO-060-DHW-2014-00903A, The Hague.

Kastelein, R.A., van der Sijs, S.J., Staal, C., and Nieuwstraten, S.H. (1997). Blubber thickness in harbour porpoises (Phocoena phocoena). In The Biology of the Harbour Porpoise, A.J. Read, P.R. Wiepkema, and P.E. Nachtigall, eds. (De Spil Publishers), pp. 179-199.

Kastelein RA, Wensveen PJ, Hoek L, Verboom WC \& Terhune JM, 2009. Underwater detection of tonal signals between 0.125 and $100 \mathrm{kHz}$ by harbor seals (Phoca vitulina). The Journal of the Acoustical Society of America 125: 1222.

Kastelein RA, Hoek L, Wensveen PJ, Terhune JM \& de Jong CAF, 2010. The effect of signal duration on the underwater detection of a harbor porpoise (Phocoena phocoena) for single frequencymodulated tonal signals between 0.25 and $160 \mathrm{kHz}$. Journal of the Acoustical Society of America 128: 3211-3222.

Kastelein RA, Gransier R, Hoek L \& de Jong CAF, 2012a. The hearing threshold of a harbor porpoise (Phocoena phocoena) for impulsive sounds (L). Journal of the Acoustical Society of America 132(2): 607-610.

Kastelein RA, Steen N, Gransier R, Wensveen PJ \& de Jong CAF, 2012b. Threshold received sound pressure levels of single 1--2 kHz and 6--7 kHz up-sweeps and down-sweeps causing startle responses in a harbor porpoise (Phocoena phocoena). Journal of the Acoustical Society of America 3: 2325-2333.

Kastelein RA, Hoek L, Gransier R \& de Jong CAF, 2013a. Hearing thresholds of a harbor porpoise (Phocoena phocoena) for playbacks of multiple pile driving strike sounds, The Journal of the Acoustical Society of America 134: 2302-2306.

Kastelein RA, Steen N, Gransier R \& de Jong CAF, 2013b. Brief Behavioral Response Threshold Level of a Harbor Porpoise (Phocoena phocoena) to an Impulsive Sound. Aquatic Mammals 39(4): 315323.

Kastelein RA, Gransier R, Hoek L \& Rambags M, 2013c. Hearing frequency thresholds of a harbour porpoise (Phocoena phocoena) temporarily affected by a continuous $1.5 \mathrm{kHz}$ tone. Journal of the Acoustical Society of America 134:2286-2292.

Kastelein RA, Van Heerden D, Gransier R \& Hoek L, 2013d. Behavioral responses of a harbor porpoise (Phocoena phocoena) to playbacks of broadband pile driving sounds. Marine Environmental Research 92: 206-214.

Kastelein RA, Hoek L, Gransier R, Rambags M \& Claeys N, 2014a. Effect of level, duration, and interpulse interval of 1-2 kHz sonar signal exposures on harbour porpoise hearing. Journal of the Acoustical Society of America 136: 412-422.

Kastelein RA, Gransier R, Schop J \& Hoek L, 2014b. Frequency of greatest temporary hearing threshold shift in harbor porpoises (Phocoena phocoena) depends on the noise level. Journal of the Acoustical Society of America 136: 1410-1418.

Kastelein R, Hoek L, Gransier R, Huybrechts J, Covi J, 2014c. Behavioral responses of a harbor porpoise (Phocoena phocoena) to sounds from Acoustic Porpoise Deterrent-01 (FaunaGuard Porpoise Module) SEAMARCO report 2014-03. 
van Kooten T, Leopold M, Lucke K, Aarts G, Geelhoed S, Brasseur S, van Bemmelen R, Joost M, Stöber $\mathrm{N}$ \& Wendeln $\mathrm{H}$, 2012. MEP-Gemini-T0. Monitoring and evaluation plan for the ecological monitoring regarding the pre-construction phase of Gemini Offshore Wind Farm.

Kyhn, LN Tougaard J, Teilmann J, Wahlberg M, Jørgensen PB \& Bech, NJ, 2008. Harbour porpoise (Phocoena phocoena) static acoustic monitoring: laboratory detection thresholds of T-PODs are reflected in field sensitivity. Journal of the Marine Biological Association of the United Kingdom, 88(6), 1085-1091.

Kyhn, LN, Tougaard J, Thomas, L, Duve, LR, Stenback J, Amundin M, Desportes G \& Teilmann J, 2012. From echolocation clicks to animal density-Acoustic sampling of harbor porpoises with static dataloggers. The Journal of the Acoustical Society of America 131/1, 550-560.

Lucke K, Wilson R, Teilmann J, Zankl S, Adelung D, Siebert U, 2000. Advances in the elucidation of cetacean behaviour: A case study on a harbour porpoise (Phocoenca phocoena). Ch IV in: J Teilman (2000): The behaviour and sensory abilities of harbour porpoises (PhD thesis, University of Southern Denmark, Odense, Denmark. 219 pp.) in relation to bycatch in gillnet fishery. PhD thesis, University of Southern Denmark, Odense, Denmark, $219 \mathrm{pp}$.

Lucke K, Siebert U, Lepper PA \& Blanchet M-A, 2009. Temporary shift in masked hearing thresholds in a harbor porpoise (Phocoena phocoena) after exposure to seismic airgun stimuli. Journal of the Acoustical Society of America, 125 (6): 4060-4070.

Otani S, Naito Y, Kato A, Kawamura A, 2001. Oxygen consumption and swim speed of the harbor porpoise Phocoena phocoena. Fisheries science 67: 894-898.

Pirotta, E., Brookes, K. L., Graham, I. M. \& Thompson, P. M. 2014. Variation in harbour porpoise activity in response to seismic survey noise. Biology Letters 10: 20131090.

van Polanen Petel T, Geelhoed S \& Meesters E, 2012. Harbour porpoise occurrence in relation to the Prinses Amaliawindpark. IMARES Report number C177/10, IMARES Wageningen UR.

R Development Core Team, 2009. R: A language and environment for statistical computing. R Foundation for Statistical Computing, Vienna, Austria. ISBN 3-900051-07-0. http://www.Rproject.org.

Scheidat M, Gilles A, Kock KH \& Siebert U, 2008. Harbour porpoise Phocoena phocoena abundance in the southwestern Baltic Sea. Endangered Species Research 5: 215-223.

Scheidat M, Tougaard J, Brasseur S, Carstensen J, Polanen Petel T van, Teilmann J \& Reijnders P, 2011. Harbour porpoisesa (Phocoena phocoena) and wind farms: a case study in the Dutch North Sea. Environ Res Lett 6: 1-10.

Scheidat M, Verdaat H \& Aarts G, 2012. Using aerial surveys to estimate density and distribution of harbour porpoises in Dutch waters. Journal of Sea Research 69: 1-7.

Siebert U, Gilles A, Dähne M, Peschko V, Krügel K, Benke H, Lucke K, Müller S, Adler S \& Sundermeyer J, 2012. Ergänzende Untersuchungen zum Effekt der Bau- und Betriebsphase im OffshoreTestfeld „alpha ventus" auf marine Säugetiere. StUKplus Fortschrittsbericht 2011.

Siebert U, Gilles A, Dähne M, Peschko V, Ruser A, Meyer-Klaeden O, Viquerat S, Giewat H \& Ronnenberg $K, 2013$. Ergänzende Untersuchungen zum Effekt der Bau- und Betriebsphase im OffshoreTestfeld „alpha ventus" auf marine Säugetiere. StUKplus Fortschrittsbericht 2012.

Teilmann J, Akamatsu T, Miller LA, Dietz R, Tougaard J \& Siebert U, 2005. Echolocation behaviour of a wild harbour porpoise during diving. Pp 12-16 In: Abstract Book of the 16th Biennal Conference On The Biology of Marine Mammals, San Diego, California.

Teilmann J, Christiansen CT, Kjellerup S, Dietz R \& Nachman G, 2013. Geographic, seasonal, and diurnal surface behavior of harbor porpoises. Marine mammal science 29(2): E60-E76.

Teilmann J, Sveegaard S, Dietz R, Krag Petersen I, Berggren P \& Desportes G, 2008. High density areas for harbour porpoises in Danish waters. NERI Technical Report No. 657. National Environmental Research Institute, University of Aarhus.

Teilmann J, Tougaard J, Carstensen J \& L Renvald, 2009. Baseline monitoring of harbour porpoises Rødsand 2 Offshore Wind Farm. NERI Commissioned Report to E-ON. Roskilde, Demark, NERI.

Thompson D, Lusseau D, Barton T, Simmons D, Rusin J \& Bailey H, 2010. Assessing the responses of coastal cetaceans to the construction of offshore wind turbines. Marine Pollution Bulletin $60(8)$ : 1200-1208.

Thompson P M, Brookes KL, Graham IM, Barton T R, Needham K, Bradbury G \& Merchant ND, 2013 Short-term disturbance by a commercial two-dimensional seismic survey does not lead to longterm displacement of harbour porpoises. Proc R Soc B 280: 20132001. 
Tougaard J, Carstensen J, Bech NL \& Teilmann J, 2006a. Final report on the effect of Nysted Offshore Wind Farm on harbour porpoises. Annual report to EnergiE2. Roskilde, Denmark, NERI.

Tougaard J, Carstensen J, Wisz MS, Teilmann J, Bech NI \& Skov H, 2006b. Harbour porpoises on Horns Reef in relation to construction and operation of Horns Rev Offshore Wind Farm. Technical report to Elsam Engineering A/S. Roskilde, Denmark, National Environmental Research Institute.

Tougaard J, Carstensen J, Teilmann J, Skov H \& Rasmussen P, 2009. Pile driving zone of responsiveness extends beyond $20 \mathrm{~km}$ for harbour porpoises (Phocoena phocoena, (L.)). Journal of the Acoustical Society of America 126: 11-14.

Tougaard J, Wright AJ \& Madsen PT, 2015. Cetacean noise criteria revisited in the light of proposed exposure limits for harbour porpoises. Mar. Pollut. Bull. 90 (1-2): 196-208.

Verfuß UK, Miller LA \& Schnitzler H-U, 2005. Spatial orientation in echolocating harbour porpoises (Phocoena phocoena). Journal of Experimental Biology 208: 3385-3394.

Verfuß U, Adler S, Brandecker A, Dähne M, Diederichs A, Gallus A, Herrmann A, Krügel K, Lucke K, Teilmann J, Tougaard J, Tregenza N, Siebert U \& Benke H, 2010. AMPOD: Applications and analysis methods for the deployment of T-PODs in environmental impact studies for wind farms: Comparability and development of standard methods (FKZ 0327587). Final report to the Federal Ministry of the Environment. German Oceanographic Museum, Stralsund.

Villadsgaard A, Wahlberg M \& Tougaard J, 2007. Echolocation signals of wild harbour porpoises, Phocoena phocoena. Journal of Experimental Biology 210(1): 56-64.

Viquerat S, Gilles A, Herr H \& Siebert U, 2015. Monitoring von marinen Säugetieren 2014 in der deutschen Nord- und Ostsee. Teil A: Visuelle Erfassung von Schweinswalen. Stiftung Tierärztliche Hochschule Hannover, Institut für Terrestrische und Aquatische Wildtierforschung (ITAW), Büsum. Im Auftrag des Bundesamtes für Naturschutz (BfN).

Wisniewska DN,Johnson M, Teilmann J, Rojano-Donate L, Shearer J, Sveegaard S, Miller LA, Siebert U \& Madsen PT, 2016. Ultra-High Foragring Raters of Harbor Porpoises Make them Vulnerable to Anthropogenic Disturbance. Current Biology 26(11): 1441-1446.

Wright AJ, Akamatsu T, Nørgaard Mouritsen K, Sveegard S, Dietz R \& Teilmann J, 2013. Silent porpoise: Potential sleeping behaviour identified in wild harbour porpoise. Pp 123 In Abstract book of the 27th conference of the European Cetacean Society. Setubal, Portugal. 


\section{Justification}

Report C020/17

Project Number: 4312100015

The scientific quality of this report has been peer reviewed by a colleague scientist and a member of the Management Team of Wageningen Marine Research

Approved: $\quad$ Dr Meike Scheidat

Senior Researcher

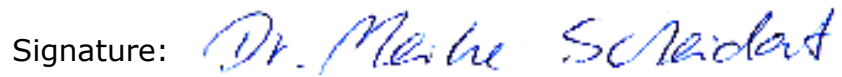

Date: 20 December 2018

Approved: $\quad$ Drs. J. Asjes

Manager integration

Signature:

Date:

20 December 2018 


\section{Annex 1 Coordinates for aerial transects and CPOD-positions}

Table A. 1 Coordinates of transect lines in the Gemini-study area.

\begin{tabular}{|c|c|c|c|c|}
\hline Start or end & WGS 84 & WGS 84 & x (ETRS89, Zone31) & y (ETRS89, Zone31) \\
\hline transect line & Latitude (N) & Longitude (E) & Northing & Easting \\
\hline DO9_S & 53.46 & 5.83 & 688188.47 & 5927358.57 \\
\hline$D 09 \_N$ & 54.21 & 5.21 & 643895.38 & 6009161.40 \\
\hline$D 08 \_N$ & 54.24 & 5.28 & 648785.26 & 6012981.87 \\
\hline D08_S & 53.47 & 5.93 & 694364.71 & 5929003.35 \\
\hline D07_S & 53.48 & 6.02 & 700703.88 & 5930355.72 \\
\hline$D 07 \_N$ & 54.28 & 5.36 & 653667.02 & 6016807.69 \\
\hline$D 06 \_N$ & 54.31 & 5.44 & 658540.67 & 6020638.85 \\
\hline D06_S & 53.49 & 6.12 & 707133.61 & 5931548.34 \\
\hline D05_S & 53.50 & 6.22 & 713663.91 & 5932564.81 \\
\hline$D 05 \_N$ & 54.34 & 5.51 & 663406.20 & 6024475.34 \\
\hline$D 04 \_N$ & 54.37 & 5.59 & 668327.36 & 6028233.80 \\
\hline D04_S & 53.50 & 6.32 & 720313.97 & 5933372.60 \\
\hline D03_S & 53.52 & 6.41 & 725968.73 & 5935959.01 \\
\hline$D 03 \_N$ & 54.41 & 5.67 & 673151.21 & 6032029.61 \\
\hline$D 02 \_N$ & 54.44 & 5.75 & 678033.76 & 6035934.44 \\
\hline D02_S & 53.55 & 6.50 & 731584.72 & 5938610.84 \\
\hline$D 01 \_S$ & 53.55 & 6.59 & 737978.20 & 5939881.20 \\
\hline$D 01 \_N$ & 54.48 & 5.83 & 683332.35 & 6040364.26 \\
\hline G03_N & 54.52 & 5.91 & 688609.97 & 6044952.35 \\
\hline G03_S & 53.60 & 6.66 & 741923.43 & 5945437.29 \\
\hline G02_S & 53.63 & 6.74 & 747279.19 & 5948498.43 \\
\hline$G 02 \_N$ & 54.56 & 5.99 & 693790.91 & 6049626.96 \\
\hline G01_N & 54.59 & 6.08 & 698731.79 & 6053704.38 \\
\hline G01_S & 53.64 & 6.83 & 753161.48 & 5950653.83 \\
\hline
\end{tabular}


Table A. 2 Location of CPODs in the Gemini-study area. Coordinates in UTM 31N ETRS89 see Table 4.

\begin{tabular}{|c|c|c|c|}
\hline \multirow[b]{2}{*}{ CPOD } & \multirow[b]{2}{*}{ Location } & \multicolumn{2}{|c|}{ ETRS89, Zone 31} \\
\hline & & North & East \\
\hline GEM 01 & $40 \mathrm{~km}$ west of Gemini & 647356.71 & 5983721.70 \\
\hline GEM 02 & $30 \mathrm{~km}$ west of ZeeEnergie & 657215.76 & 5985401.43 \\
\hline GEM 03 & $20 \mathrm{~km}$ west of Gemini & 667068.68 & 5987102.22 \\
\hline GEM 04 & $10 \mathrm{~km}$ west of Gemini & 676924.69 & 5988793.22 \\
\hline GEM 05 & $5 \mathrm{~km}$ west of Gemini & 681852.69 & 5989638.92 \\
\hline GEM 06 & ZeeEnergie North & 687321.67 & 5994210.29 \\
\hline GEM 07 & ZeeEnergie center & 689219.69 & 5990903.08 \\
\hline GEM 08 & ZeeEnergie South & 690782.71 & 5988177.62 \\
\hline GEM 09 & between ZeeEnergie and Buitengaats & 694339.68 & 5991781.29 \\
\hline GEM 10 & Buitengaats North & 697784.69 & 5996029.50 \\
\hline GEM 11 & Buitengaats center & 699098.71 & 5992630.79 \\
\hline GEM 12 & Buitengaats South & 700693.67 & 5988518.05 \\
\hline GEM 13 & $7.5 \mathrm{~km}$ south of Buitengaats & 703407.68 & 5981508.58 \\
\hline GEM 14 & $15 \mathrm{~km}$ south of Buitengaats & 706121.74 & 5974499.13 \\
\hline GEM 15 & Outside Buitengaats & 704823.66 & 5989782.85 \\
\hline
\end{tabular}




\section{Annex 2 Characteristics of pile driving events}

\begin{tabular}{|c|c|c|c|c|c|c|c|c|c|c|}
\hline ID & & & Date & $\begin{array}{l}\text { Start } \\
\text { (Local time }\end{array}$ & $\begin{aligned} & \text { Stop } \\
= & \text { UTC }+2 \mathrm{~h})\end{aligned}$ & $\begin{array}{l}\text { Duration } \\
\text { (hrs) }\end{array}$ & $\begin{array}{l}\text { Piling } \\
\text { (hrs) }\end{array}$ & $\begin{array}{l}\text { Pause } \\
\text { (hrs) }\end{array}$ & $\mathrm{N}$ blows & $\begin{array}{l}\text { Energy } \\
(\mathrm{kJ})\end{array}$ \\
\hline OHVS1-B1 & 689155 & 5991011 & $5-8-2015$ & $2: 56: 48$ & $4: 40: 10$ & 1:43 & 1:38 & & 4373 & 2874644 \\
\hline OHVS1-B3 & 689155 & 5991011 & $4-8-2015$ & 7:07:20 & $8: 54: 10$ & 1:46 & 1:36 & & 4421 & 2718286 \\
\hline OHVS1-D1 & 689155 & 5991011 & $5-8-2015$ & $16: 56: 42$ & $18: 32: 33$ & 1:35 & 1:32 & & 4307 & 2665486 \\
\hline OHVS1-D3 & 689155 & 5991011 & $4-8-2015$ & $17: 45: 30$ & 19:30:06 & 1:44 & 1:31 & & 4134 & 2541069 \\
\hline OHVS2-B1 & 699185 & 5991907 & 9-8-2015 & 21:10:57 & $22: 51: 14$ & $1: 40$ & 1:34 & & 4343 & 2442874 \\
\hline OHVS2-B3 & 699185 & 5991907 & $10-8-2015$ & $13: 52: 36$ & $15: 26: 00$ & $1: 33$ & 1:29 & & 4178 & 2335875 \\
\hline OHVS2-D1 & 699185 & 5991907 & $10-8-2015$ & $21: 45: 54$ & $23: 16: 32$ & $1: 30$ & 1:24 & & 3907 & 2304805 \\
\hline OHVS2-D3 & 699185 & 5991907 & $10-8-2015$ & $5: 27: 52$ & $6: 48: 15$ & $1: 20$ & 1:17 & & 3600 & 2231851 \\
\hline WTG-A1 & 687953 & 5991145 & 28-sep-15 & 1:41:47 & $3: 41: 33$ & 1:59 & 1:09 & $0: 50$ & 3086 & 2361657 \\
\hline WTG-A2 & 686884 & 5991341 & 25-sep-15 & 22:01:56 & $23: 34: 48$ & $1: 32$ & 1:02 & $0: 30$ & 2791 & 2425745 \\
\hline WTG-A3 & 686016 & 5991223 & 26-sep-15 & $19: 25: 35$ & $20: 56: 37$ & 1:31 & 1:05 & $0: 25$ & 2899 & 2429951 \\
\hline WTG-A4 & 685585 & 5991767 & 27-sep-15 & 11:03:17 & $12: 42: 23$ & $1: 39$ & 1:02 & $0: 36$ & 2726 & 2039470 \\
\hline WTG-A5 & 685154 & 5992311 & 28 -aug-15 & $6: 25: 29$ & $8: 38: 24$ & $2: 12$ & 1:38 & $0: 34$ & 3319 & 3045484 \\
\hline WTG-A6 & 684722 & 5992855 & 30-aug-15 & $2: 07: 16$ & 4:03:36 & $1: 56$ & 1:05 & $0: 50$ & 3044 & 2008846 \\
\hline WTG-A7 & 684291 & 5993398 & 25 -aug-15 & $0: 44: 52$ & 2:54:11 & 2:09 & 1:15 & $0: 54$ & 3008 & 2128664 \\
\hline WTG-A8 & 685282 & 5993579 & 27 -aug-15 & $14: 06: 45$ & $16: 15: 01$ & 2:08 & 1:16 & $0: 51$ & 2998 & 2749772 \\
\hline WTG-B1 & 687617 & 5991668 & 1-okt-15 & $2: 22: 50$ & 4:13:21 & $1: 50$ & 1:12 & $0: 37$ & 3132 & 3435819 \\
\hline WTG-B2 & 687281 & 5992190 & 5-aug-15 & 21:20:57 & $23: 29: 51$ & $2: 08$ & 1:14 & $0: 54$ & 2782 & 3420634 \\
\hline WTG-B3 & 686944 & 5992713 & 10 -sep-15 & $14: 08: 24$ & $16: 26: 49$ & $2: 18$ & 1:26 & $0: 51$ & 2919 & 2659851 \\
\hline WTG-B4 & 686608 & 5993236 & 5-aug-15 & $0: 30: 56$ & $3: 10: 27$ & $2: 39$ & 1:13 & $1: 25$ & 2885 & 2755998 \\
\hline WTG-B5 & 686272 & 5993759 & 29 -aug-15 & $10: 39: 23$ & $13: 07: 38$ & $2: 28$ & 1:20 & 1:08 & 3342 & 2678523 \\
\hline WTG-B6 & 685682 & 5993019 & 7-sep-15 & $17: 43: 49$ & $19: 45: 28$ & 2:01 & 1:16 & $0: 45$ & 3467 & 2974854 \\
\hline WTG-B7 & 686083 & 5992460 & 4-sep-15 & $21: 30: 54$ & $23: 22: 36$ & $1: 51$ & $0: 58$ & $0: 52$ & 2621 & 1845141 \\
\hline WTG-C1 & 688804 & 5991254 & 14 -aug-15 & 18:39:37 & $20: 54: 20$ & 2:14 & 1:27 & $0: 47$ & 3379 & 3455088 \\
\hline WTG-C2 & 688496 & 5991791 & 8-sep-15 & 21:01:04 & 23:09:14 & $2: 08$ & 1:32 & $0: 42$ & 3240 & 2777712 \\
\hline WTG-C3 & 688187 & 5992328 & 10 -aug-15 & 19:40:07 & $21: 40: 29$ & $2: 00$ & 1:15 & $0: 44$ & 2925 & 2821796 \\
\hline WTG-C4 & 687879 & 5992866 & 28 -aug-15 & 20:36:47 & 23:00:59 & $2: 24$ & 1:49 & $0: 34$ & 3575 & 4249687 \\
\hline WTG-C5 & 687571 & 5993402 & 31-jul-15 & $23: 21: 26$ & $1: 15: 23$ & $1: 53$ & 1:07 & $0: 46$ & 2646 & 3227670 \\
\hline WTG-C6 & 687262 & 5993939 & 1-aug-15 & 21:07:18 & $23: 34: 20$ & $2: 27$ & 1:17 & $1: 10$ & 2984 & 3468006 \\
\hline WTG-C7 & 688260 & 5994121 & 6 -aug-15 & $19: 44: 21$ & 22:04:11 & $2: 19$ & 1:29 & $0: 49$ & 3571 & 3643794 \\
\hline WTG-D1 & 689380 & 5991915 & 12 -sep-15 & $6: 20: 35$ & $7: 42: 24$ & 1:21 & 0:58 & $0: 23$ & 3070 & 2434119 \\
\hline WTG-D2 & 689100 & 5992467 & 10 -aug-15 & 0:47:15 & $2: 54: 26$ & 2:07 & 1:14 & $0: 52$ & 2886 & 2394622 \\
\hline WTG-D3 & 688821 & 5993018 & 28-jul-15 & $11: 40: 35$ & $14: 38: 29$ & $2: 57$ & 1:15 & $1: 41$ & 3167 & 3047946 \\
\hline WTG-D4 & 688540 & 5993569 & 2 -aug-15 & $18: 43: 53$ & 21:04:48 & $2: 20$ & 1:22 & $0: 58$ & 3285 & 3357336 \\
\hline WTG-D5 & 689251 & 5994301 & 17 -aug-15 & $1: 55: 27$ & $4: 48: 13$ & $2: 52$ & 1:46 & 1:06 & 3927 & 3347484 \\
\hline WTG-D6 & 689528 & 5993679 & 11 -sep-15 & 7:10:01 & $9: 28: 55$ & $2: 18$ & 1:26 & $0: 52$ & 3020 & 3253891 \\
\hline WTG-D7 & 689805 & 5993057 & 20 -aug-15 & $23: 18: 42$ & 1:44:49 & $2: 26$ & 1:39 & $0: 53$ & 3717 & 3194737 \\
\hline WTG-D8 & 690083 & 5992434 & 9 -aug-15 & 4:53:46 & 8:01:14 & 3:07 & 1:15 & $1: 51$ & 2949 & 2151838 \\
\hline WTG-E1 & 689661 & 5991364 & 21 -aug-15 & $21: 29: 10$ & $23: 40: 24$ & 2:11 & 1:14 & $0: 57$ & 2920 & 2415696 \\
\hline WTG-E2 & 690360 & 5991812 & 24-aug-15 & 7:07:03 & $9: 24: 29$ & $2: 17$ & $1: 40$ & $0: 36$ & 3553 & 2940808 \\
\hline
\end{tabular}




\begin{tabular}{|c|c|c|c|c|c|c|c|c|c|c|}
\hline ID & & & Date & $\begin{array}{l}\text { Start } \\
\text { (Local time }\end{array}$ & $\begin{aligned} & \text { Stop } \\
&=\text { UTC }+2 \mathrm{~h}) \\
&\end{aligned}$ & $\begin{array}{l}\text { Duration } \\
\text { (hrs) }\end{array}$ & $\begin{array}{l}\text { Piling } \\
\text { (hrs) }\end{array}$ & $\begin{array}{l}\text { Pause } \\
\text { (hrs) }\end{array}$ & $\mathrm{N}$ blows & $\begin{array}{l}\text { Energy } \\
(\mathrm{kJ})\end{array}$ \\
\hline WTG-E3 & 691362 & 5991582 & 11-sep-15 & $17: 51: 23$ & $19: 24: 49$ & $1: 33$ & 1:00 & $0: 32$ & 2988 & 2531090 \\
\hline WTG-E4 & 691138 & 5992162 & 16 -aug-15 & $17: 41: 22$ & $20: 49: 26$ & $3: 08$ & $1: 25$ & 1:42 & 3298 & 2674883 \\
\hline WTG-E5 & 690914 & 5992742 & 13 -aug-15 & 13:56:09 & $17: 22: 39$ & $3: 26$ & 1:29 & 1:56 & 3535 & 3322163 \\
\hline WTG-E6 & 690690 & 5993322 & 1-sep-15 & $18: 43: 03$ & $20: 32: 41$ & $1: 49$ & 1:09 & $0: 40$ & 3154 & 2327272 \\
\hline WTG-E7 & 690465 & 5993901 & 31 -aug-15 & $13: 48: 32$ & $16: 13: 46$ & $2: 25$ & 1:50 & $0: 34$ & 3790 & 3519773 \\
\hline WTG-E8 & 690241 & 5994481 & 12 -aug-15 & $18: 01: 23$ & 21:00:46 & $2: 59$ & $1: 24$ & $1: 34$ & 3355 & 2982185 \\
\hline WTG-F1 & 690553 & 5991180 & 2-okt-15 & $9: 28: 33$ & 11:17:59 & $1: 49$ & 1:12 & $0: 36$ & 3189 & 2747111 \\
\hline WTG-F2 & 691588 & 5990999 & 17 -aug-15 & $13: 26: 44$ & $15: 43: 28$ & $2: 16$ & $1: 28$ & $0: 48$ & 3426 & 3445568 \\
\hline WTG-F3 & 691812 & 5990420 & 18 -aug-15 & 7:19:42 & $10: 29: 48$ & $3: 10$ & 1:34 & 1:35 & 3695 & 3191952 \\
\hline WTG-F4 & 692036 & 5989840 & 25-sep-15 & $6: 48: 33$ & 8:19:00 & $1: 30$ & 1:03 & $0: 26$ & 2864 & 1975898 \\
\hline WTG-F5 & 692260 & 5989260 & 20 -aug-15 & 6:09:32 & $8: 56: 12$ & $2: 46$ & 1:22 & $1: 24$ & 3273 & 3543364 \\
\hline WTG-F6 & 692484 & 5988680 & 6-okt-15 & $16: 10: 23$ & $17: 55: 12$ & $1: 44$ & 1:14 & $0: 30$ & 3417 & 3004750 \\
\hline WTG-F7 & 692709 & 5988100 & 24-sep-15 & $18: 28: 00$ & 20:00:59 & $1: 32$ & 1:07 & $0: 25$ & 3089 & 2487053 \\
\hline WTG-G1 & 689610 & 5990772 & 14-okt-15 & $5: 32: 18$ & 7:45:16 & $2: 12$ & 1:32 & $0: 40$ & 3612 & 2822677 \\
\hline WTG-G2 & 690753 & 5990548 & 1-okt-15 & $18: 48: 08$ & $20: 24: 53$ & $1: 36$ & 1:09 & $0: 27$ & 3042 & 2292163 \\
\hline WTG-G3 & 691037 & 5989929 & 21 -aug-15 & 0:33:55 & 2:39:54 & 2:05 & 1:15 & $0: 50$ & 3019 & 3134297 \\
\hline WTG-G4 & 691320 & 5989310 & 11-okt-15 & $3: 01: 15$ & $4: 55: 58$ & $1: 54$ & 1:16 & $0: 38$ & 2970 & 2464299 \\
\hline WTG-G5 & 691605 & 5988691 & 8-okt-15 & $11: 59: 53$ & $13: 47: 53$ & $1: 48$ & 1:12 & $0: 35$ & 3232 & 2923239 \\
\hline WTG-G6 & 691887 & 5988072 & 9-sep-15 & $10: 34: 26$ & 13:51:38 & $3: 17$ & 1:45 & 1:48 & 3226 & 3420374 \\
\hline WTG-G7 & 691065 & 5988044 & 6-okt-15 & 3:38:07 & $5: 17: 40$ & $1: 39$ & 1:11 & $0: 30$ & 3252 & 2579584 \\
\hline WTG-H1 & 689901 & 5990226 & 9-okt-15 & 0:04:59 & 1:51:05 & $1: 46$ & 1:15 & $0: 34$ & 3400 & 2928924 \\
\hline WTG-H2 & 690192 & 5989681 & 16-okt-15 & $9: 57: 22$ & $12: 28: 10$ & $2: 30$ & 1:26 & 1:04 & 3412 & 2700696 \\
\hline WTG-H3 & 690483 & 5989135 & 10-okt-15 & $10: 56: 50$ & 13:06:31 & 2:09 & 1:16 & $0: 52$ & 2989 & 2374527 \\
\hline WTG-H4 & 690774 & 5988588 & 8-sep-15 & $6: 03: 40$ & $8: 15: 33$ & 2:11 & 1:37 & $0: 34$ & 3426 & 3017444 \\
\hline WTG-H5 & 689923 & 5988544 & 9-okt-15 & $18: 58: 30$ & $21: 10: 28$ & $2: 11$ & $1: 24$ & $0: 47$ & 3259 & 2717790 \\
\hline WTG-H6 & 689597 & 5989073 & 17-okt-15 & 1:06:22 & 3:09:18 & $2: 02$ & 1:25 & $0: 37$ & 3346 & 2620495 \\
\hline WTG-H7 & 689272 & 5989601 & 30 -aug-15 & $13: 46: 14$ & $15: 56: 42$ & $2: 10$ & 1:38 & $0: 31$ & 3268 & 2508448 \\
\hline WTG-J2 & 687847 & 5990238 & 4-okt-15 & $5: 54: 23$ & 7:37:26 & $1: 43$ & 1:16 & $0: 26$ & 3525 & 2657915 \\
\hline WTG-J3 & 688243 & 5989675 & 13-okt-15 & $13: 16: 24$ & $15: 29: 34$ & $2: 13$ & 1:26 & $0: 46$ & 3380 & 2957524 \\
\hline WTG-J4 & 688637 & 5989113 & 12-okt-15 & $20: 30: 58$ & $22: 40: 03$ & 2:09 & 1:21 & $0: 47$ & 3193 & 2782489 \\
\hline WTG-J5b & 689032 & 5988549 & 20 -aug-15 & $11: 26: 04$ & $12: 41: 59$ & 1:15 & 1:06 & 0:09 & 2485 & 2720526 \\
\hline WTG-J6 & 689426 & 5987987 & 21 -aug-15 & 12:39:06 & 15:09:54 & $2: 30$ & 1:42 & $0: 48$ & 3650 & 3399814 \\
\hline WTG-J7 & 690248 & 5988016 & 5-okt-15 & $16: 41: 07$ & $18: 22: 15$ & 1:41 & 1:09 & $0: 31$ & 3169 & 2853604 \\
\hline WTG-K1 & 688622 & 5990659 & 5-okt-15 & $14: 24: 35$ & $16: 38: 34$ & $2: 13$ & 1:18 & $0: 55$ & 3130 & 2412704 \\
\hline WTG-K2 & 687368 & 5990792 & 24 -aug-15 & $6: 24: 03$ & $9: 25: 23$ & 3:01 & 1:31 & $1: 29$ & 3594 & 4004350 \\
\hline WTG-K3 & 686447 & 5990679 & 3-okt-15 & 3:18:02 & 4:50:44 & $1: 32$ & 1:07 & $0: 25$ & 3040 & 2456669 \\
\hline WTG-K4 & 686870 & 5990146 & 30 -aug-15 & $17: 41: 00$ & 19:29:36 & $1: 48$ & 1:04 & $0: 44$ & 3007 & 1893087 \\
\hline WTG-K5 & 687291 & 5989616 & 9-okt-15 & 11:49:01 & $13: 27: 02$ & $1: 38$ & 1:09 & $0: 28$ & 3118 & 2532892 \\
\hline WTG-K6 & 687732 & 5989059 & 17-okt-15 & 18:09:33 & 20:08:34 & $1: 59$ & 1:23 & $0: 35$ & 3236 & 2609914 \\
\hline WTG-K7 & 688173 & 5988503 & 12 -sep-15 & $23: 35: 29$ & 1:48:04 & $2: 12$ & 1:17 & $0: 42$ & 3255 & 3315031 \\
\hline WTG-K8 & 688604 & 5987959 & 23 -aug-15 & 1:58:38 & 4:14:43 & $2: 16$ & 1:41 & $0: 44$ & 3516 & 3468946 \\
\hline WTG-Q1 & 697865 & 5991937 & 28-jul-15 & $0: 20: 52$ & 2:22:34 & 2:01 & 1:21 & $0: 40$ & 3525 & 2654716 \\
\hline WTG-Q2 & 696889 & 5992175 & 27-jul-15 & $10: 23: 23$ & 12:21:07 & $1: 57$ & 1:27 & $0: 29$ & 3865 & 2718860 \\
\hline WTG-Q3 & 696638 & 5992821 & 17-jul-15 & 4:07:00 & $6: 16: 58$ & 2:09 & 1:17 & $0: 52$ & 3528 & 3024397 \\
\hline WTG-Q4 & 696387 & 5993467 & 26-jul-15 & $17: 12: 39$ & 19:17:22 & 2:04 & 1:21 & $0: 43$ & 3574 & 2744377 \\
\hline WTG-Q5 & 696136 & 5994113 & 31-jul-15 & $16: 55: 53$ & $18: 47: 13$ & 1:51 & 1:22 & $0: 28$ & 3486 & 2889686 \\
\hline WTG-Q6 & 695885 & 5994759 & 1-aug-15 & $6: 47: 46$ & $8: 28: 28$ & $1: 40$ & 1:18 & $0: 22$ & 3398 & 2620016 \\
\hline
\end{tabular}




\begin{tabular}{|c|c|c|c|c|c|c|c|c|c|c|}
\hline ID & $\begin{array}{l}X \\
{[\mathrm{~m}]} \\
\end{array}$ & & Date & $\begin{array}{l}\text { Start } \\
\text { (Local time }=\end{array}$ & $\begin{aligned} & \text { Stop } \\
&=\text { UTC }+2 \mathrm{~h}) \\
&\end{aligned}$ & $\begin{array}{l}\text { Duration } \\
\text { (hrs) }\end{array}$ & $\begin{array}{l}\text { Piling } \\
\text { (hrs) }\end{array}$ & $\begin{array}{l}\text { Pause } \\
\text { (hrs) }\end{array}$ & $\mathrm{N}$ blows & $\begin{array}{l}\text { Energy } \\
(\mathrm{kJ})\end{array}$ \\
\hline WTG-R1 & 698586 & 5992355 & 12-jul-15 & $9: 45: 20$ & $11: 59: 50$ & 2:14 & $1: 23$ & $0: 51$ & 3624 & 2655726 \\
\hline WTG-R2 & 697632 & 5992538 & 7-jul-15 & $3: 43: 26$ & 6:19:45 & $2: 36$ & 1:15 & $1: 20$ & 3157 & 2605969 \\
\hline WTG-R3 & 697399 & 5993139 & 18-jul-15 & $8: 19: 34$ & $10: 42: 54$ & $2: 23$ & 1:11 & 1:11 & 3230 & 3044104 \\
\hline WTG-R4 & 697165 & 5993741 & 15-jul-15 & 9:46:13 & $13: 11: 46$ & $3: 25$ & $1: 27$ & 1:58 & 3749 & 2888607 \\
\hline WTG-R7 & 696464 & 5995545 & 16-jul-15 & $6: 05: 16$ & 9:09:47 & 3:04 & $1: 20$ & 1:43 & 3464 & 2639700 \\
\hline WTG-R8 & 697294 & 5995684 & 11-jul-15 & $5: 06: 42$ & 7:18:01 & $2: 11$ & 1:09 & 1:01 & 3206 & 3103779 \\
\hline WTG-S3 & 697812 & 5994353 & 4-jul-15 & $19: 44: 34$ & $22: 10: 46$ & $2: 26$ & $1: 28$ & $0: 57$ & 4012 & 4073280 \\
\hline WTG-S4 & 697554 & 5995019 & 3-jul-15 & 9:43:45 & $13: 24: 38$ & $3: 40$ & 1:14 & $2: 26$ & 4002 & 3521254 \\
\hline WTG-S5 & 698372 & 5995206 & 6-jul-15 & $20: 24: 29$ & $22: 57: 11$ & $2: 32$ & $1: 28$ & 1:03 & 4050 & 3572111 \\
\hline WTG-S6 & 698613 & 5994587 & 12-jul-15 & $11: 36: 18$ & 13:50:37 & $2: 14$ & $1: 13$ & 1:01 & 3274 & 3441436 \\
\hline WTG-S7 & 698851 & 5993967 & 11-jul-15 & $15: 29: 21$ & 19:43:52 & 4:14 & $1: 36$ & $2: 38$ & 4181 & 3238879 \\
\hline WTG-S8 & 699092 & 5993346 & 13-jul-15 & $13: 37: 13$ & $16: 07: 47$ & $2: 30$ & $1: 23$ & 1:06 & 3846 & 3571441 \\
\hline WTG-T1 & 699332 & 5992727 & 10 -aug-15 & $20: 27: 34$ & $22: 12: 38$ & $1: 45$ & 1:11 & $0: 33$ & 3147 & 2418289 \\
\hline WTG-T2 & 700024 & 5993222 & 10 -aug-15 & 7:45:04 & 9:31:34 & $1: 46$ & 1:19 & $0: 27$ & 3475 & 2493508 \\
\hline WTG-T3 & 699759 & 5993908 & 9-aug-15 & $18: 23: 17$ & $20: 05: 52$ & $1: 42$ & 1:14 & $0: 28$ & 3268 & 2448913 \\
\hline WTG-T4 & 699494 & 5994594 & 6 -aug-15 & $7: 15: 23$ & 9:32:09 & $2: 16$ & $1: 17$ & $0: 59$ & 3320 & 2528053 \\
\hline WTG-T5 & 699228 & 5995281 & 6-aug-15 & $21: 36: 23$ & $23: 35: 35$ & $1: 59$ & 1:19 & $0: 39$ & 3491 & 2901970 \\
\hline WTG-T6 & 698963 & 5995967 & 7 -aug-15 & $13: 44: 03$ & $15: 38: 32$ & $1: 54$ & $1: 24$ & $0: 29$ & 3689 & 3378778 \\
\hline WTG-T7 & 698133 & 5995827 & 22-jul-15 & 15:29:09 & 17:59:50 & $2: 30$ & 1:15 & 1:14 & 3454 & 3100103 \\
\hline WTG-U1 & 699572 & 5992107 & 14-sep-15 & $15: 45: 01$ & $17: 17: 22$ & $1: 32$ & 1:06 & $0: 25$ & 3068 & 2393261 \\
\hline WTG-U2 & 700289 & 5992536 & 11-sep-15 & 4:23:39 & 6:03:15 & 1:39 & 1:06 & $0: 33$ & 3171 & 2512537 \\
\hline WTG-U3 & 701026 & 5992916 & 13 -sep-15 & 21:36:59 & $23: 29: 36$ & $1: 52$ & 1:17 & $0: 34$ & 3540 & 3111627 \\
\hline WTG-U4 & 700778 & 5993554 & 22 -sep-15 & $10: 46: 29$ & $13: 52: 25$ & 3:05 & 1:14 & 1:51 & 3366 & 2860059 \\
\hline WTG-U5 & 700533 & 5994192 & 21-sep-15 & $11: 27: 02$ & 13:04:37 & 1:37 & 1:07 & $0: 30$ & 3030 & 2859317 \\
\hline WTG-U6 & 700287 & 5994831 & 19-sep-15 & $16: 16: 15$ & $18: 04: 53$ & $1: 48$ & 1:15 & $0: 32$ & 3427 & 3418402 \\
\hline WTG-U7 & 700040 & 5995469 & 1-okt-15 & 4:57:36 & 6:46:12 & $1: 48$ & $1: 12$ & $0: 35$ & 3260 & 3168536 \\
\hline WTG-U8 & 699794 & 5996107 & 21-jul-15 & $13: 10: 25$ & $16: 03: 15$ & $2: 52$ & 1:13 & 1:39 & 3361 & 3258197 \\
\hline WTG-V1 & 700556 & 5991846 & 13 -sep-15 & $16: 18: 02$ & 18:10:12 & $1: 52$ & 1:15 & $0: 36$ & 3363 & 2311855 \\
\hline WTG-V2 & 701272 & 5992278 & 14-sep-15 & 7:31:19 & 10:13:03 & $2: 41$ & $1: 12$ & $1: 29$ & 3184 & 2507813 \\
\hline WTG-V3 & 701520 & 5991636 & 16 -sep-15 & $11: 22: 11$ & $13: 08: 25$ & $1: 46$ & 1:03 & $0: 42$ & 2926 & 2385960 \\
\hline WTG-V4 & 701766 & 5990998 & 25-sep-15 & $0: 27: 24$ & $2: 24: 41$ & $1: 57$ & 1:11 & $0: 45$ & 3178 & 2420174 \\
\hline WTG-V5 & 702013 & 5990360 & 24-sep-15 & 2:18:03 & 4:08:08 & 1:50 & 1:14 & $0: 35$ & 3349 & 2329296 \\
\hline WTG-V6 & 702259 & 5989721 & 23-sep-15 & $3: 15: 16$ & 6:03:28 & $2: 48$ & $1: 12$ & 1:36 & 3182 & 2197081 \\
\hline WTG-V7 & 702505 & 5989083 & 30-sep-15 & 4:00:06 & $5: 23: 47$ & $1: 23$ & 1:03 & $0: 20$ & 2849 & 2349970 \\
\hline WTG-V8 & 702752 & 5988445 & 4-okt-15 & $2: 37: 08$ & 4:29:56 & $1: 52$ & 1:17 & $0: 35$ & 3177 & 2418195 \\
\hline WTG-W1 & 699813 & 5991485 & 16 -sep-15 & 9:00:29 & 10:43:03 & $1: 42$ & 1:04 & $0: 38$ & 2859 & 2437848 \\
\hline WTG-W2 & 700821 & 5991160 & 19-sep-15 & 4:13:08 & 5:44:55 & $1: 31$ & 1:02 & $0: 29$ & 2827 & 2233311 \\
\hline WTG-W3 & 701086 & 5990474 & 18-sep-15 & $14: 22: 20$ & $16: 29: 50$ & 2:07 & 1:15 & $0: 51$ & 3342 & 2398543 \\
\hline WTG-W4 & 701352 & 5989788 & 17 -sep-15 & $13: 24: 48$ & $15: 25: 18$ & $2: 00$ & 1:06 & $0: 53$ & 2951 & 2595795 \\
\hline WTG-W5 & 701617 & 5989101 & 18 -sep-15 & $14: 53: 42$ & $16: 49: 50$ & $1: 56$ & 1:05 & $0: 50$ & 2955 & 2508850 \\
\hline VTG-W6 & 701882 & 5988415 & 20-sep-15 & :30:02 & $8: 20: 48$ & $1: 50$ & 1:04 & :46 & 2873 & 2568491 \\
\hline WTG-W7 & 701013 & 5988385 & 30-sep-15 & $16: 08: 08$ & $17: 35: 06$ & $1: 26$ & 1:07 & $0: 19$ & 3052 & 2841426 \\
\hline WTG-X1 & 700053 & 5990865 & 16 -aug-15 & $10: 56: 24$ & $13: 12: 03$ & $2: 15$ & 1:32 & $0: 43$ & 3519 & 2599624 \\
\hline WTG-X2 & 700292 & 5990245 & 15 -aug-15 & $21: 55: 18$ & $23: 52: 30$ & $1: 57$ & $1: 26$ & $0: 30$ & 3420 & 2248143 \\
\hline VTG-X3 & 700532 & 5989625 & 18-jul-15 & $12: 21: 38$ & $14: 46: 24$ & $2: 24$ & 1:19 & 1:05 & 3437 & 2346190 \\
\hline WTG-X4 & 700772 & 5989005 & 12 -aug-15 & $21: 55: 02$ & $23: 30: 35$ & 1:35 & 1:15 & $0: 20$ & 3073 & 2538800 \\
\hline WTG-X5 & 699878 & 5989021 & 13 -aug-15 & $12: 00: 48$ & 13:49:31 & $1: 48$ & $1: 23$ & $0: 24$ & 3214 & 2422987 \\
\hline
\end{tabular}




\begin{tabular}{|c|c|c|c|c|c|c|c|c|c|c|}
\hline ID & & $\begin{array}{l}Y \\
{[\mathrm{~m}]}\end{array}$ & Date & $\begin{array}{l}\text { Start } \\
\text { (Local time }=\end{array}$ & $\begin{array}{l}\text { Stop } \\
=\text { UTC }+2 \mathrm{~h})\end{array}$ & $\begin{array}{l}\text { Duration } \\
\text { (hrs) }\end{array}$ & $\begin{array}{l}\text { Piling } \\
\text { (hrs) }\end{array}$ & $\begin{array}{l}\text { Pause } \\
\text { (hrs) }\end{array}$ & $\mathrm{N}$ blows & $\begin{array}{l}\text { Energy } \\
(\mathrm{kJ})\end{array}$ \\
\hline WTG-X6 & 699620 & 5989689 & 14 -aug-15 & 4:56:05 & 7:13:29 & 2:17 & 1:33 & 0:44 & 3405 & 2803998 \\
\hline WTG-X7 & 699362 & 5990354 & 14-jul-15 & $16: 44: 00$ & $19: 26: 40$ & 2:42 & 1:18 & 1:24 & 3343 & 2217461 \\
\hline WTG-Y1 & 699104 & 5991020 & 27-sep-15 & 7:59:44 & 10:03:09 & 2:03 & 1:09 & 0:54 & 3033 & 2481641 \\
\hline WTG-Y2 & 698333 & 5990731 & 27-sep-15 & 19:50:10 & $21: 14: 49$ & 1:24 & 1:02 & $0: 21$ & 2794 & 2107046 \\
\hline WTG-Y3 & 698566 & 5990129 & 28-sep-15 & 7:21:04 & 8:41:02 & 1:19 & $0: 58$ & $0: 21$ & 2675 & 2092712 \\
\hline WTG-Y4 & 698801 & 5989528 & 22-sep-15 & $23: 25: 40$ & $0: 44: 30$ & 1:18 & $0: 57$ & $0: 21$ & 2578 & 1750255 \\
\hline WTG-Y5 & 699033 & 5988927 & 21-sep-15 & $12: 31: 12$ & $14: 37: 39$ & 2:06 & 1:16 & 0:50 & 3336 & 2678465 \\
\hline WTG-Y6 & 699266 & 5988325 & 20-sep-15 & $22: 10: 10$ & $23: 49: 56$ & 1:39 & 1:15 & 1:01 & 3233 & 2669585 \\
\hline WTG-Y7 & 700136 & 5988355 & 4-okt-15 & $20: 58: 14$ & $23: 10: 41$ & 2:12 & 1:24 & 0:48 & 3397 & 3055829 \\
\hline WTG-Z1 & 698846 & 5991686 & 27-aug-15 & $11: 55: 47$ & $14: 13: 52$ & $2: 18$ & 1:35 & 0:42 & 3394 & 2413971 \\
\hline WTG-Z2 & 698099 & 5991333 & 22-jul-15 & 6:04:01 & $8: 24: 21$ & $2: 20$ & 1:21 & $0: 58$ & 3560 & 2285504 \\
\hline WTG-Z3 & 697141 & 5991526 & 23-jul-15 & $16: 10: 00$ & $17: 46: 01$ & 1:36 & 1:06 & $0: 29$ & 3045 & 2849450 \\
\hline WTG-Z4 & 697392 & 5990880 & 22-jul-15 & $20: 31: 34$ & $22: 42: 27$ & 2:10 & 1:20 & 0:50 & 3425 & 2130878 \\
\hline WTG-Z5 & 697643 & 5990235 & 23-jul-15 & $12: 01: 11$ & $14: 07: 12$ & 2:06 & 1:21 & 0:44 & 3473 & 2469744 \\
\hline WTG-Z6 & 697895 & 5989588 & 27-jul-15 & $6: 46: 26$ & 9:34:00 & 2:47 & 1:13 & 1:34 & 3086 & 2506420 \\
\hline WTG-Z7 & 698146 & 5988943 & 19-jul-15 & $5: 46: 57$ & $8: 25: 52$ & $2: 38$ & 1:31 & 1:07 & 3972 & 3125132 \\
\hline WTG-Z8 & 698397 & 5988296 & 20-jul-15 & $5: 04: 12$ & $7: 20: 16$ & $2: 16$ & 1:21 & $0: 50$ & 3548 & 2882354 \\
\hline
\end{tabular}




\section{Annex 3 CPOD post-processing data}

\begin{tabular}{|c|c|c|c|c|c|c|c|c|c|}
\hline Position & POD ID & Lat & Lon & North & East & Start time & Recovery date & $\begin{array}{c}\text { Subtract from } \\
\text { start [min] }\end{array}$ & $\begin{array}{l}\text { End file } \\
\text { [min] }\end{array}$ \\
\hline GEM01 & 1883 & 53.98 & 5.247 & 647357 & 5983721.7 & 30-6-2015 7:42 & 29-9-2015 11:32 & 12 & 23 \\
\hline GEM01 & 1747 & 53.98 & 5.247 & 647357 & 5983721.7 & 29-9-2015 11:27 & $16-2-201613: 10$ & 15 & \\
\hline GEM02 & 377 & 53.99 & 5.398 & 657216 & 5985401.43 & $30-6-2015$ 6:08 & $29-9-2015$ 12:45 & 12 & 210 \\
\hline GEM02 & 1519 & 53.99 & 5.398 & 657216 & 5985401.43 & 29-9-2015 12:41 & $16-2-2016$ 11:05 & 13 & \\
\hline GEM03 & 717 & 54.01 & 5.459 & 667069 & 5987102.22 & $30-6-2015$ 4:58 & & 14 & 24 \\
\hline GEM03 & 1752 & 54.01 & 5.459 & 667069 & 5987102.22 & 29-9-2015 13:55 & $12-2-2016$ 14:00 & & \\
\hline GEM04 & 375 & 54.02 & 5.701 & 676925 & 5988793.22 & $25-6-2015$ 13:13 & & 9 & 25 \\
\hline GEM04 & 1875 & 54.02 & 5.701 & 676925 & 5988793.22 & 29-9-2015 16:22 & $12-2-201612: 15$ & & \\
\hline GEM05 & 714 & 54.02 & 5.776 & 681853 & 5989638.92 & $25-6-2015$ 11:10 & 29-9-2015 17:18 & 19 & \\
\hline GEM05 & 394 & 54.02 & 5.776 & 681853 & 5989638.92 & 29-9-2015 17:12 & $12-2-2016$ 11:05 & 8 & \\
\hline GEM06 & 1878 & 54.06 & 5.862 & 687322 & 5994210.29 & 25-6-2015 9:25 & 29-9-2015 18:11 & & \\
\hline GEM06 & 1884 & 54.06 & 5.862 & 687322 & 5994210.29 & 29-9-2015 18:06 & $17-2-201612: 00$ & & \\
\hline GEM07 & 393 & 54.03 & 5.889 & 689220 & 5990903.08 & $23-6-2015$ 14:58 & 30-9-2015 11:56 & & 0 \\
\hline GEM07 & 1817 & 54.03 & 5.889 & 689220 & 5990903.08 & 30-9-2015 11:48 & $15-12-2015$ 15:30 & & \\
\hline GEM08 & 395 & 54.01 & 5.911 & 690783 & 5988177.62 & $23-6-2015$ 13:41 & $30-9-2015$ 12:32 & 84 & -7 \\
\hline GEM08 & 862 & 54.01 & 5.911 & 690783 & 5988177.62 & $30-9-2015$ 12:29 & 17-2-2016 9:30 & 20 & \\
\hline GEM09 & 1887 & 54.04 & 5.968 & 694340 & 5991781.29 & 25-6-2015 8:07 & 30-9-2015 11:01 & 19 & \\
\hline GEM09 & 1876 & 54.04 & 5.968 & 694340 & 5991781.29 & $30-9-2015$ 10:55 & $17-2-201610: 25$ & 12 & \\
\hline GEM10 & 1744 & 54.07 & 6.023 & 697785 & 5996029.5 & 1-7-2015 8:02 & $30-9-2015$ 10:01 & 0 & \\
\hline GEM10 & 392 & 54.07 & 6.023 & 697785 & 5996029.5 & 30-9-2015 9:49 & $15-12-2015$ 13:55 & 0 & $\begin{array}{l}\text { Delete from 25-8- } \\
2015 \text { 5:44:00 PM }\end{array}$ \\
\hline GEM11 & 1876 & 54.04 & 6.041 & 699099 & 5992630.79 & 1-7-2015 7:23 & 30-9-2015 9:10 & 12 & \\
\hline GEM11 & 716 & 54.04 & 6.041 & 699099 & 5992630.79 & 30-9-2015 9:07 & $15-12-2015$ 13:15 & 150 & $\begin{array}{l}\text { Delete from 13-10- } \\
2015 \text { 12:00:00 PM }\end{array}$ \\
\hline GEM12 & 1859 & 54.01 & 6.063 & 700694 & 5988518.05 & 1-7-2015 6:32 & 30-9-2015 8:13 & 11 & \\
\hline GEM12 & 1882 & 54.01 & 6.063 & 700694 & 5988518.05 & 30-9-2015 8:08 & $15-12-2015$ 12:35 & 0 & \\
\hline GEM13 & 1760 & 53.94 & 6.099 & 703408 & 5981508.58 & 1-7-2015 5:56 & $30-9-2015$ 6:33 & 6 & \\
\hline GEM13 & 889 & 53.94 & 6.099 & 703408 & 5981508.58 & $30-9-2015$ 6:27 & $15-12-2015$ 9:20 & 8 & \\
\hline GEM14 & 1873 & 53.88 & 6.136 & 706122 & 5974499.13 & 1-7-2015 4:59 & 30-9-2015 5:36 & 13 & \\
\hline GEM14 & 1756 & 53.88 & 6.136 & 706122 & 5974499.13 & 30-9-2015 5:32 & $15-12-20156: 30$ & 7 & \\
\hline GEM15 & 1861 & 54.01 & 6.126 & 704824 & 5989782.85 & 25-6-2015 6:48 & 30-9-2015 7:32 & 22 & \\
\hline GEM15 & 390 & 54.01 & 6.126 & 704824 & 5989782.85 & $30-9-2015$ 7:22 & $15-12-2015$ 10:30 & 5 & \\
\hline
\end{tabular}




\section{Annex 4 Seasonal patterns in acoustic activity of Harbour porpoise}

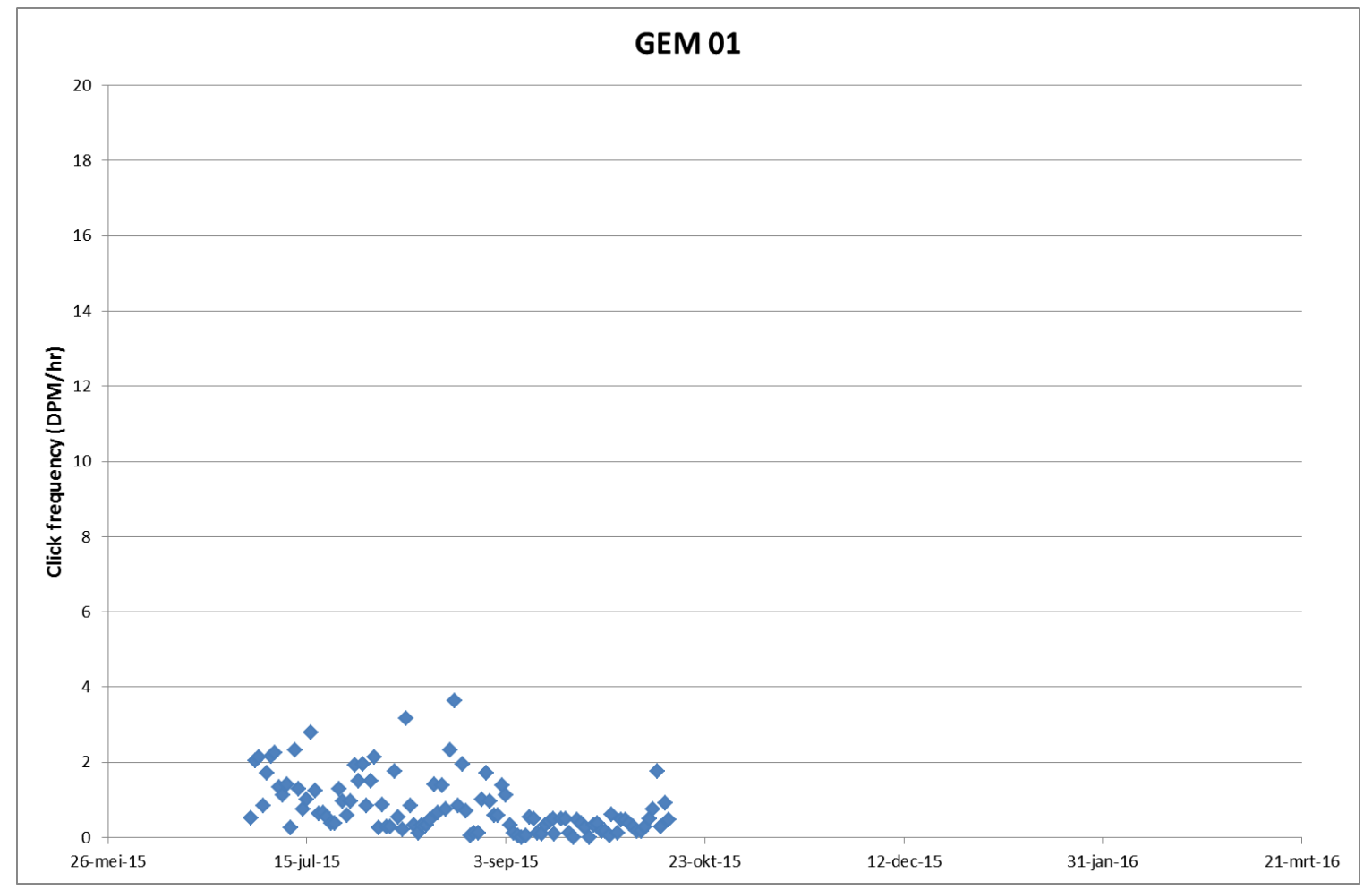

Figure A. 1 Seasonal patterns in acoustic activity of harbour porpoises at CPOD location GEM 01.

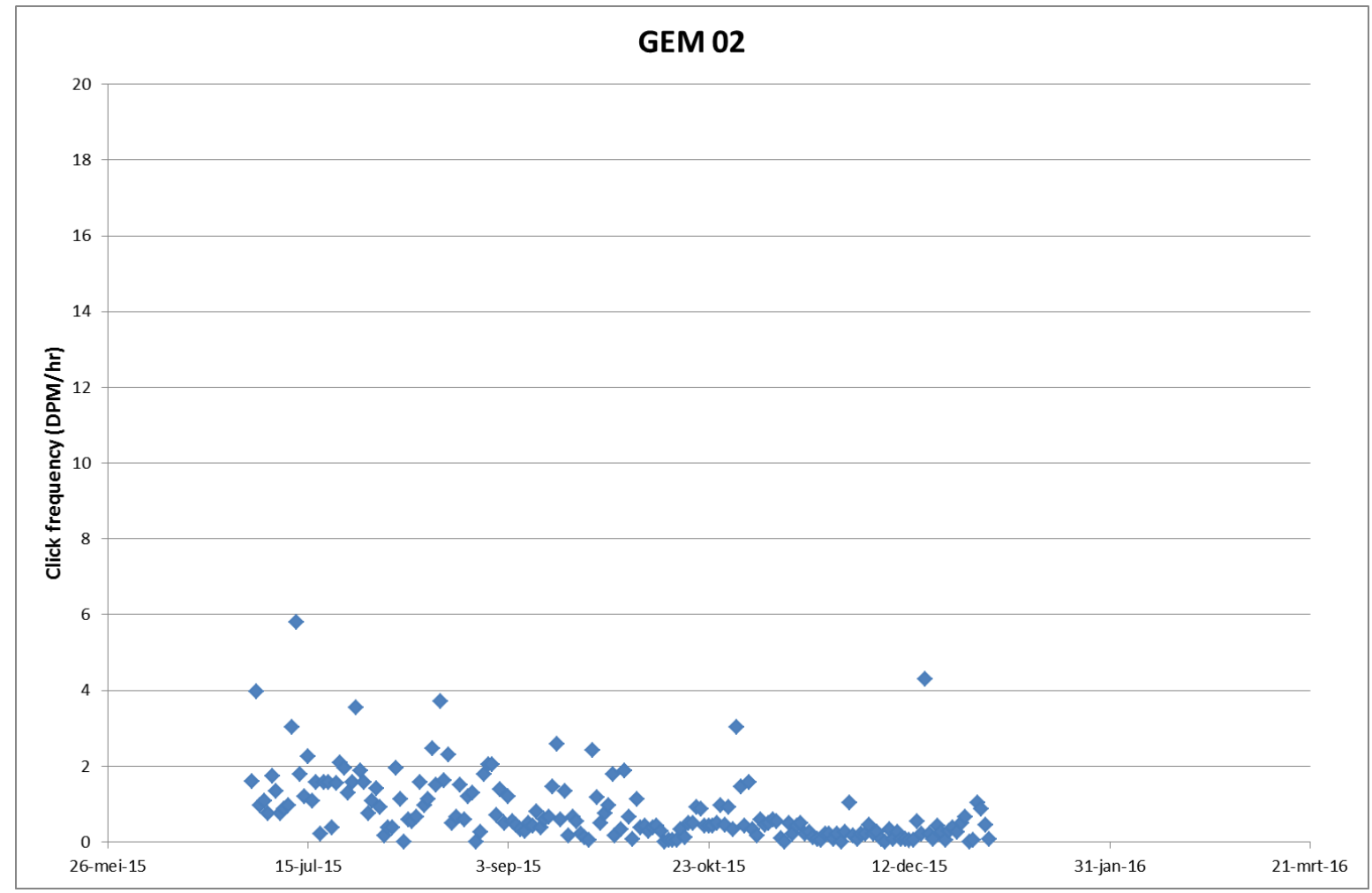

Figure A. 2 Seasonal patterns in acoustic activity of harbour porpoises at CPOD location GEM 02. 


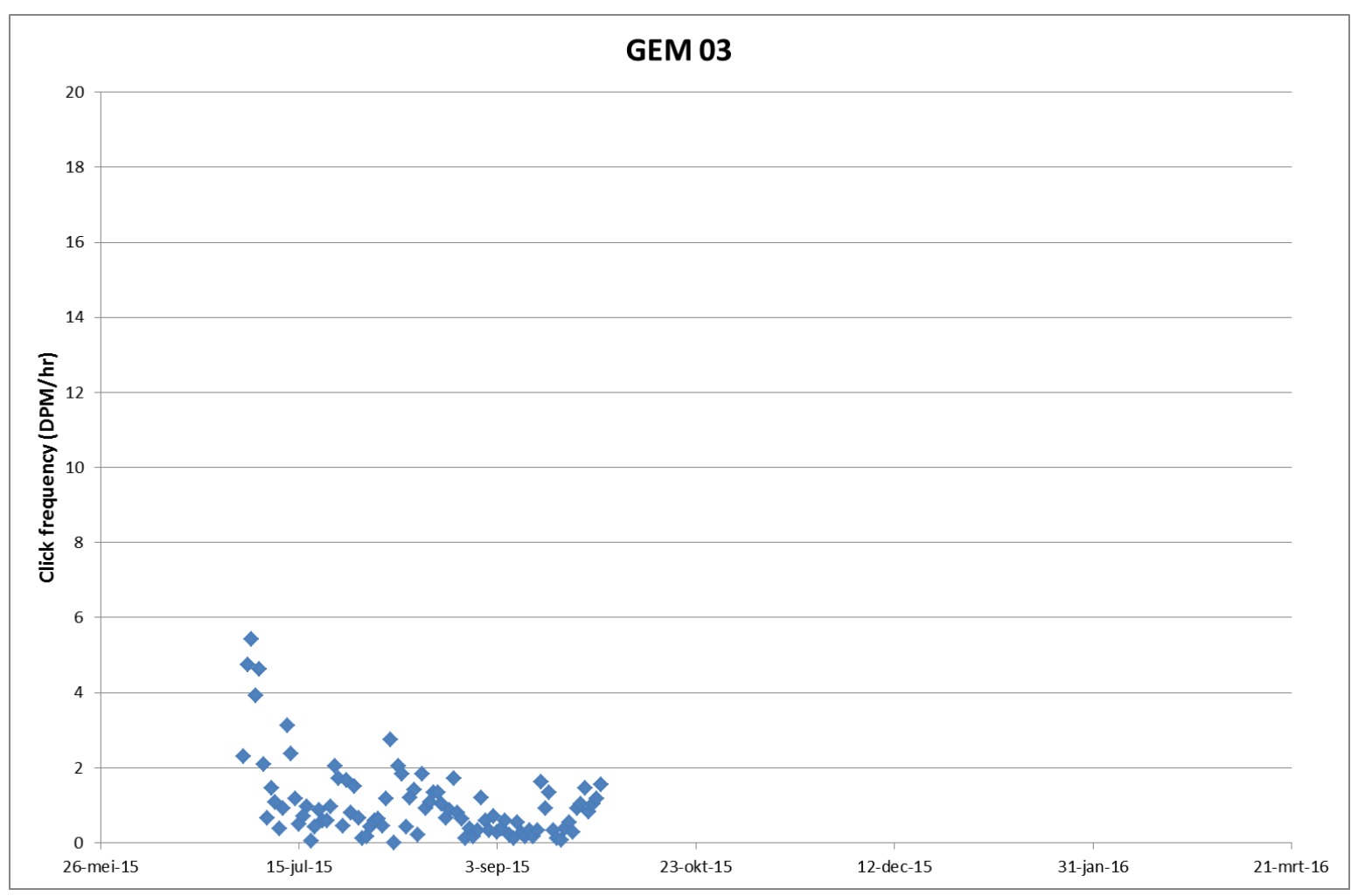

Figure A. 3 Seasonal patterns in acoustic activity of harbour porpoises at CPOD location GEM 03.

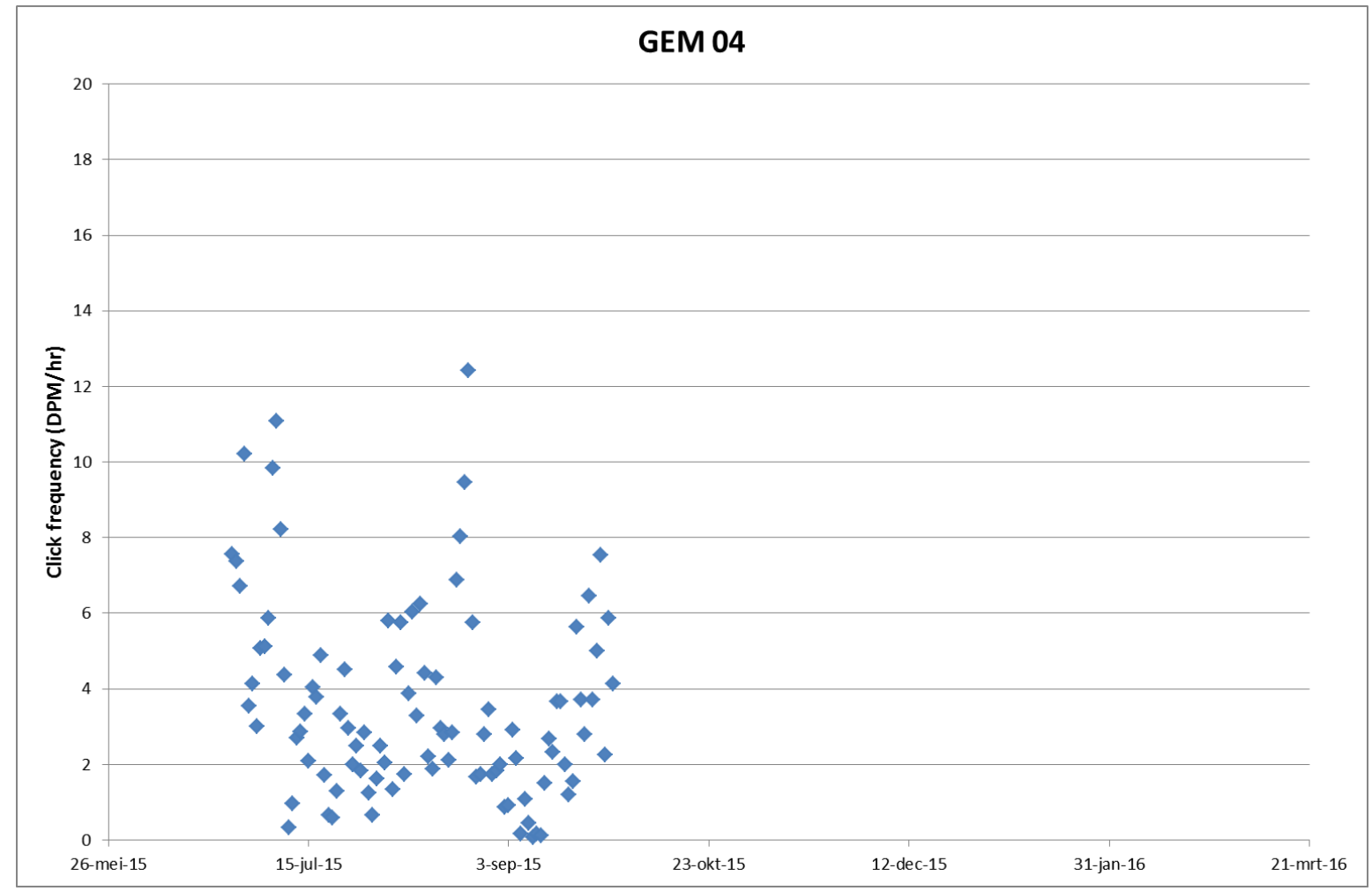

Figure A. 4 Seasonal patterns in acoustic activity of harbour porpoises at CPOD location GEM 04. 


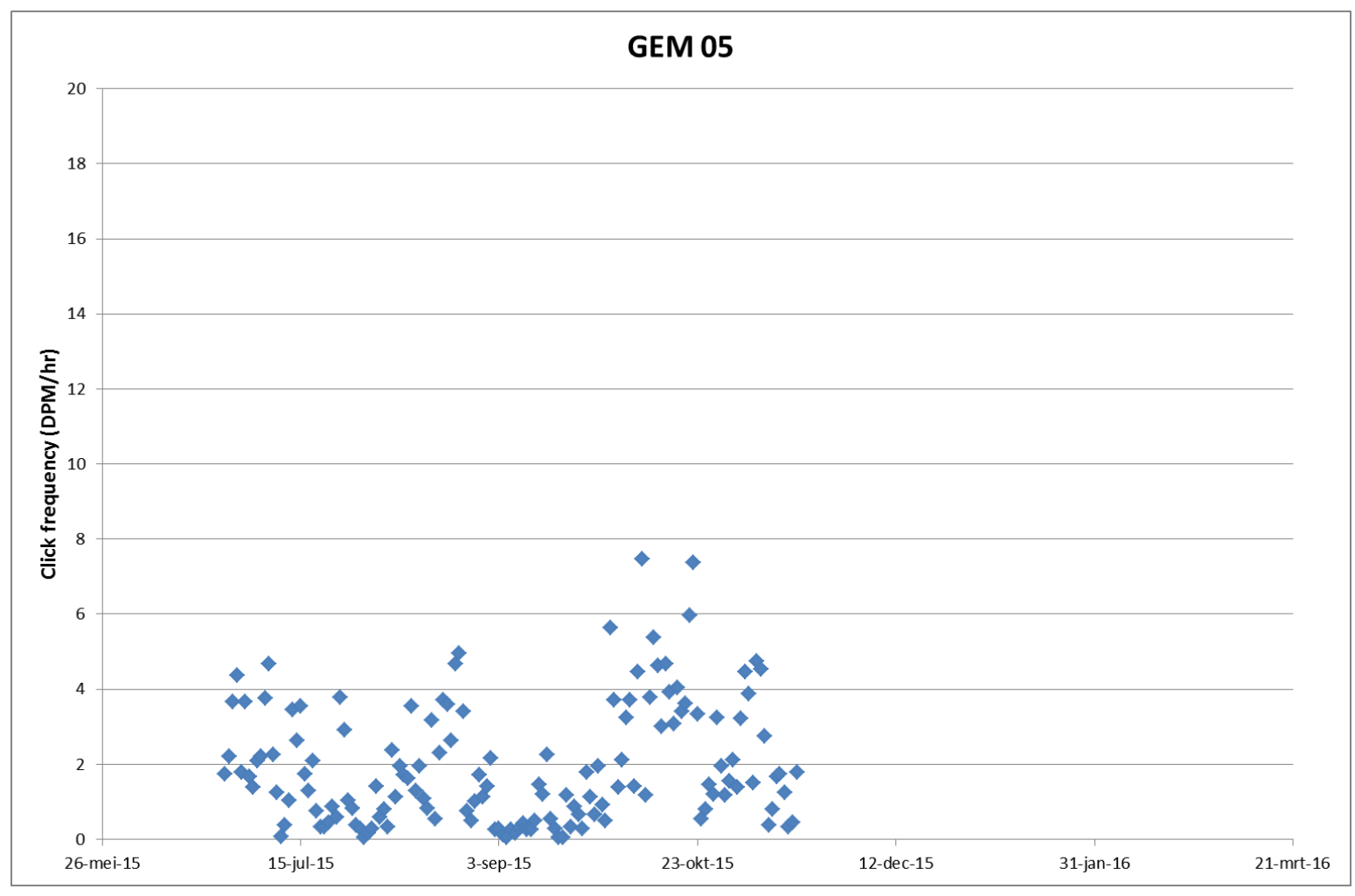

Figure A. 5 Seasonal patterns in acoustic activity of harbour porpoises at CPOD location GEM 05.

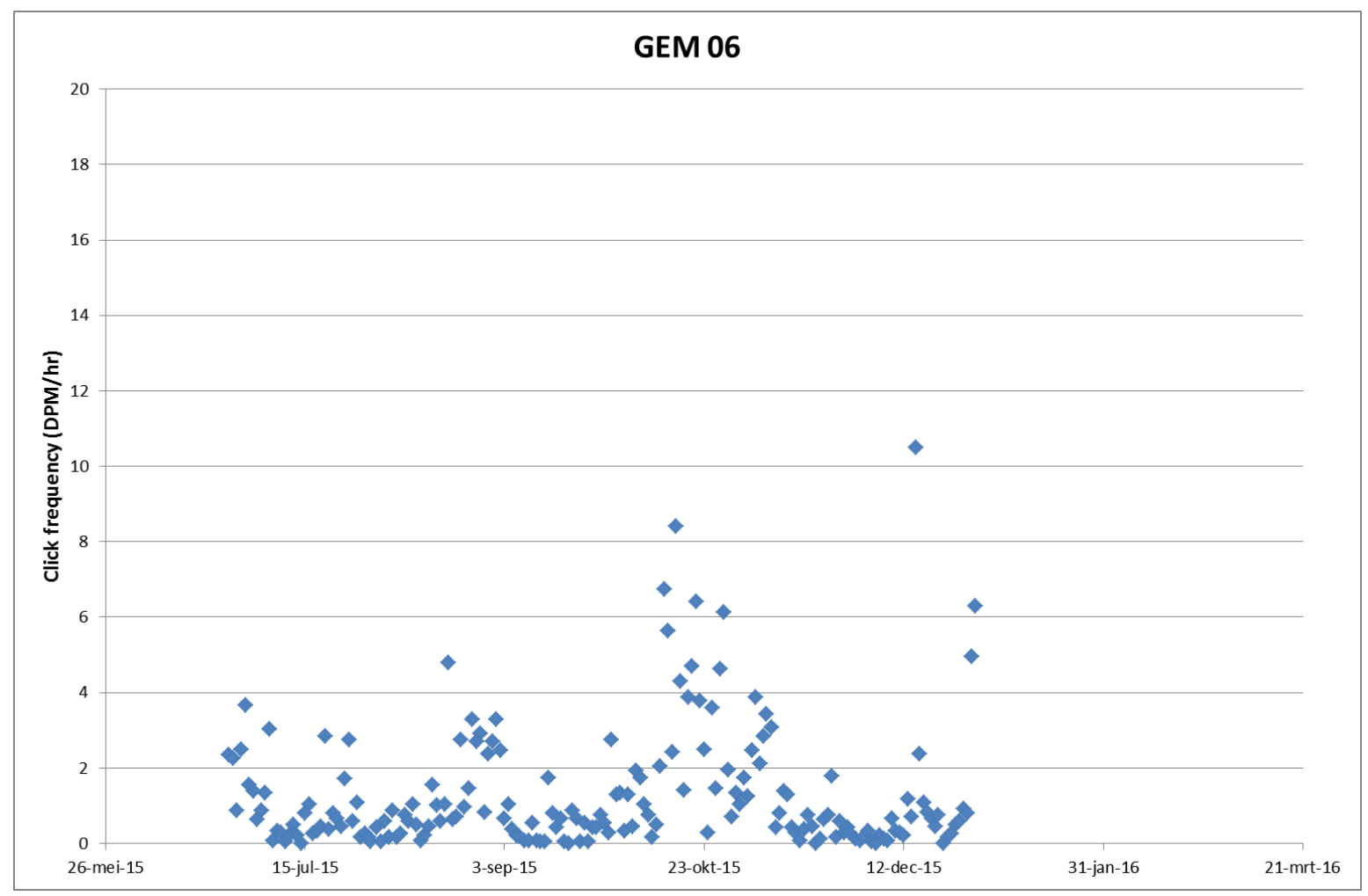

Figure A. 6 Seasonal patterns in acoustic activity of harbour porpoises at CPOD location GEM 06. 


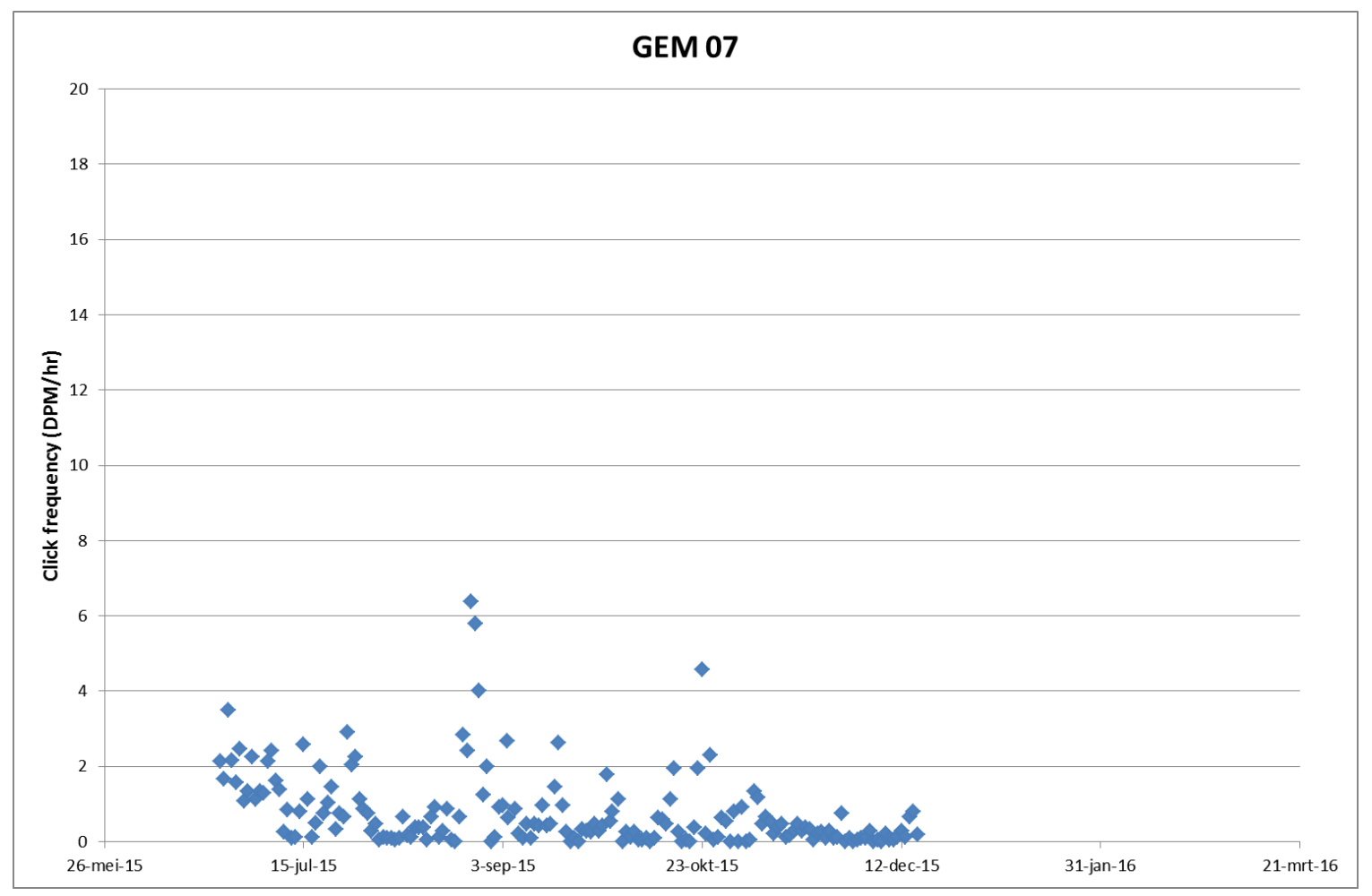

Figure A. 7 Seasonal patterns in acoustic activity of harbour porpoises at CPOD location GEM 07.

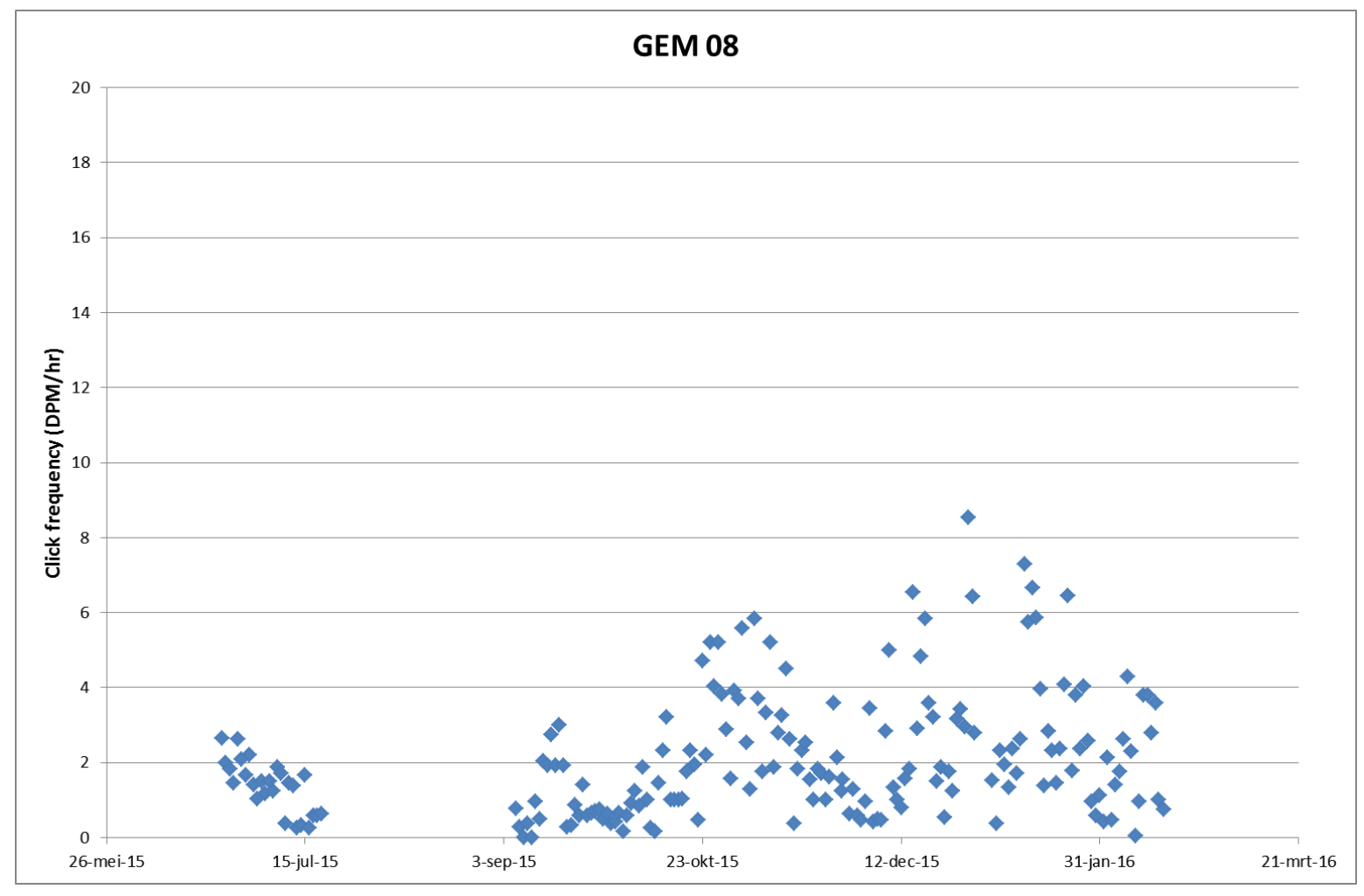

Figure A. 8 Seasonal patterns in acoustic activity of harbour porpoises at CPOD location GEM 08. 


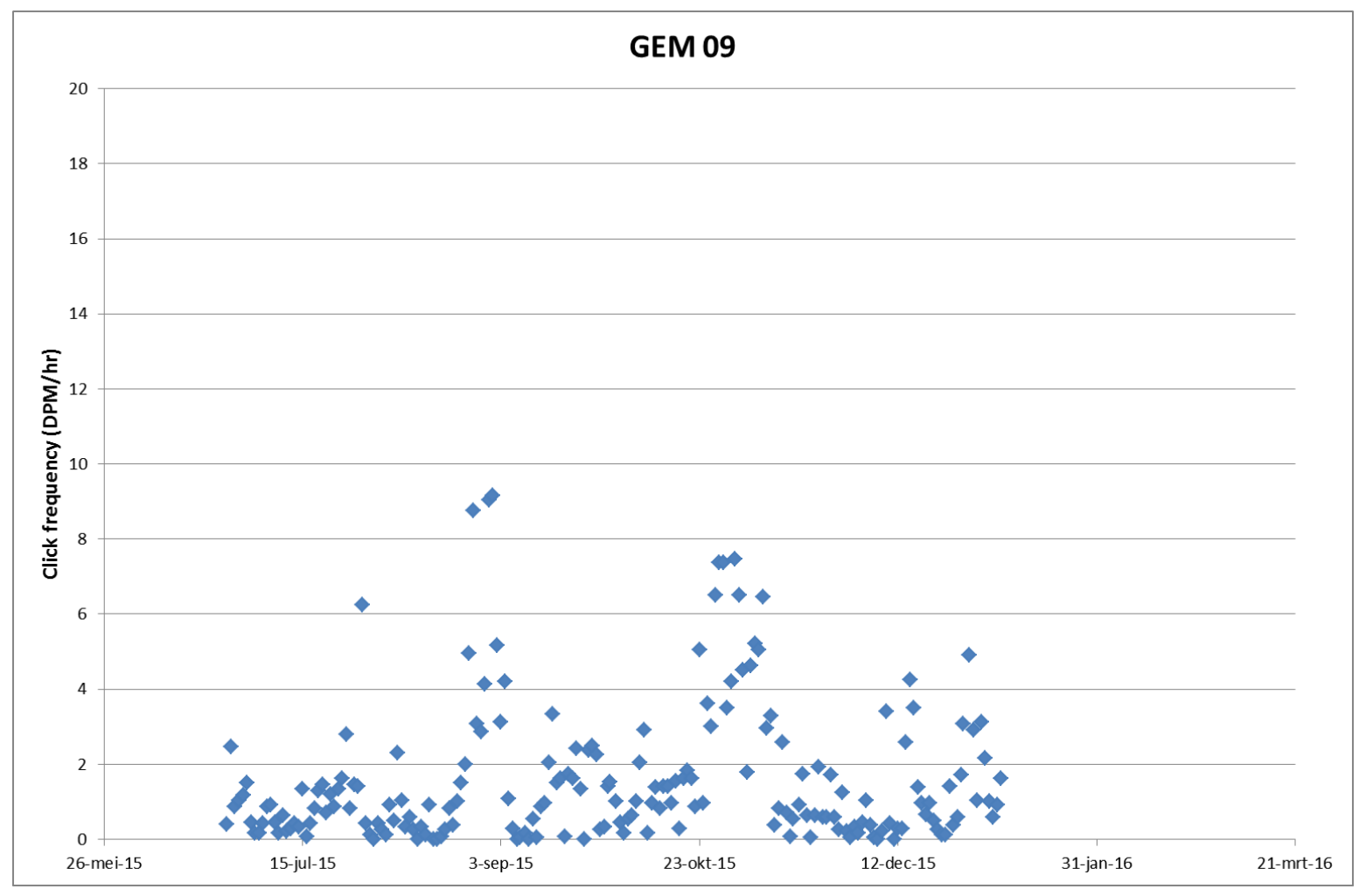

Figure A. 9 Seasonal patterns in acoustic activity of harbour porpoises at CPOD location GEM 09.

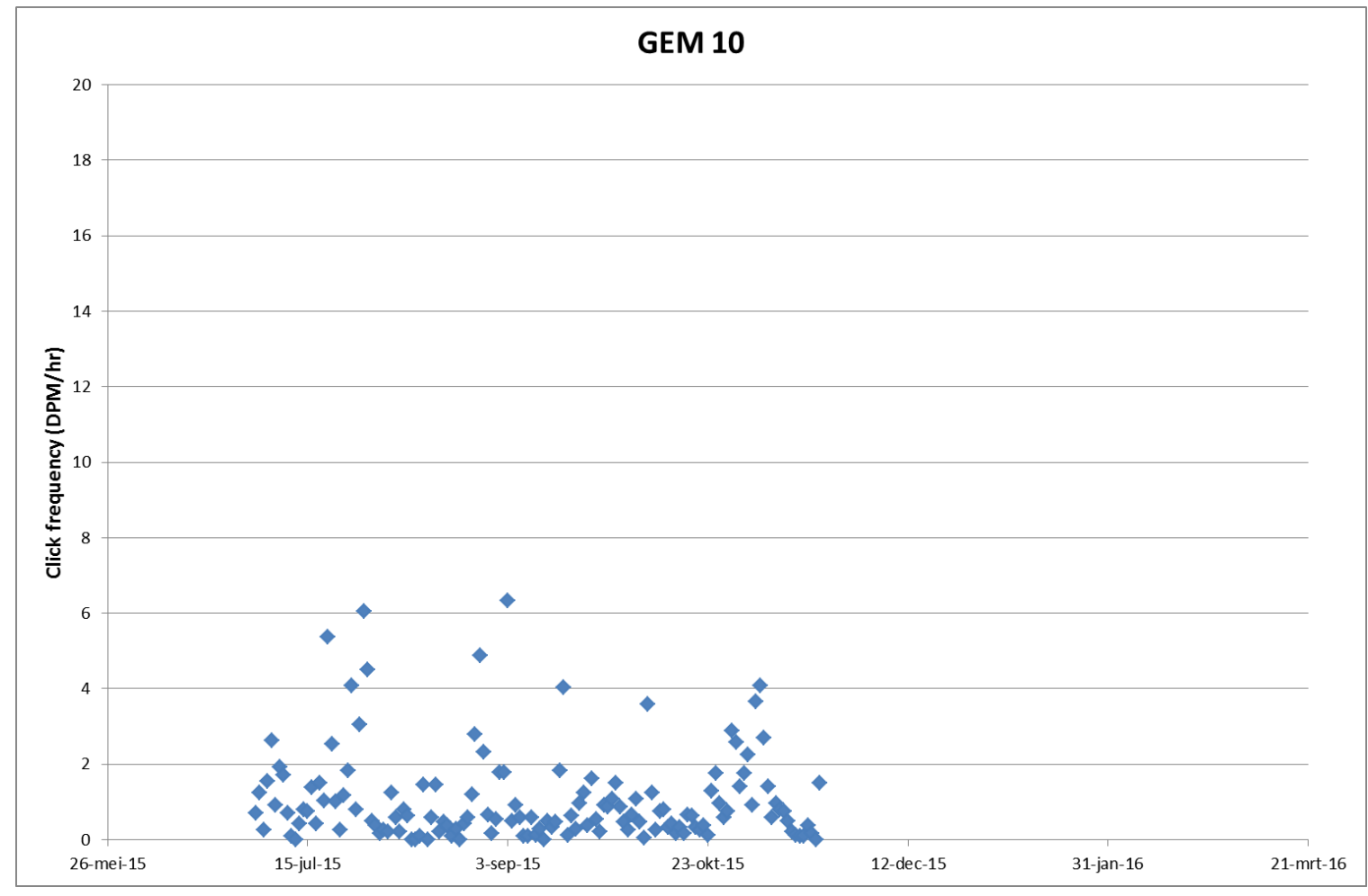

Figure A. 10 Seasonal patterns in acoustic activity of harbour porpoises at CPOD location GEM 10. 


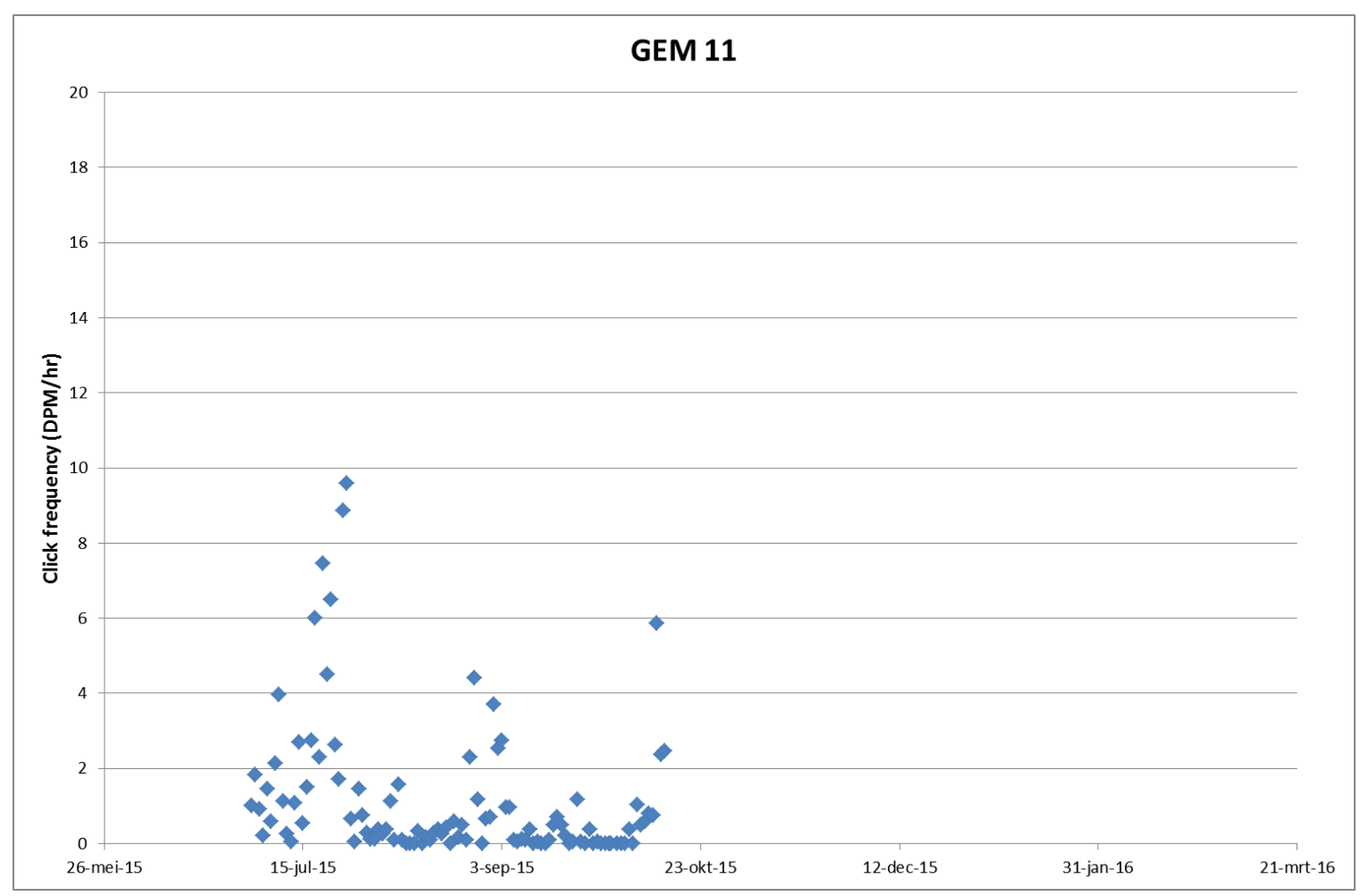

Figure A. 11 Seasonal patterns in acoustic activity of harbour porpoises at CPOD location GEM 11.

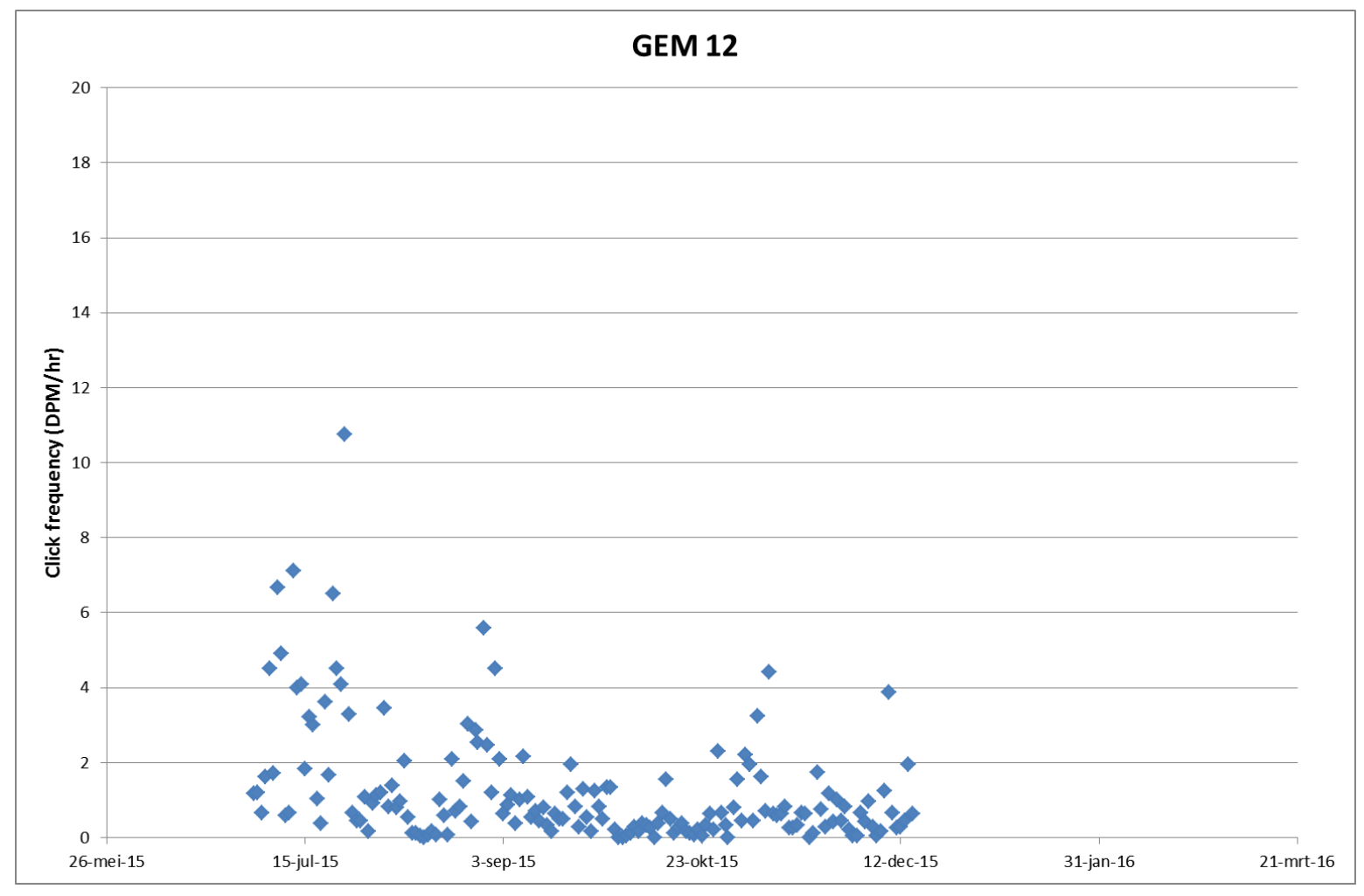

Figure A. 12 Seasonal patterns in acoustic activity of harbour porpoises at CPOD location GEM 12. 


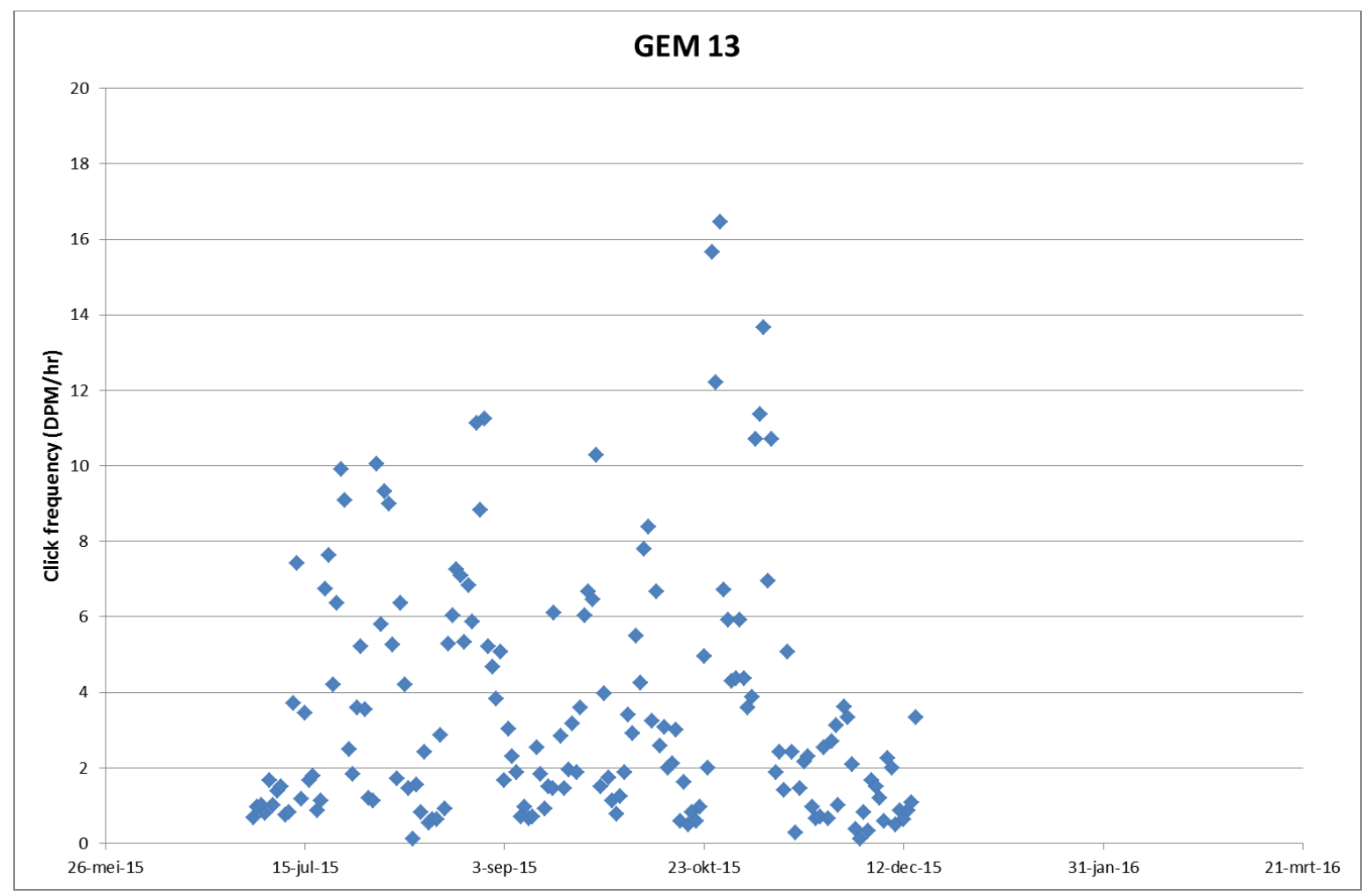

Figure A. 13 Seasonal patterns in acoustic activity of harbour porpoises at CPOD location GEM 13.

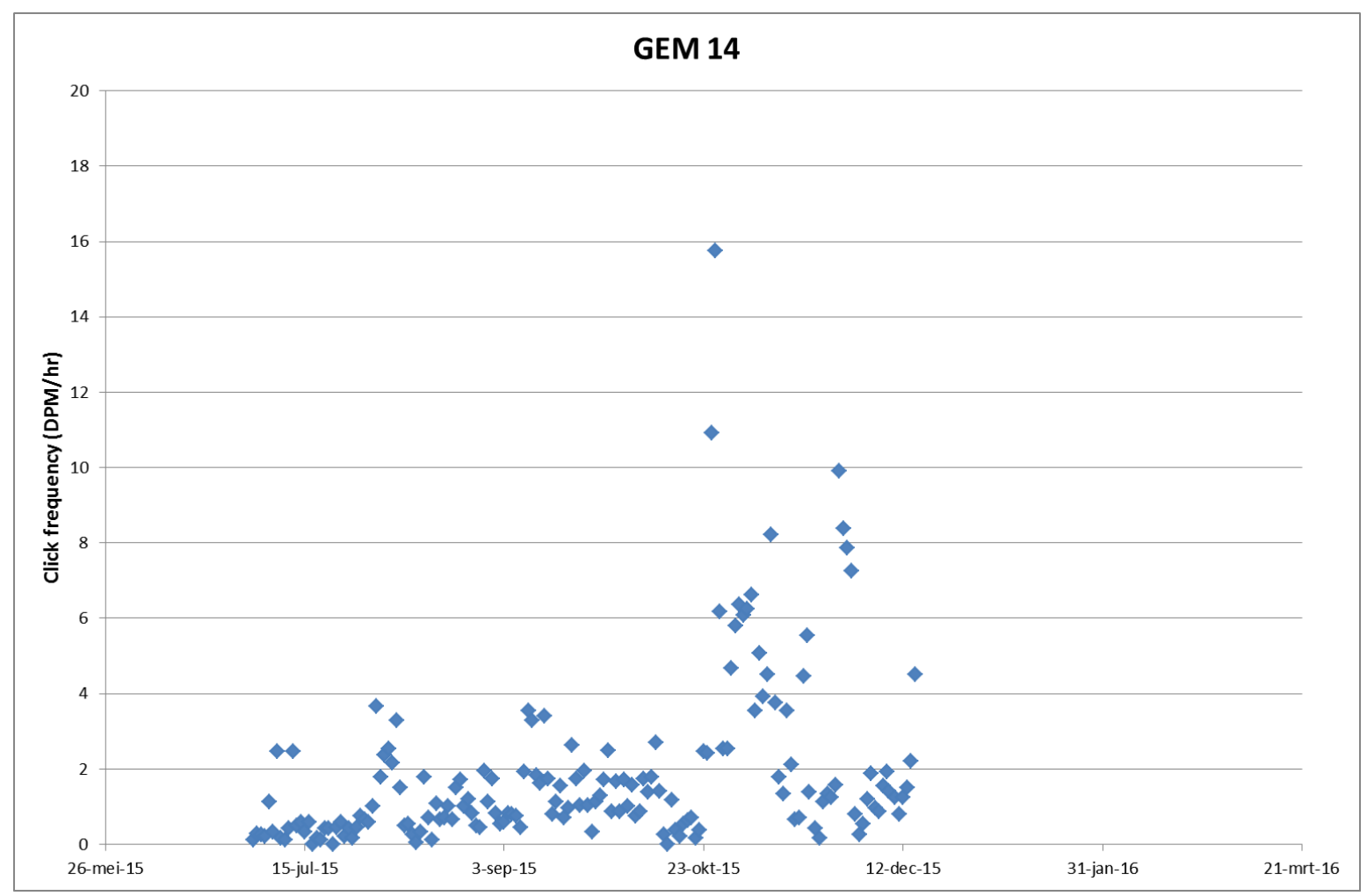

Figure A. 14 Seasonal patterns in acoustic activity of harbour porpoises at CPOD location GEM 14. 


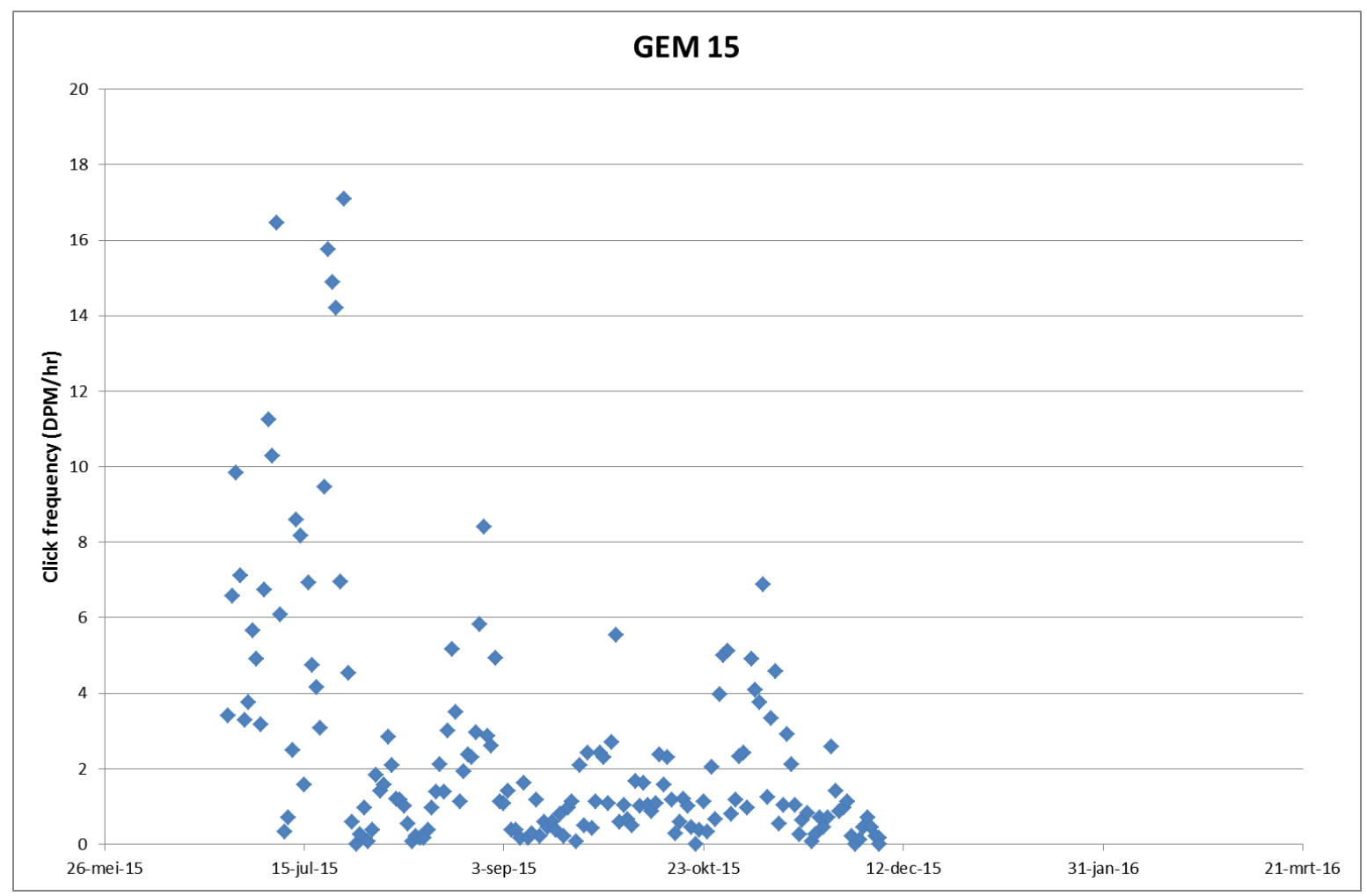

Figure A. 15 Seasonal patterns in acoustic activity of harbour porpoises at CPOD location GEM 15. 


\section{Annex 5 Calibration results: Ppp vs receiving levels}

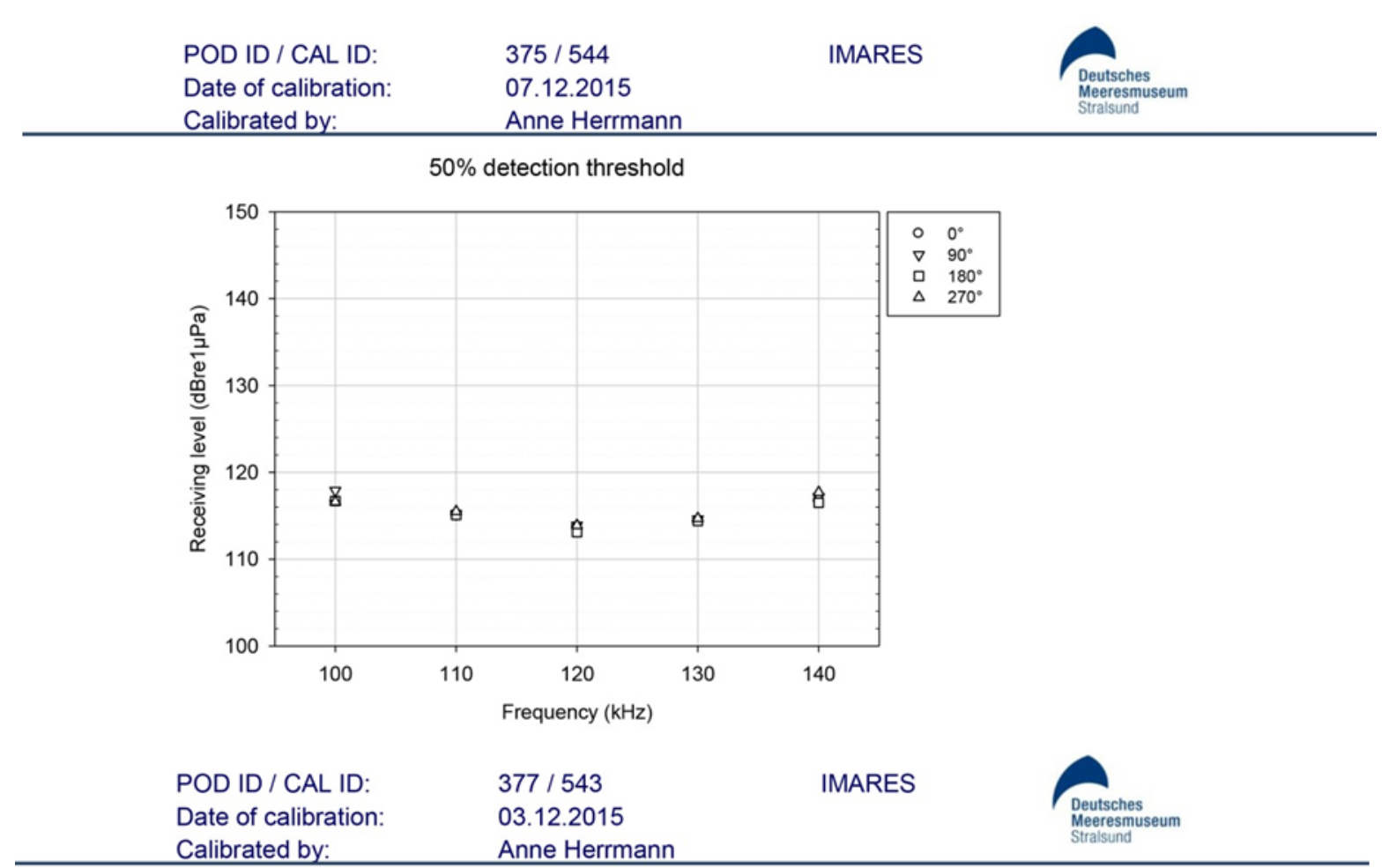

Calibrated by:

$50 \%$ detection threshold

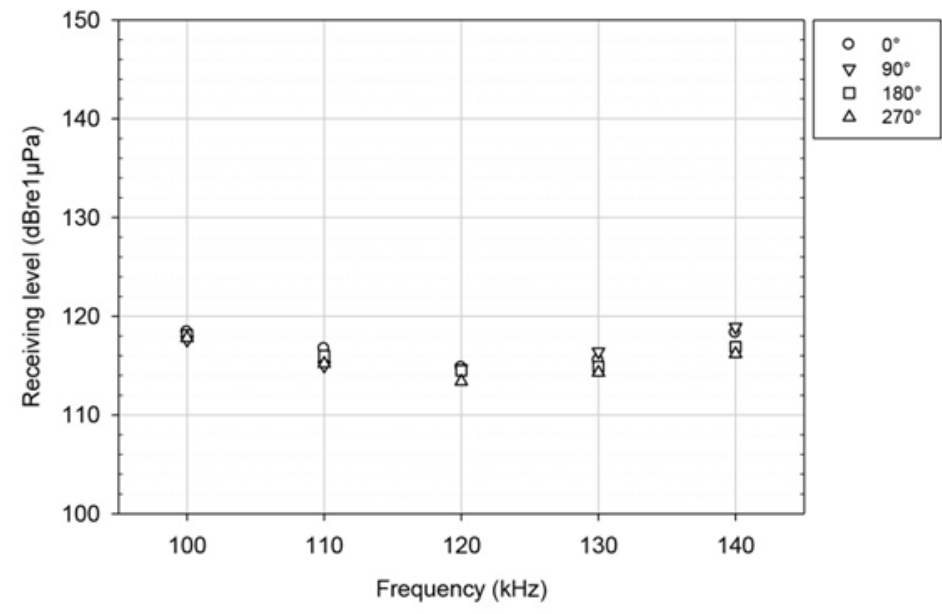

Figure A. 16 Calibration results of CPODs 375 and 377. 


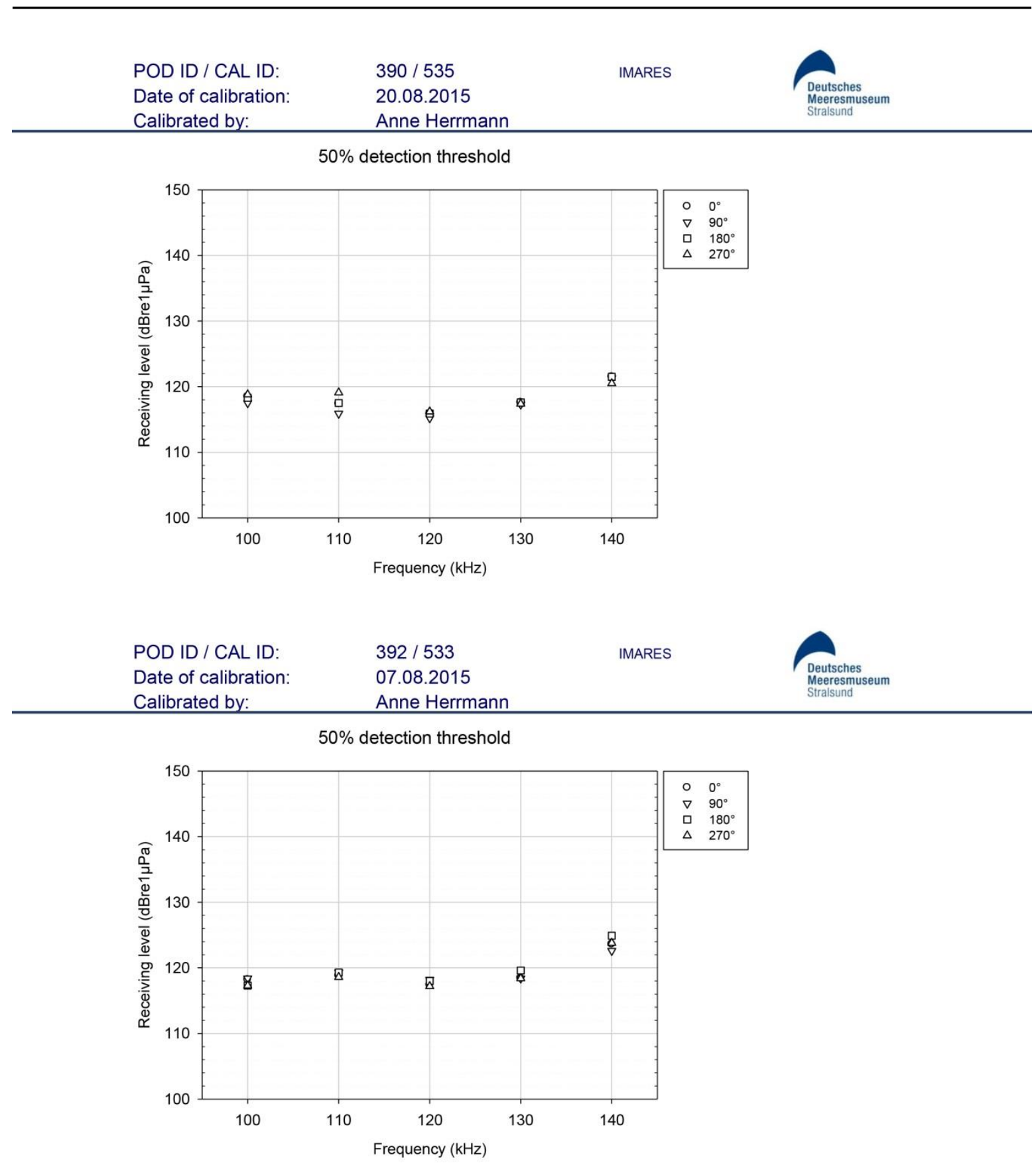

Figure A. 17 Calibration results of CPODs 390 and 392. 


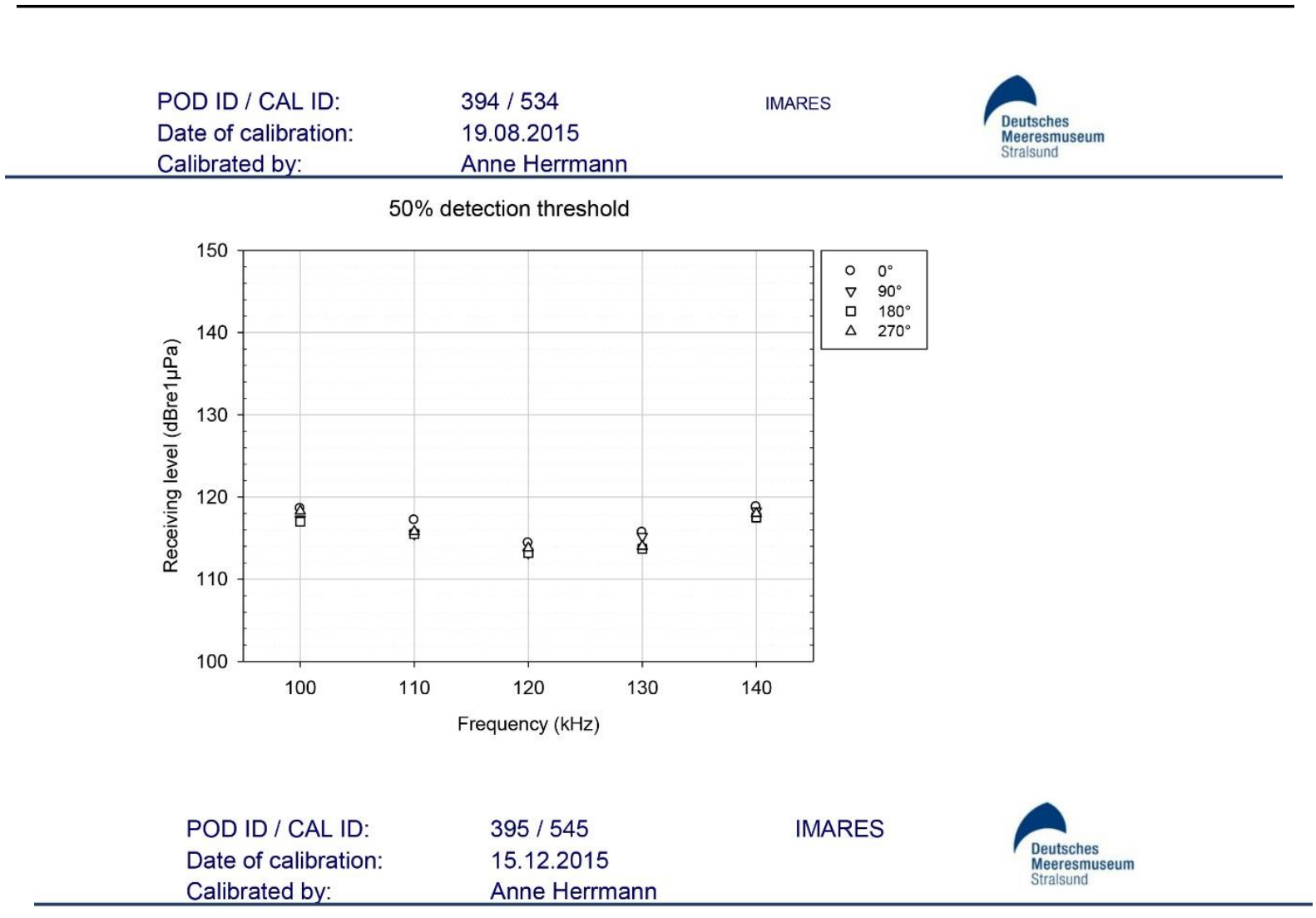

$50 \%$ detection threshold

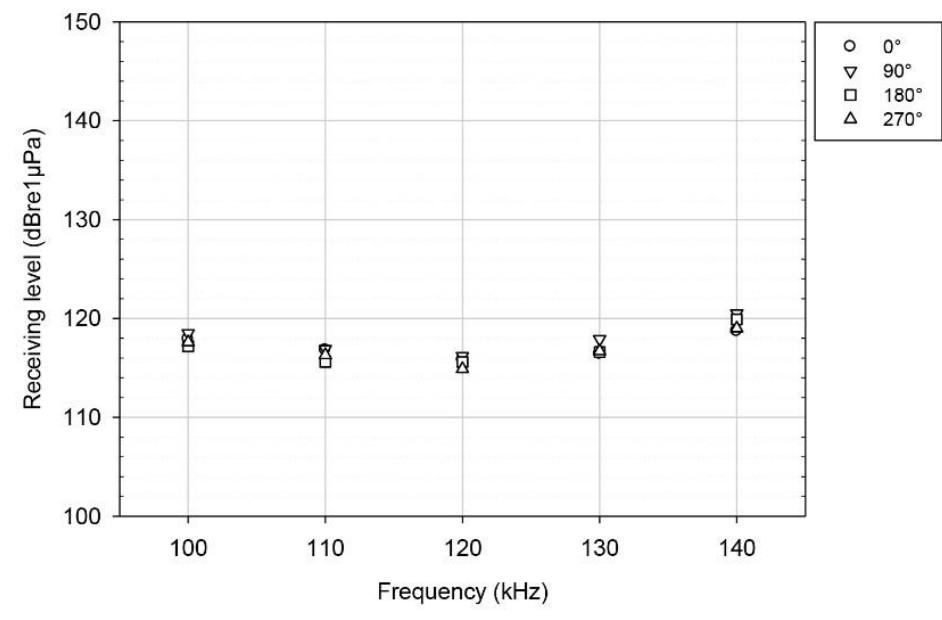

Figure A. 18 Calibration results of CPODs 394 and 395. 


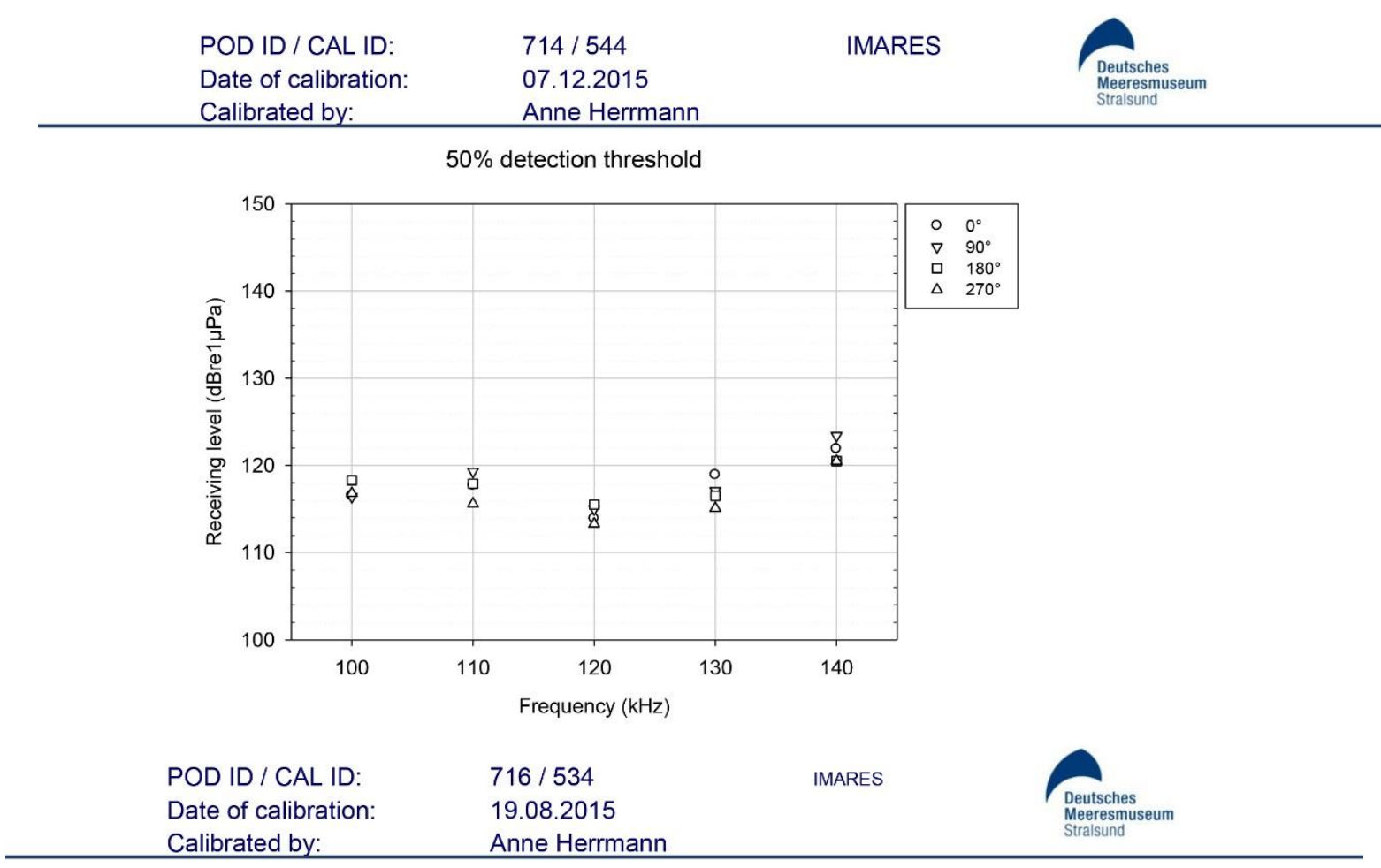

$50 \%$ detection threshold

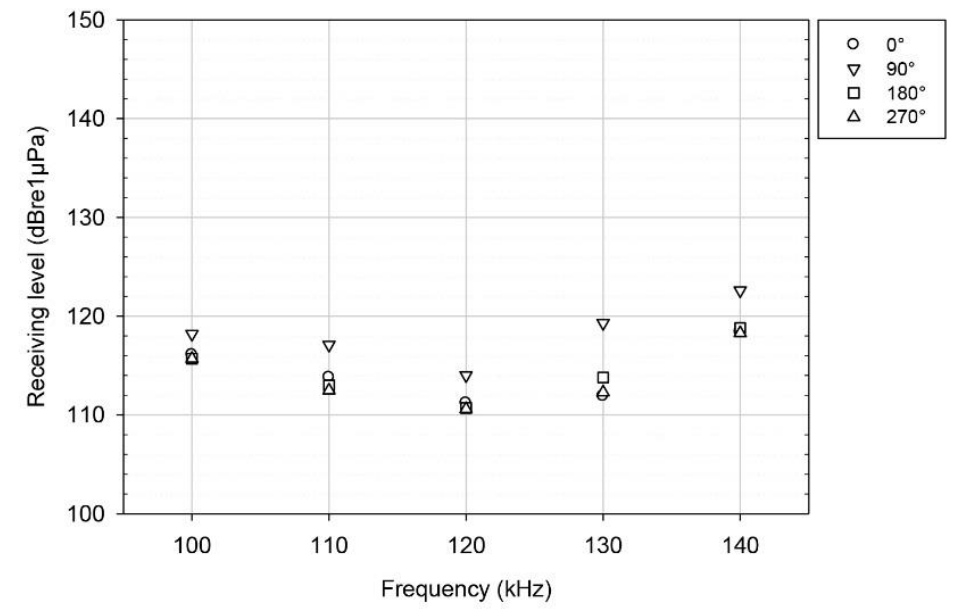

Figure A. 19 Calibration results of CPODs 714 and 716. 


$\begin{array}{lll}\text { POD ID / CAL ID: } & 717 / 543 & \text { IMARES } \\ \text { Date of calibration: } & 03.12 .2015 & \\ \text { Calibrated by: } & \text { Anne Herrmann } & \text { Deutsches } \\ \text { Meeressuseum } \\ \text { Stralsund }\end{array}$

$50 \%$ detection threshold

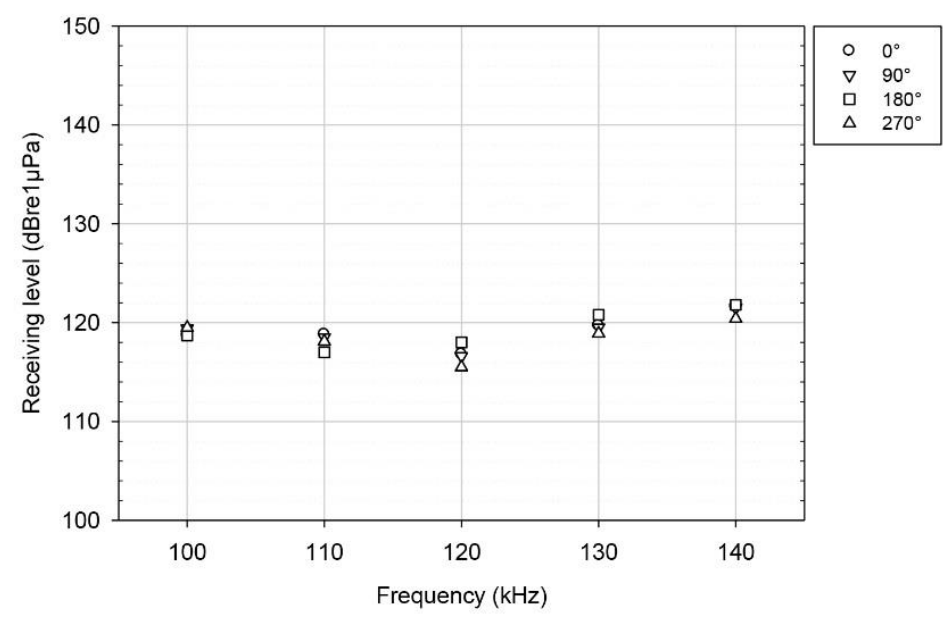

POD ID / CAL ID

$889 / 535$

IMARES

Date of calibration:

20.08.2015

Calibrated by:

Anne Herrmann

$50 \%$ detection threshold

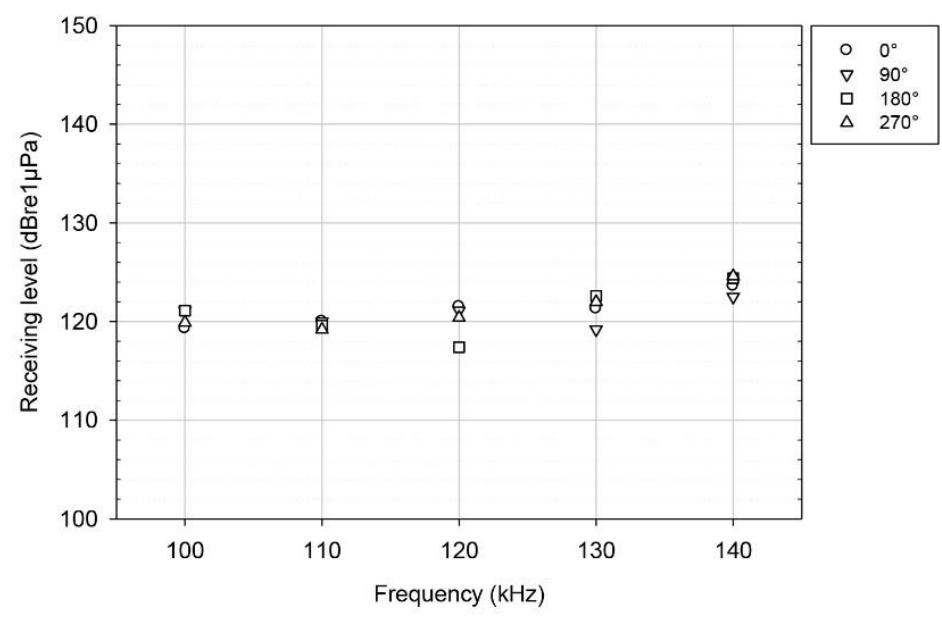

Figure A. 20 Calibration results of CPODs 717 and 889. 


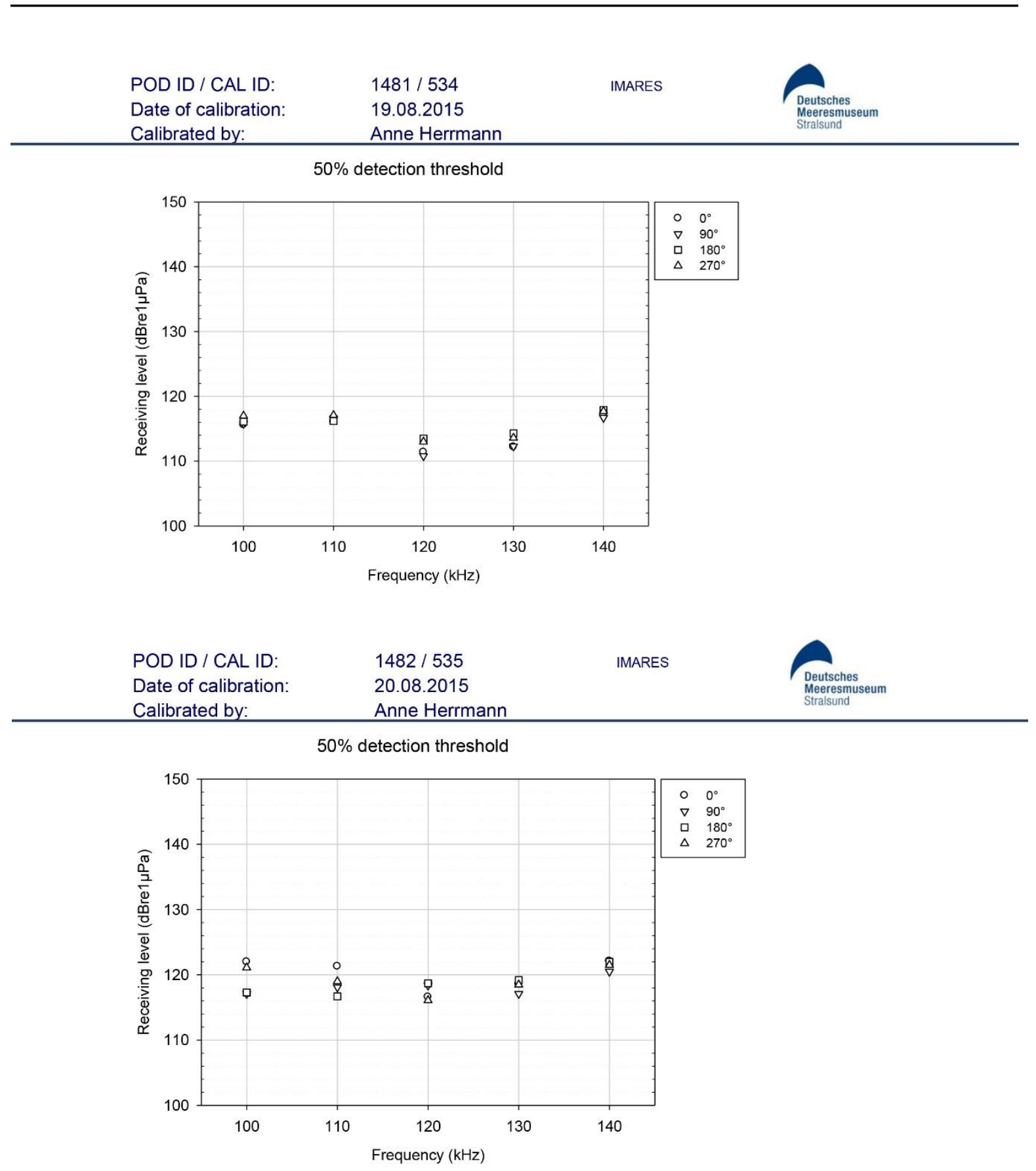

Figure A. 21 Calibration results of CPODs 1481 and 1482. 


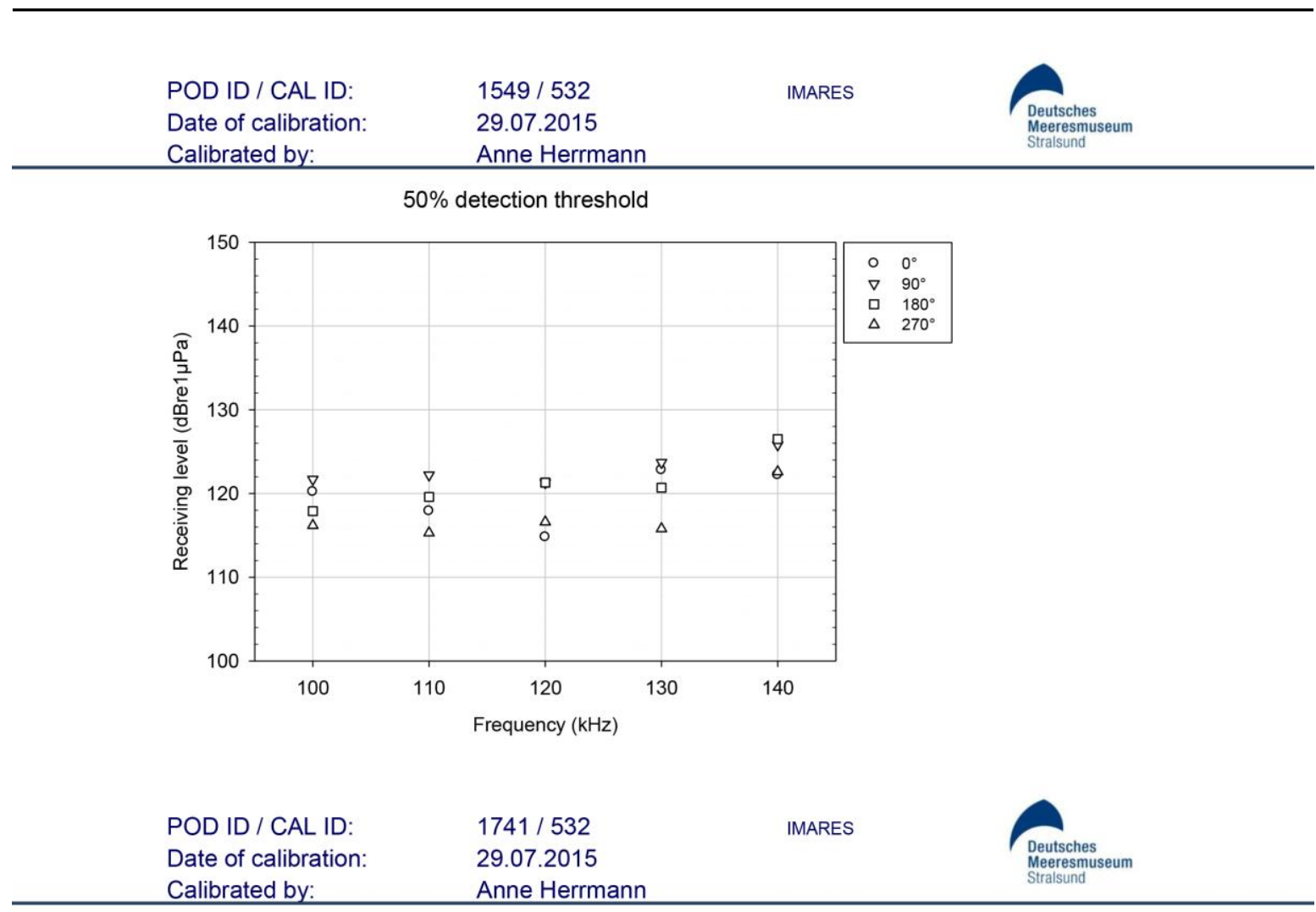

Calibrated by:

$50 \%$ detection threshold

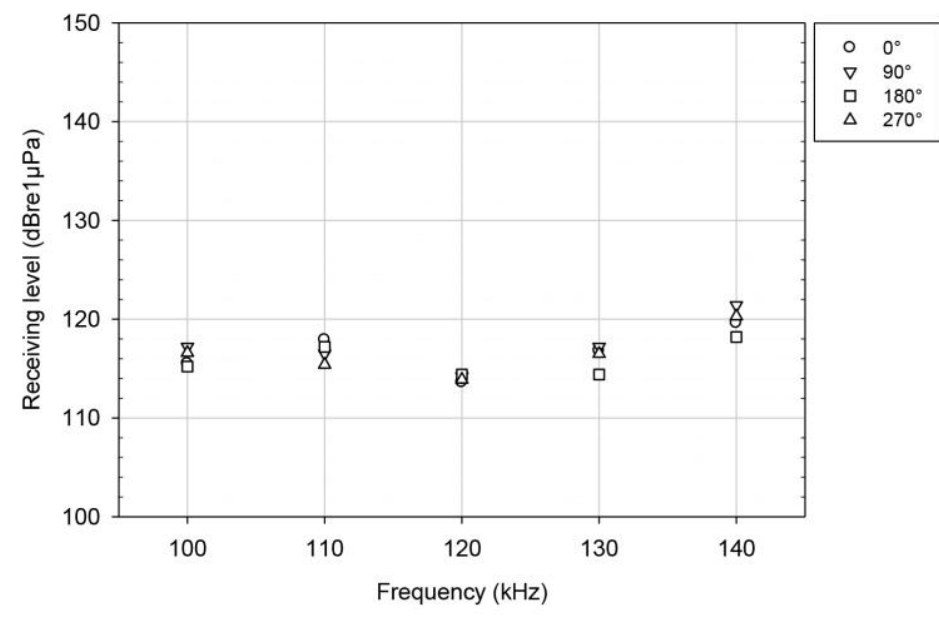

Figure A. 22 Calibration results of CPODs 1549 and 1741 . 


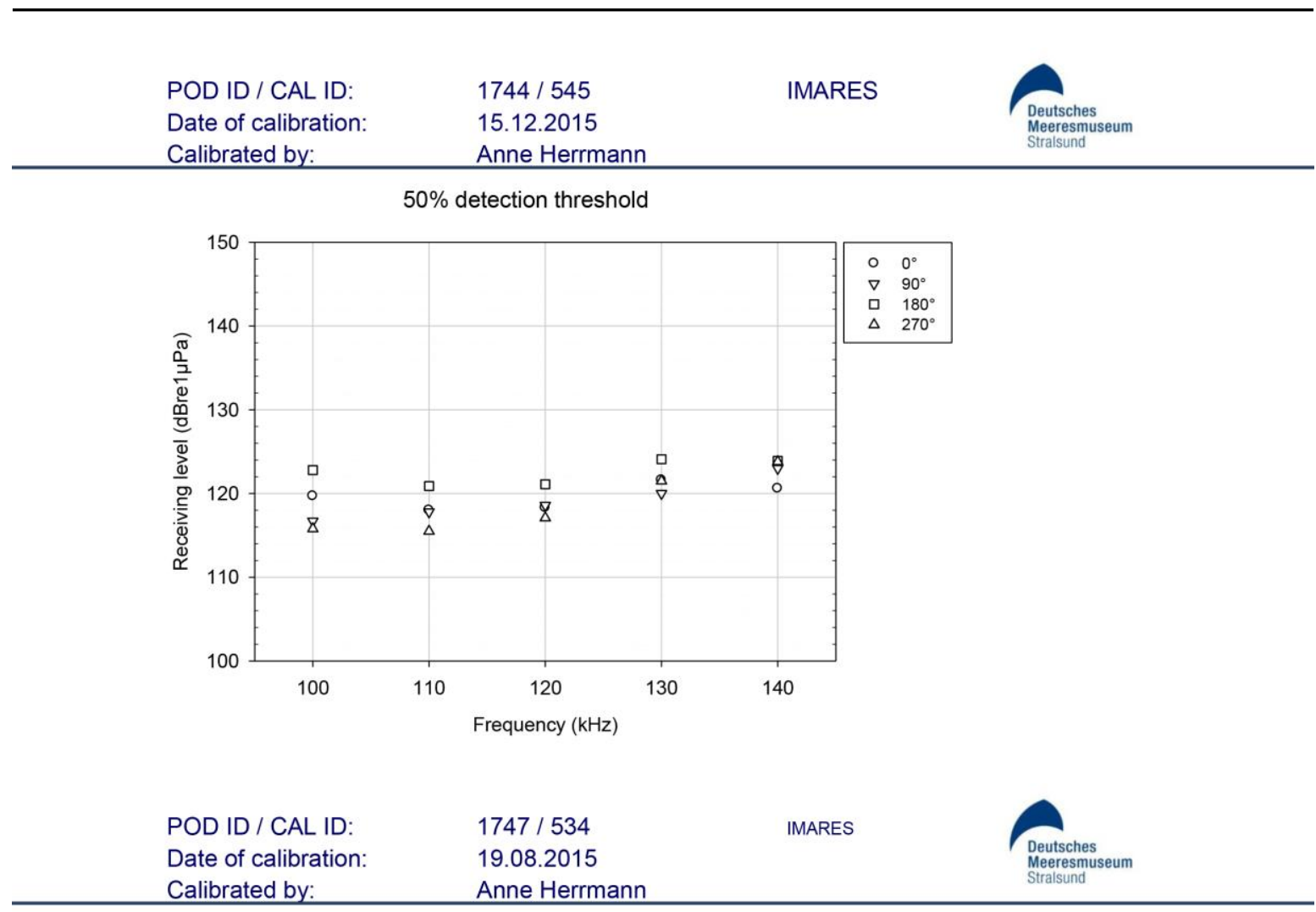

Calibrated by:

$50 \%$ detection threshold

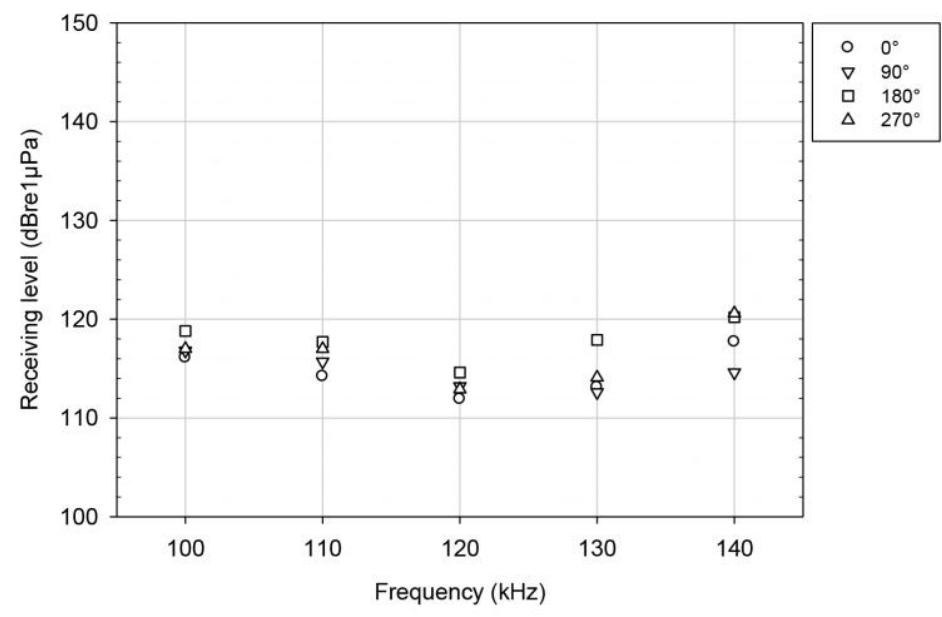

Figure A. 23 Calibration results of CPODs 1744 and 1747. 


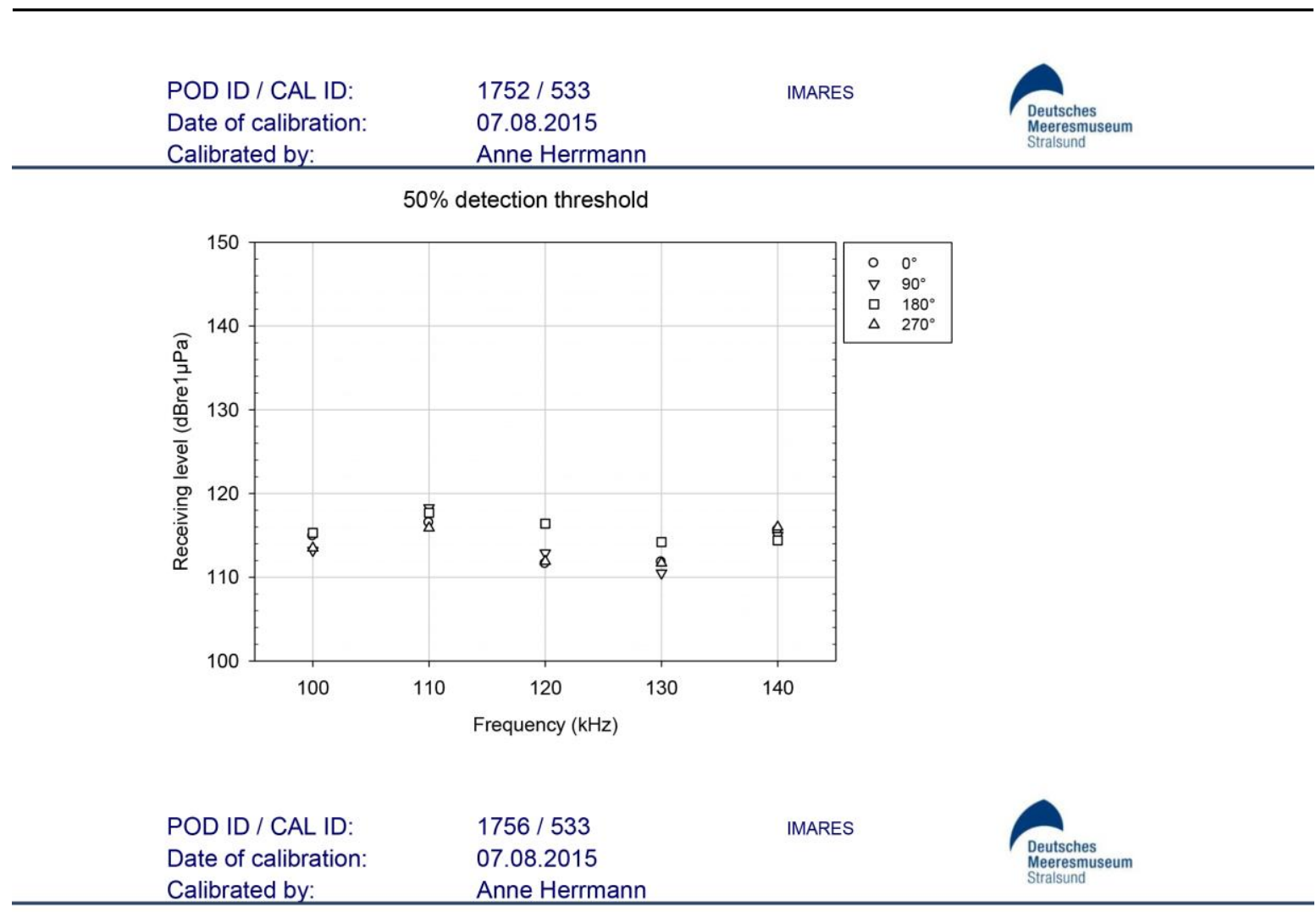

Calibrated by:

$50 \%$ detection threshold

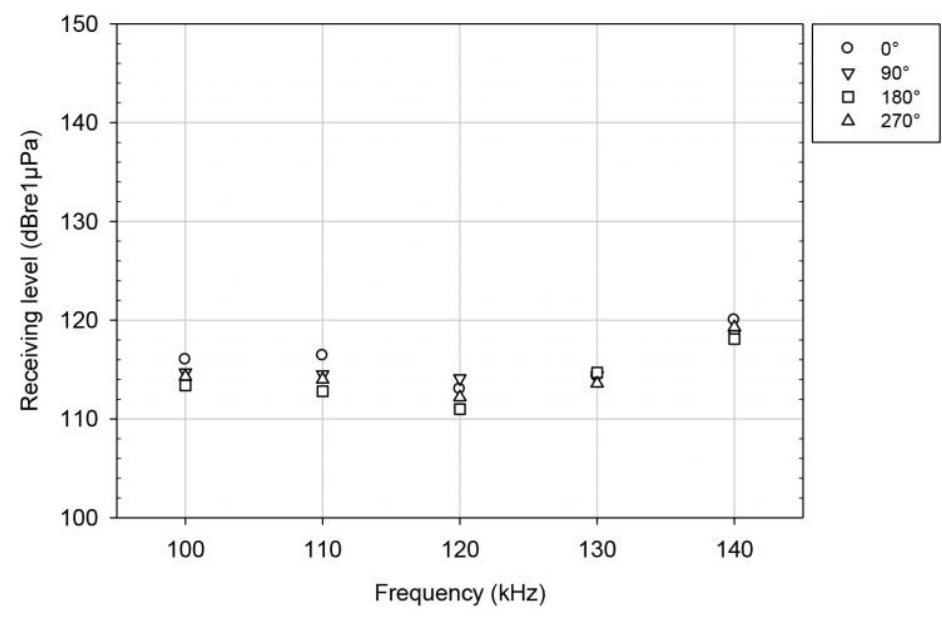

Figure A. 24 Calibration results of CPODs 1752 and 1756. 


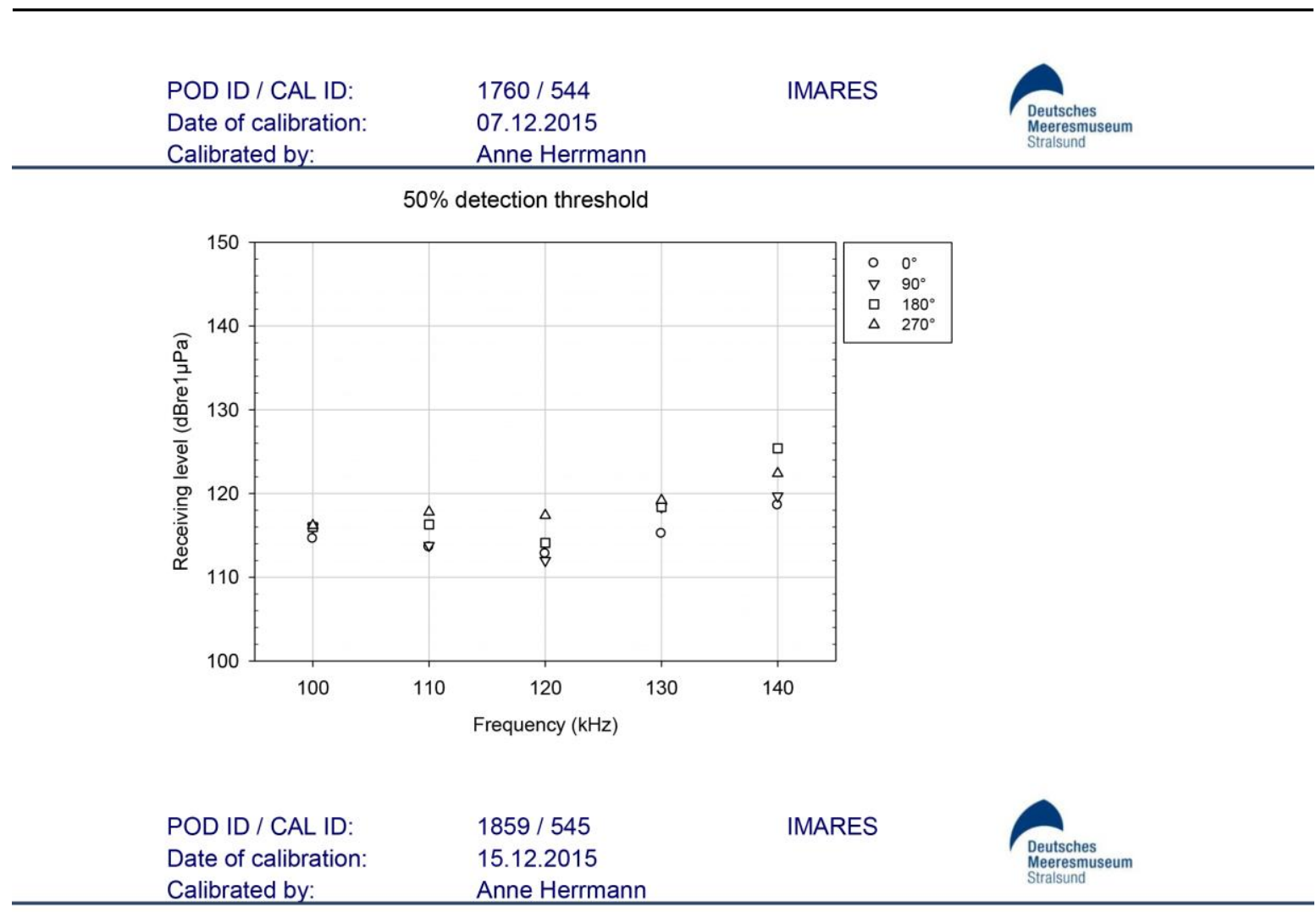

Calibrated by:

$50 \%$ detection threshold

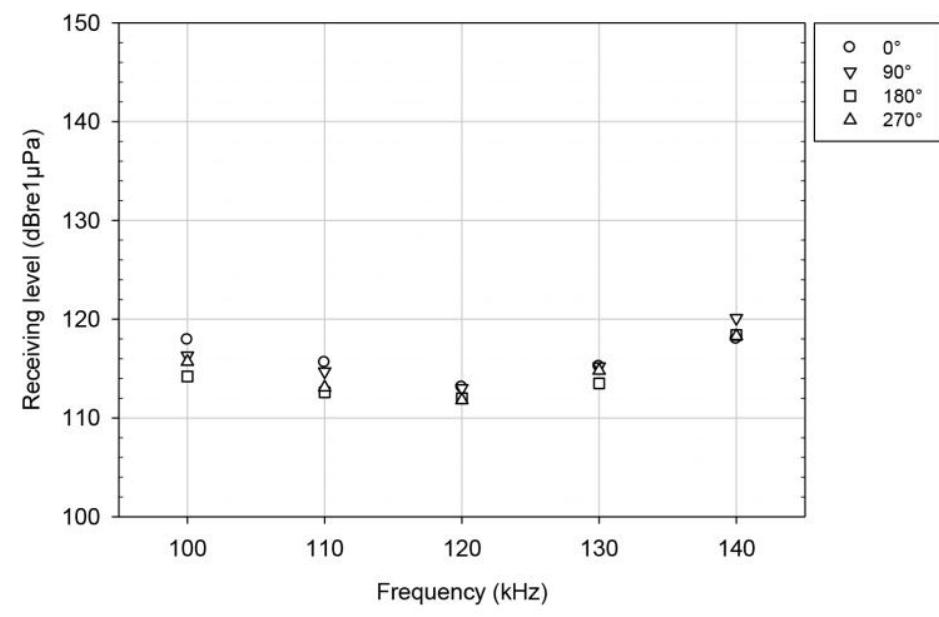

Figure A. 25 Calibration results of CPODs 1760 and 1859. 


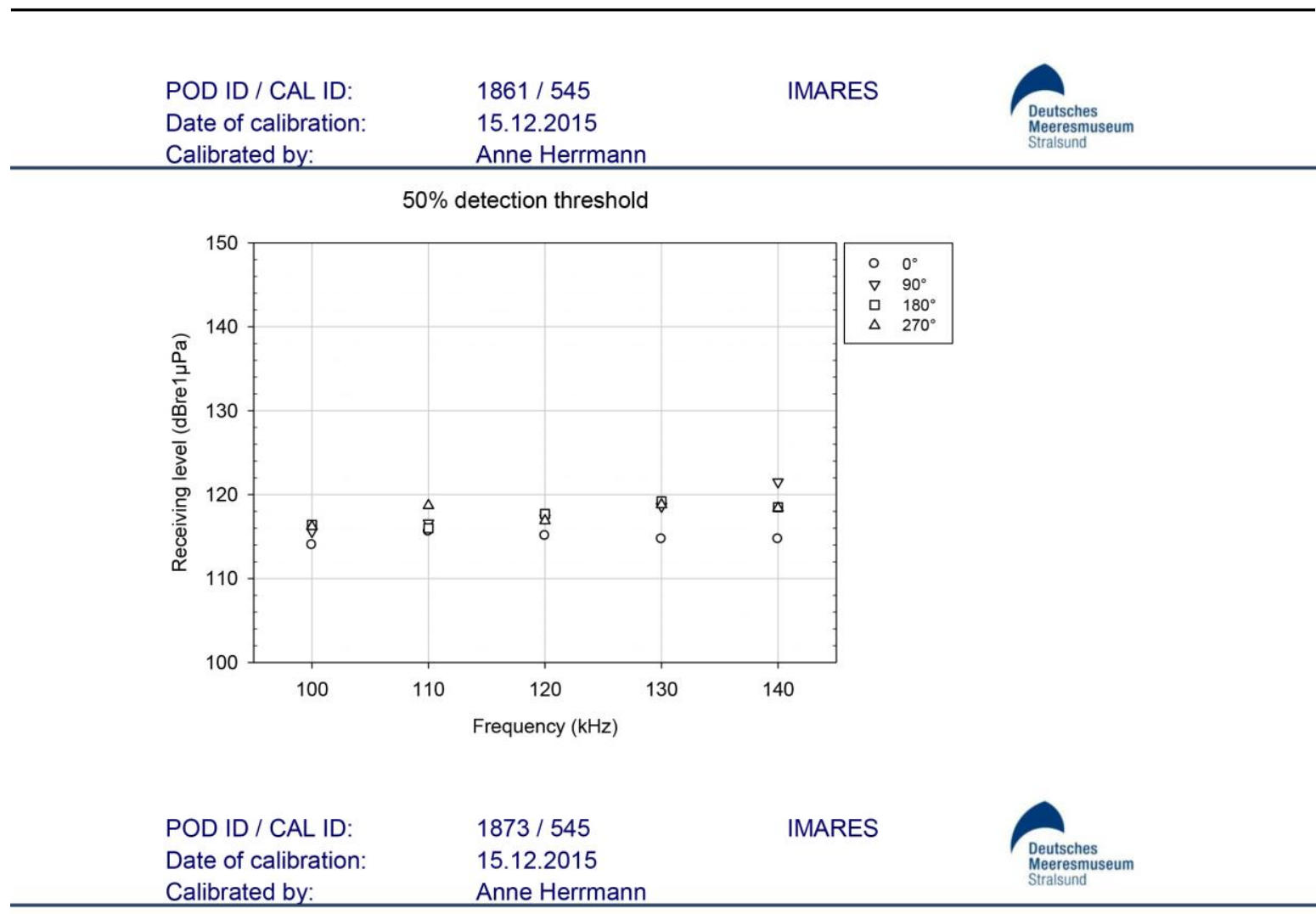

Calibrated by:

$50 \%$ detection threshold

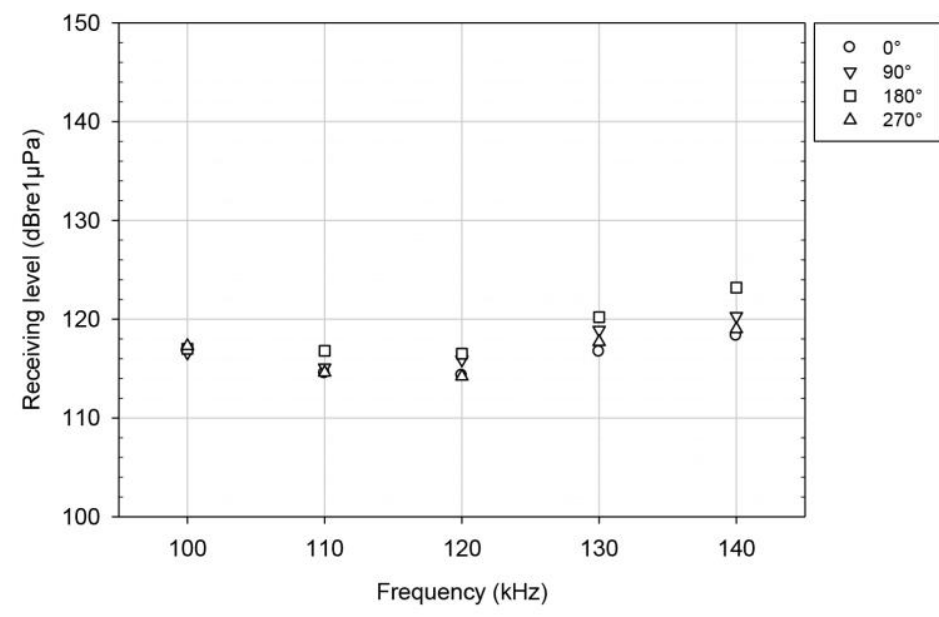

Figure A. 26 Calibration results of CPODs 1861 and 1873. 


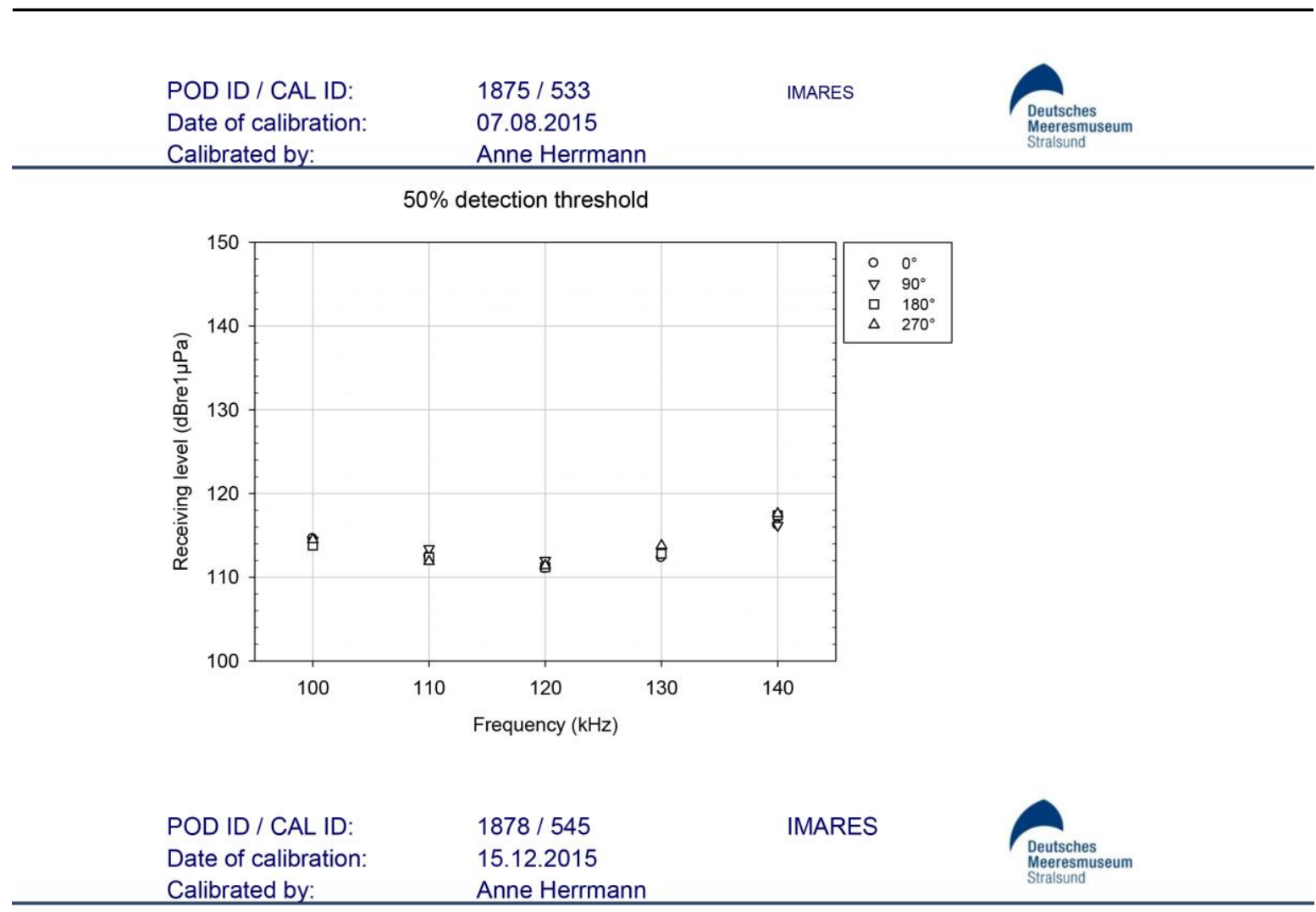

Calibrated by:

$50 \%$ detection threshold

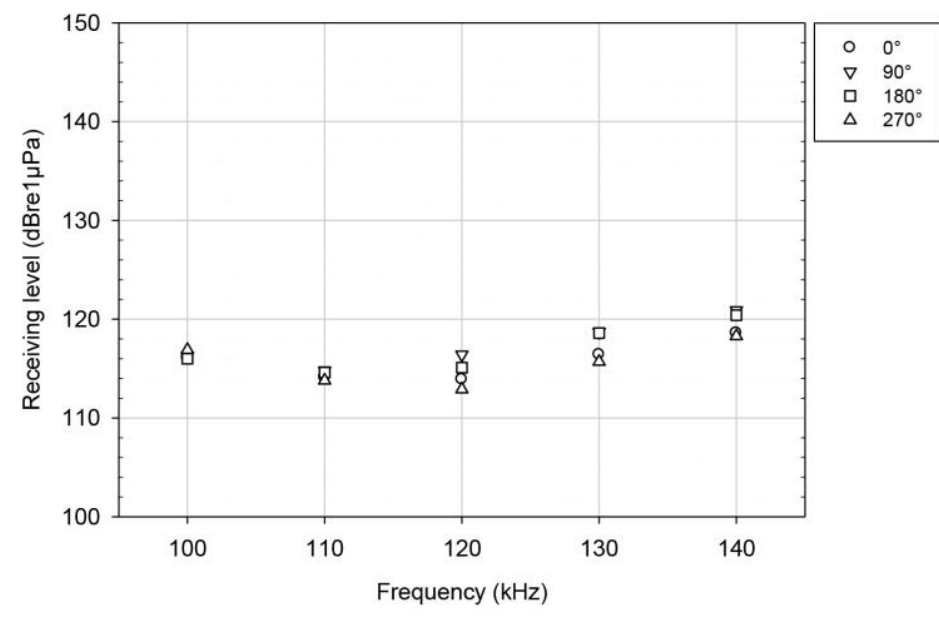

Figure A. 27 Calibration results of CPODs 1875 and 1878. 


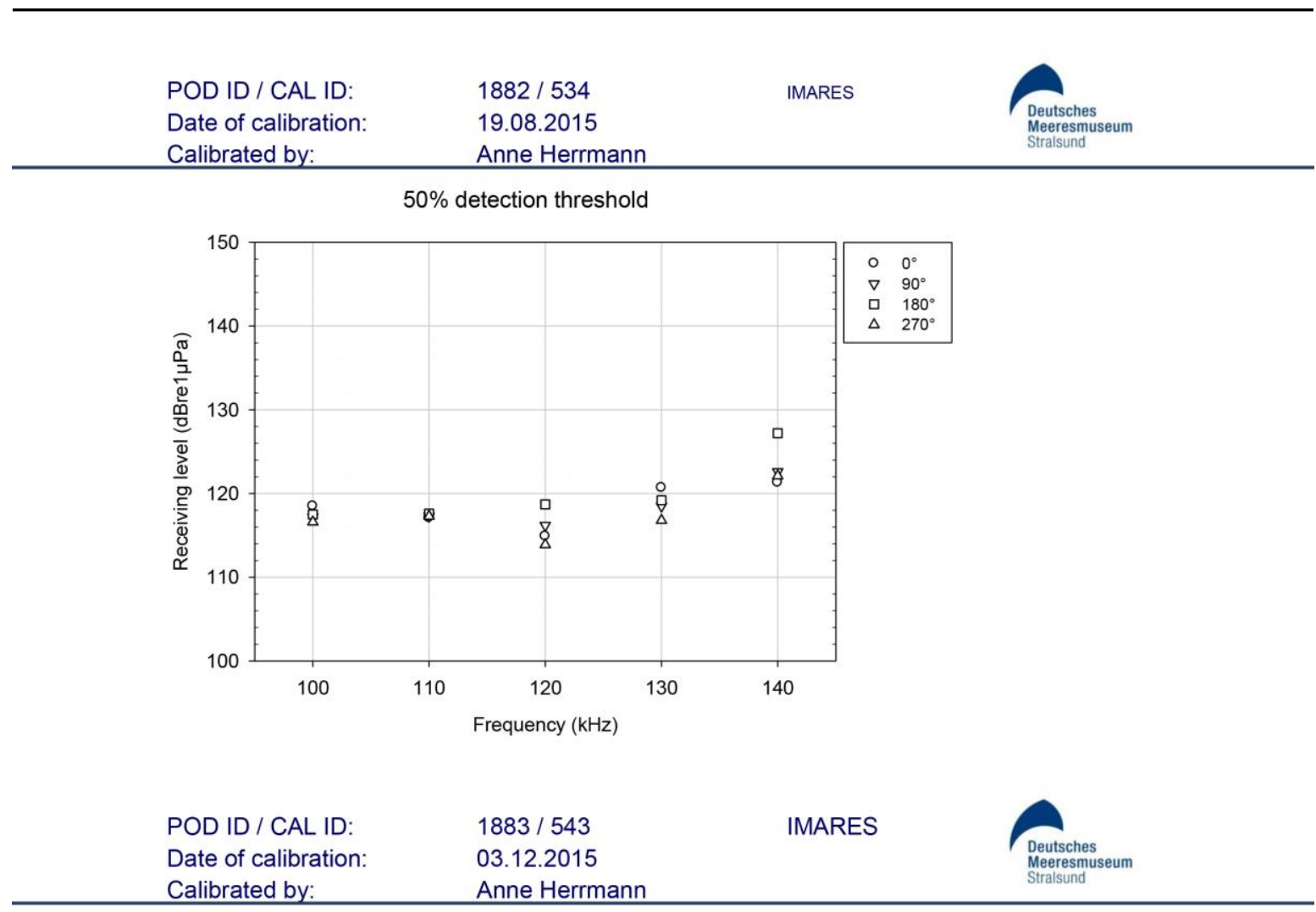

Calibrated by:

$50 \%$ detection threshold

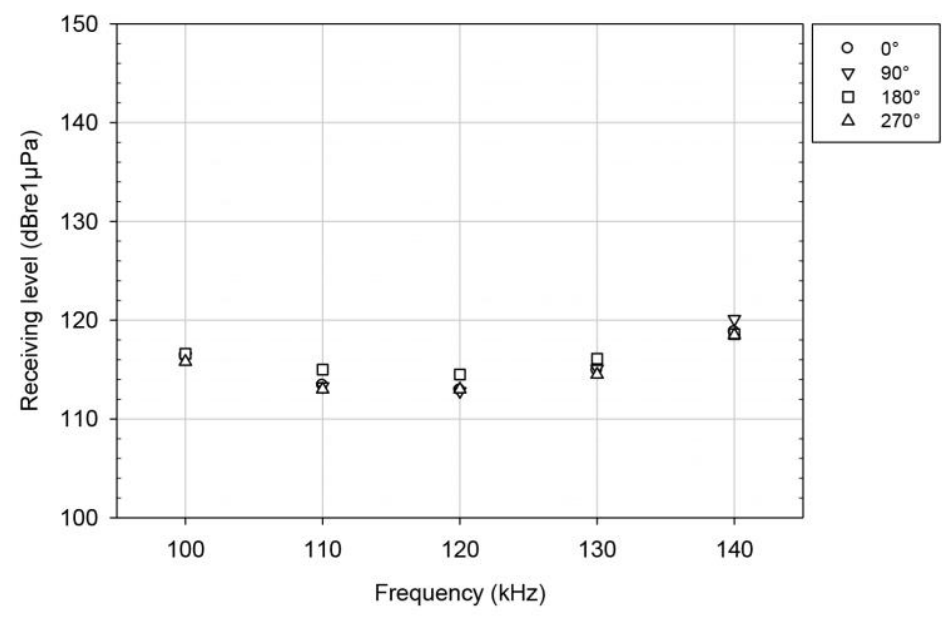

Figure A. 28 Calibration results of CPODs 1882 and 1883. 


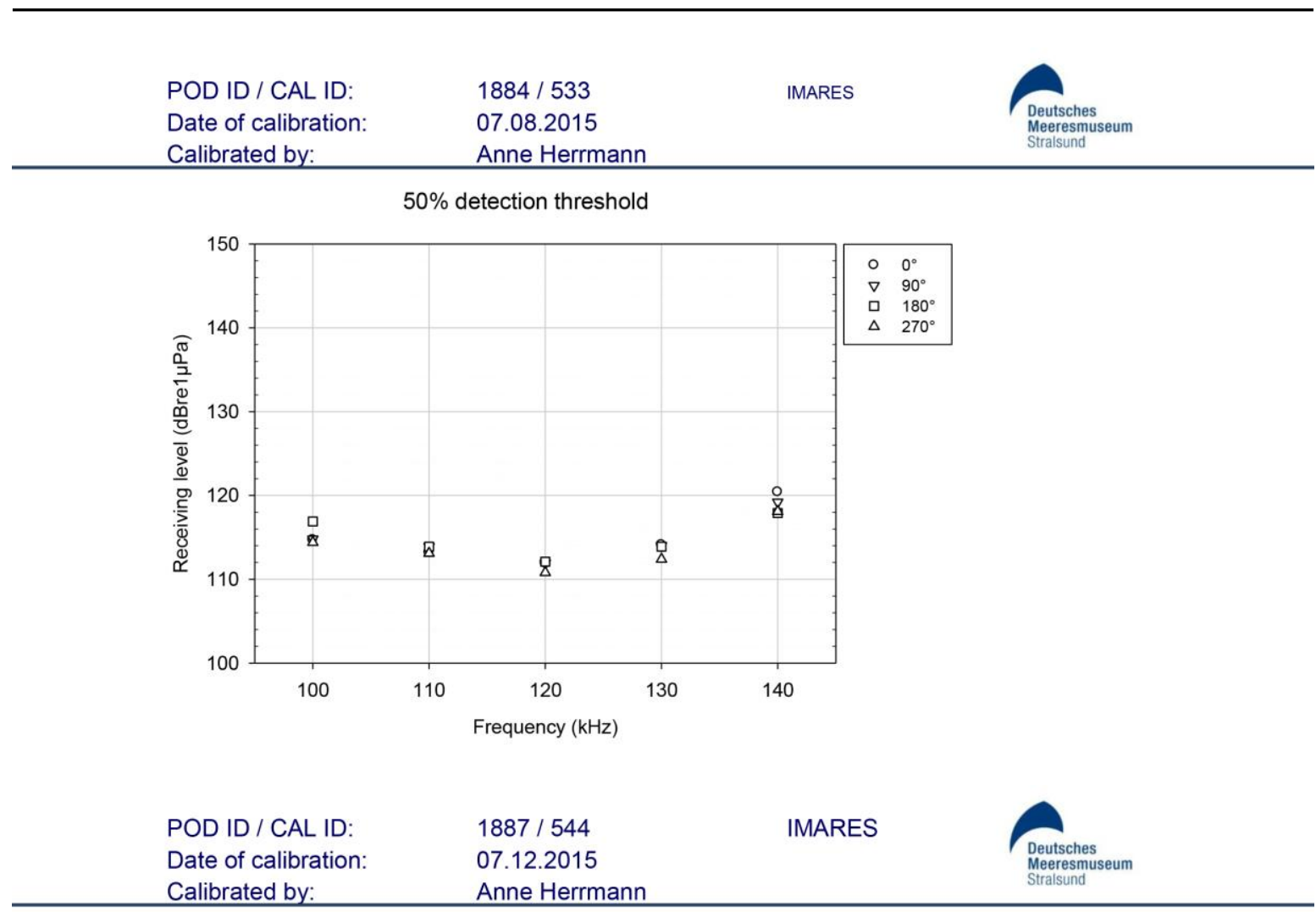
Calibrated by:

$50 \%$ detection threshold

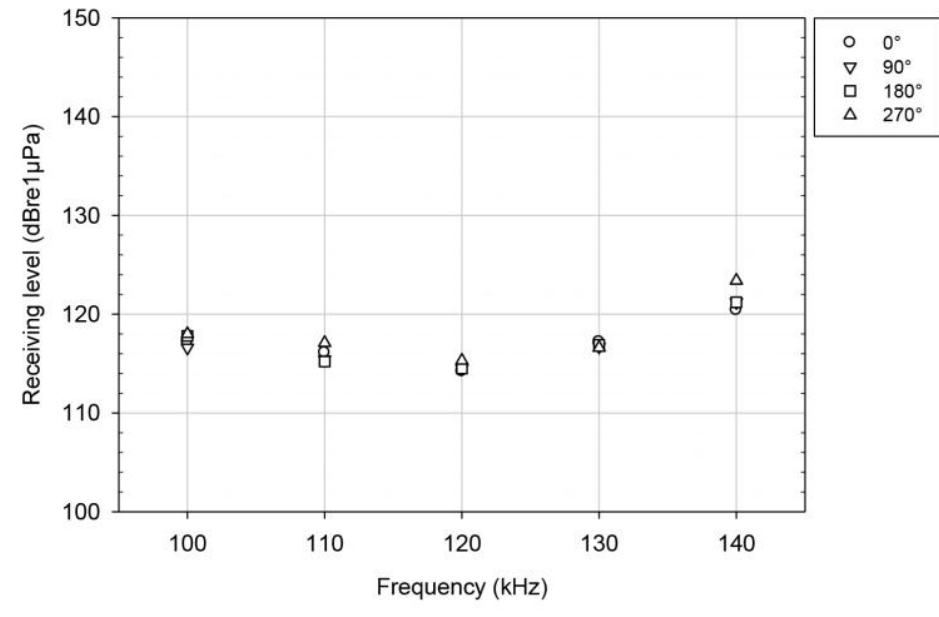

Figure A. 29 Calibration results of CPODs 1884 and 1887. 


\section{Annex 6 Calibration results: Ppp vs frequency}

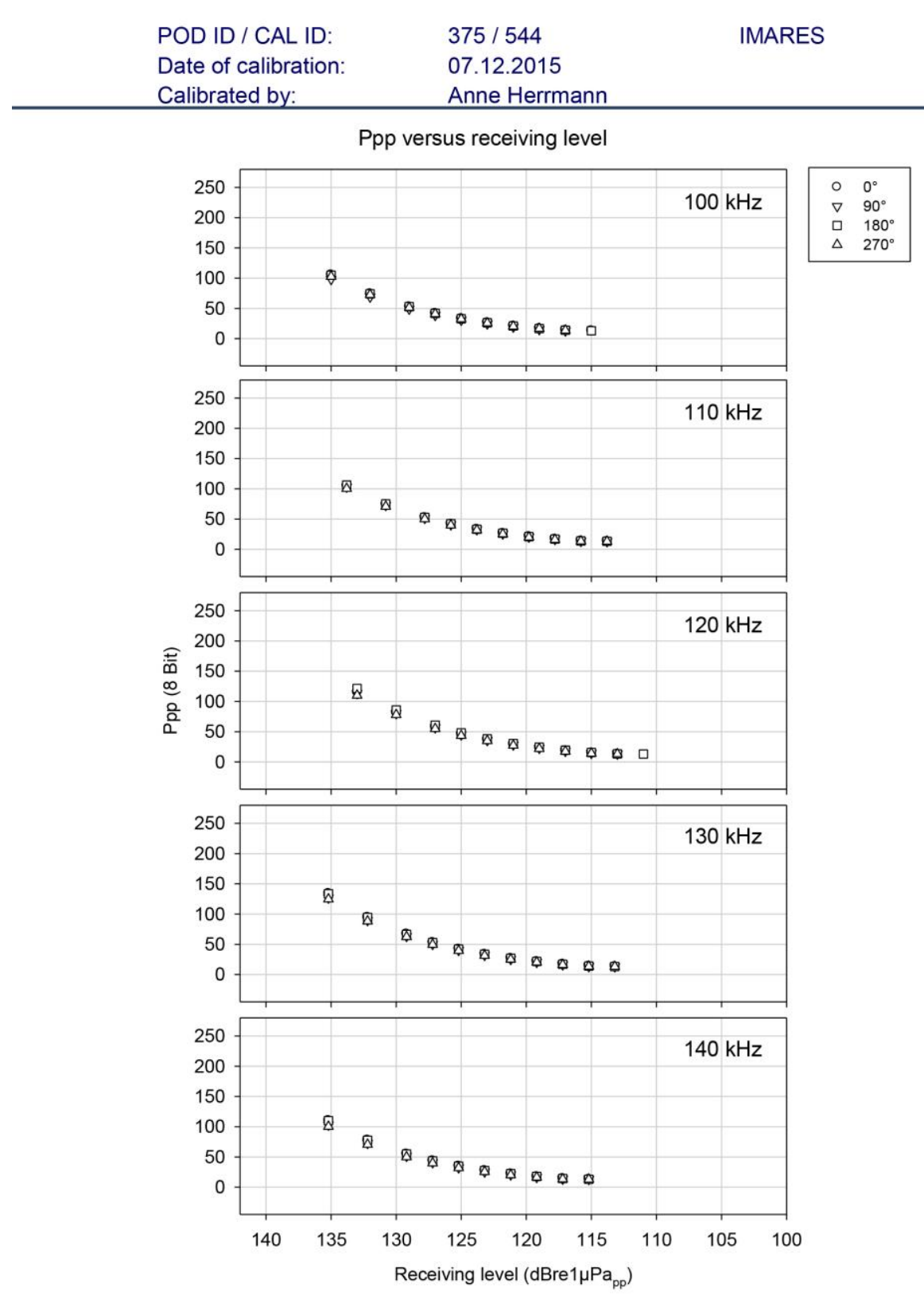

Figure A. 30 Calibration results of CPOD 375. 
POD ID / CAL ID:

Date of calibration:

Calibrated by:

377 / 543

03.12.2015

Anne Herrmann

Ppp versus receiving level
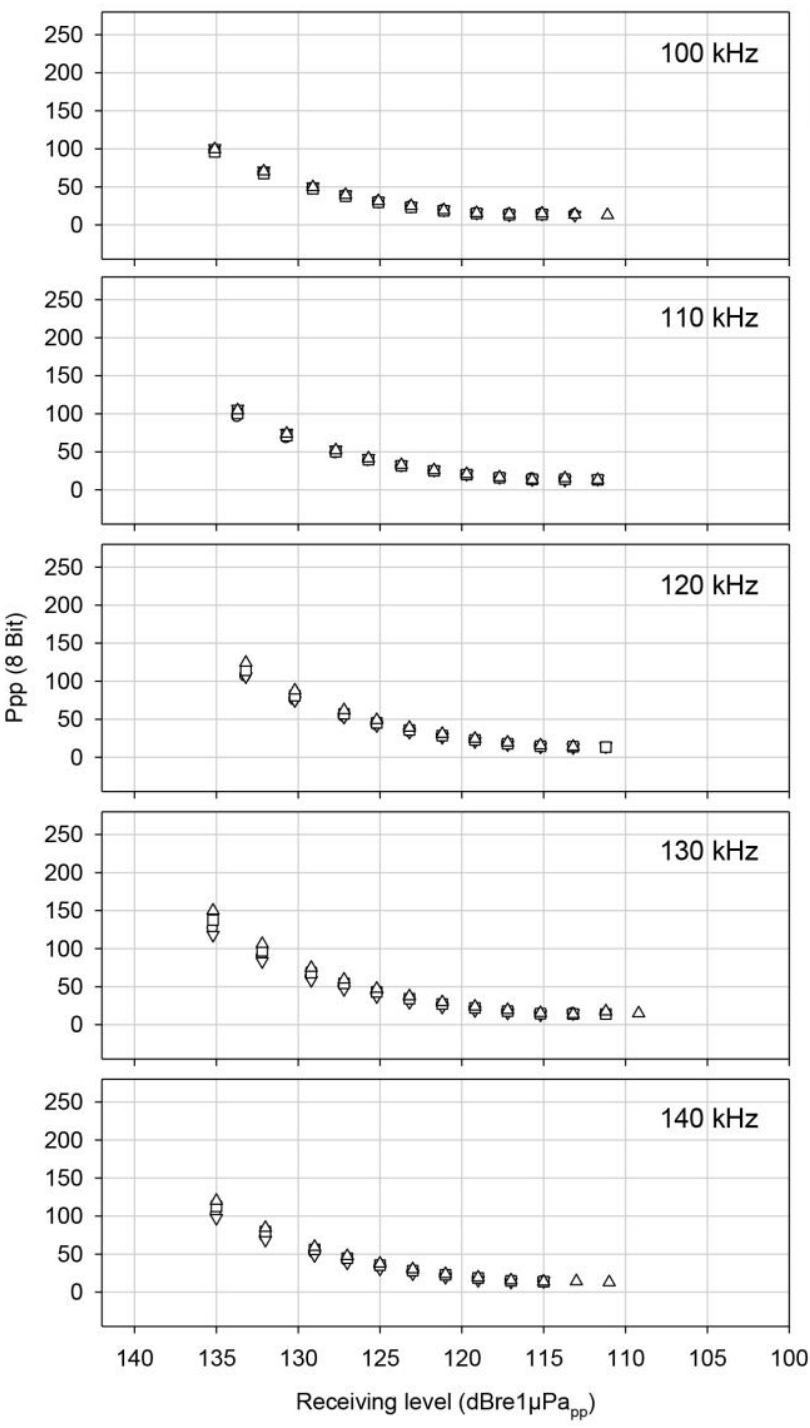

Figure A. 31 Calibration results of CPOD 377. $\begin{array}{ll}\circ & 0^{\circ} \\ \nabla & 90^{\circ} \\ \square & 180^{\circ}\end{array}$

$\square \quad 180^{\circ}$
$\triangle \quad 270^{\circ}$ 


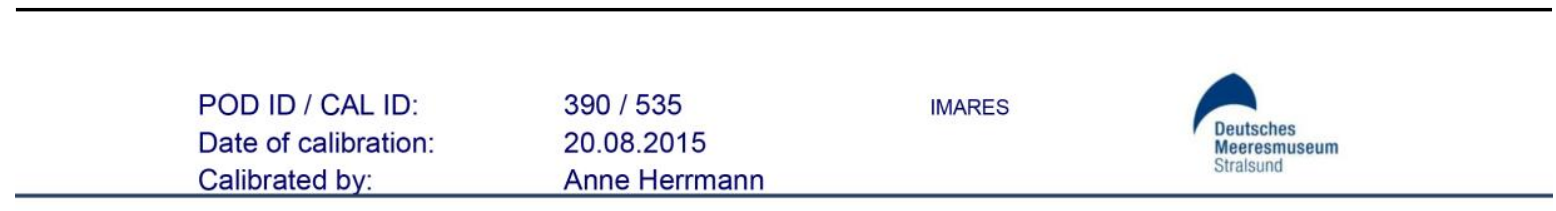

Calibrated by:

Anne Herrmann

Ppp versus receiving level
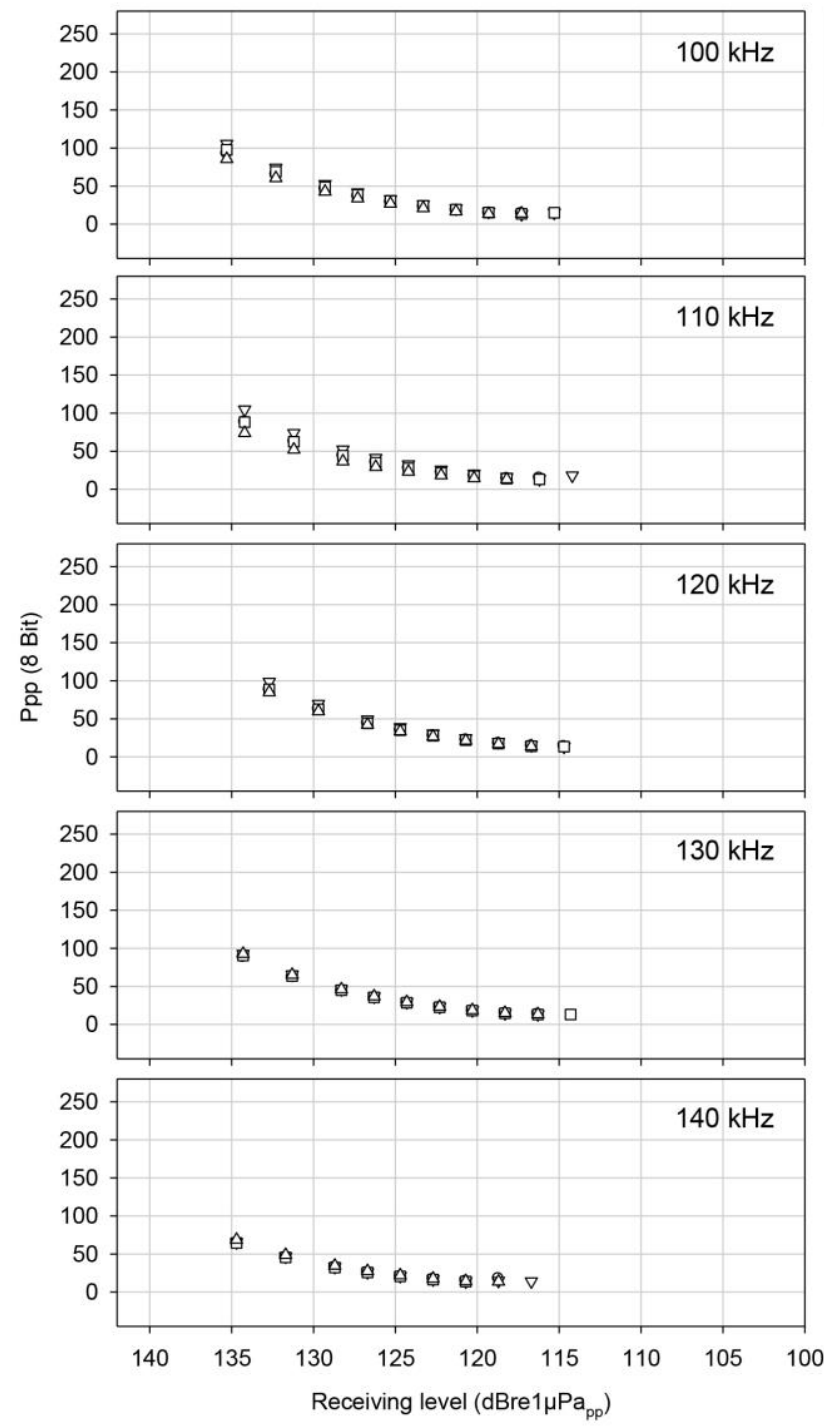

Figure A. 32 Calibration results of CPOD 390. 


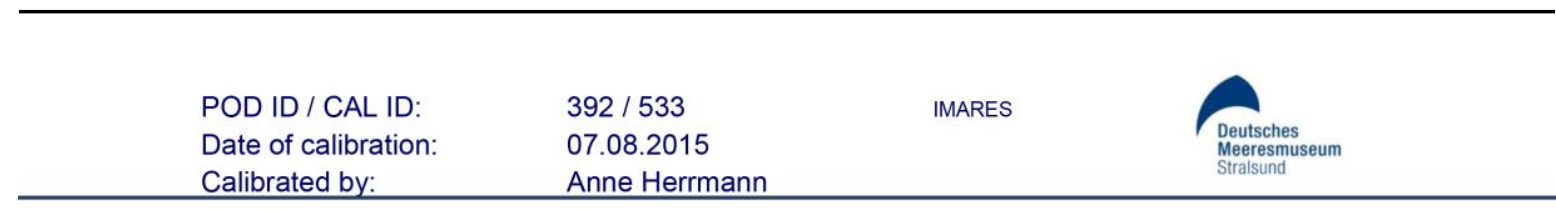

Calibrated by:

Anne Herrmann

Ppp versus receiving level
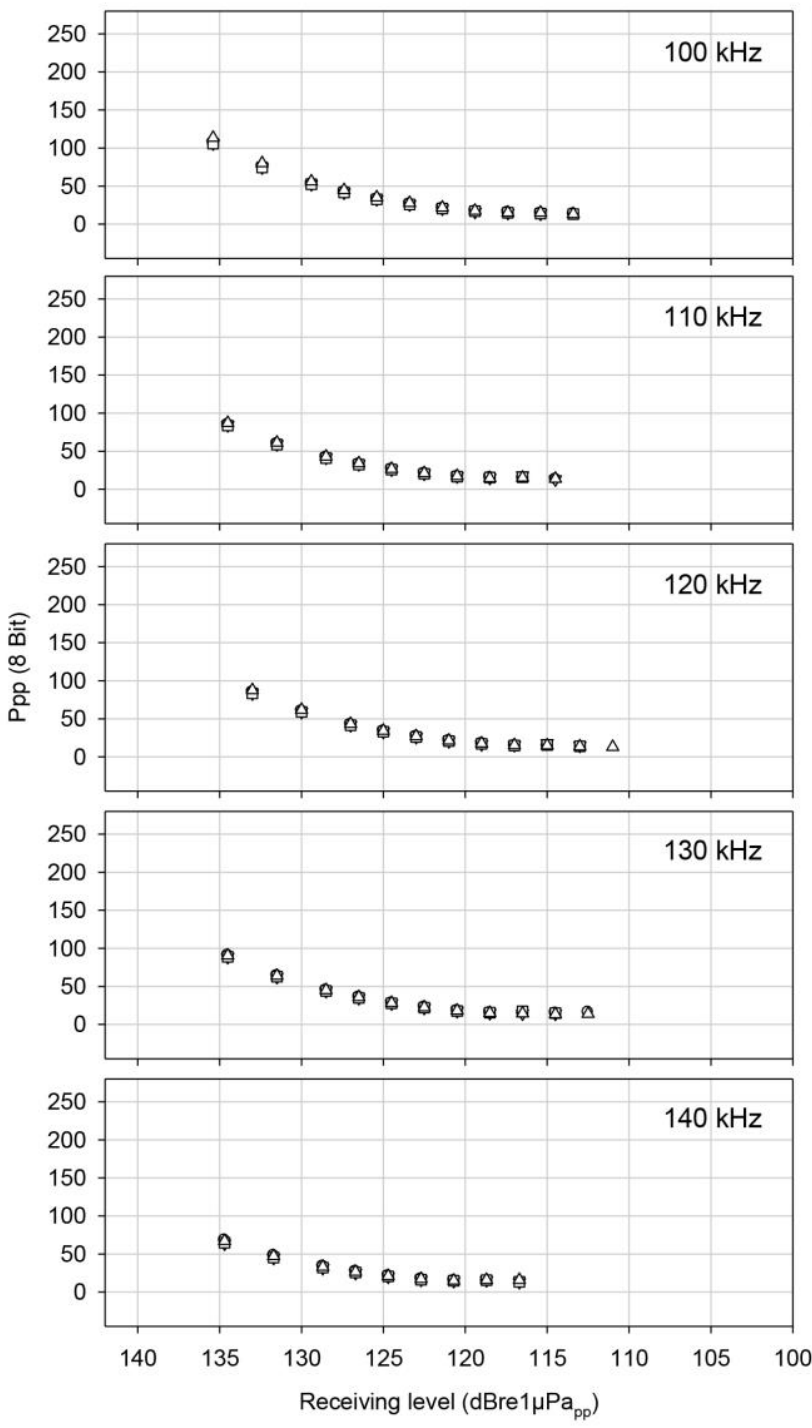

Figure A. 33 Calibration results of CPOD 392. 


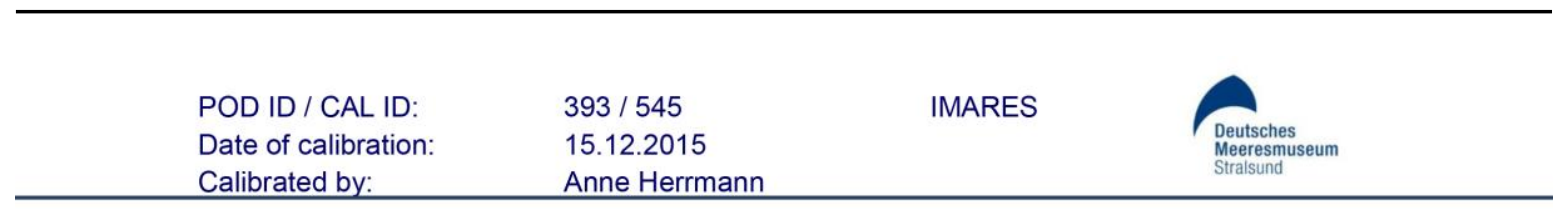

Calibrated by:

Anne Herrmann

Ppp versus receiving level
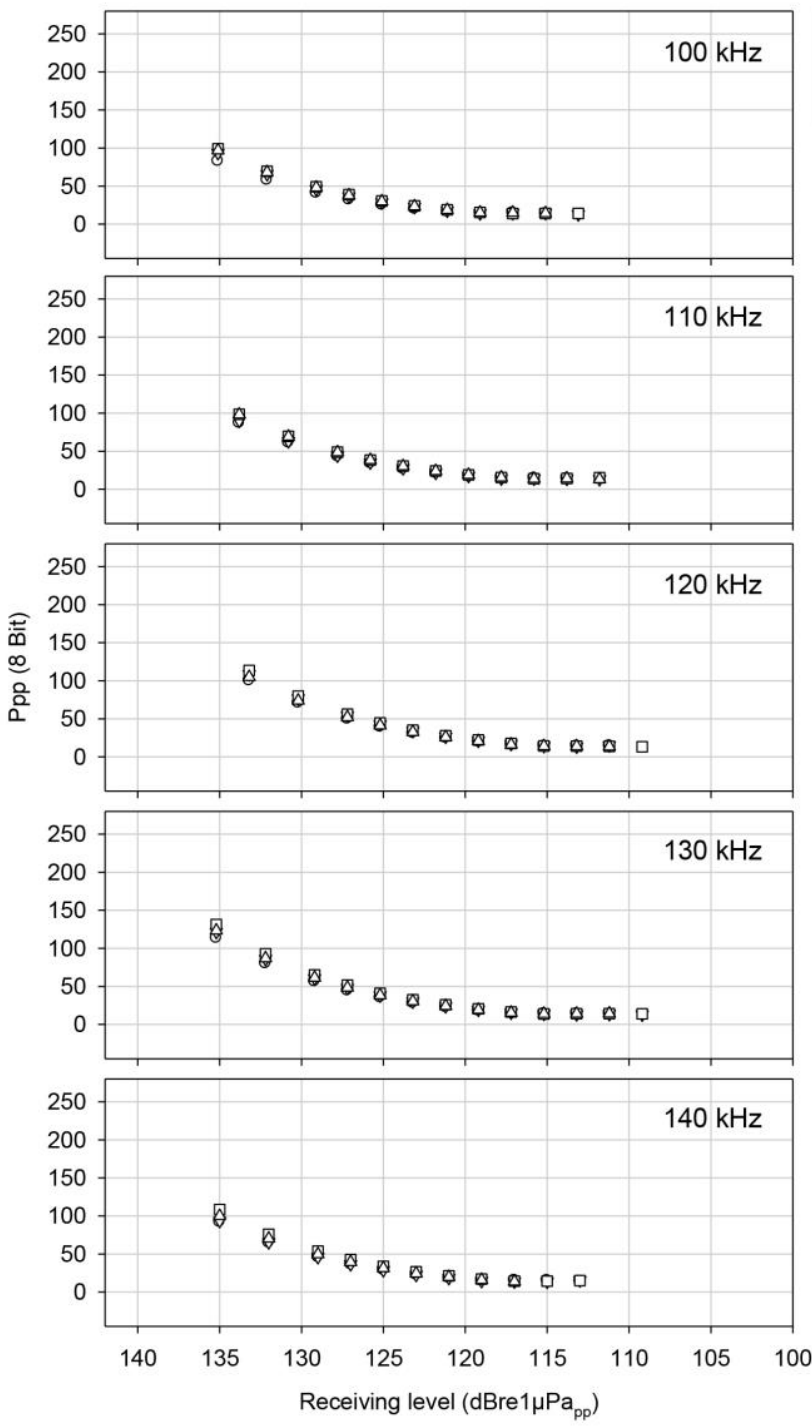

Figure A. 34 Calibration results of CPOD 393. 


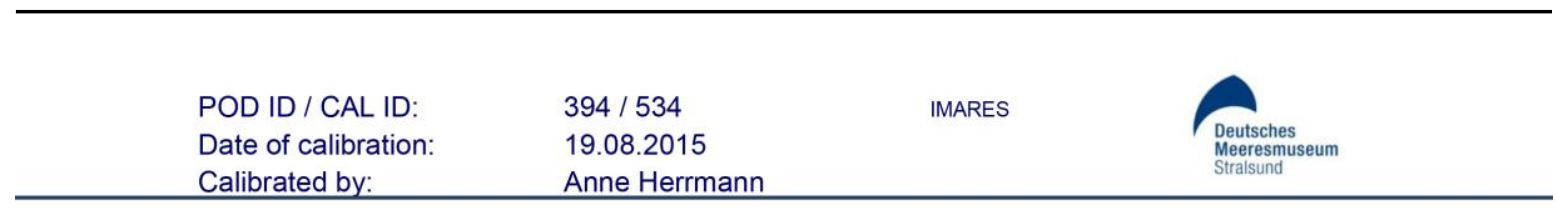

Calibrated by:

Anne Herrmann

Ppp versus receiving level
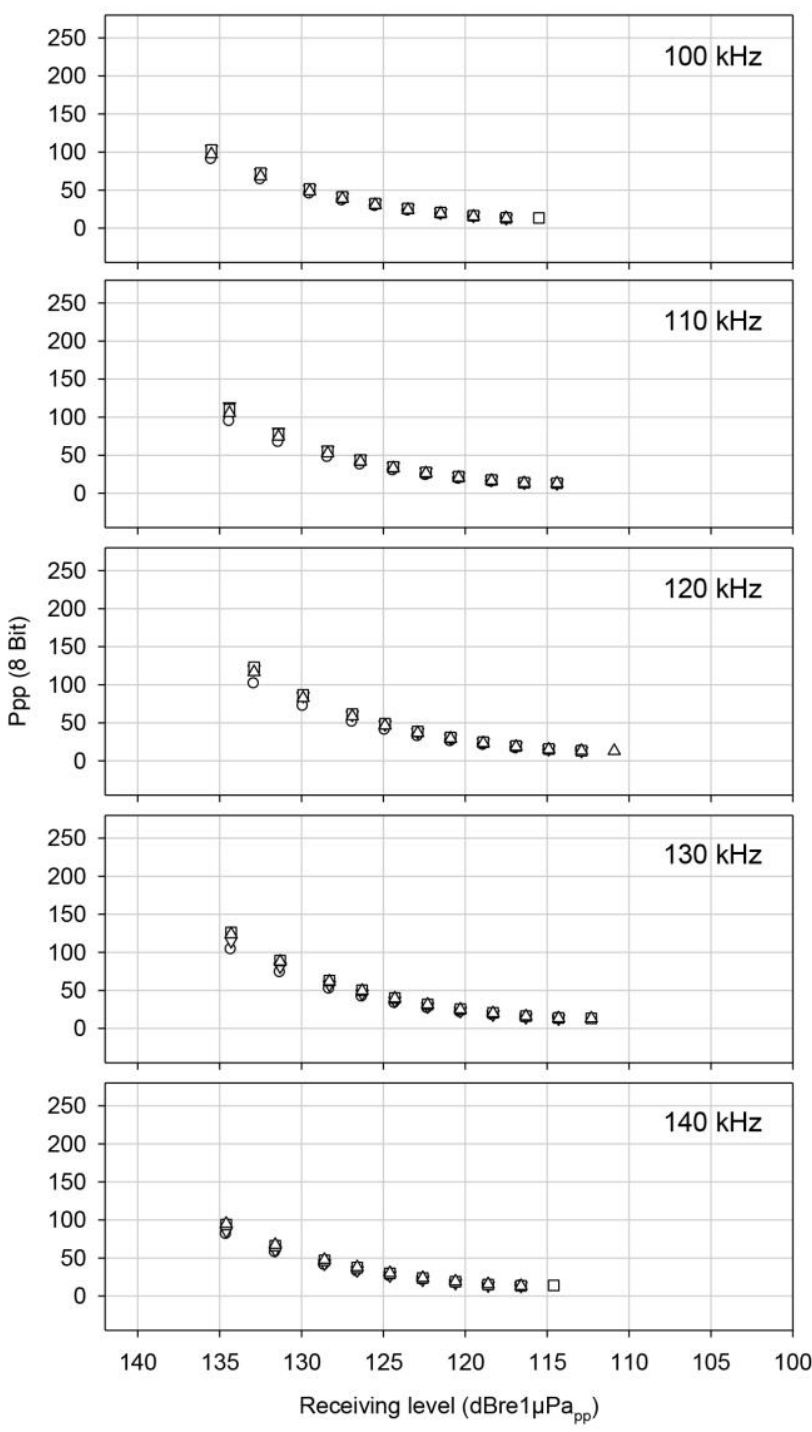

Figure A. 35 Calibration results of CPOD 394. 


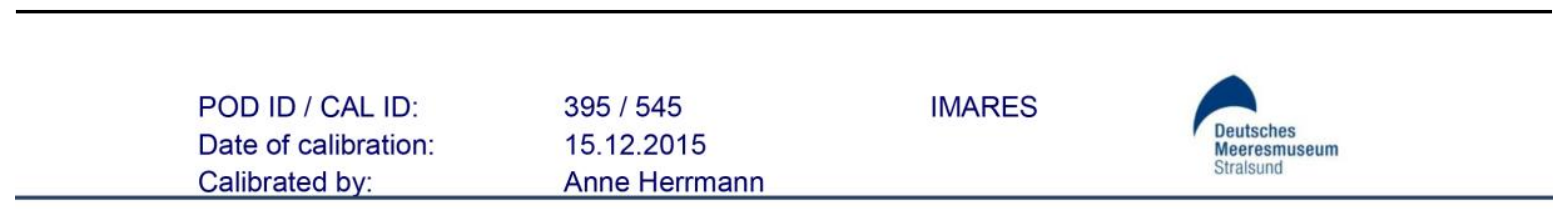

Calibrated by:

Anne Herrmann

Ppp versus receiving level
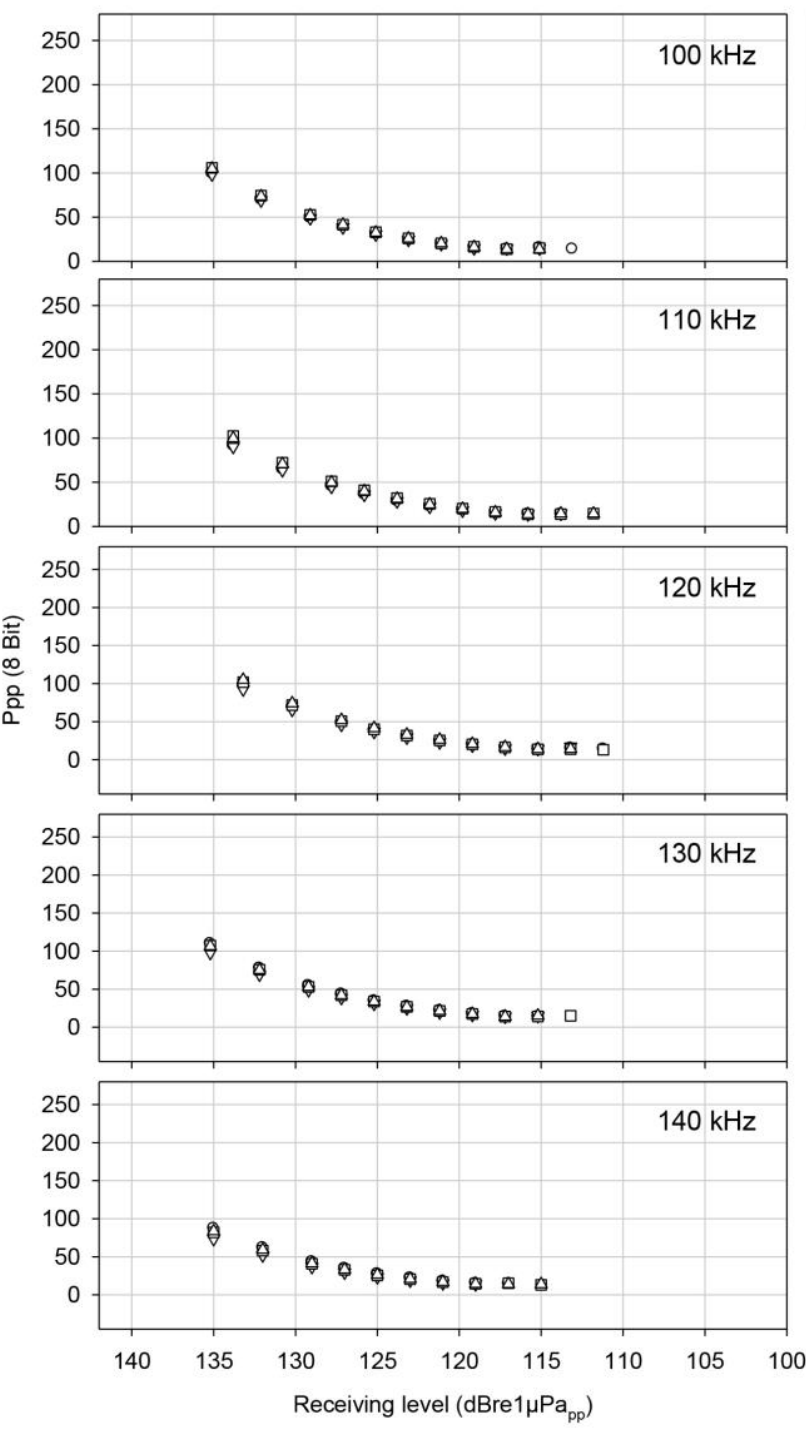

Figure A. 36 Calibration results of CPOD 395. 


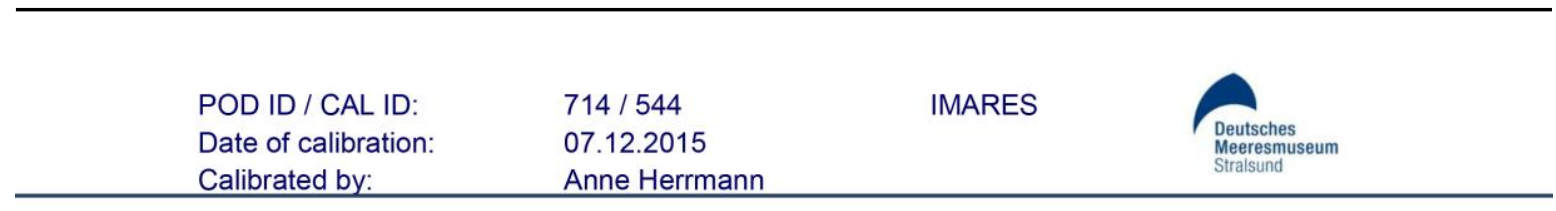

Calibrated by:

Anne Herrmann

Ppp versus receiving level
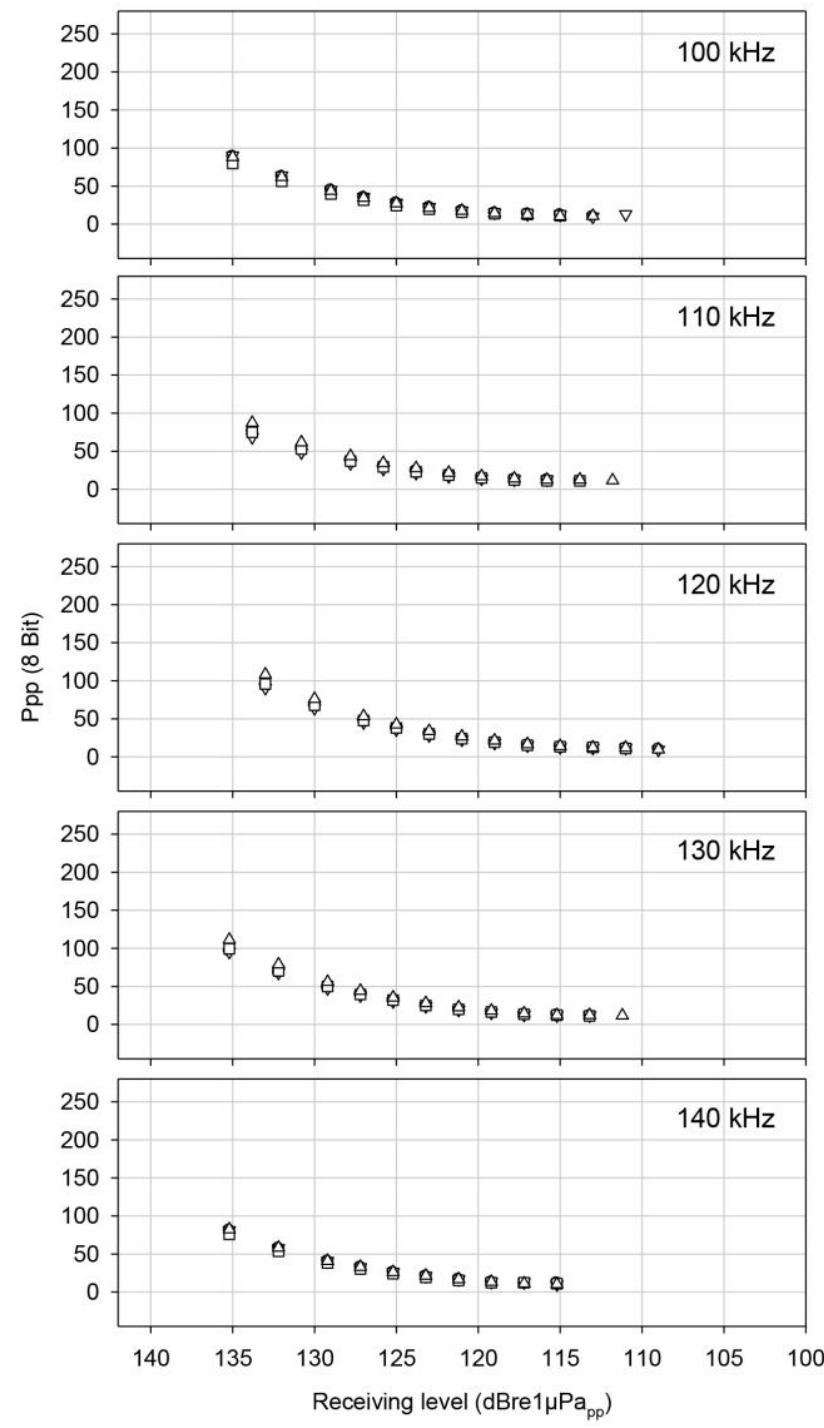

Figure A. 37 Calibration results of CPOD 714 . 


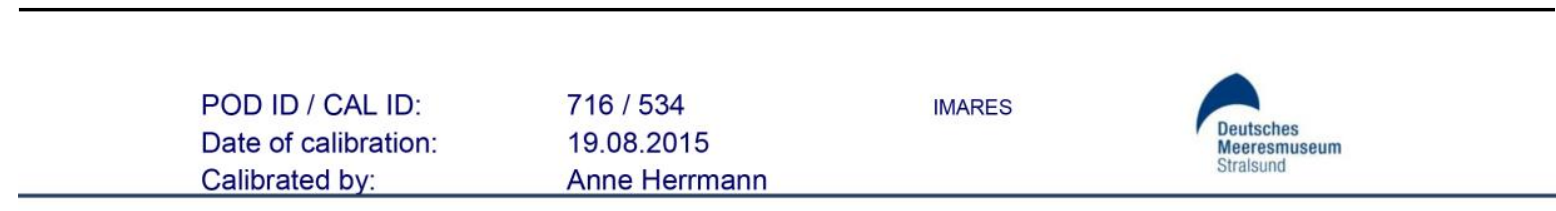

Calibrated by:

Anne Herrmann

Ppp versus receiving level
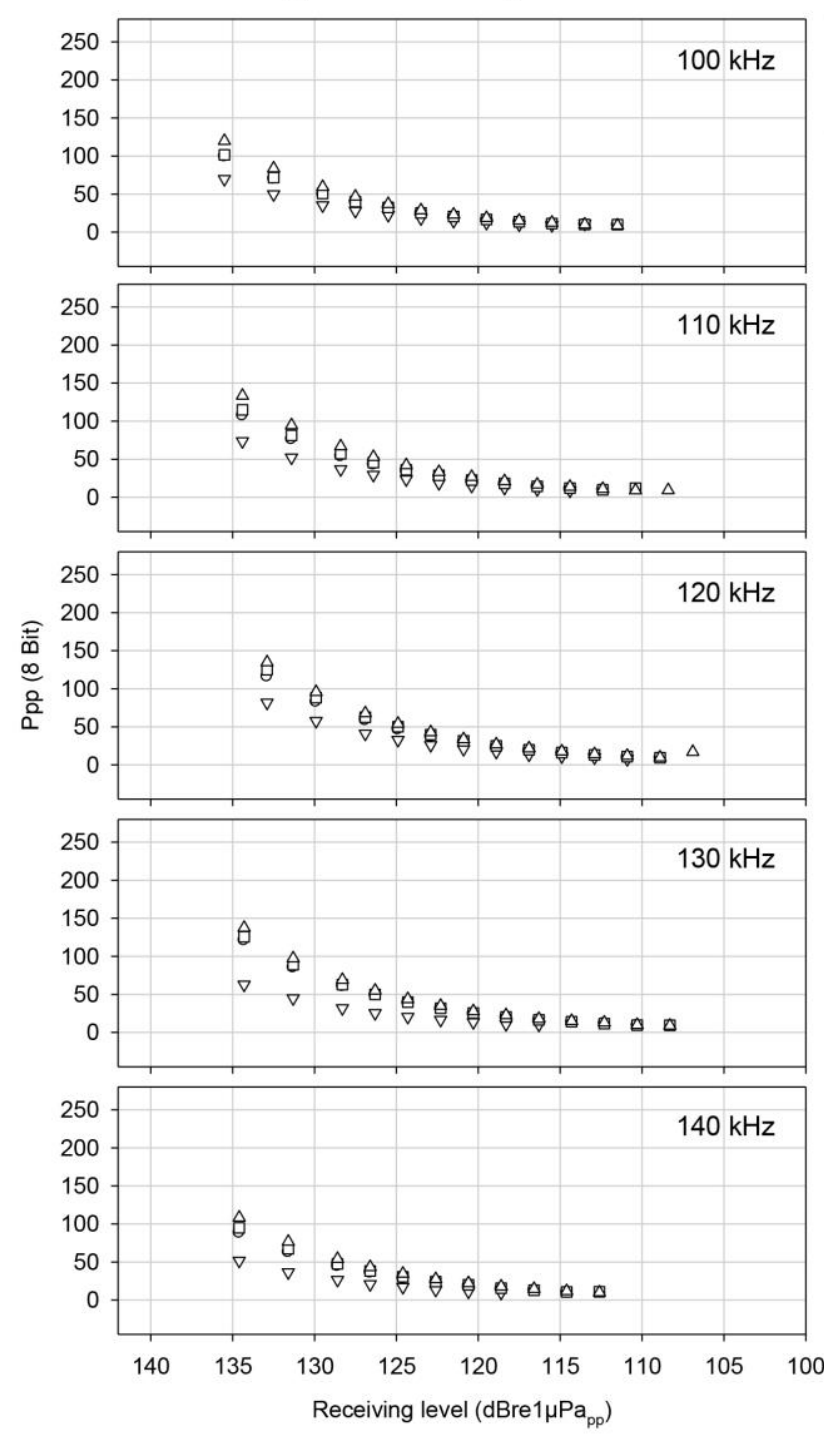

Figure A. 38 Calibration results of CPOD 716. 


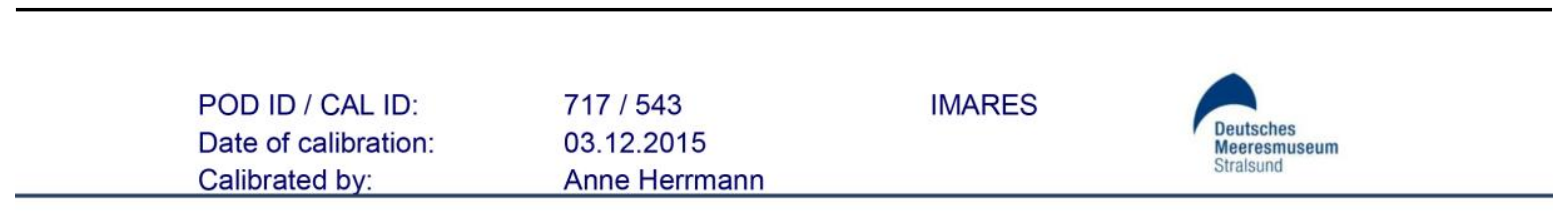

Calibrated by:

Ppp versus receiving level
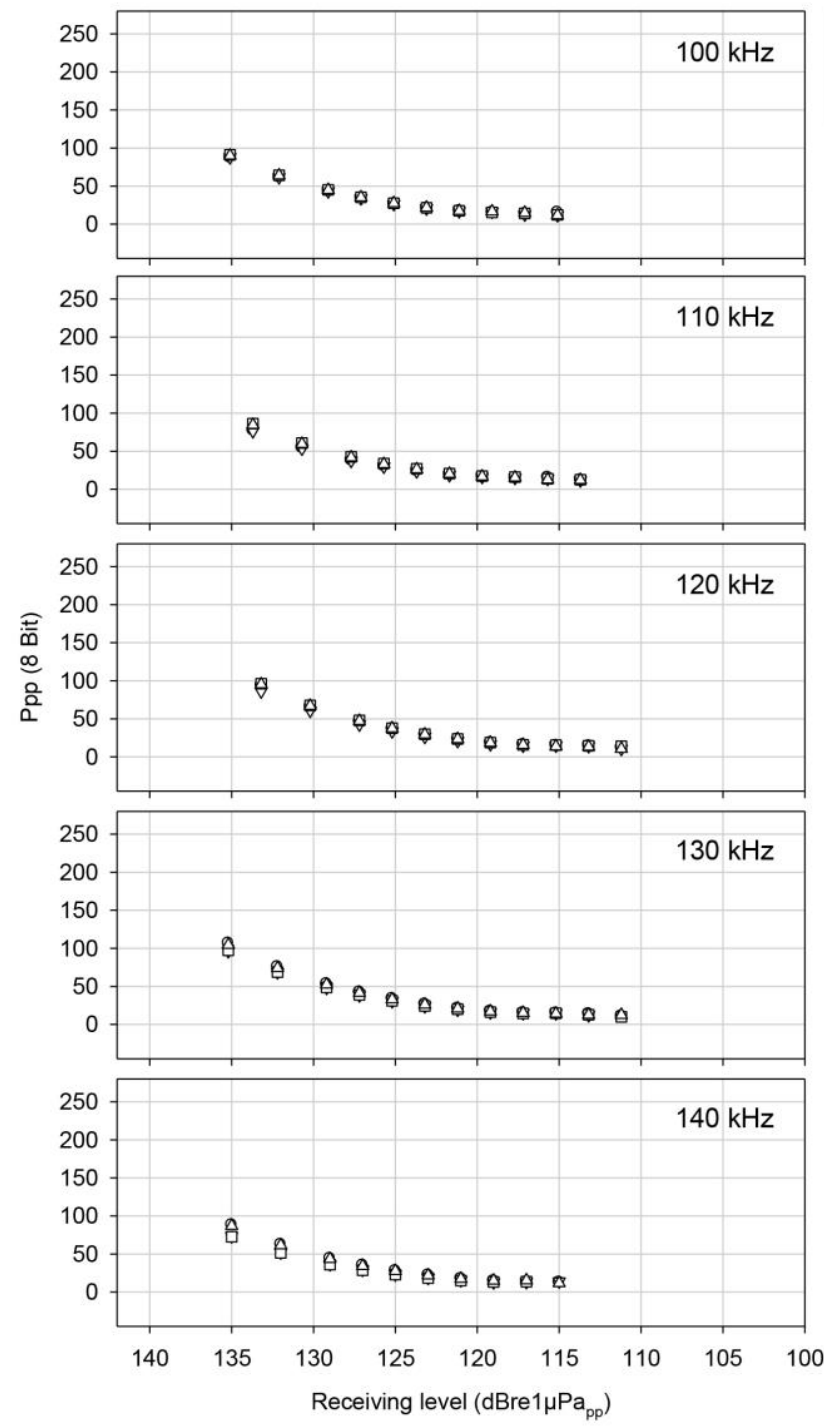

Figure A. 39 Calibration results of CPOD 717. 


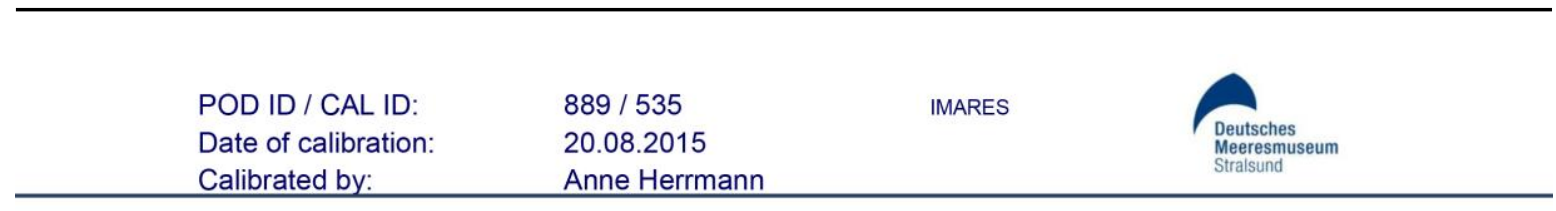

Calibrated by:

Anne Herrmann

Ppp versus receiving level
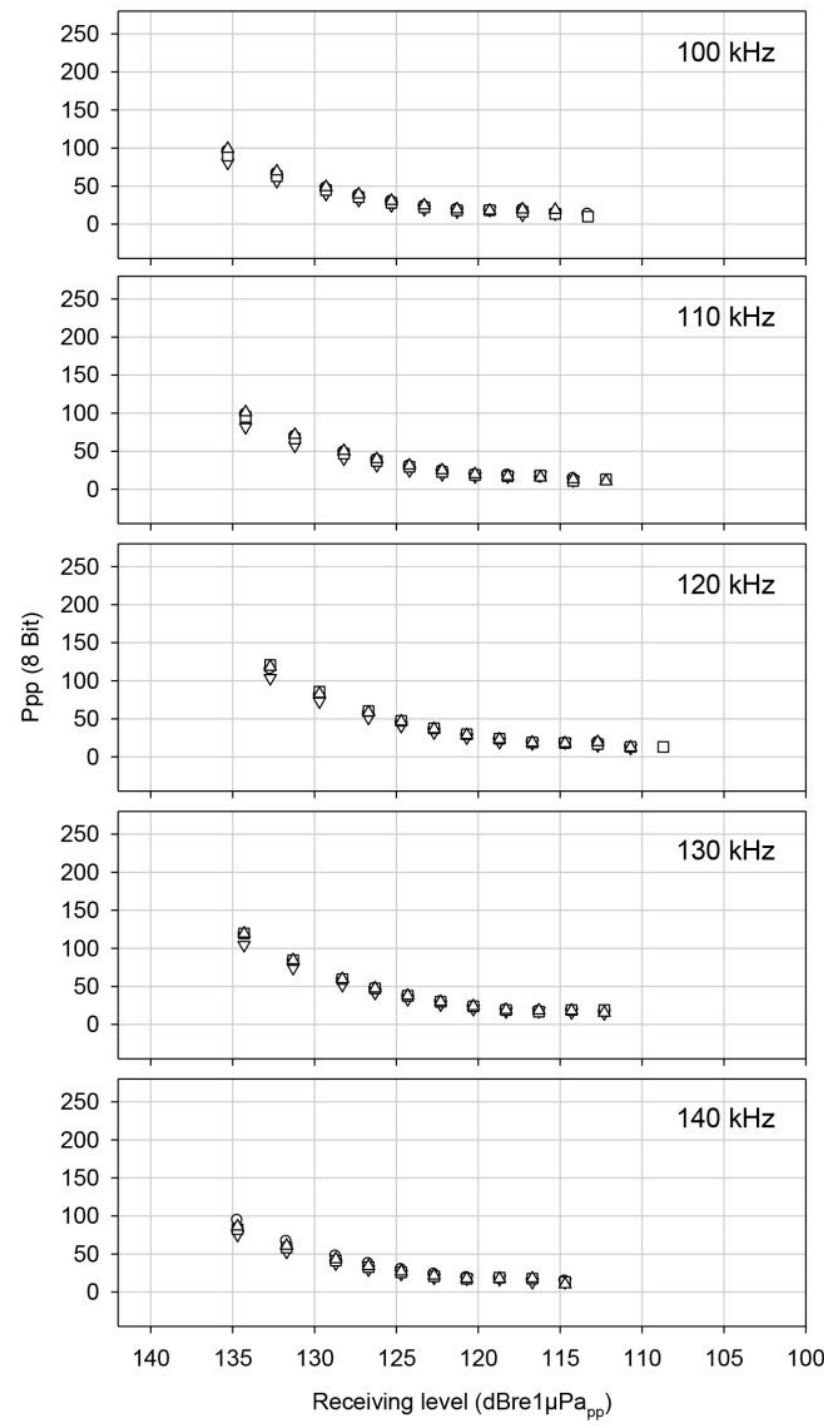

Figure A. 40 Calibration results of CPOD 889. 


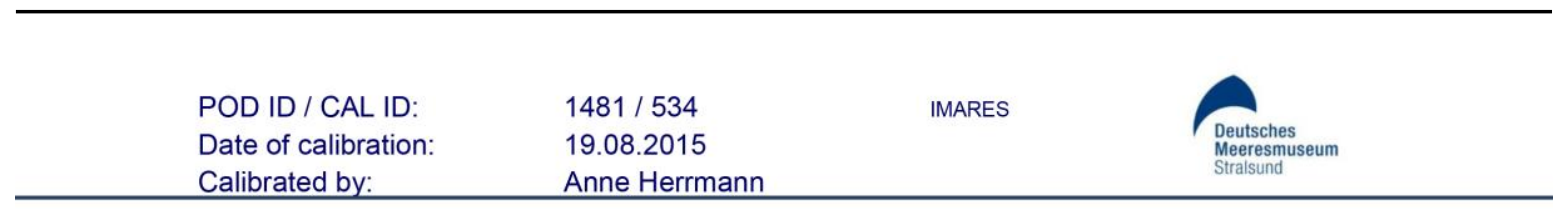

Calibrated by:

Anne Herrmann

Ppp versus receiving level
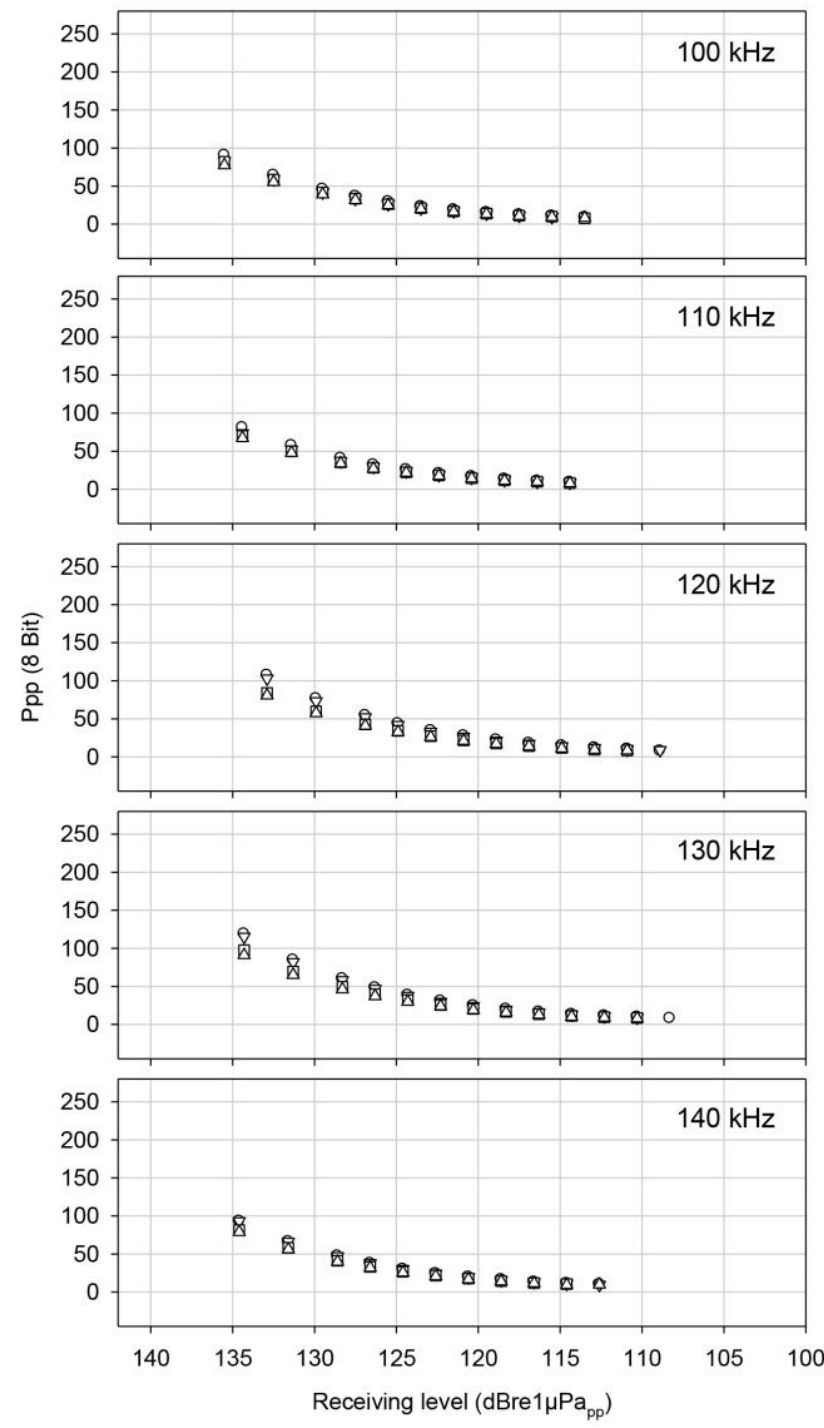

Figure A. 41 Calibration results of CPOD 1481. 


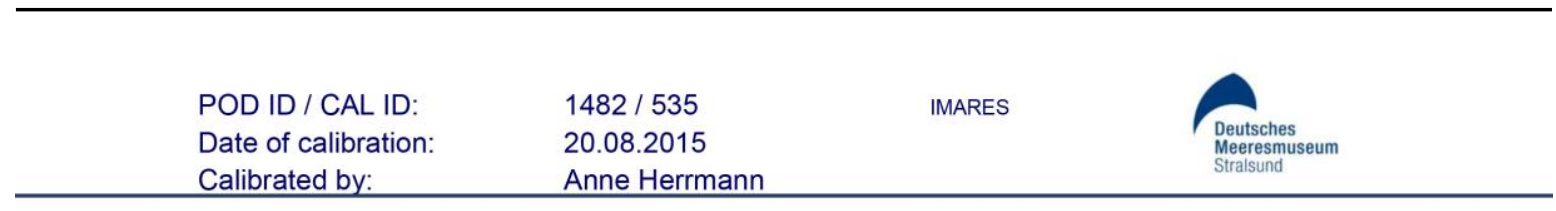

Calibrated by:

Anne Herrmann

Ppp versus receiving level
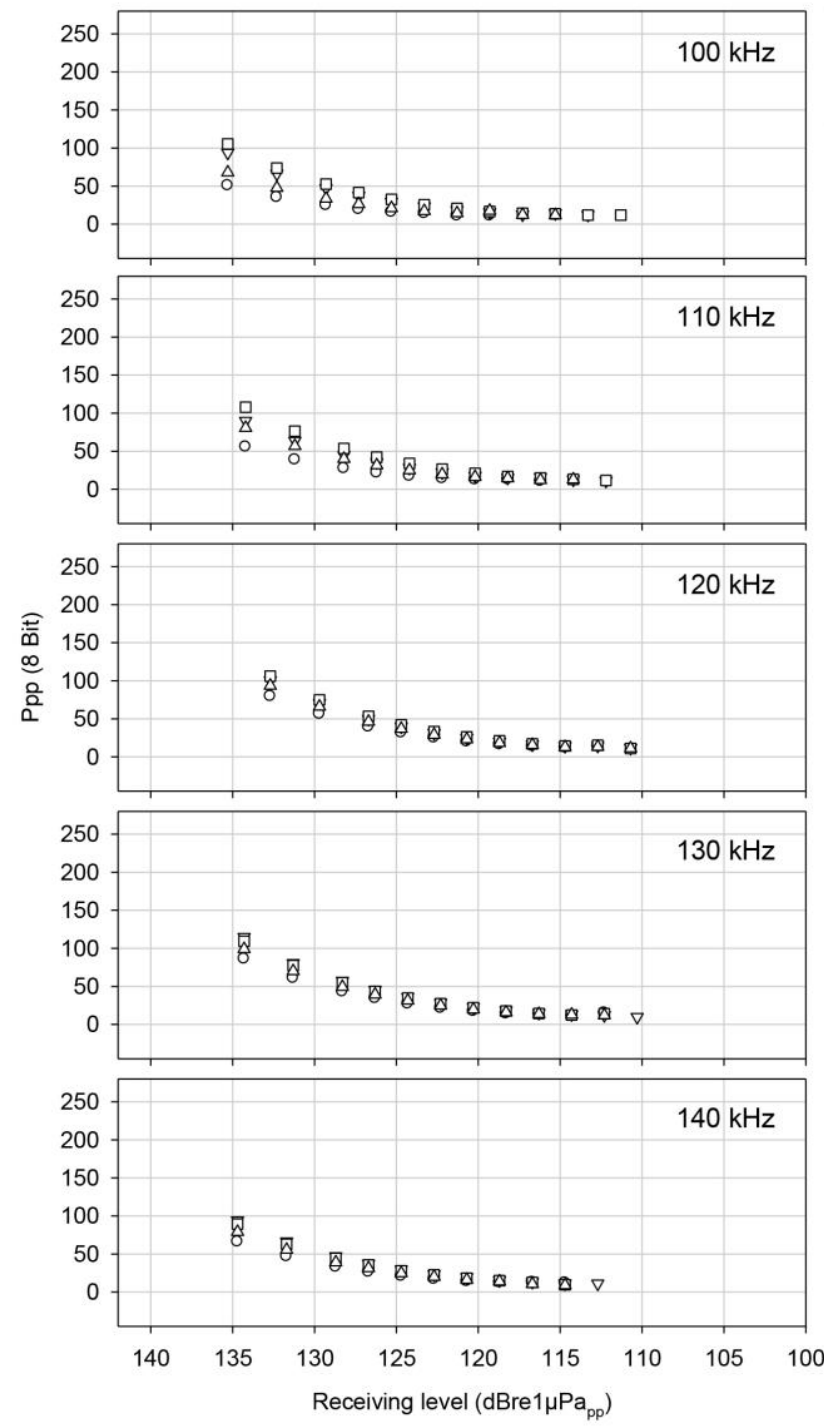

Figure A. 42 Calibration results of CPOD 1482. 


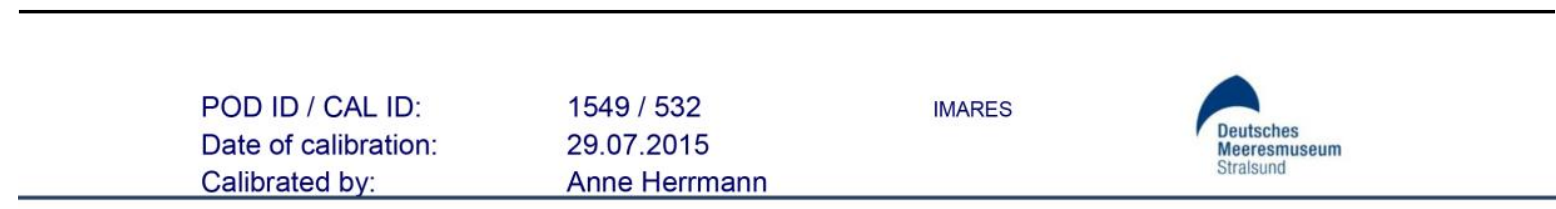

Calibrated by:

Anne Herrmann

Ppp versus receiving level
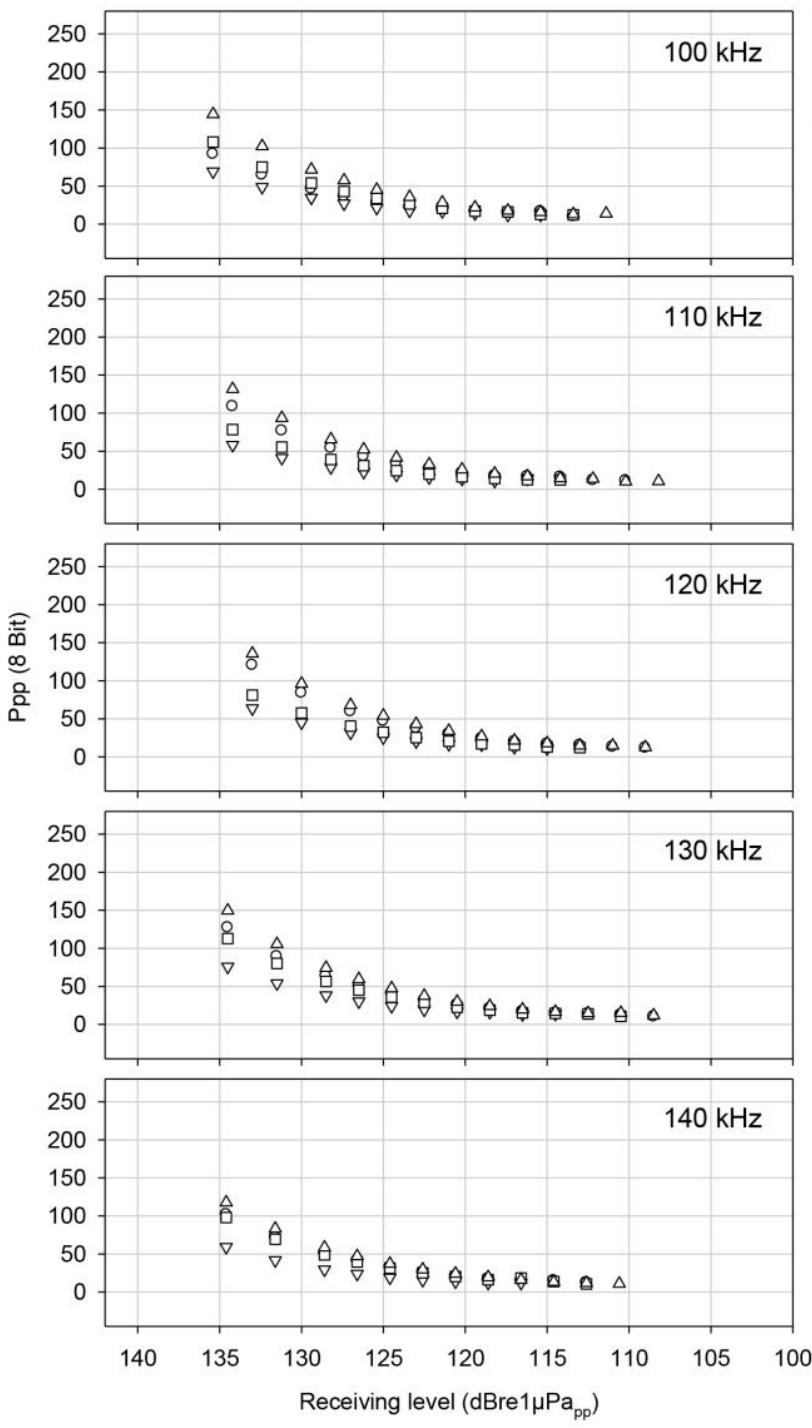

Figure A. 43 Calibration results of CPOD 1549. 


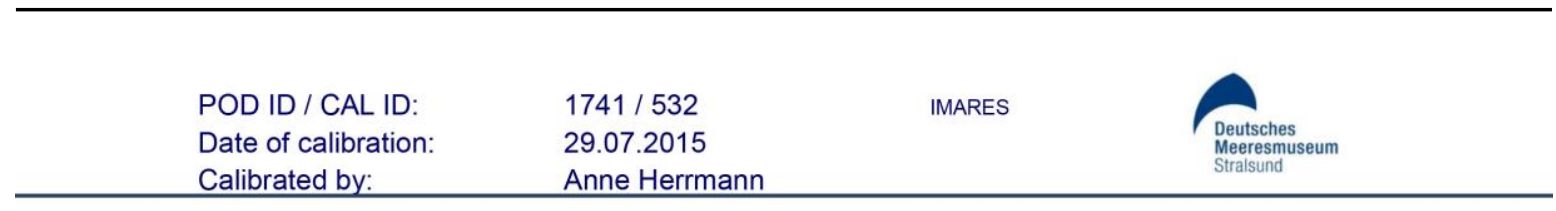

Calibrated by:

Anne Herrmann

Ppp versus receiving level
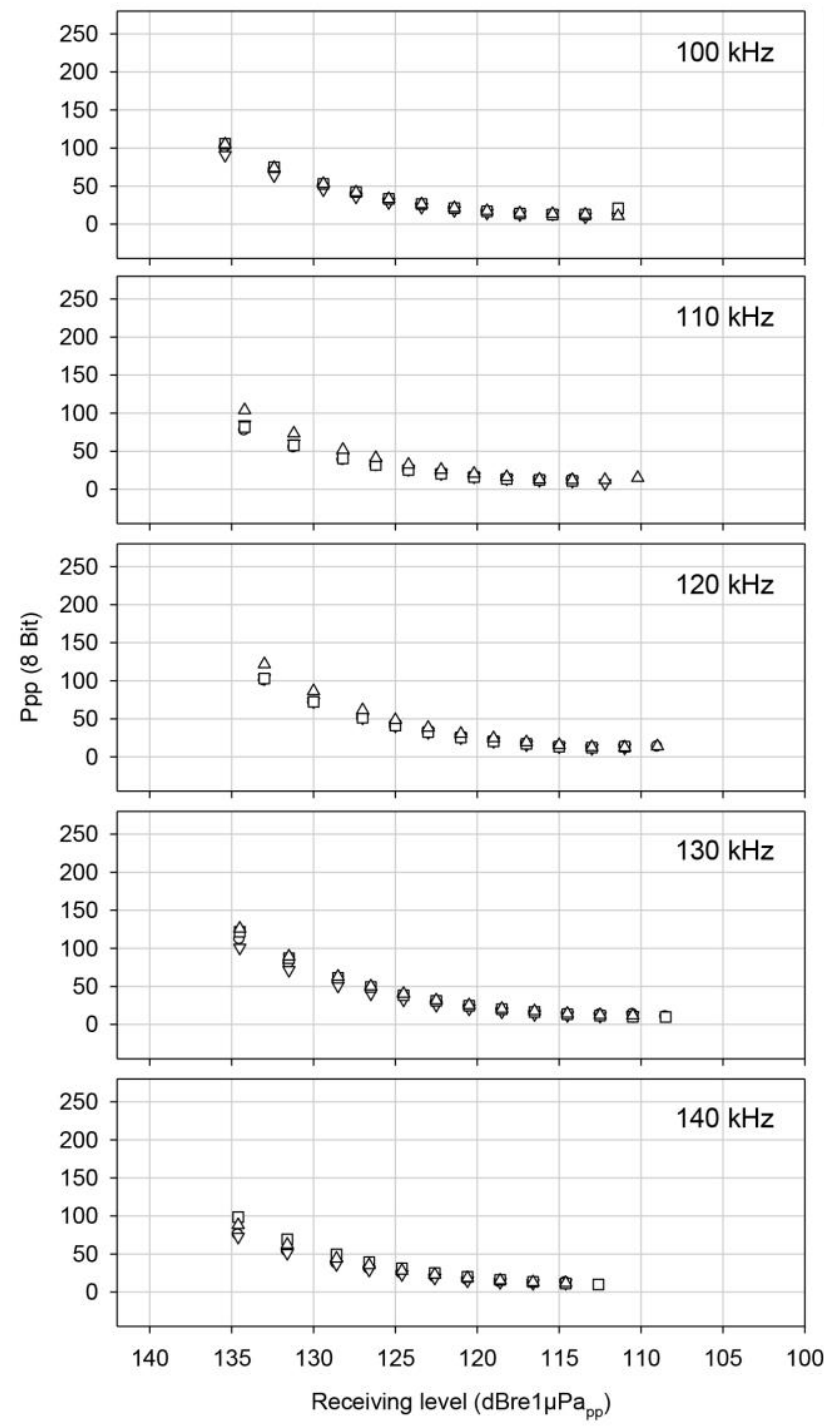

Figure A. 44 Calibration results of CPOD 1741. 


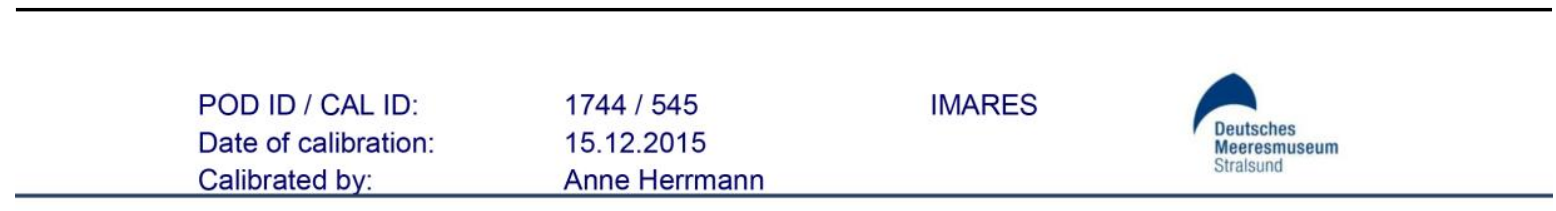

Calibrated by:

Anne Herrmann

Ppp versus receiving level
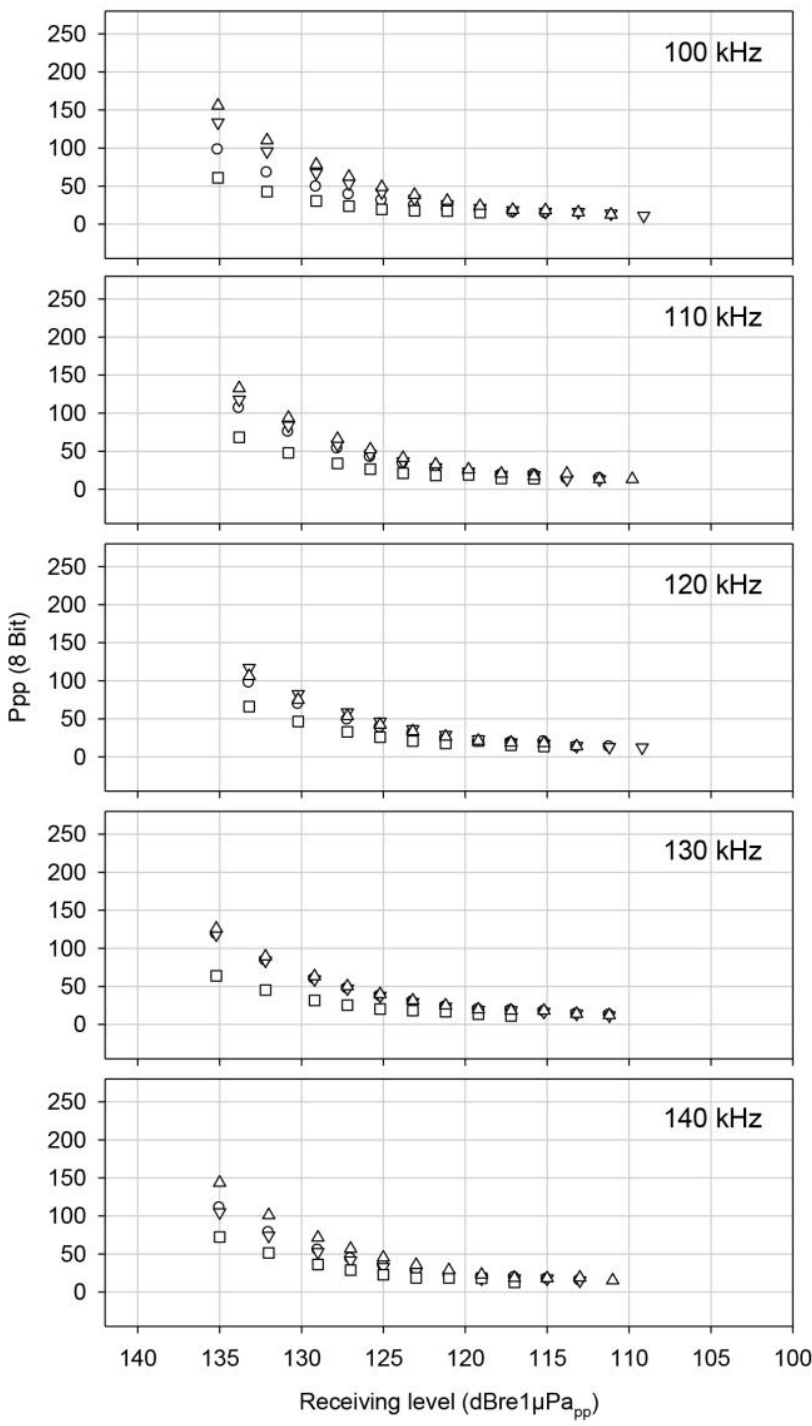

Figure A. 45 Calibration results of CPOD 1744. 


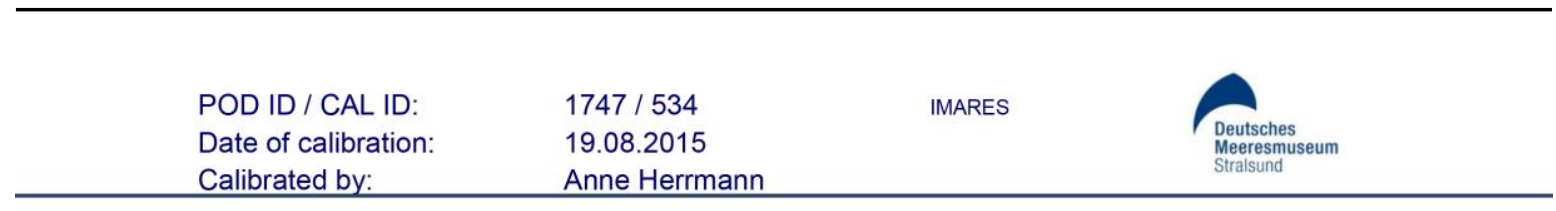

Calibrated by:

Anne Herrmann

Ppp versus receiving level
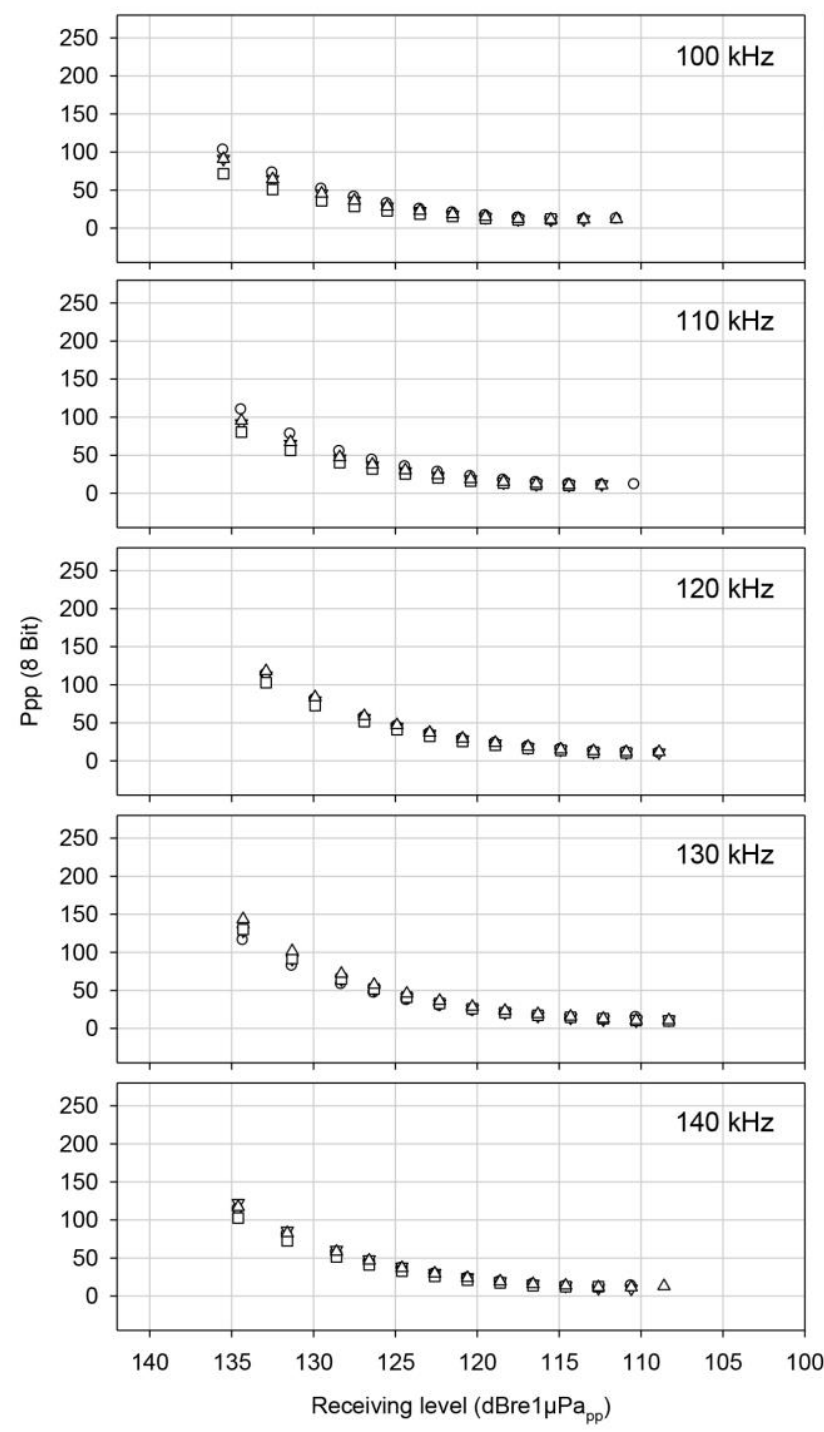

Figure A. 46 Calibration results of CPOD 1747. 


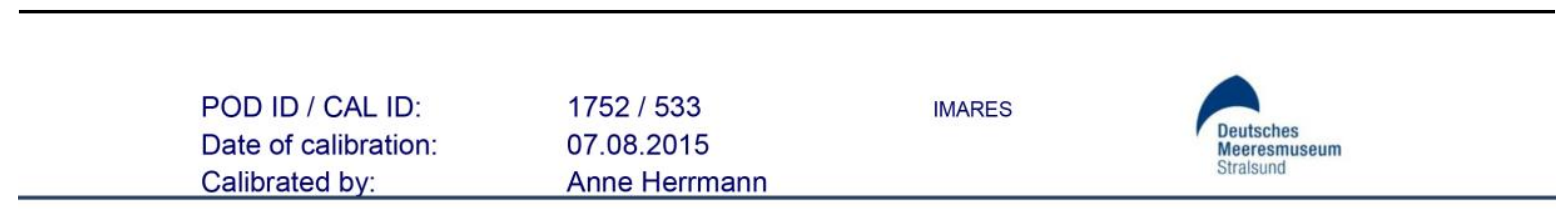

Calibrated by:

Anne Herrmann

Ppp versus receiving level
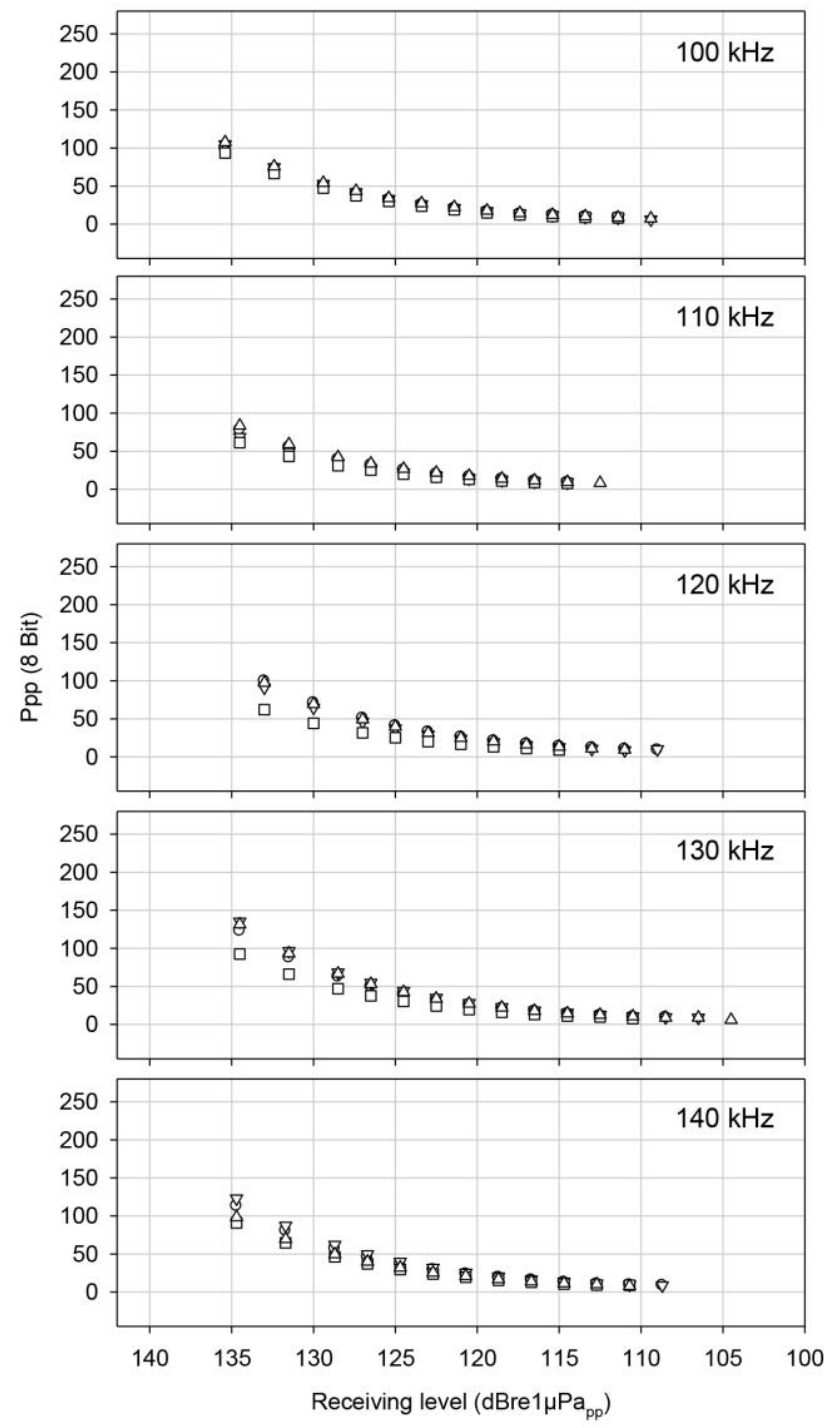

Figure A. 47 Calibration results of CPOD 1752. 


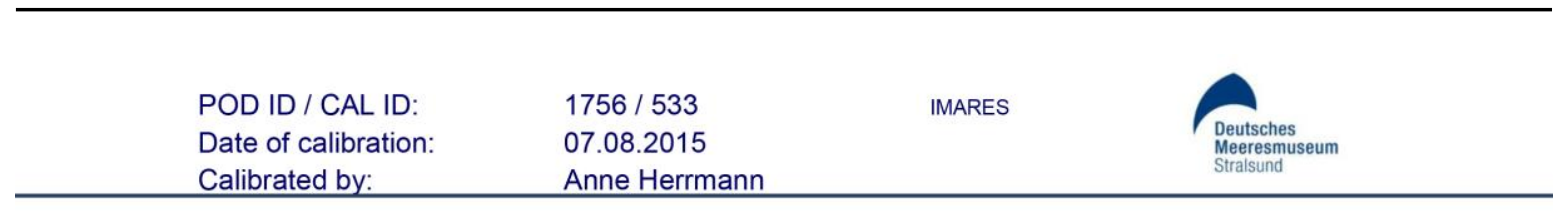

Calibrated by:

Anne Herrmann

Ppp versus receiving level
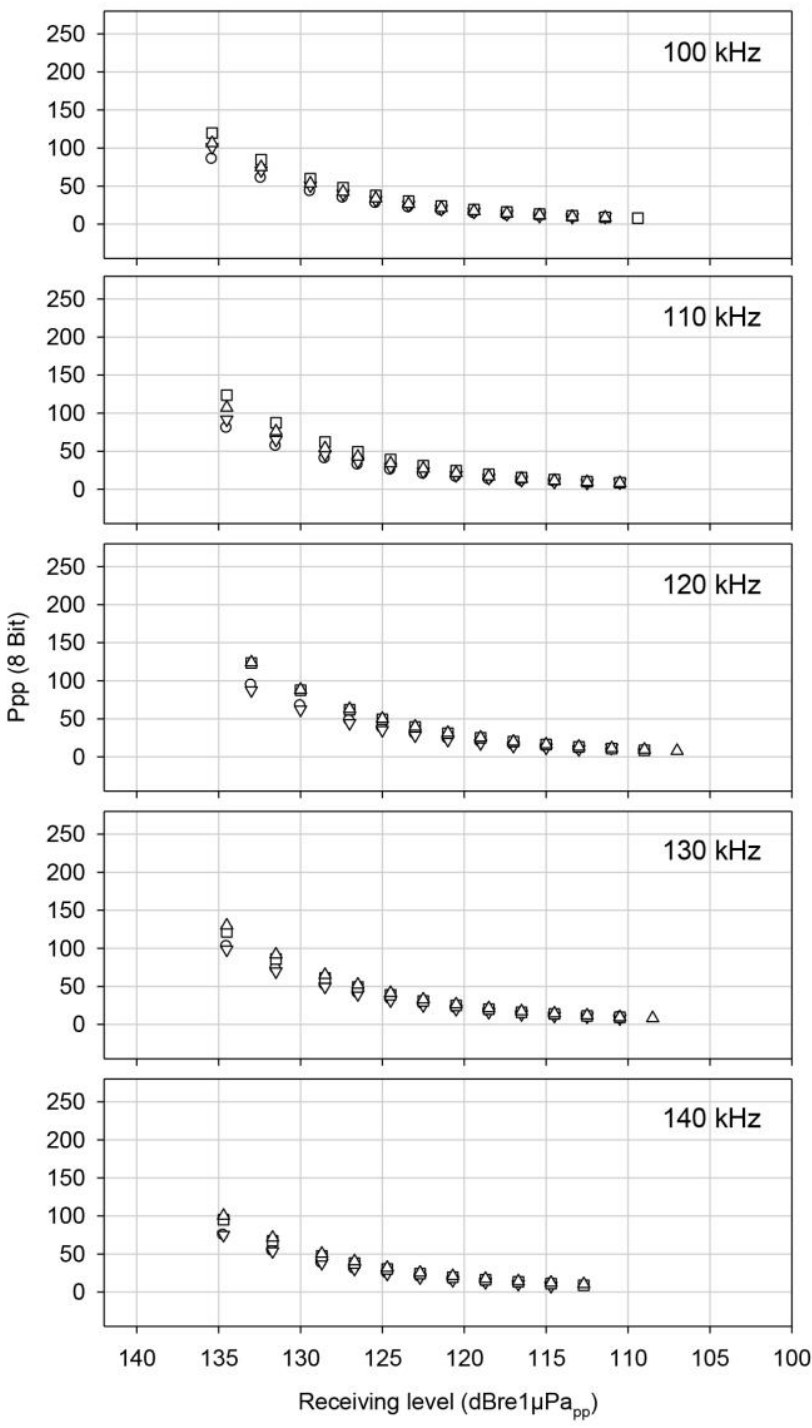

Figure A. 48 Calibration results of CPOD 1756. 


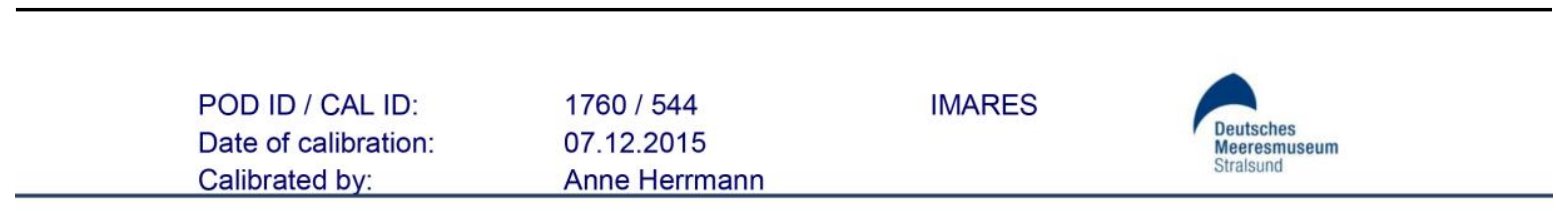

Calibrated by:

Anne Herrmann

Ppp versus receiving level
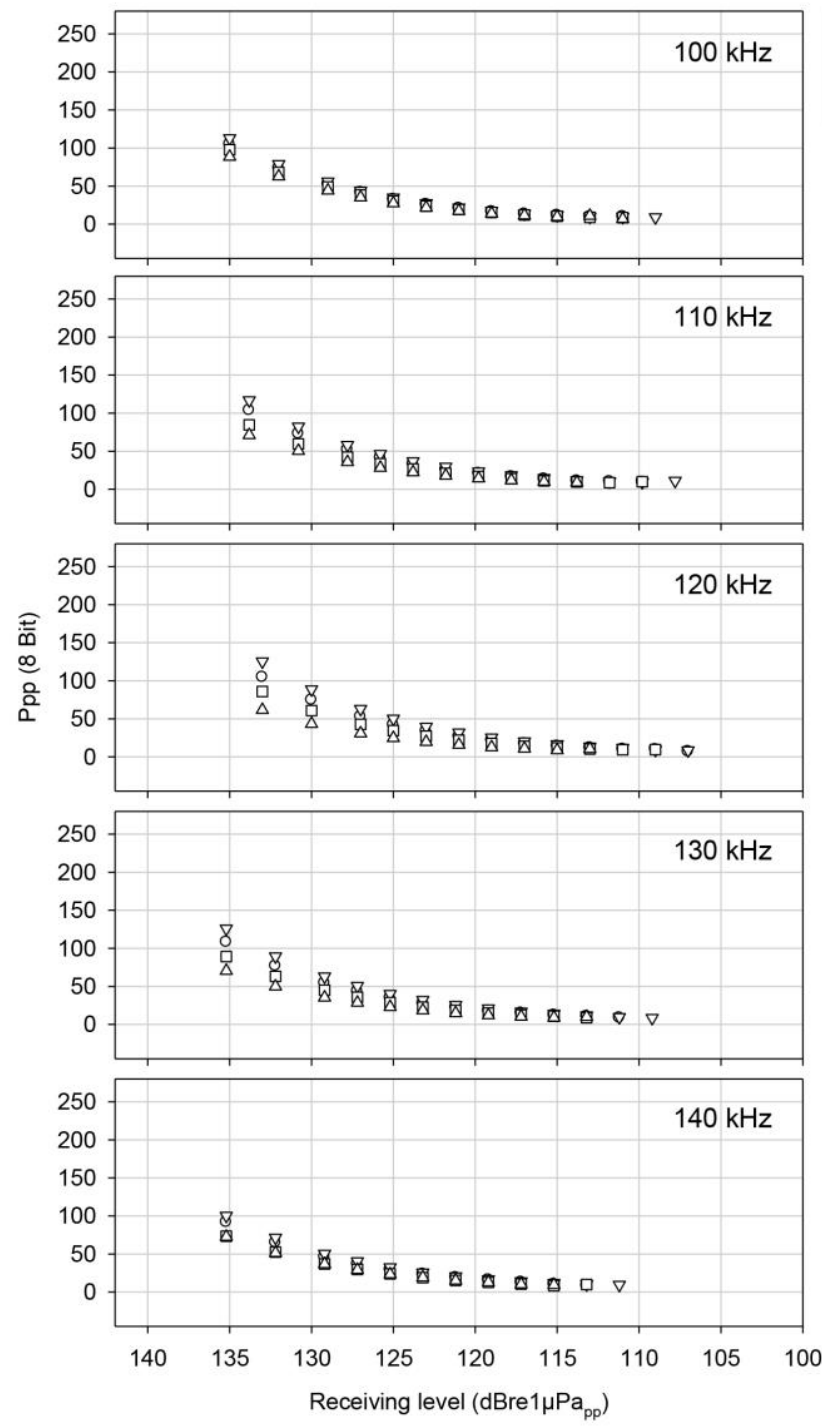

Figure A. 49 Calibration results of CPOD 1760. 


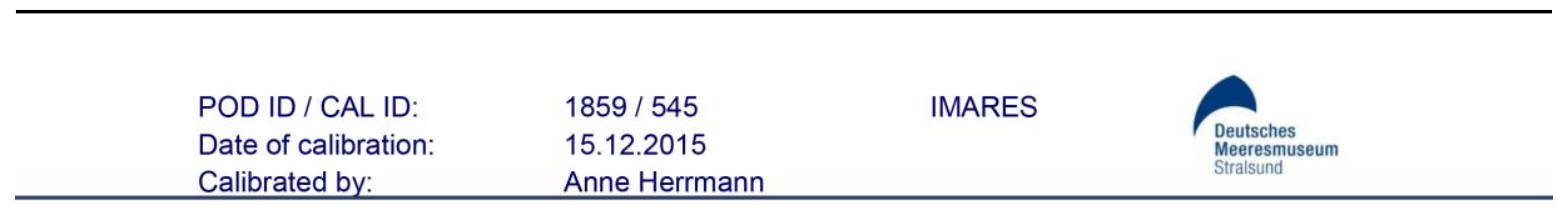

Calibrated by:

Anne Herrmann

Ppp versus receiving level
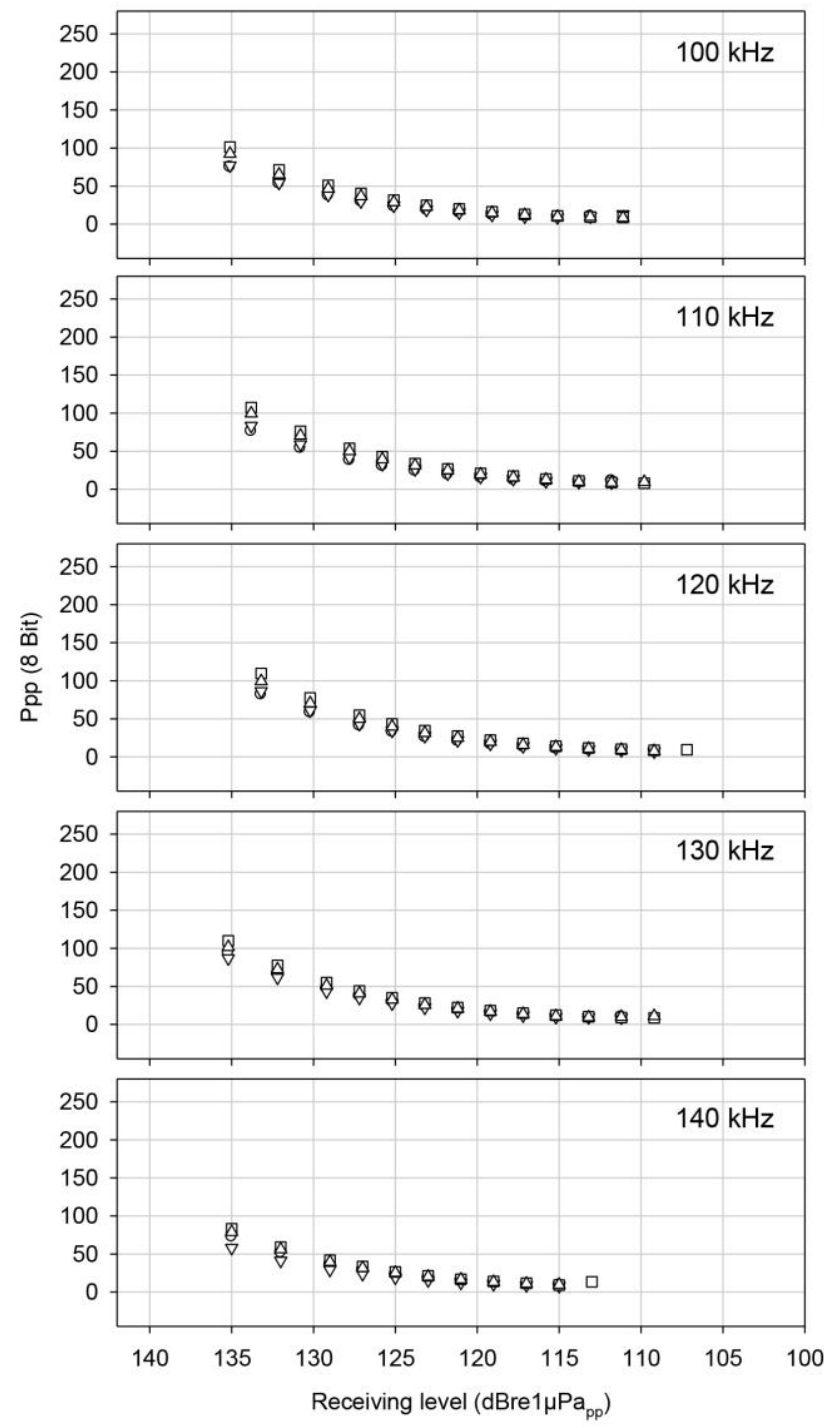

Figure A. 50 Calibration results of CPOD 1859. 


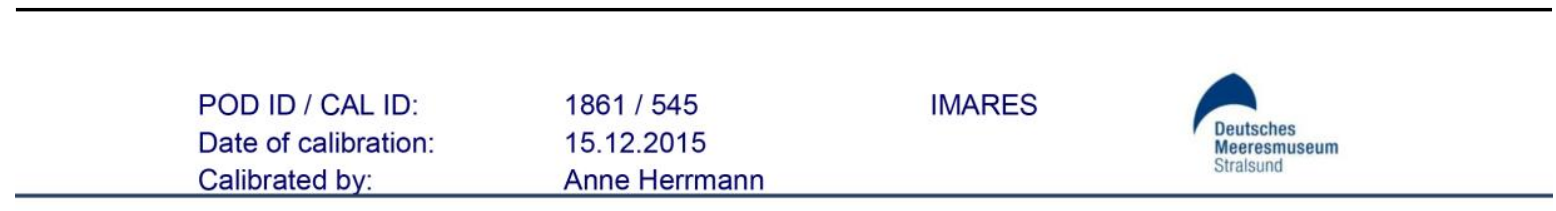

Calibrated by:

Anne Herrmann

Ppp versus receiving level
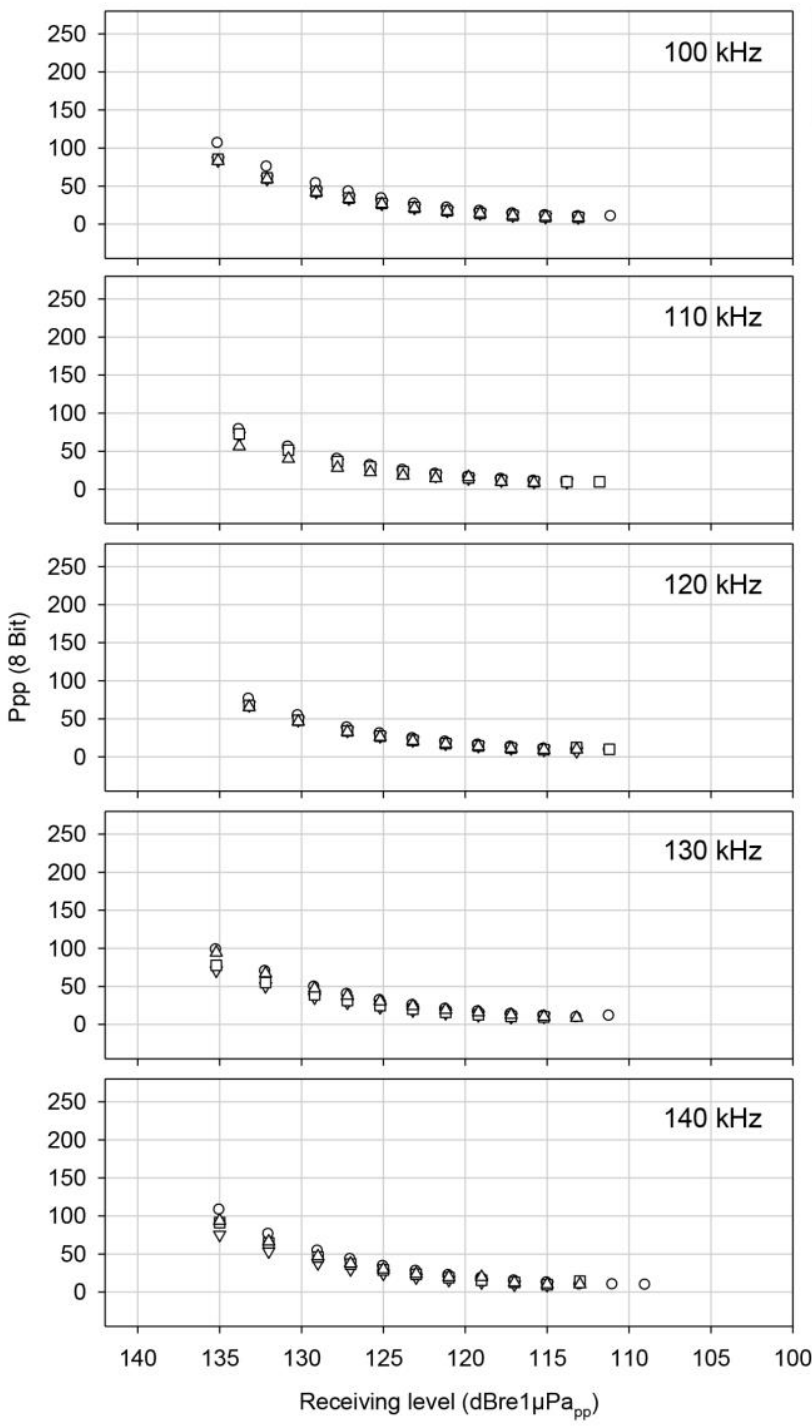

Figure A. 51 Calibration results of CPOD 1861. 
POD ID / CAL ID:

Date of calibration: Calibrated by:
IMARES

$1873 / 545$

15.12.2015

Anne Herrmann

Ppp versus receiving level

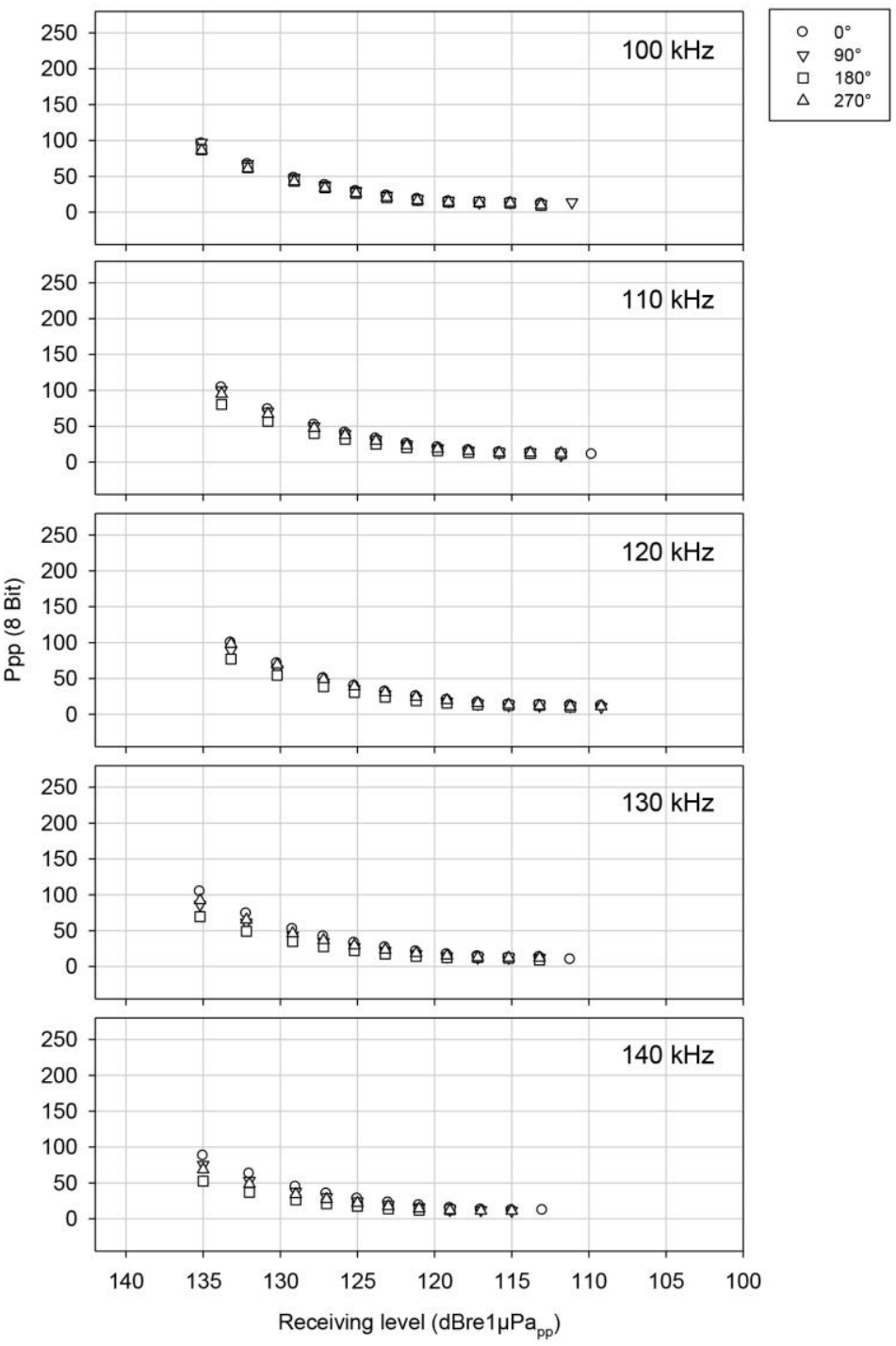

Figure A. 52 Calibration results of CPOD 1873. 


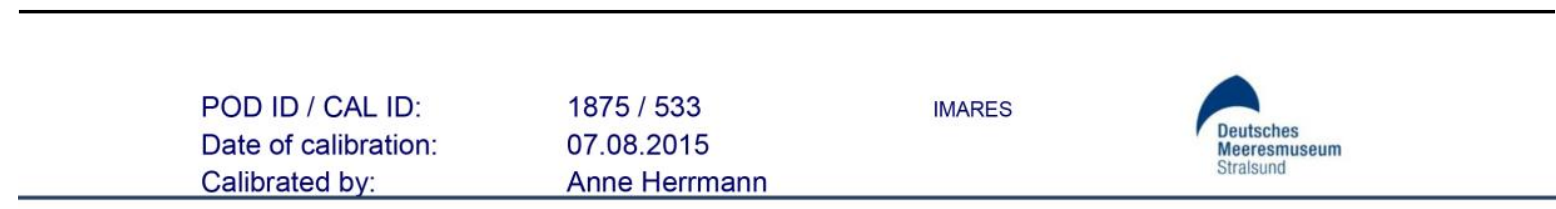

Calibrated by:

Anne Herrmann

Ppp versus receiving level
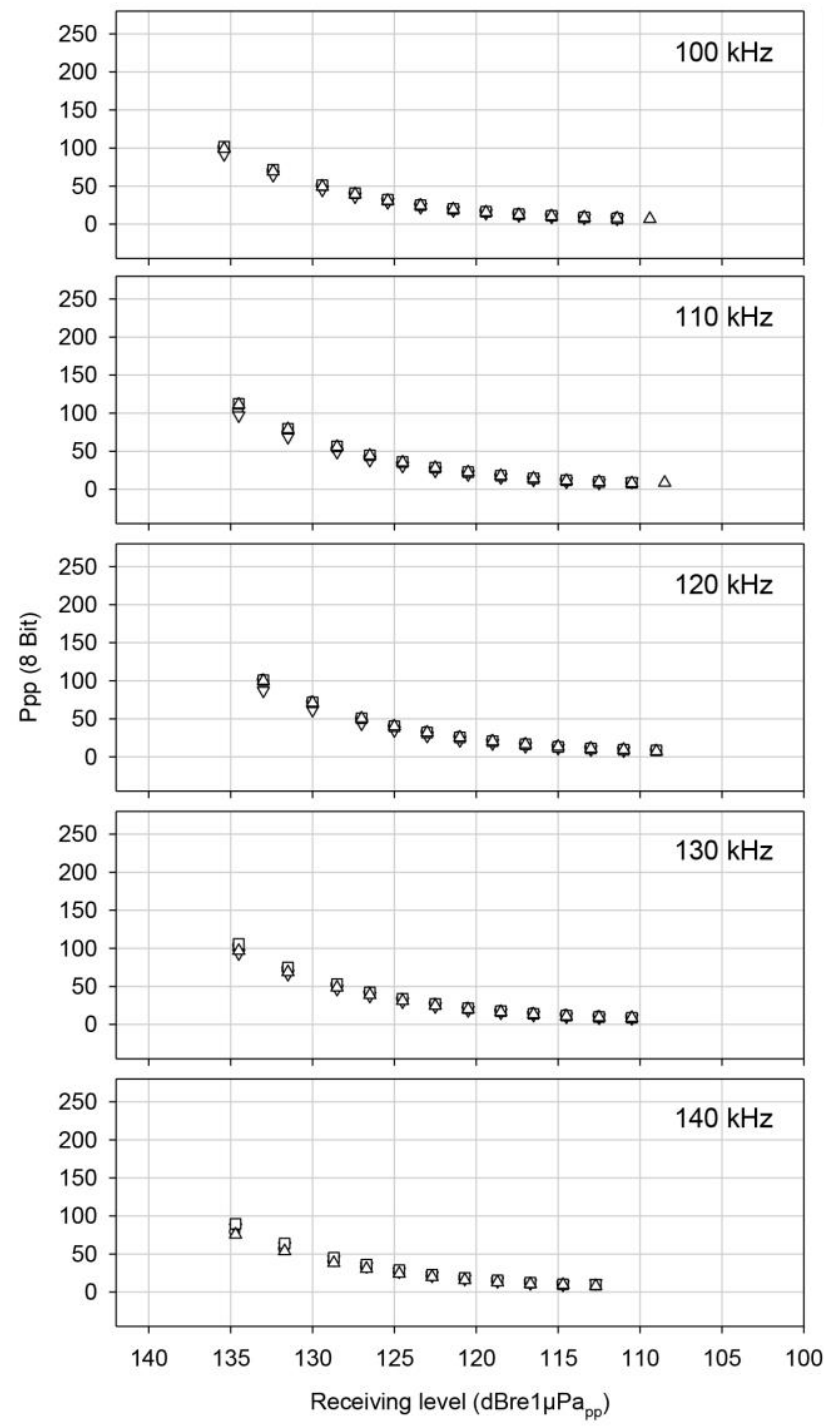

Figure A. 53 Calibration results of CPOD 1875. 


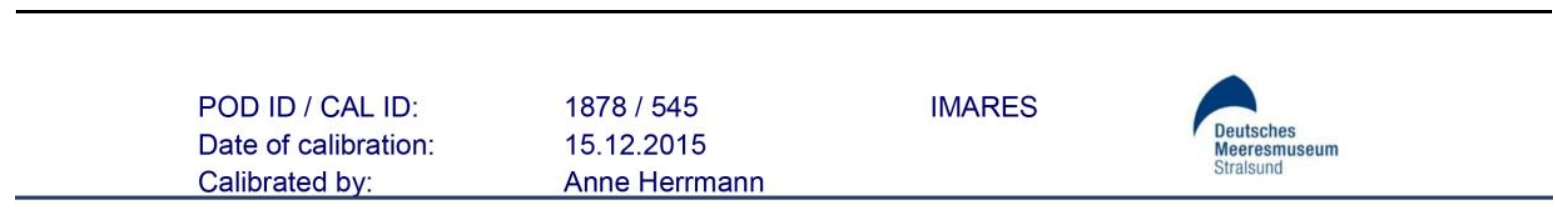

Calibrated by:

Anne Herrmann

Ppp versus receiving level
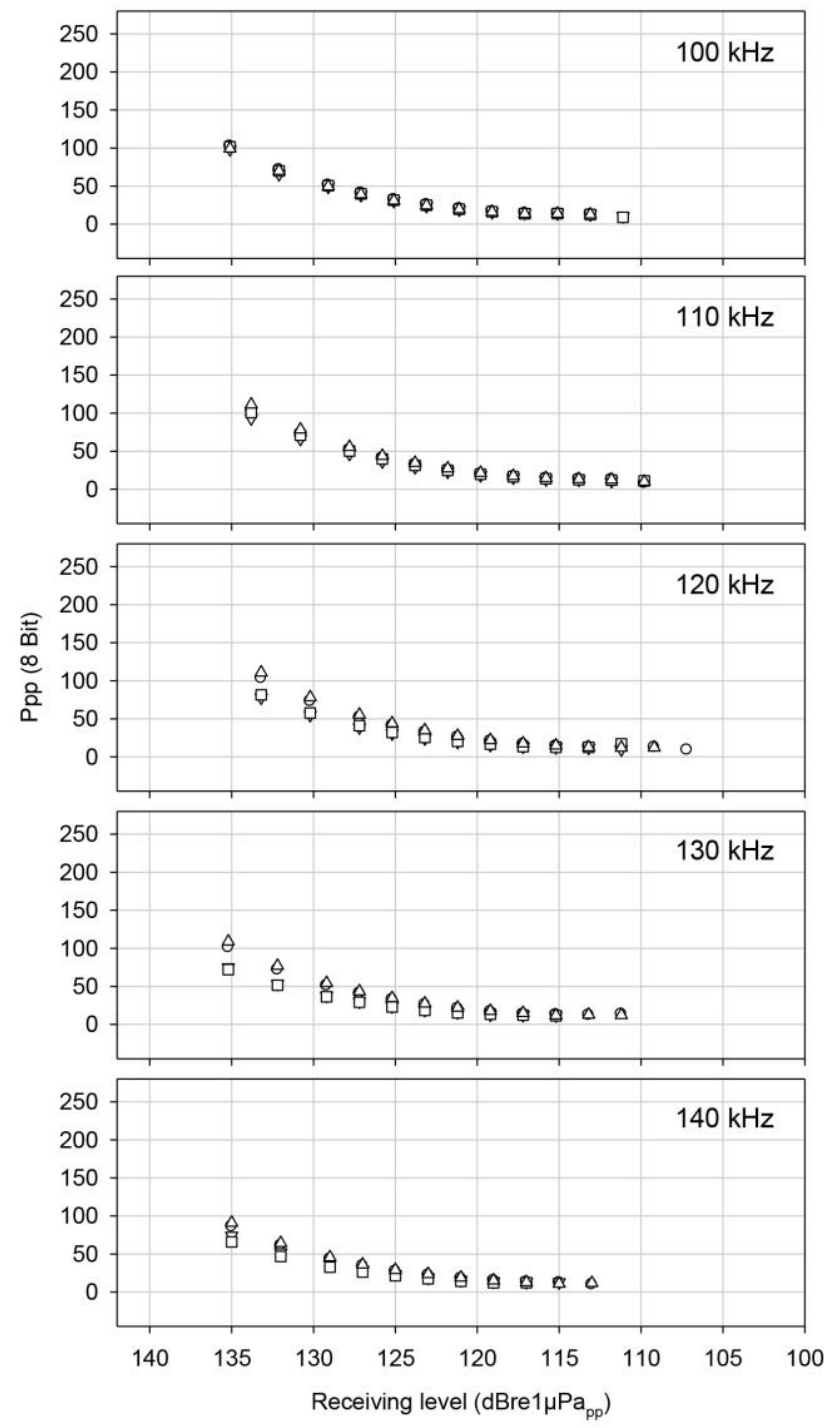

Figure A. 54 Calibration results of CPOD 1878. 


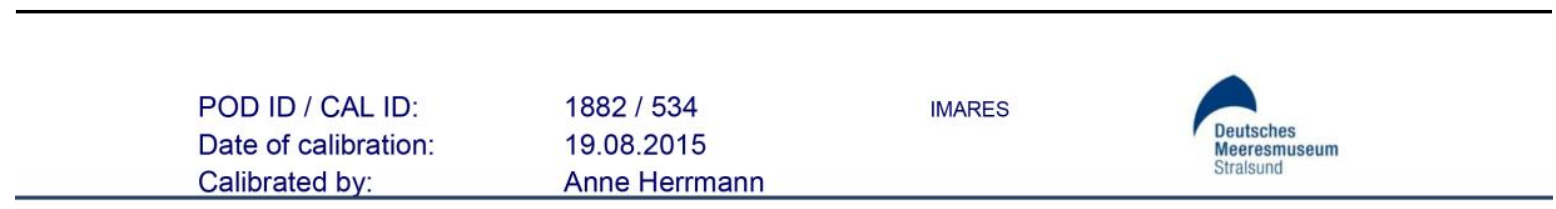

Calibrated by:

Anne Herrmann

Ppp versus receiving level
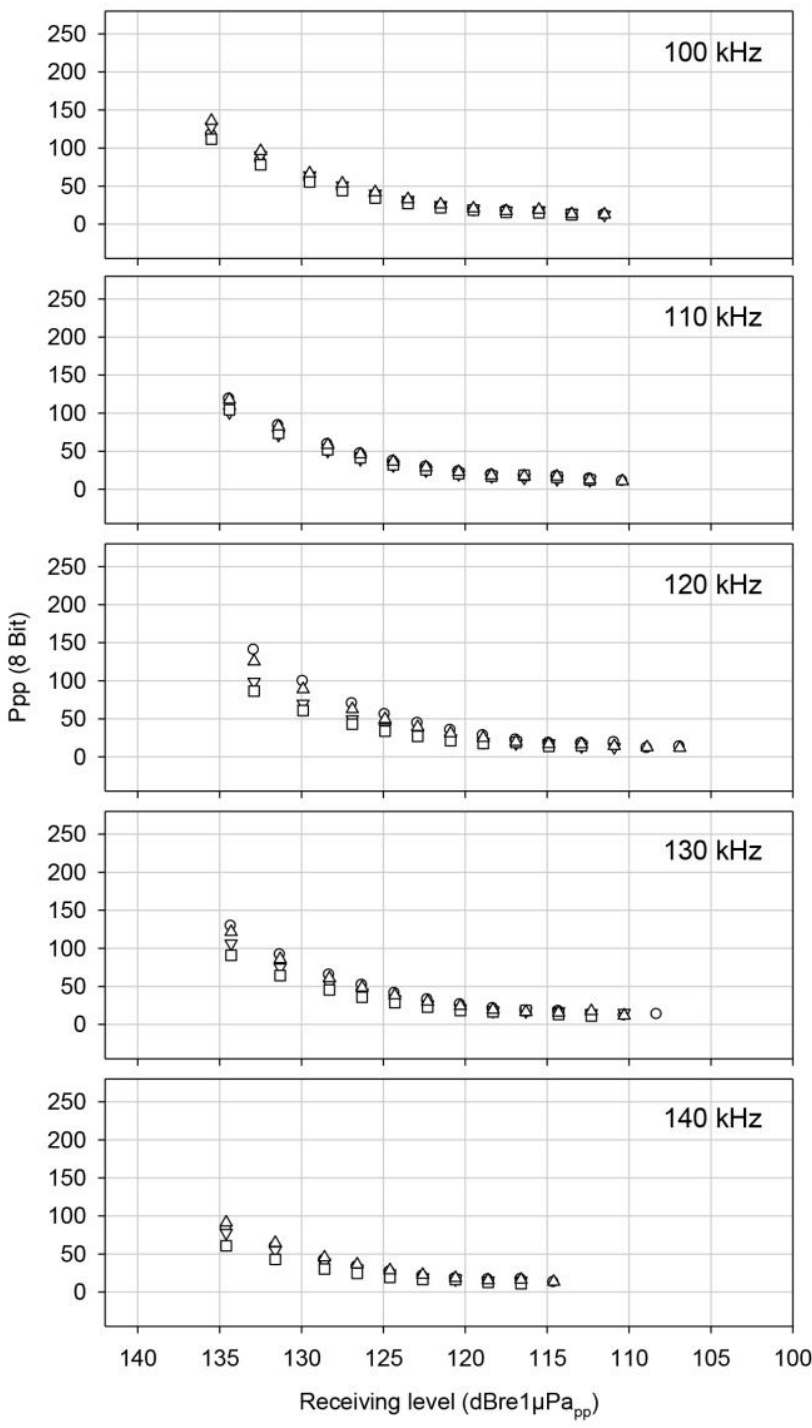

Figure A. 55 Calibration results of CPOD 1882. 


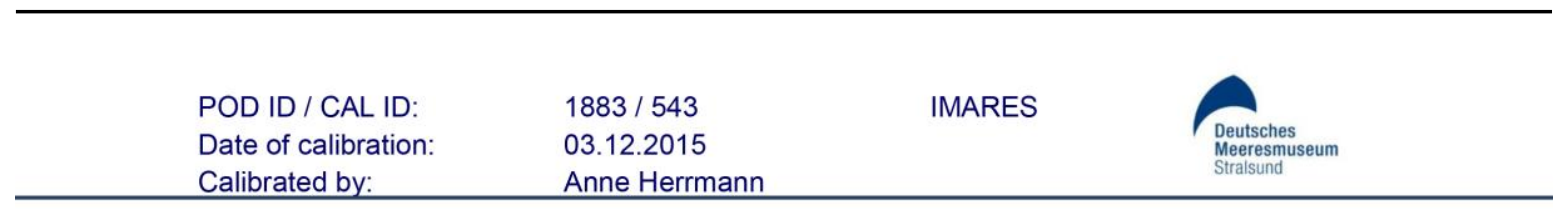

Calibrated by:

Anne Herrmann

Ppp versus receiving level
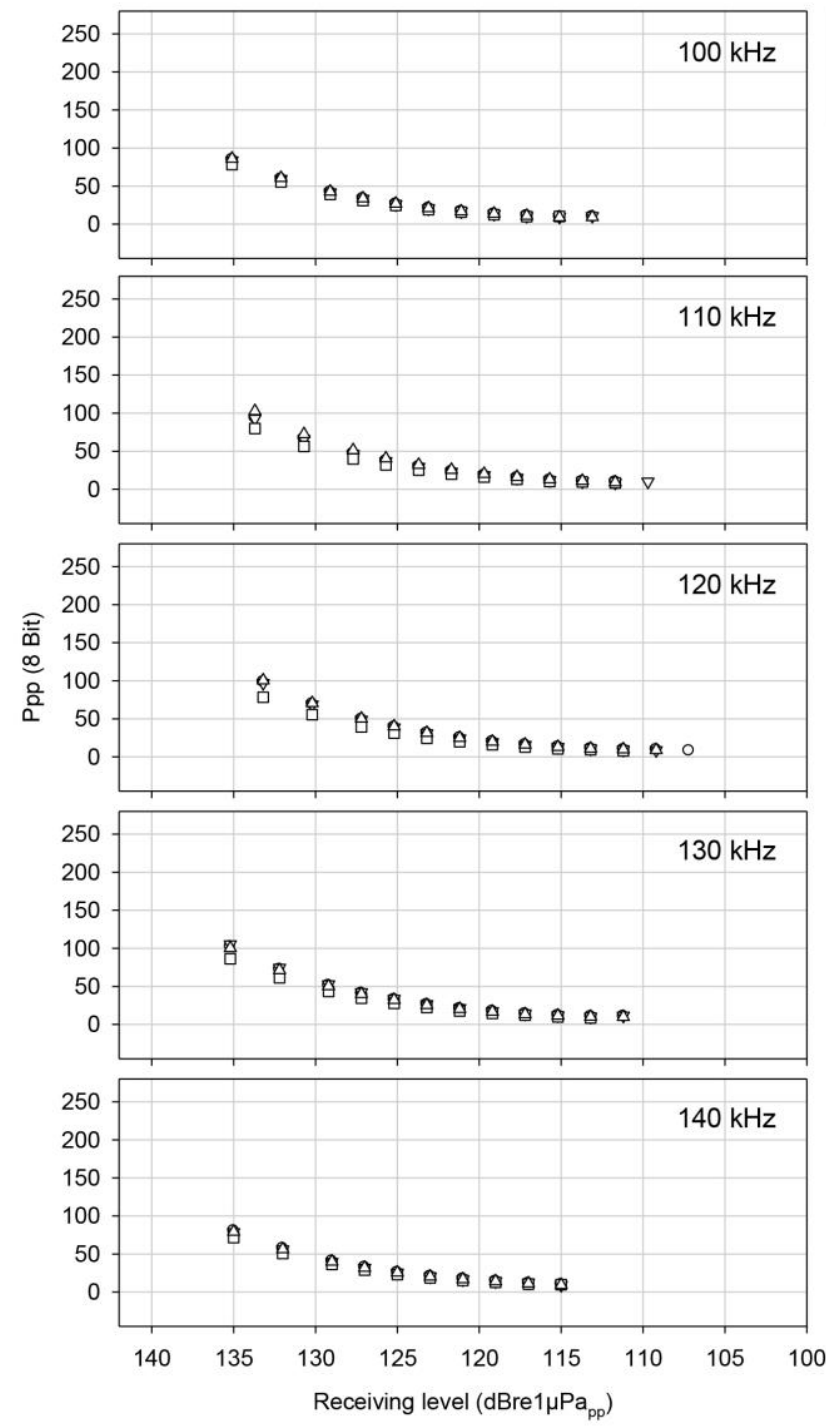

Figure A. 56 Calibration results of CPOD 1883. 


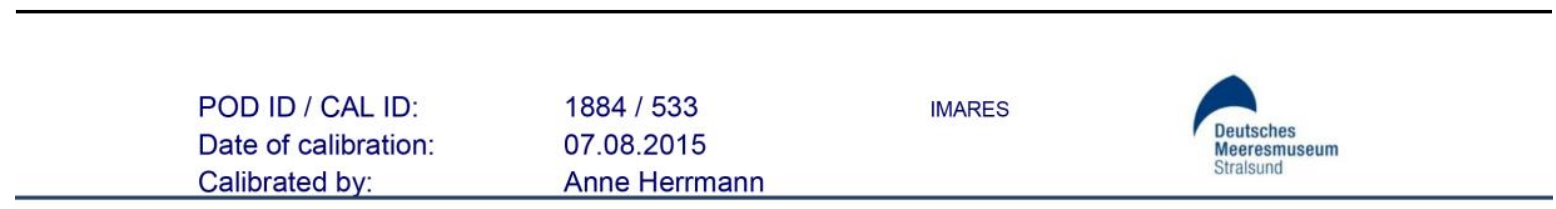

Calibrated by:

Anne Herrmann

Ppp versus receiving level
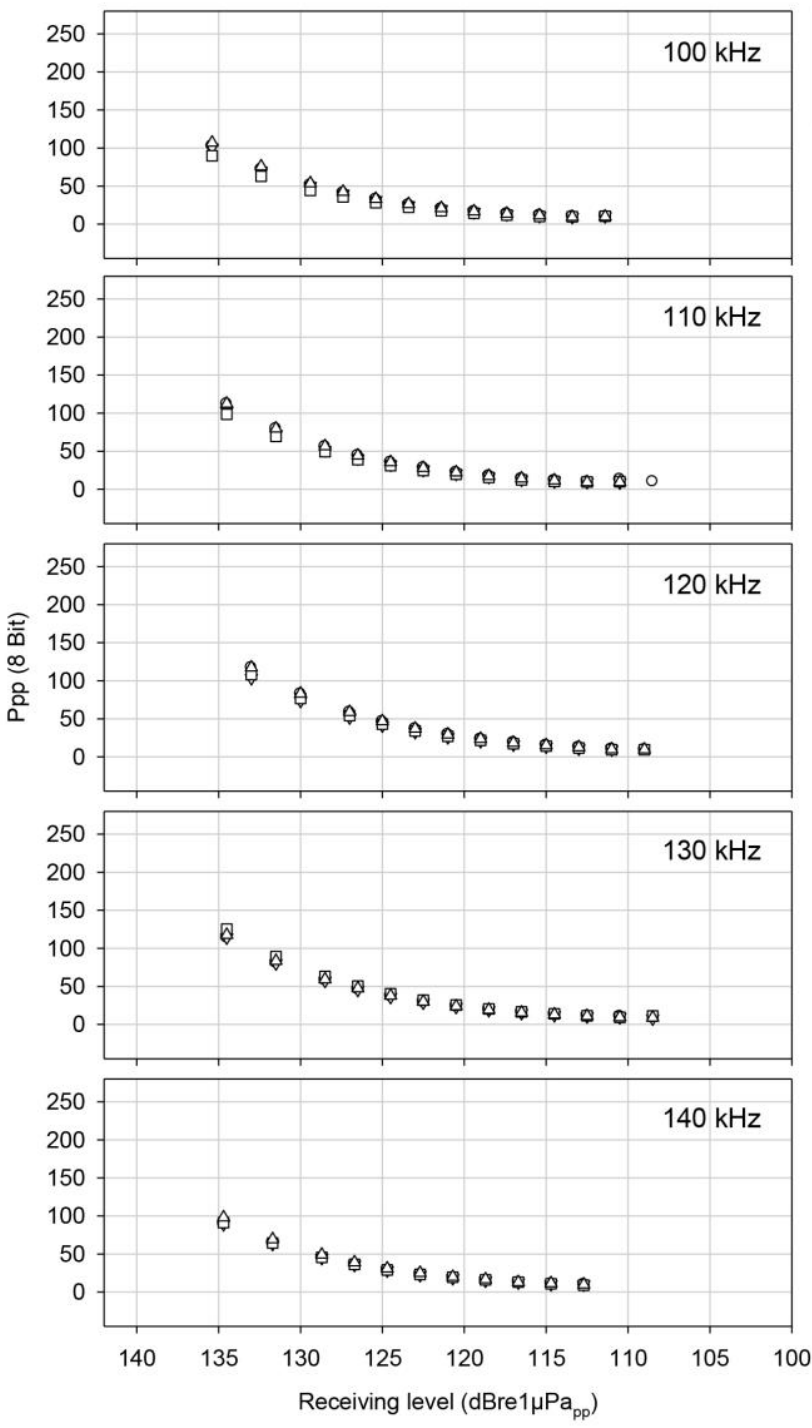

Figure A. 57 Calibration results of CPOD 1884. 


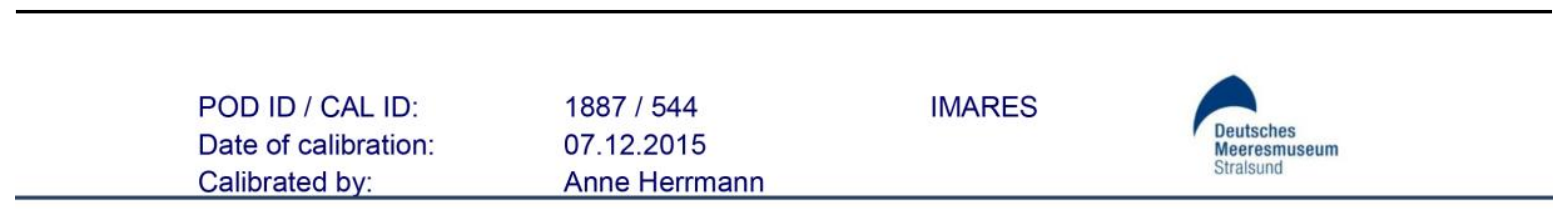

Calibrated by:

Anne Herrmann

Ppp versus receiving level
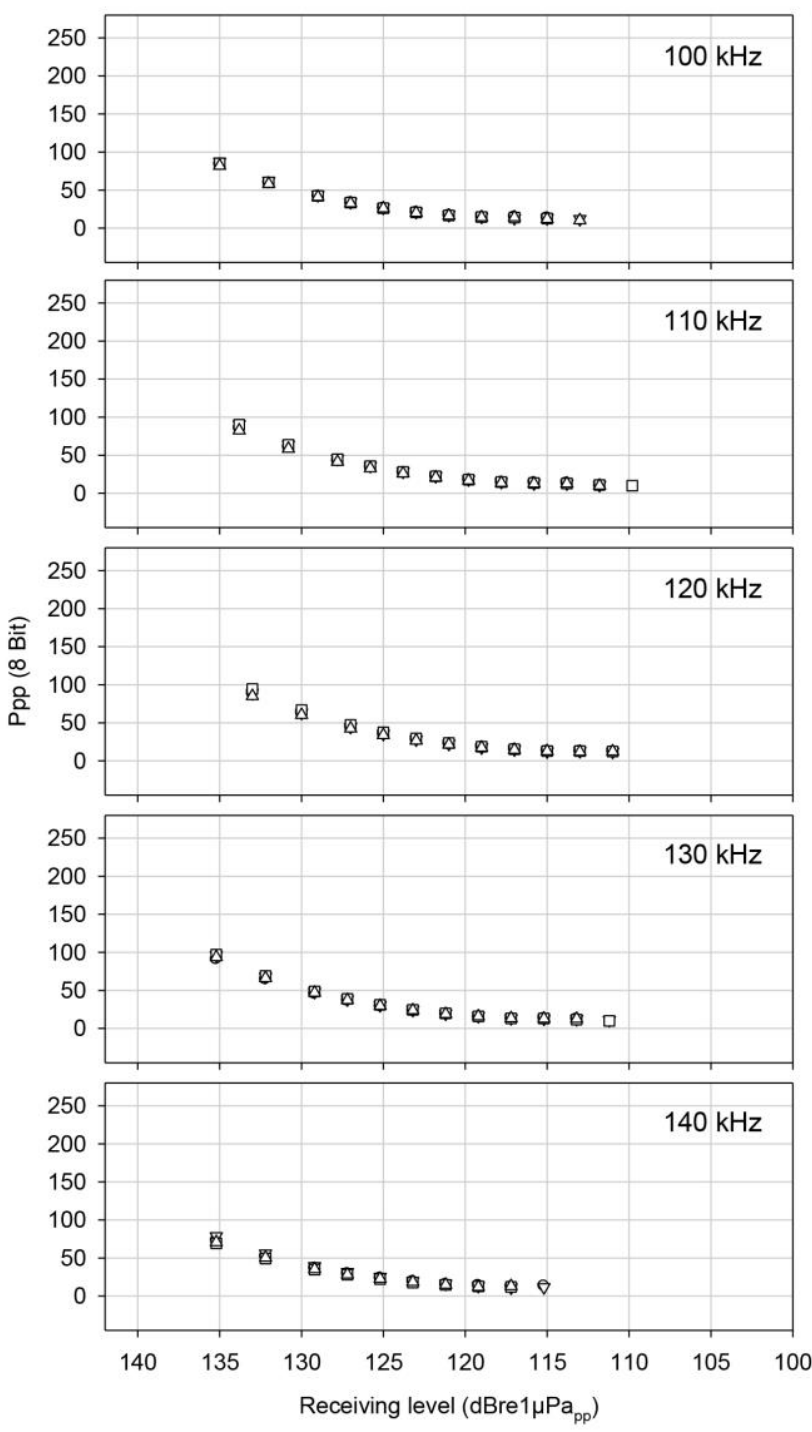

Figure A. 58 Calibration results of CPOD 1887. 
Wageningen Marine Research

$\mathrm{T}+31(0) 317480900$

E: marine-research@wur.nl

www.wur.eu/marine-research

Visitors' address

- Ankerpark 271781 AG Den Helder

- Korringaweg 7, 4401 NT Yerseke

- Haringkade 1, 1976 CP IJmuiden
With knowledge, independent scientific research and advice, Wageningen Marine Research substantially contributes to more sustainable and more careful management, use and protection of natural riches in marine, coastal and freshwater areas.

Wageningen Marine Research is part of Wageningen University \& Research. Wageningen University \& Research is the collaboration between Wageningen University and the Wageningen Research Foundation and its mission is: 'To explore the potential for improving the quality of life' 